


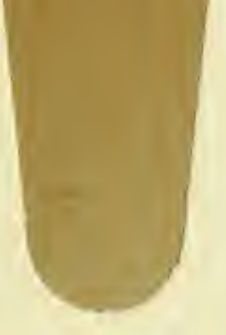





\section{UNSERE KORPERFORII}

[NI)

DAS PHYSIOLOGISCHE PROBLEM IHRER ENTSTEHUNG.

\section{BRIEFE}

AN EINEN BEFREUNDETEN NATURFURSCHER

VON

WILHELM HIS.

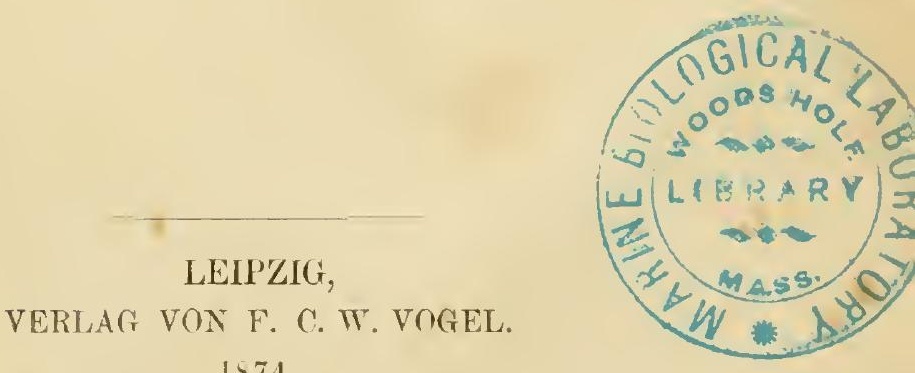

1574. 

IIAN

\section{I)ER FREUND IEM FREUNI)E S(HRIER}

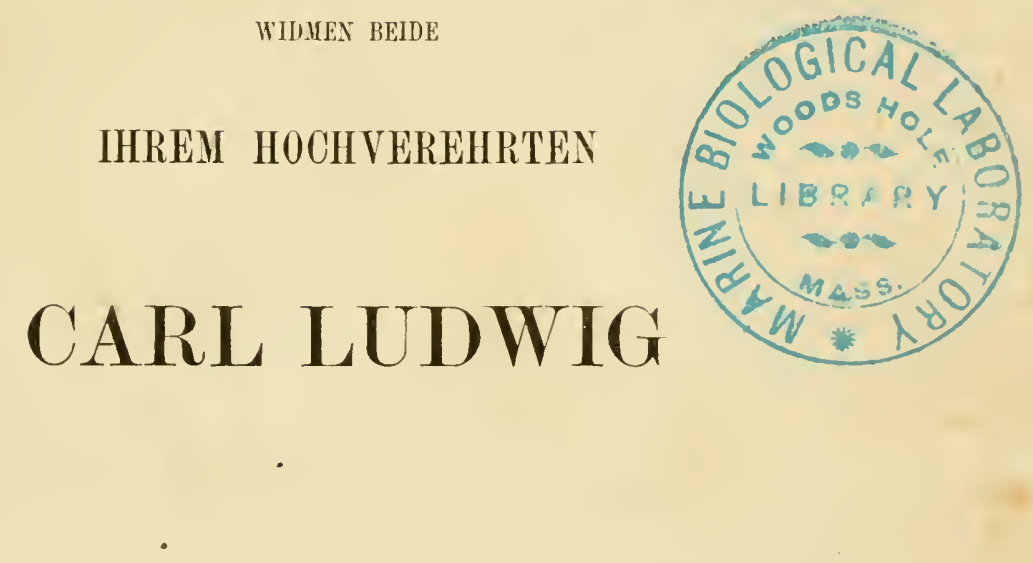

ZUR FEIER INES 2ちJ JÄHRIGEN LEIIRAVTS

IES 15. OCTOBER $18 Y 4$ 



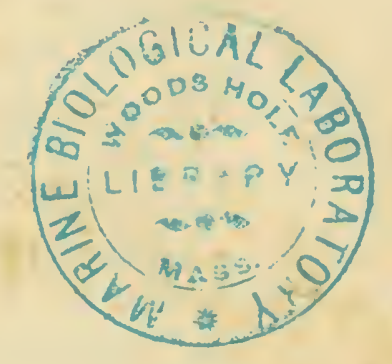

\section{VORWOR'T.}

Die naehfolgenden Briefe, auf Anregung eines nahe befreundeten Naturforschers und unter dessen lebhafter kritiseher Theilnahme geschrisben, sollen in gedrängter und iibersiehtlicher Form die Stellung auseinandersetzen, welche die Entwicklungsgeschichte bei den Grundfragen organischer Naturforschung zu behaupten hat. Dass diese Stellung eine hervolragende sein miisse, wird kaum mehr bestritten. Wiederholt schon hat man es in nenerer Zeit unternommen, bei Begriindnng der Descendenzlehre entwicklungsgesehichtliches Material weiteren Kreisen vorzulegen. Jedoeh ist dies nicht durchweg: mit der nöthigen Sachkenntniss geschehen, und so darf wohl die Stimme eines Forschers, der der Entwicklungsgeschichte seit Jahren seine verfiigbaren Kräfte gewidmet hat, trotz der Unrollkommenheit des Dargebotenen einen Anspruch auf Beachtung erheben. Es sind die "Briefe" fuir einen weiteren Kreis, als denjenigen reiner Fachlente bestimmt, sie sind an naturwissenschaftlich gebildete Leser gerichtet, welche Ausdaner genug besitzen, um sachliehen Erörterungen sowohl, als Gedankengängen zu folgen, die ihrem Wesen nach nicht zu 
den lcichtesten gehören. Einzehe zu weit ins anatomische Detail abschweifende Absehnitte können ron denjenigen, die kein Interesse dafuir haben, leieht iibersehlagen werden.

Besonders soll es mich frenen, wemn es den Bricfen gelingen wird, ihre Fremde in der Generation heranwachsender Forscher zu gewimnen. Dass die Schrift, anstatt mit einer abgerundeten Weltansehaumg, mit der Aufstellung neuer Arbeitsziele schliesst, werden mir diejenigen gerade nicht verdenken, die, noch unbefangenen Simnes, ihre frischen Kräfte der wissenschaftliehen Arbeit zu widmen entschlossen sind.

Dem Herrn Verleger meinen besten Dank fiir die Sorgfalt der Ausstattung:

Leipzig, im Januar 1875.

Der Yerfasser. 


\section{Inhaltsverzeichniss.}

Erster Brief.

Seite

Die embryouale Körperform und ihre Eutstehungsgeschichte .

Zweiter Brief.

Princip ler organbildenden Keimbezirke, dorsale und ventrale Flächen der Embryonalanlage und deren Sonderung; vorderes und hinteres Körperende; allgemeine Topographie der Keimbezirke

\section{Dritter Brief.}

Die Schichten der Embryonalanlage. Keimblattlehre. Parablastische und archiblastische Anlagen

\section{Vierter Brief.}

Faltenbildung im Keim und deren Bedingungen . . . . . . .

\section{Fiinfter Brief.}

Nechanik der Blätterspaltung, Eintluss der Keimscheibenspannungen auf die Form der Zellen. Ueberschreitung der Elasticitäts- und der Festigkeitsgränzen, Bildung des Axenstrangs und der Urwirbel, Bildung ron Näthen . . . . . . . . . . . .

\section{Seehster Brief.}

Allgemeinheit des Faltungsprineipes bei der Bildung von Organanlagen. Bildung von Herz, Luftrölre, Lungen, Leber, Schilddrüse, Nagen und Milz . . . . . . . . . . . . . . 66

\section{Siebenter Brief.}

Die weiteren Folgen rom Princip ungleichen Wachsthums. Die Folgen der Abflachung des Körpers; Umbildung des Gesichtes.

\section{Achter Brief.}

Das embryonale Gehim. Formen einer sich biegenden elastischen Röhre. Ableitung der ersten Gehirnformen .

\section{Neunter Brief.}

Bedeutung der Brückenkrümmung für die Entwicklung des Kleinhirus und der Medulla oblongata; Hemisphären des Grosshirns und deren Umbildung. Auftreten der Neissen Substanz . . 
Zelinter Brief.

Das Wachsthumsgesetz; räumliches und zeitliches Wachsthumsgefälle und deren Bedeutung für die schliessliche Ausbildung des Körpers .

Elfter Brief.

Theorien der Zeugung, Lxtract- und Präformationstheorien, Theorien formbildender Kräfte . . . . . . . . . . . . 130

\section{Zwölfter Brief.}

Die Theorien G.er übertragenen Bewegung

Dreizehnter Brief.

Vermittelung erblicher Uebertragung. Die Descendenzlehre und die Beziehangen der Morphologie zu derselben . . . . . . 156

\section{Vierzehnter Brief.}

Die Erklärung organischer Körperform durch das Descendenzprincip, das „biogenetische Grundgesetz" und seine Begründung. Unmittelbare und mittelbare Erklärung

Fuinfzehnter Brief.

Die Beziehungen embryonaler Formen zu einander; die erste Entwicklung des Amphioxus und des Petromyzon verglichen mit derjenigen von Knochenfischen

Sechszehuter Brief.

Ueber die specifische Physiognomie jüngerer Embryonen.

Siebzehnter Brief.

Beziehungen zwischen Descendenzprincip und Wachsthumsprincip. Schlusswort . . . . . . . . . . . . . . . . . . . 207

Bemerkungen . . . . . . . . . . . . . . . . . . . . 216 


\section{Verzeichniss der Abbildungen.}

In Betreff der Fig. 1, 2, 5, 6, 4, 10, $14 \mathrm{u} .15$ ist die Bemerkung I, 1 S. 216 zu vergleichen.

Fig. 1. Hühnchen vom 4. Tage der Bebrïtung. Dorsalansicht. 20mal vergrössert.

Fig. 2. Dasselbe. Ansicht yon der Banchseite.

Fig. 3. Querschnitt durch obigen Embryo. 40mal vergrössert. Prismazeichunng nach der Natur.

Fig. 4. Querschnitt desselben Embryo durch die Herzgegend. Zeichnung und Vergrösserung wie oben.

Fig. う. Hühnchen vom 3. Tage der Bebrütung. 20mal vergrösserte Rückenansicht.

Fig. 6. Dasselbe. Bauchansicht.

Fig. 7. Querschnitt durch den Embryo. Vergrösserung 40. Prismazeichnung nach der Natur.

Fig. 5. Primitivdarm des obigen Embryo. 20mal vergrössert. Form und Ausdehunng des geschlossenen Vorterdarms sind auf dem Wege der Construction festgestellt (siche meine Entwicklung des Hühnchens. S. 15\%) und nach dem Modell gezeichnet.

Fig. 9. Hühnchen vom Beginne des 3. Bebrütungstages. Vergrösserung $20 \mathrm{mal}$. Dorsalansicht.

Fig. 10. Hühnchen vom 2. Bebrütungstag. Vergrösseruug 20. Dorsalansicht.

Fig. 11. Querschnitt durch den Embryo Fig. 9. Vergrösserung 40. Prismazeichnung nach der Natur.

Fig. 12. Läugsschnitt durch das vordere Körperende eines Hühnerembryo vom 2. Bebrütungstage. Vergrösserung 40. Prismazeichnung nach der Natur.

Fig. 13. Querschnitt durch den Embryo Fig. 10. Vergrösserung 40. Prismazeichnung nach der Natur. 
Fig. 14. Hïhnerembryo vom Ende des 1. Bebrütungstages. Yergrösserung 20. Dorsalansicht.

Fig. 15. Embryonalanlage aus cinem etwa is Stunden bebruteten Hühnerei. Vergrösserung 20. Dorsalansicht.

Fig. 16. Schema zur Veranschaulichung der Keimfaltenumlegung.

Fig. 17. Gesicht des Embryo Fig. 9. Vergrösserung 211, nach Modell.

Fig. 15. Querschnitt durch den Kopt von Embryo Fig. 17,

Fig. 19.

Fig. 5 ; beide Figuren $40 \mathrm{mal}$ vergrössert. Prismazeichnung nach der Natur.

Fig. 20. Hinteres Leibesende eines Embryo vom 5. Bebrütungstage. Vergrösserung 20. Prismazeichmung nach der Natur.

Fig. 21. Schnitt durch das hintere Rumpfende eines Hühnchens vom 5. Bebrütungstage. Vergrösserung 10. Prismazeichnung nach der Natur.

Fig. 22. Gleicher Schnitt, etwas weiter hinten geführt.

Fig. 23. Schematischer Längsschnitt, um die Zusammenfaltung der primitiven Körperanlage zu veranschaulichen.

Fig. 24. Schema zur Darstellung der ursprünglich flächenhaften Vertheilung der Organanlagen.

Fig. 25. Wiederholung von Fig 1.

Fig. 2ti. Wiederholung von Fig. 5.

Fig. 27. Wiederholung ron Fig. 13.

Fig. 24. Wiederholung von Fig. 11.

Fig. 29. Querschnitt durch den Rumpf desselben Hühnchens wie Fig. 25, etwas weiter rom durchgeführt.

Fig. 30. Wiederholung ron Fig. i.

Fig. 31. Wiederholung von Fig. 3.

Fï. 32. Querschnitt durch eiu Hühnchen vom 4. Bebrütungstage. Vergrösserung 40. Prismazeichnung nach del Natur.

Fig. 33. Querschnitt durch den Rumpf eines Hühnerembryo rom Beginn des 3. Bebrütungstages. Vergrösserung ४.. Prismazeichnung nach der Natur.

Fig. 31. Querschnitt durch denselben, etwas weiter hinten.

Fig. 35. Wiederholung von Fig. 15.

Fig. 36-39. Schematische Figuren zur Veranschaulichung der Folgen ungleichen Wachstlums.

Fig. 40. Wiederholung von Fig. 34 .

Fig. 41. Stück lieimscheibe des unbebrüteten Hühnereies im senkrechten Durchschnitt. Vergrösserung 25!). Prismazeichnung nach der Natur.

Fig. 42. Stück Keimscheibe des Hühnereies nach Sstündiger Bebrütung, im senkrechten Durchschnitt Vergrösserung 250. Prismazeichnung nach der Natur. 
Fig. 43. Keimscheibe des Hühntreies. 15 Stmnlen bebrütet. Fergrösserung 10. Prismazeichnung nach der Natur.

Fig. 4t. Embryonalbezirk der Keimscheile im Stadium der Blätterspaltung, senkrechter Durchschnitt. Yergrësserung 250. Prismazeichnung nach der Natur.

Fig. 45. Keimscheibe des Huhnes nach 2tistündiger Bebrütnng, senkrechter Durchschnitt. Vergrösserung 150. Prismazcichnung nach der Natur.

Fig. 46. Wiederholung ron Fig. 15.

Fig. 47. Wiederholung ron Fig. 19.

Fig. 45. Querschnitt des Lachskeimes s Tage nach der Befruchtung. Vergrösserung 55. Prismazeichnumg vach der Natur.

Fig. 49. Dasselbe etwas reiter hinten.

Fig. 50. Wiederholung von Fig. 13.

Fig. 51. Schema der Nathbililung.

Fig. 52-5i. Querschnitte znr Bihlungsgeschichte des Herzens. Vergrösserung fo. I'rismazeichnungen nach der Natur.

Fig. 55. Querschnitt durch einen Hühnerembryo, woran gleichzeitig die Anlage der Brust- und diejenige der Banchhöhle zu sehen sind Yergrösserung 40. Prısmazeichnmng nach der Natur.

Fig. 59. Wiederholung ron Fig. 12.

Fig. 60. Wiederholung ron Fig. 4.

Fig. 61. Querschnitt turch den Aussenbezirk einer heimscheibe, vom Begimn des 3. Taģes. Blutgefässe und Blutinseln. Vergrösserung 250.

Fig. ti2. Wiederholnng ron Fig. 18.

Fig. 63. Wiederhohlung ron Fig. 19.

Fig. 64. Querschnitt durch cinen 3tägigen Hühnerembryo. Luftröhrenanlage. Vergrösserung 40. Prismazeichnung nach der Natur.

Fig. 1:5. Dasselbe etwas weiter hinten, Lungenanlage.

Fig. t6. Wiederholung von Fig. S.

Fig. 67. Schema zur Abschnürung der Gebilde des Vorderdarms $O G \mid C A L$

Fig. (is. Wiederholung ron Fig. 23.

Fig. 69. Wiederholung von Fig. 2.

Fig. 70. WiederhoInng ron Fig. 32.

Fig. i1-it. Wielerholung ron Fig. 2i-32.

Fig $i$. Wiedreholung ron Fig. 17.

Fig. 7 . Wiederhohng von Fig. 6.

Fig. 79. Wiellerholung von Fig. 2.

Fig. so. Gesicht eines Hühnchens nach כtägiger Bebrütıng. Smal rergrössert. Prismazeichnung nach ller Natur.

Fig. S1. Wiederholnng ron Fig. 9.

Fig. ৎ2. Gehirn eines Hülnnchens rom 2. Bebrütungstage. Vergr. 40. 
Hinsichtlich dieser und der zwei folgenden Figuren gilt dasselbe wie von Fig. 1, 2 n. s. w. Die Contouren sind nach der Natur, die körperliche Schraffirung nach dem Wachsmodelle ausgeführt.

Fig. 53. Gehirn eines Hühnchens vom Beginn des 3. Bebrïtungstages. Vergrösserung 40.

Fig. \$4. Gehirn eines 3tägigen Hühnchens. Vergrösserung 40.

Fig. 55. Gummischlauch, oben convex, unten concav gebogen.

Fig. \&6. Gummischlauch, dessen oberes Ende durch einen eingesetzten Zwirnfaden zurückgezogen ist.

Fig. 57. Geschlitzter Gummischlauch mit concaver Biegung.

Fig. S8. Geschlitzter Gummischlauch mit convexer Biegung.

Fig. 89. Geschlitzter und der Länge nach zusammengestossener Gummischlauch

Fig. 90. Wiederholung ron Fig. 10.

Fig. 91. Wiederholung ron Fig. S.

Fig. 92. Gehirn eines Hechtembryo, 3 Tage nach der Befruchtung. Vergrösserung 30 Hinsichtlich der Ausführung gilt von Fig. 92-94 dasselbe, wie von Fig. $\$ 2-\$ 4$.

Fig. 93. Gehirn eines Forellenembryo, 4 Wochen nach der Befruchtung. Vergrösserung 30.

Fig. 94. Dassclbe von oben gesehen.

Fig. 95. Hirn eines Salmenembryo von $2 \mathrm{Cm}$. Länge im Medianschnitt. Vergrösserung 20. Prismazeichnung nach der Natur.

Fig. 96. Hirn eines menschlichen Fötus aus der i. Woche. Seitenansicht, $2 \mathrm{mal}$ vergrössert.

Fig. 97. Gehirn eines menschlichen Fötus aus der 10. Woche. Seitenansicht, 2mal vergrössert.

Fig. 9S. Dasselbe, Ansicht vou hinten.

Fig. 99. Mediale Fläche der abgetragenen Hemisphäre. Die Fig. 17 -99 wurden nach Photographien gezeichnet, welche nach der Natur aufgenommen sind. Für die vordere Hälfte von Fig. 96 und von 99 habe ich ausgeführte Wachsmodelle mit benutzt.

Fig. 100. Wiederholung von Fig. S4.

Fig. 101. Gehirn des Hülnchens, Profilansicht. Vergrösserung 30. Nach Wachsmodell.

Fig. 102. Gehirn des Froschembryo, Profilansicht. Vergrösserung 30. Nach Wachsmodell.

Fig. 103. Gehirn des erwachsenen Huhnes. 2fache Vergrösserung.

Fig. 104. Gehirn des Frosches. jmal vergrössert.

Fig. 105. Gehirn ron Petronyzon fluviatilis nach Joh. Müller.

Fig. 106. Horizontalschnitt durch das Gehirn eines Rehfötus. Vergrösserung 6. Prismazeichunng nach der Natur. 
Fig. 107. Frontalschnitt durch den Kopf eines Kaninchenfötus. Vergrösserung 10. Prismazeichnung nach der Natur.

Fig. 10s. Gleicher Schnitt, etwas weiter hinten geführt.

Fig. 109-112. Wiederholung von Fig. 96-99.

Fig. 113. Gehirn eines ca. $4^{1}{ }^{1}$ monatlichen menschlichen Fötus vou aussen her gesehen. Der hintere Theil des Seitenventrikels ist eröffnet; nach der Natur.

Fig. 114. Hemisphäre desselben Gehirns von der medialen Seite her gesehen.

Fig. 115. Gehirn des Schafes nach Leuret, anf $3 / 5$ reducirt.

Fig. 116. Schematische Wachsthumscurven.

Fig. 117. Figuren zur Entwicklung des Amphioxus lanceolatus. Copien nach A. Kow alewsky auf halbe Grösse der Originalien reducirt.

Fig. 11s. Figuren zur Entwicklung von Petromyzon Planeri. Copien nach Max Schultze anf $2 / 3$ der 30 fach vergrösserten Originale reducirt.

Fig. 119. Lachskeim im Beginn des 6. Tages nach der Befruchtung, senkrecht durchschnitten. 40mal vergrössert. Prismazeichnung nach der Natur.

Fig. 120. Lachskeim im Beginn des 7. Tages nach der Befruchtuug, senkrecht durchschnitten. 40mal vergrössert. Prismazeichnung nach der Natur.

Fig. 121. Lachsembryo rom Beginn des 12. Tages. Prismazeichnung nach der Natur.

Fig. 122. Forellenembryo vom 12. Tage; beide Figuren sind in der Reliefansicht bei Beleuchtung von oben gezeichnet. Prismazeichnung nach der Natur.

Fig. 123. Lachsembryo vom Beginn des 14. Tages, ist ursprünglich im auffallenden Lichte gezeichnet. Prismazeichnung nach der Natur.

Fig. 124. Lachsembryo rom Beginn des 15. Tages, im durchfallenden Lichte gezeichnet. Prismazeichnung nach der Natur.

Fig. 125. Profilansicht von 123. Prismazeichuung nach der Natur.

Fig. 126. Schema zur Veranschaulichung der Körperbildung beim Knochentischembryo.

Fig. 12 $7-130$. Schematische Zeichnungen, um die Umwachsung des Dotters durch die Keimscheibe und die gleichzeitige Verläugerung des Embryo darzustellen.

Fig. 131. Lachsei 10mal vergrössert. Der Embryo im Profil gesehen, der Randwulst für vier verschiedene Entwicklungsstadien eingezeichnet.

Fig. 132. Menschlicher Embryo. Vergrösserung S. Prismazeichnung nach der Natur.

Fig. 133. Schweinsembryo. Vergrösserung S. Prismazeichnung nach der Natur. 

Natur.

Fig. 134. Rehembryo Vergrösserung \&. Prismazeichnung nach der

Fig. 135. Kaninchenembryo. Vergrösserung ऽ. Prismazeichnung nach der Natur.

Fig. 136. Meerschweinchenembryo. Vergrösserung \&. Prismazeichnung nach der Natur.

Fig. 13i. Hühnerembryo. Vergrösserung s. Prismazeichnung nach der Natur.

Fig. 135. Gesicht eines 5tägigen Hühnerembryo's. Vergrösserung :. Prismazeichunng nach der Natur.

Fig. 139. Gesicht eines 11 tïgigen Kaninchenembryo's. Vergr. 8. Prismazeichnung nach der Natur.

Fig. 140. Gesicht eines btägigen Hühnerfötus. Vergrösserung 8 . Prismazeichnnng nach der Natur. 


\section{Erster Brief.}

Die embryonale Körperform und ihre Entstehungsgeschichte.

Lieber Freund! Bei unserer jüngsten persönlichen Begegnung ist die Bedentung der thierisehen Körperform lebhaft zwischen uns besprochen worden, sowie anch die Rolle, welche der Entwieklmngsgeschichte bei deren Erklïrung zukommt. Dariiber sind ja zur Zeit alle Naturforscher einig, dass die Entwicklungsgesehichte ein Grundstein unseres Verstïndnisses organiseher Formen sei, nicht aber dariiber, wie dieser Grundstein bearbeitet und wie er beim Aufban einer wissensehaftlichen Biologie rerwendet werden miisse. Sïmmtliche Forseher, die in den Thatsachen der Entwicklungsgesehichte Höheres suchen, demn eine zeitliche Anfeinanderfolge mehr oder minder versehiedenartiger Bilder, verfolgen das Ziel, werdende und fertige Formen organiseher Wesen in ihrer Zusammengehörigkeit zu verstehen. Aluer wann ist iiberhaupt eine Form geistig verstanden?

Den Lehren der Deseendenztheorie gemïss sieht dermalen eine grosse Zahl von morphologisehen Sehriftstellern eine organische Form als verstanden an, wemn sie dieselbe einer Reihe von ähnnlichen Formen als ein, durch Uebergänge rermitteltes Glied eingereiht hat. Alsdaun nämlich ist, der Lehre zufolge, die Blutrerwandtsehaft der Form mit den iibrigen Gliedern der Reihe erwiesen, und rermöge der Gesetze der Erblichkeit und der Anpassung sofort auch erklärt. Der wissensehaftliche Schwerpmnkt der Entwickhngssesehichte wird in die Aufdeckung der Formähnlichkeiten verlegt, welche auf frühen Embryonalstufen selbst zwischen solehen Wesen bestehen, deren 'H is, Briefe. 
reife Gestalt der Vergleichung geringe Anhaltspunkte bietet. In dieser Hinsicht lietet die Entwicklungsgeschichte eine änserst reiehe Ausbente, und ihre Ergebnisse werlen ganz allgemein und mbedenklich als directe Beweisstiicke für den genetischen Zusammenhang organiseher Formen verwendet. Consequenterweise faillt damit der Entwicklungsgesehichte die Rolle' zu, der Descendenzlehre als Dienerin das Material herbeizuschaffen, dessen diese zum speziellen Ausbau des systems bedarf.

Alle Erfahrungen iiber Erlolichkeit und iiber Ampassung können uns mun aher, meiner Ueberzengung nach, der Nothwendigkeit nicht entheben, der Entwieklungsgeschichte ihre selbstständige Stellung und ilıre selbststindligen Anfigahen zu vindiciren. Die Entwicklnngsgesehichte ist ihrem Wesen nach eine physiologische Wissenschaft, sie hat den Aufban jeder einzelnen Form aus dem Ei nach den verschiedenen Phasen nicht allein zu beschreiben, sondern derart abzuleiten, dass jede Entwieklungsstufe mit allen ihren Besonderheiten als nothwendige Folge der numittelbar vorangegangenen erscheint. Als entfernteres 'Ziel steht vor ihr die Untersuchmog der Bedingurugen erblicher Uebertragmg sellost. Hat erst die Entwicklungsgeschichte fiir eine gegehene Form die Anfgabe plyssiologischer Ableitung durehgreifend erfiillt, dann darf sie mit Recht von sich sagen, dlass sie diese Form als Einzelform erklairt hahe. Schon bei der physiologisehen Erklairung einer einzelnen Form, noch mehr aber bei derjenigen ganzer Formenreilıen kömen Gesichtspmkte allgemeiner Art nicht ansbleiben, Gesichtspunkte, von welehen sicherlich nenes Licht iiber das Problem der organischen Form ansgehen wird. Sollte eine, anf solcher Grundlage sich erhebende Morphologie die Gedankenkreise nicht zu iiberschreiten hahen, in welchen hentige Schulen sich bewegen?

Als wir diese und andere verwandte Fragen erïrterten, da hast Du mir den Wunseh nach eingehenderer Begriundung der Ansichten ansgesprochen, die ich mir, an der Hand meiner Erfahrungen iiber die Entwieklung einiger höherer 'Thiere, von den Aufgaben und Methoden, sowie von der Tragweite embryologischer Forschung gebildet habe. Ich halye Dir meine Bereitwilligkeit erklärt, nenerding's iiber diese Dinge mich 
auszusprechen, allein das eine musst Du mir gestatten, dass ich Dich vorerst mit einer gewissen summe entwieklungsesehichtlicher Anschaumgen vertraut mache, als dem Boden, von dem ans wir späiter die Fragen allgemeinerer Natur in Angriff nehnien kömen. Zwar beabsichtige ich nieht, Dir melir Detailmitzutheilen, als einen Naturforscher, oder iiberhaupt einen grebildeten Mensehen interessiren kann. Immerhin werden wir manche in den Lehrbiichern wenig beachtete Verhailtnisse mit einander zu betrachten haben, die fiil das Verstaindniss entstehendel Formen bedeutungsvoll sind, andeles dafiì weglassend, woriiber jedes Lehrbuch geniigende Belehrung gielst.

Zum Begimm lege ich Dir die Zeichnumg eines Hiiluehens vor, so weit inseiner Form entwickelt, dass die Grundziige der späteren Kör'pergliedle- | Fig. I. Hühnchen vom vierten Tage der Bebrütung. rung daran eben erkenn-

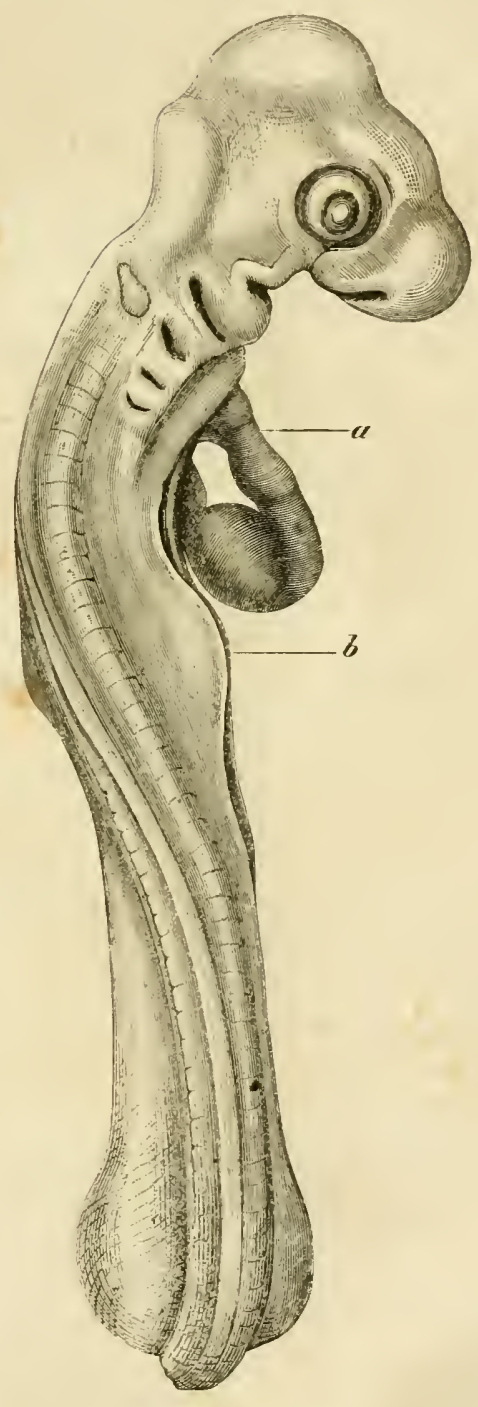

bar sind. 1) Den Kopf mit seinen grossen Augen, den Rumpf mit seinel queren Gliederung, die Extremitätenstummel und 


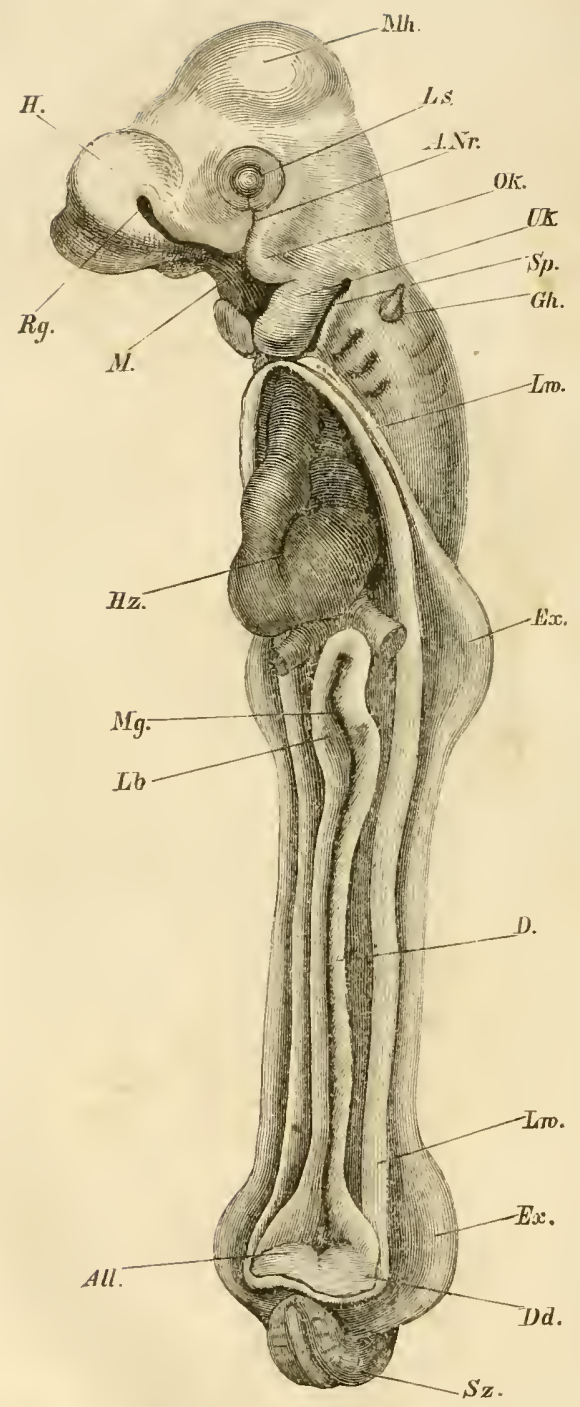

Fig. 2. Dasselbe in der Ansicht von der Bauchseite. Rg. Riechyrube.

H. Hemisphäre.

Mih. Mittelhirn.

Ls. Linse.

Ok. Oberkieferfortsatz

Uk. Unterkieferfortsatz.

M. Munđhöhle.

Gh. Gehörblase.

Lw. Umschlagsstelle der Leibeswand am Leibesnabel in das Amnion.

Dd. Umschlagsstelle des Darmdrūsenblattes. das Schwanzende des Körpers wird anch der Laie leicht unterschei(den. $\left.{ }^{1}\right)$ Von imnerenHauptorganen sehimmert das Hirn durch die :inssere Decke durch, während das Herz als doppelt gekriimmiter schlanch die Bauchfliche des Leibes fiei iberragt. Noch ist nïmlich der Leih nicht gesehlossen, eine schmale Spalte, der Leibesnabel genannt, beginnt hinter der Unterkiefergegend und zieht sieh ron da bis zwischen die hinteren Extremitiitenstummel. Du kamnst somit den Körper, in seiner vorliegenden Gestalt, als ein langgestrecktes Rohr auffassen, das beiderseits blind endigt und das an seiner Banchseite anfgeschlitzt ist. Das Kopfende des Rohres ist verdickt und vorn iibergehogen, seine Seitenwand mit den als Höcker hervortretenden Anlagen der viel Extremitaiteu besetzt. Der Sehluss des Leibes erfolgt allmaihlig dureh Ancinanderlegen und VerwachsenderRänder derNabelspalte. Der letzte Rest 
einer Oeffumng erhält sich beim Vogel, wie beim Sïngethier, bis zur Zeit der Geburt und dient bis zuletzt wichtigen Ernährungsgefaissen als Pforte. So lange häingt auch die Leibeswand lanfangs ummittelbar, spoiter durch Vermittelung des Nabelstranges) mit einer diumen, den Körper umgebenden Hiille, dem Amnion zusammen.

In dem ron der Leibeswand gebildeten Rohr liegt ein zweites, das, wie jenes, nach vorn und nach hinten hin blind endigt, in seinem Mittelstiick aber durch eine Spalte zuginglich ist. Es ist dies der sog. Primitivdarm, der in erster Linie die Anlage des Verdaumgsschlauches rom Pharynx bis zum After, näichstdem aber anch diejenige der Luftröhre nebst Kehlkopf, der Lungen, der Schilddriise, der Leber und des Pankreas unfasst. Sein geschlossener vorderer Theil heisst der Vorderdarm, der hintere der Hinterdarm. Der mittlere Theil öfnet sich am Darmnabel gegen den Dotterraum, und seine Wand setzt sich fort in eine den Dotter umgebende Haut, den Dottersack, oder die Nabelb lase. Der Unschlagsand der Wand deckt ron unten her ringsum den Zugang zur Leibeshöhle und die Ränder des Leibesnabels, wie Dir ans dem an der Stelle a durch den Embryo gelegten Quersehnitte Fig. 3 wird ersichtlich werden.

Der beistehende Quersehnitt giebt Dir gleieh anch einen summarischen Ueberblick iiber die Gliederung des embryonalen Leibes. Zunäichst unterseheidest Du an ihm zwei Platten, deren eine die aussere Leibeswand, die andere den Primitivdarm bildet, und von denen jede zu einem, nach abwïrts offenen Rohr zusammengerollt ist. Läugs der Mittellinie sind die beiden Platten unter einander verwaehsen, seitlieh davon dureh eine Spalte, die Leibeshöhle getrennt. Die obere ist bedentend mäiehtiger als die untere, und sie nimmt von der Mittellinie naeh den Seiten hin raseh an Dicke ab. Aus ihr entwickeln sich das Centrahnervensystem, die Simesorgane und rlie willkiirlichen Muskelı, sie heisst, mit Riieksicht daranf, die animale Schicht. Die untere Platte, nur solehe Organe bildend, welche dem directen Willenseinflusse entzogen sind, wird als vegetative Sehieht, las ans ihr gebildete Rohr als vegetatives Rohr bezeichnet, welch letztere Bezeichnung synonym mit Primitivdarm gebraueht wird. So treffend im All- 
gremeinen diese Bezeichnungen der beiden Schichten sind, so bietet doch ihre Anwendung, wie Du sehen wirst, innerhalb gुewisser Gränzgebiete Schwierigkeiten, mol lisst sich, wie alle Schematisirungen, nicht his anf das Aeusserste durehfiilren.

Das dickwandige, etwas plattgedriickte Rohr inmitten der animalen Platte, Medullarrohr genamnt, ist die Anlage des Centralnervensystems. An seiner Bauchseite liegt die Chorda dorsalis, ein eylindrischer Strang, um welchen herum sich

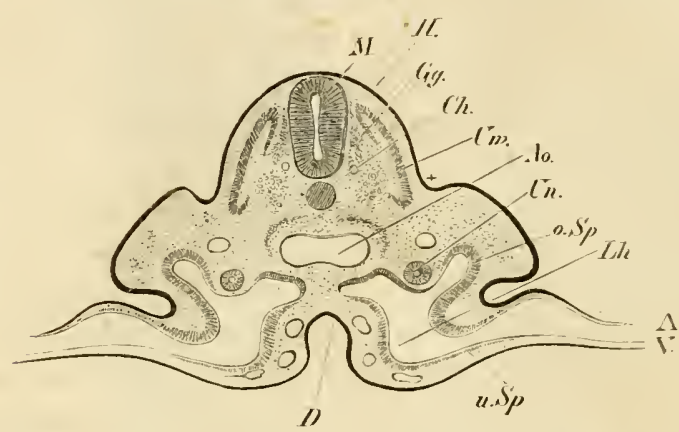

Fig. 3. Querschnitt durch obigen Enbryo. 4(1mal vergrössert.

A. animale Schicht.

H. Hornblatt.

M. Medullarrohr.

Ch. Chorda dorsalis.

Uw. Aus den Urwirbeln stammende Mnskelplatte.

G. Ganglienanlagen.

Ao. Aorta.

Tn. Urnierengang.

0 . Sp. Obere Seitenplatte.

V. Vegetative Schicht sich gliedernd im Darmdrüsenblatt. Gefässblatt und MuskelpIatte.

L. h. Leibeshōhle.

D. Darminne.

$\dagger$ Gränze ron Stammzone und Parietalzone.

später die Wirbelkürper bilden, darunter ein doppeltes Blutgetaiss, die alssteigende Aorta. Die Riickfliche des Medullarrohres, sowie die gresammte Anssenfliehe der animalen Platte ist von einer diumen Schicht bekleidet, welche die Anlage der Oberhant und der von ilı alsstammenden Horngebilde ist, und das Hornblatt heisst. Sie setzt sich jenseits rom Leibesnabel in das Amnion fort.

Der Theil der animalen Platte, welcher seitwärts rom. Medullarrohr und vou der Chorda liegt, gliedert sich auf sehr kenntliche Weise in zwei ungleich starke Zonen. Die imnere behält auch in der Folge ihre Lage neben den Axial- 
gebilden des Körpers, und kamn als Sta m $\mathrm{mz}$ one bezeichnet werden, ans der andern bilden sich die seitliche und die vordere Leibeswand, sie heisst daher Wand-oder Parietalz 0 n e. In beiden Zonen liegt unter dem Hormblatt eine radiärstreifige Schicht, die Anlage quergestreifter oder a 1 i m a l e r M u s e 1 latur. Den Stammtheil der animalen Muskelsehicht nennen wir mit Remak die R ii ckentafel, den Parictaltheil die obere Seitenplatte. Auf unserer rorliegenden Entwicklungsstufe sind die Muskelanlagen iiberlagert und theilweise bereits untermengt mit Gewelsamlagen fiir Bindegewebe und Gefiisse.

Auch die regetative Platte zeigt eine Gliederung in Schichten. Die nnterste, dem Dotter aufliegende Schicht liefert nur Epithelien und drisige, ans ihnen hervorgehende Parenehyme. Sie heisst das Darmdriisenblatt. Die der Leibeshöhle zugewendete obere Schicht liefert regetative Muskeh (vegetative Muskelplatte), zwischen ihr und dem Darmdrisenblatt liegt eine mittlere Gefäis- und Bindegewebsschicht (das Gefässblatt). Du bemerkst die symmetrie in der Schiehtengliederung beider Rïhrenwandungen, die animale gliedert sieh in Epithelialplatte, Bindesubstanz- und Muskelplatte, die regetative in Inskelplatte, Bindesubstanz- und Epithelialplatte. Die beiden Epithelialschichten bilden den änssern und den innern Abschluss, und kïnnen mit Riicksicht hieraut als Gränzblätter zusammengefasst werden, die beiden M uskel plat te $n$ aber begräinzen die Leibeshïhle und wenden ihre freien Fliichen einander zit.

Endlieh ist noch auf die Leiste aufurerksam zu machen, welche jederseits auf der Grinze der Stammzone gegen die Leibeshöhle vorspringt, die Uruicrenleiste, und welche die Anlage der sog. Urnieren nud der Sexualorgane enthïlt.

schnitte, die in anderen Höhen durch den Körper gelegt werden, ergeben im Allgemeinen iibereinstimmende Gliederung,

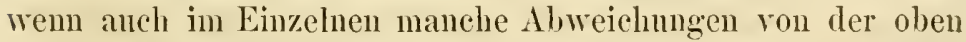
beschriebenen Form vorhanden sind. Zur Tergleichung lege ich Dir einen Schnitt bei, der in der Herzgegend dureh den Körper gefiihrt worden ist. Die wiehtigsten Unterschiede sind:

Geschlossensein des regetativen Rohres; Tremunng seiner Lichtung in eine vordere Abtheilung, die Luftröhren-, und in eine hintere, die Speiseröhrenanlage; Torhandensein des Her- 
zens, das hier noch durch ein diimmes Gekröse mit der Mnskelwand des vegetativen Rohres zusammenhängt; Fehlen der Urwirbelleiste und starke Abplattmng der Stammzone.

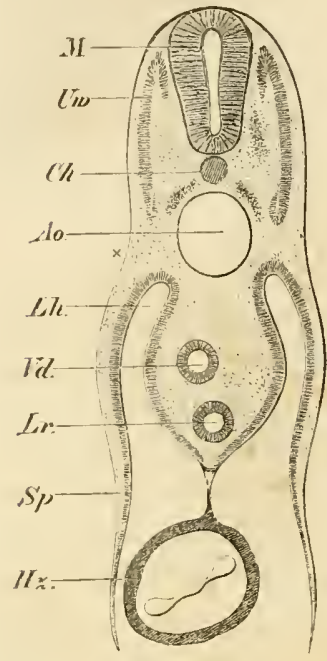

Fig. 4. Querschnitt durch den Embryo bei $b$. 4 (imal vergrössert. Die Buchstabenbezeichnungen sind dieselben wie bei Fig. 3.

Vd. Vorderdarm.

Lr. Luftröhre.

Hz. Herz.

Noch grössere Abweichnngen wiirden die dureh den Kopf gelegten Schuitte ergeben. Da es mir indess daran liegt, Dir vorerst in grossen Ziigen die Geschichte des ersten Körperaufbanes zu entwerfen, verspare ich alle weitern Einzelbetrachtungen unseres Embryo anf spiter, und gehe zu einer etwas friihern Entwicklungsstufe iiber, wie sie Dir Fig. 5 in der dorsalen, Fig. 6 in der ventralen Ansicht darstellt. Auch bei dieser wirst Du den Kopf und den vordern Rumptabsehnitt leieht verstehen, wenn auch diese Theile in ihren absoluten und in ihren relativen Dimensionen verschiedentlich von der vorhin betrachteten Form abweichen. Fremdartigere Verhältnisse bietet der hintere, etwa zwei Drittheile der Länge umfassende Abschinitt des Körpers. Noch unvollkommen von der Ungebung abgegliedert, erscheint er als flache, dorsalwaits vortretende Erhebung, und wird seitlich sowohl, als anch riickwairts von einer seichten Furche umgrünt. Ein Bliek auf den Durchschnitt Fig. 7 erginzt das, was wir ans dem Fliichenbilde erfahren. Es verhält sich näimlieh dieser Sehnitt zu dem von Fig. 3, als ob man jenen an seinen Rändern gefasst und auseinander gezogen hïtte: animale und regetative Platte sind abgeflaeht und breiter, die freie Oberflaiche der ersteren ist gan/ und gar dorsalwärts gerichtet. Analog der seitliehen verhält sich die hintere Leibesgränze, anch da ist hinter einander flach ausgebreitet, was auf späterer Stnfe, in starkem Sförmigen Bogen zusammengedräingt ist.

Die Modellirmng der Riickenfläche entspricht der innern Gliederung der animalen Platte. Eine mittlere Leiste, die 
Med ull a r le is te, bezeichnet das Medullarohr. Nochinnerhalb der Stanmzone liegen neben ihr die zwei Urwirbelleisten, dureh ihre queren Einschnitte auffallend. Damn folgt, durch eine Rimne getrenut, jene der Parietalzone zugehörige Er-

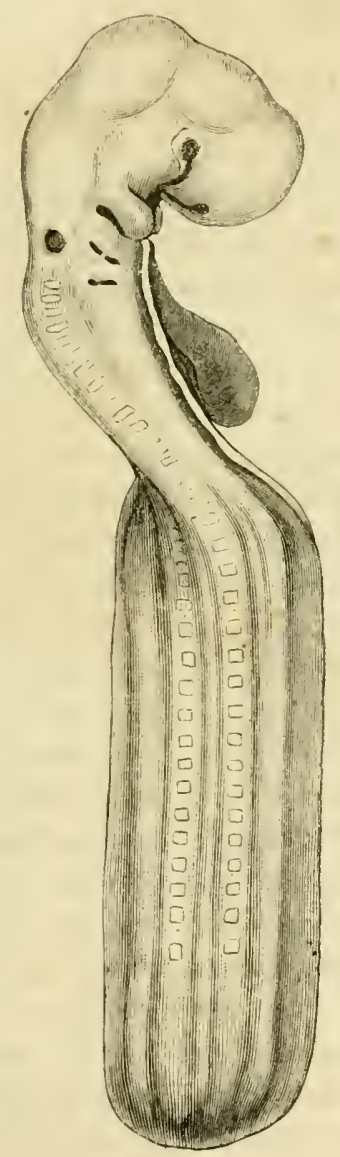

Fig. 5. Hūhnchen rom dritten Tage der Bebrūtung. 20mal rergrösserte Dorsalansicht.

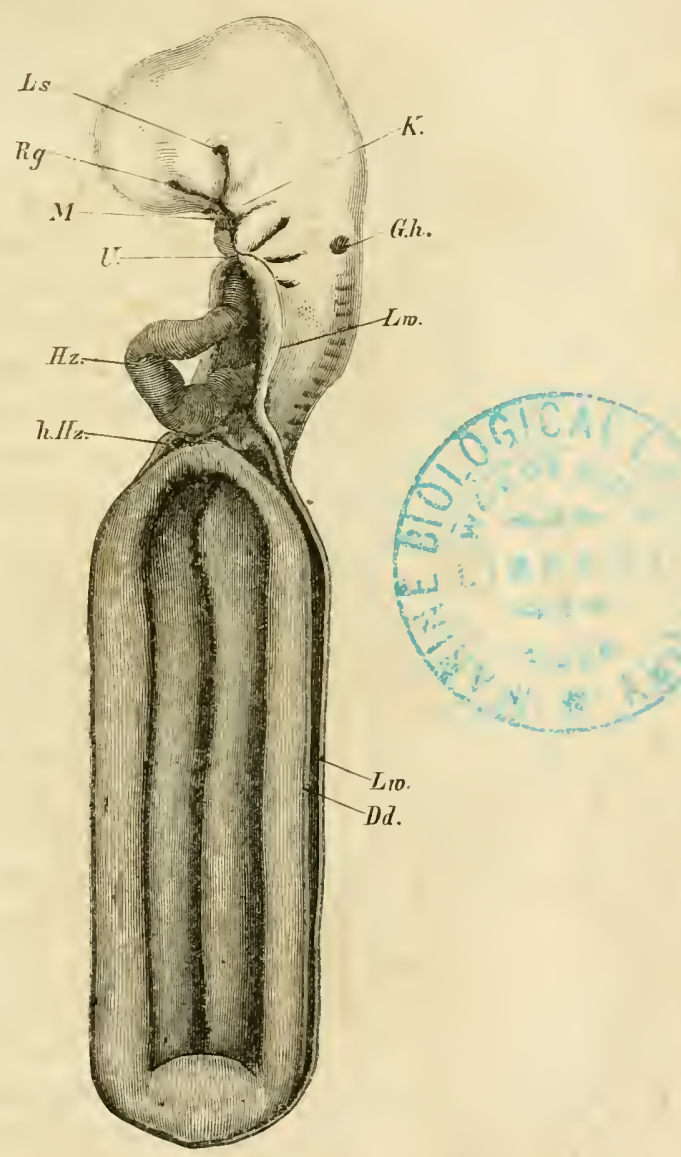

Fig. 6. Dasselbe in der Ventralansiclit.
R. Riechgrube.
Ls. Linsengrube.
Gh, Gehörgrube.
M. Mundhöhle.
0 . Oberkieferfortsatz.
U. Unterkieferfortsatz.
Hz. Herz.
h. Hz. II interer Herzschenkel.
Lw. Umschlagsstelle der Leibes- wand in das Amnion.
Dd. Darmdrūsenblatt. 


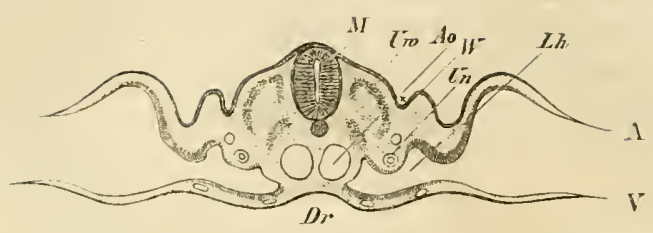

Fig. 7. Querschnitt durch obigen Eıbryo in der Gegend a. 4umal vergrössert. Bedeutung der Buchstaben wie bei Fig. 3.

hebung, die, wie wir oben sahen, mit fortschreitender Entwicklung sich mmlegt und dam eine Art seitlicher Kante der Leiljeswand darstellt. Anf diese Kante latte schon in vorigen Jahrhundert C. Fr. Wolff aufmerksam gemacht und sie mit der Extremitaitenbildung in Beziehmng gebracht, wir kïmnen sie daher als Wolff"sehe Leiste bezeichnen.

Die Extremitaten sind an mserm Embryo nur leicht, aber immerdin dentlich angelegt. Als Ort der vordern Extremititen erkemust Du die Krenzungsstelle zwischen der Wolffschen Leiste und einer, rom Vordertheile des Rumpfes herkommenden schrägen Falte. Dic Anlagen der hinteren Extremititen sind da, wo die Wolffsche Leiste mit einer am hintern leibesende befindlichen Querfalte sich sehmeidet. Anf die merkwiirdige Seitwiirtslegmng ron Kopt- und vorderem Rumpftheil, sowie auf die versehiedenen Biegmgen der Körperaxe mache ich Dich nur im Vorbeigehen anfmerksam; liese Dinge werden ms spaiter nochmals beschïftigen.

Sowie die iussere Leibeswand dermalen mur in ihrem vordem Abschmitt den Charakter eines Rohres träigt, in ihrem hintern aber den einer dotterwärts breit geöffneten Rimne, so anch der Primitivdarm. Der Vorderdarm ist (Fig. 8) ein bis hinter das Her\% vollständig umwandetes Rohr, sein Sehluss reicht somit bedentend weiter nael riickwiirts, als der des ainssem Leibes. Nittel- und Hinterdarm dagegen sind erst als eine flache, breite limme angelegt, in der drei Partialrinnen unterseheidbar sind: eine mittlere, die eigentliche Anlage rom Magen und Darm, und zwei seitliche, deren oberer Abschnitt hei Bildung der Leber betheiligt ist.

Wir begleiten den Embryo zu noeh fribheren Stufen, deren zwei in den Figuren 9 und 10 wiedergegeben sind. Da die 
beiden Stufen nur gradweise ron einander muterschieden sind, kömnen sie leicht anf einander bezogen und gemeinsam betrachtet werden. Die eine, Fig. 9, mag die Briicke zu den rorgeriickteren, dic andere, Fig. 10, die zu den unentwickelteren Formen bilden. Ein Zeitraum ron wenigen Stumden tremnt die Form Fig. 9 rou derjenigen der Fig. 5, und docll ist, wie Du siehst, der Sprung ein ziemlich hedentender. Der Körper liegt gestreckt mud liisst sich (wemn wir rom Herzen absehen) durch eine Ebene in zwei symmetrisehe Hailften theilen. Der Kopf entbelurt einer stärkeren Axenknickmo lind ist, wie der gesammte Vorderkiorper, erheblich breiter und niedriger als späiter. Mittelund Hinterkörper sind noch flacher, als auf der Stufe Figur 5, allein anch der Vorderkörper erscheint nummehr mur als breite, faltenartige Emporwölbung einer, im Uebrigen flach iiber den Dotter sich ausbreitenden Seheibe, der Keimscheibe. Nur das Kopfende des Körpers tritt selbstständiger herror, und iiberragt als freier Fortsatz eine rou der Keimhaut ror dem Embryo gebildete Grube. Scine dem Grubengrunde zugewendete Flïche entspricht der späteren Gesichtsflaiche des Kopfes. Eimzig dies vorderste Ende des Kürpers hat sonach den Charakter eines Rolıres, was dahinter liegt, denjenigen einer flachen Rimne.

Das Medullarrohr ist, wie Dir anch Fig. 11 zeigt, bereits vorhanden, sein rorderer breiter und dureh Einschnitte gegliederter Theil ist Anlage des Gehirns und der sog. Angenblasen,

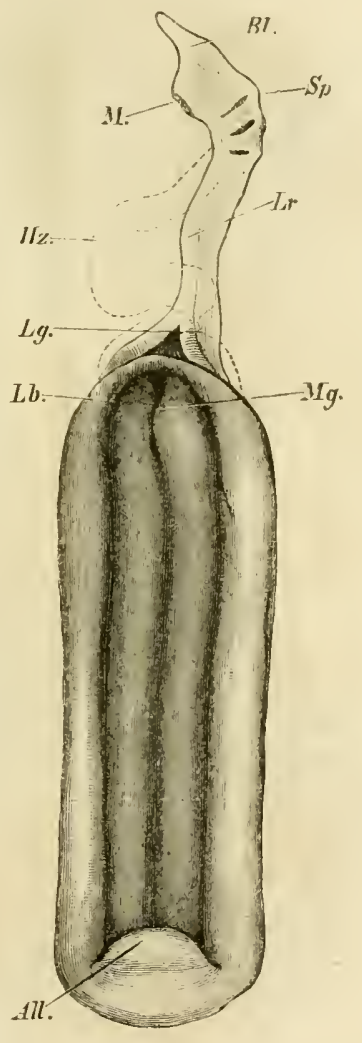

Fig. S. Prinitivdarm des obigen Lmbryo. 20mal vergrössert. Die punktirte Linie zeigt die Lage des

B1. Blindes mit dem Hirn rerbundenen Ende des Vorderdarms (sog. Rathkesche Tasche).

I. Berūhrungsstelle des Yorderdarms mit dem Grand der Mnndhöhle.

Sp. Sehlundspalten.

IIz. Herz.

Lr. Luftröhrenanlagre.

Lg. Lungenanlage.

Lb. Ort der Leberanlage.

Mg. Ort der Magenanlage.

All. Ort der Allantoisanlage. 
der Rest die Anlage des Riickenmarks. Daneben liegt jederseits eine Reihe viereckiger Tafeln, d e r U rwirbel, deren Zahl,

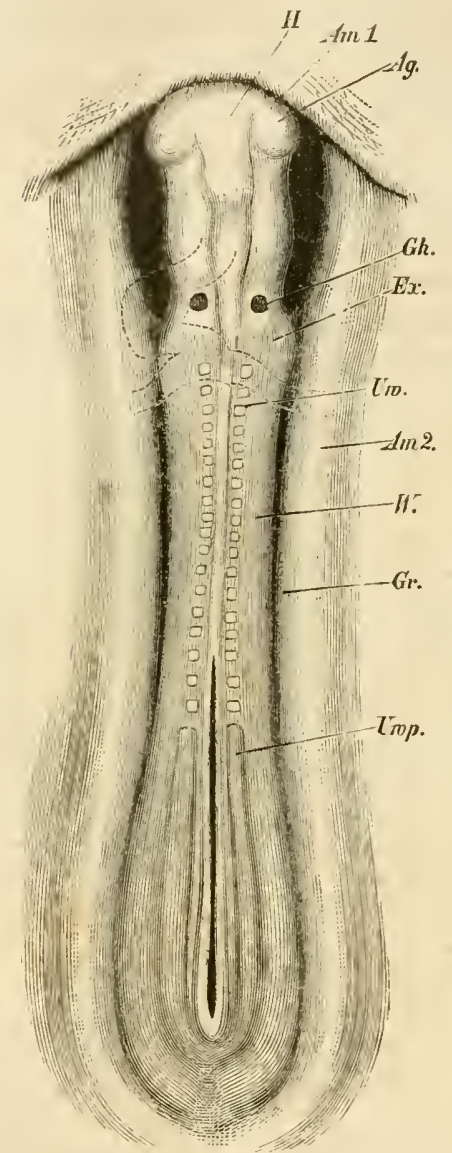

Fig. 9. Hühnchen zwischen dem zweiten und dritten Bebrütungstag. $20 \mathrm{mal}$ vergrösserte

H. Hirn, Dorsalansiclit. Dorsalansicht.
Vorderhirn, Mittelhirn und Hinterhirn sich gliedernd.

Ag. Augenblase.

Gh. Gehörblase.

Ex. Formanlage der vorderu Extremitāten.

W. Wolffsche Leiste.

s. Gr. Seitliche Gränzrinne.

Uw. Urwirbel.

Uwp. Urwirbelplatte.

Am. 1. Vordere Amnionfalte.

,2. Seitliche

G. Grube unter dem" freien Kopfende.

Die punktirte Linie bezeichnet den Ort des Herzens.

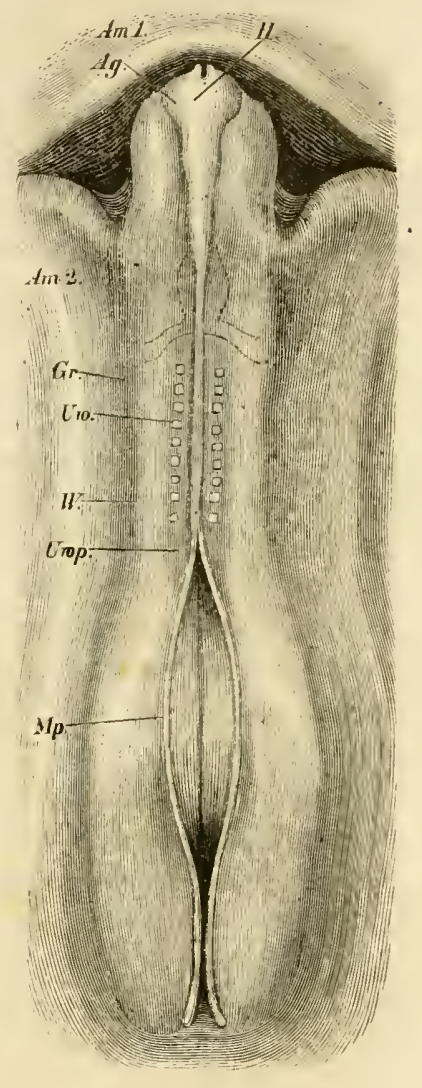

Fig. 10. Hühnchen rom zweiten Bebrütungstag. 20mal vergrösserte Dorsalansicbt.

Bezeichnungen wie bei Fig. 9 .

Mp. Offener Theil des Medullarrohres, Medullarplatte.

(Der Ort des IIerzens ist durch punktirte Linien angegeben, das Herz ist noch gestreckt). 
wie die Vergleichung versehiedener Entwicklungsstufen ergiebt, wïhrend mehrerer Tage zunimmt. Nur sehr wenige Urwirbel entstehen vor den zuterst angelegten, die iibrigen nen hinzukommenden treten hinter den bereits rorhandenen anf. Die Urwirbel liegen unter dem Hornblatt, iiber dem Darmdriisenblatt, seitlich ron den Medullarrohr und von der Chorda dorsalis. Sie sind nicht die ummittelbaren Vorliufer der bleibenden Wirbel, nur insoweit stehen sic mit diesen in Beziehung, als die spätere Gliedermug der Wirbelsäule ron ilırer Gliederung bestimmt wird. Der Ort eines Wirbels naimlich entspricht dem Zwischenranme zwisehen zwei Urwirbeln.

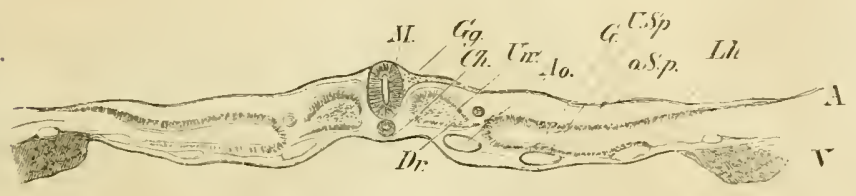

Fig. 11. Querschritt durch den Embryo Fig. ?. 40mal vergrössert. Buchstabenbezeichnung wie bei Fig. 3.

Dic Bezielumg zwischen Urwirbelı nud Wirbeln giebt cin Mittel an die Hand, schon friihzeitig zu erkennen, wo die Gränze zwischen Kopf und Rnmpf liegt. Der vorderste Urwirbel bezeichnet eben diese Grinze, und eine Controlle dafiir liefert die sog. Gehörblase. Es ist dies ein, auf unserer Stufe noch als offene Grube angrelegtes Organ (Gh. Fig. 9), das sich spïter zu einer geschlossenen Blase nmbildet. Dies Oroan ist die Anlage des Gehörlabyrinthes mol als solches jedenfalls dem Kopf angehörig, seine Lage hat es jederseits in geringer Entfernung vor dem rordersten Liwirbel.

Mit Hiilfe der amgegebenen Kriterien erfahren wir, dass der freie vordere Körperfortsatz die vordere Hailtte des Kopfes ist, die lintere Hiilfte besitzt noch die Gestalt einer offenen Rinne. Die beiden Abtheilungen sollen in Zukunft als Vorderk op fund als Hin terkopf unterschieden werden. In Bereiche des Hinterkopfes liegt das Herz, das mit seinem hintersten Ende eben noch die Gegend der ersten Urwirbel erreicht. Noch bestimmtere Aufschliisse iiber die Gliederung des Kopfes giebt Dir ein in der Mittelebene geführter Längssehnitt Fig. 12. 


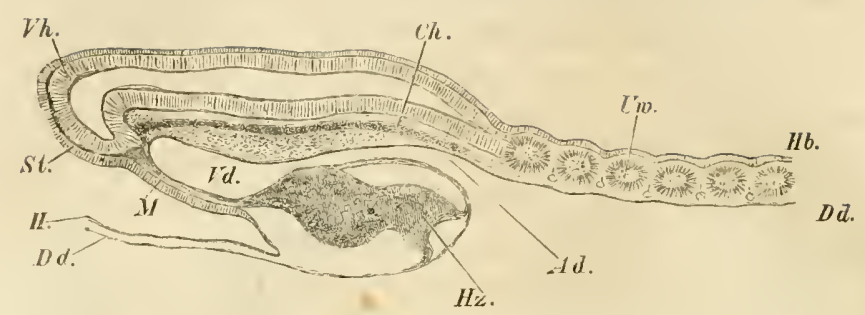

Fig. 12. Längsschnitt durch einen Embryo vom zweiten Bebrütungstage. 4/mal vergrossert.

Vh. Vorderhirn.

Vd. Vorderdarm.

Ad. Zugang zum Vorderdarm.

Hz. Herz.

Ch. Cliorda dorsalis.

Uw. Urwirbel.

St. Stirnwulst.

M. Mundbucht.

Dd. Darmdrüsenblatt.

$\mathrm{Hb}$. Hornblatt.

Du siehst nämlich daran, dass das vordere Ende des Vorderdarms das äusserste Koptende nicht erreicht, sondern vorher schon blind endigt. Sein Ende ist mit der mutern Fliiche des Medullarrohres und mit dem vordern Ende der Chorda dorsalis verwachsen, und der Vorderkopt zerfailt demmat in zwei $A b$ schnitte, den Stirntheil und den Gesiehtstheil. Der Stimtheil wird rom vordersten Gehimalsehnitte und von seinen Hiillen gebildet, der Gesiehtstheil musehliesst unterhalb des Gehirnes die Chorda dorsalis und das blinde Ende des Vorderdarms. Anf der Grïnze rom Stimtheil und rom Gesiehtstheil liegt die Anlage des Anges, die A ugenblase, in der Fläehenansicht als ein seitlich aus dem Gehim hervortretender Fortsatz, erkembar. Im Gesichtstheile ruht, wie Du an der Fig. 12 bemerken wirst, die mitere Wand des Vorderdarms, eine Strecke weit ummittelbar auf dem Hormblatt auf. An der Beriihrungsstelle beider bildet sich später ein Durchbruch, welcher den Blindsack des Vorderdarms, den später'n Pharynx mit der von aussen daran sieh anlegenden Mundhöhle in Verbindung. setzt.

Anf' eine neue Eigenthim lichkeit stossen wir beim Embryo von Fig. 10. Das Medullarrohr uämlich ist nur in Kopt- und im vordern Rumptheile geschlossen, dahinter iffinct es sich mit weit auseinander klaffenden Rändern, eine zweite kleinere Oeffnumg zeigt auch das allerrorderste Ende. Um Dich 


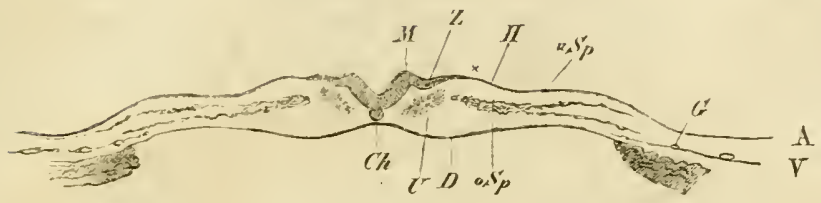

Fig. 13. Querschnitt durch den Embryo Fig. 10 bei a. Itmal rergrössert Dorsalansicht.

M. Medullarplatte.

Z. Zwischenrinne.

11. Hornblatt.

U. Urwirbelplatte.

S. Seitenplatte.

D. Darmarüsentlatt.

Ch. Chorda dorsalis.

zu orientiren, lege ich Dir einen Querschnitt durch diesen Embryo bei, der denselben in a trifft. Du erkemnst lier das Medullarrohr als eine gebogene Platte, deren Riander sich durch Vermittlung eines kleinen, rinmentömig' eingebogenen ' Zwischenstiickes in das Homblatt fortsetzen. Nedullarplatte, Zwischenstiick und Hornblatt sind somit zusammenhängende Bestandtheile einer und derselben Schicht, des oberen Grïnzblattes. Die Medullarplatte legt sich in der Folge zum Rohre zusammen und ilure Seitenränder gelaugen zur Vereinigung. Gleichzeitig verbinden sich die imeren Rimder des Hornblattes, während das Zwischenstiick als dreikantiges Einschicbsel in den Winkel zwischen Hornblatt und Medullarohr zu liegen kommt. Aus dem Zwischenstiick gebén die Anlagen der Gauglien lerror; der Boden des Medullarrohres ist mit der Chorda, und diese wiederum mit dem Darmdriisenblatt verwachsen.

Denke Dir das Medullarrohr seiner gauzen Lïnge nach aufgerissen und zugleich den frei rortretenden Toiderkopf relkiirzt, so erhïltst Du cin Gebilde, das im Wesentlichen der Entwicklungsstufe von Fig. It entspricht mul bei seiner noch weiteren Flachstreckung der Stufe Fig. 15. Schon hei Fig. 14 kannst Du kein bestimut abgegliedertes Organ meln erkemnen. Die Medullarplatte hebt sich zwal deutlich rom iibrigen Grïnzblatt ab, aber noch ist sie an keiner Stelle von ilnn geschieden, ein Herz ist nicht rorhanden, ron Lrwirbeln zeigen sich nur die ersten spuren. Die dotterwärts offene Rimne der itusseren Leibeswand zeichnet sich aus dureh ihre Breite 
und durch ihre geringe Tiefe. Dasselbe gilt rom Primitirdarm. Beide Rimnen laufen nach vorn in einen kurzen breiten Blindsack aus. Bei Fig. 15 fehlt endlich auch dieser, an seiner Stelle liegt eine, im Bogen verlaufende Querfalte, an welcher beide Sehichteu der Embryonalanlage betheiligt sind. Zwisehen dem vordern Ende der Stufen 14 und 15 besteht somit der-

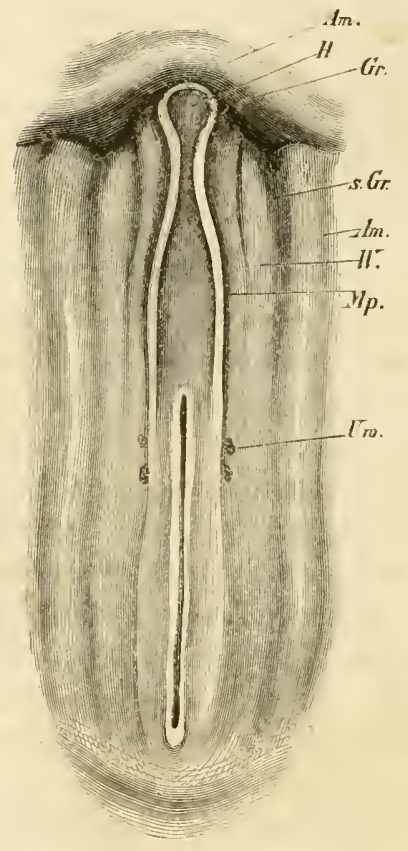

Fig. 14. Hühnerembryo vom Ende des ersteu Bebrütungstages. 20mal rergrössert. Dorsalansicht. Bezeichung wie bei Fig. 9 .

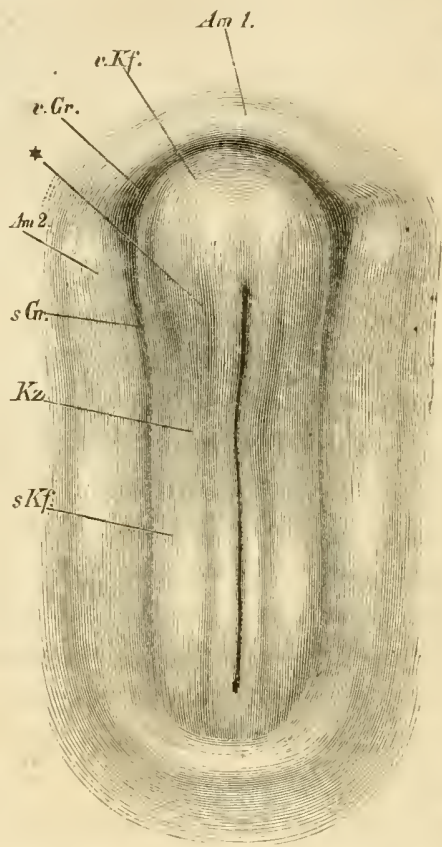

Fig. 15. Embryonalanlage aus einem etwa 1) Stunden bebrüteten Hühnerei. Dorsalansicht.

selbe Formunterschied, wie zwisehen den hinteru Enden oder den hintern Seitenrändern ron Fig. 1 und 5. Was bei Fig. 14 Sförmig zusanmengedrängt ist, liegt bei Fig. 15 hintereinander und es sieht die Gesichtsfliehe der Vorderkopfanlage nummehr greichfalls dorsalwäirts. Der embryonale Körper charakterisirt sich jetzt, äusserlich betrachtet, nur durch ein System sich kreuzender Falten und wird von einem gleichfalls sich kreuzenden Strstem von Rinnen umgeben. Eine rordere, bogen- 
förmig vorgetriebene Querfalte bezeiehnet das vordere Kopfende, und wird dureh eine davor liegende Rimue abgegränzt. Zwei seitliche, anch wiedermm an Rinnen anstossende Falten bezeiehnen die Seitentheile des Leibes, wïhrend das hintere Leibesende noeh wenig bestimmt sich hervorhebt. Im Bereiehe der Körperanlage seheidet eine mediane, in Kopftheil seichte, im Rumpftheil tiefe Längsfurehe die reehte von der linken Hailfte. Zwei sehwäehere Furehen deuten auf die Abgräinzmg der Medullarplatte, eine breite Querfurehe auf die ron Kopf und Rumpf. Glätte anch diese letzten Falten und Furehen noeh aus, so erhältst Du eine ebene Seheibe und als solche erscheint in der That der Keim des Vogeleies vor, und in den allerersten Stunden nach Beginn der Bebriitung. 


\section{Zweiter Brief.}

Princip der organbildenden Keimbezirke, dorsale und ventrale Flächen der Embryonalanlage und deren Sonderung; vorderes und hinteres Körperende; allgemeine Topographie der Keimbezirke.

Lieber Freund! Im vorigen Briefe habe ich versucht, in riickliufiger Reihenfolge Dir vom Hiihnerembryo die Grundziige des Körperaufbanes verstindlich zu machen. Wiirde Dir aufgegeben, den reifen Vogel- oder den in iibereinstimmender Weise entstehenden Sängethierkörper durch eine Reihe von Operationen wieder auf seine elementare Form zuriekzutïhren, so wiirdest Du damit beginnen mïissen, die Hals-, Brust- Ind Bauchwand dureh einen medianen Sehnitt voun Kinn bis zum Damm aufzuschlitzen, dann wiirdest Du die Leibeswand der Quere nach auseinander ziehen, und mehr und mehr flach ausbreiten. Vom Ruicken her wiirdest Du in der Folge das Gehirn und das Riickenmark einschneiden, und so die Mögliehkeit gewinnen, diese Theile in dieselbe Fläche anfzuklappen, in welehe Du die Leibeswand ausgebreitet hast. Der Vorderkopf wiirde als ein Blindsack verbleiben, den Du durch Zug' in der Laingsrichtung und durch Flachstreichen zu beseitigen hïttest, und auch das hintere Leibesende wïrde ein Auseinanderzielıen in longitudinalem Sinn erforderu. - Aehnliche Operationen wie mit der Leibeswand, d. h. Autschlitzen, flaches Ausbreiten der geöffneten Wand und schliessliehes Ausgleiehen zweier Endtaschen, häittest Du gleichzeitig mit dem Verdaumgsehlauche volzunehmen, und als Endergebniss vou allem dem wiirdest Du zwei Platten iibrig behalten, welche liing's einer, als Axe zu bezeichneuden Linie zusanmenhängen wiirden.

Diese sïmmtlichen Operationen wirst Du selbstrerstaudlich nur in Gedanken ausfiilıren können, denn dereu wirkliche 
Austiihrung setzt eine Weichheit und Dehnbarkeit, sowie eine innere Gleichartigkeit der Körpergewebe voraus, welche factisch nicht vorhanden ist. Hast Du indess in Gedanken die Flachlegung des Körpers versucht, so wird Dir klar geworden sein, dass einestheils jeder Punkt im Embryonalbezirke der Keimseheibe einem späteren Organ oder Organtheil entsprechen muss, und dass anderntheils jedes ans der Keimseheibe hervorgehende Organ in irgend einem, räumlich bestimmbaren Bezirk der flachen Scheibe seine vorgebildete Anlage hat. Wem wir die Anlage eines Theiles in einer bestimmten Periode entstehen lassen, so ist dies genauer zu präcisiren: Das Material zur Anlage ist schon in der ebenen Keimscheibe vorhanden, aber morphologisch nicht abgegliedert, und somit als solches nicht ohme Weiteres erkennbar. Auf dem Wege riickläufiger Verfolgung werden wir dahin kommen, auch in der Periode nuvollkommener oder mangelnder morphologiseher Gliederung den Ort jeder Anlage räumlich zu bestimmen, ja wenn wir consequent sein wollen, haben wir diese Bestimmung anch anf das eben befiruchtete, und selbst anf das unbefinchtete Ei auszudehnen. Das Princip, wonach die Keimscheibe die Organanlagen in flacher Ausbreitung vorgebildet enthält, und umgekehrt, ein jeder Keimscheibenpunkt in einem spätern $\mathrm{Or}^{-}$ gan sich wiederfindet, neme ich das Princip der organbildenden Keimbezirke.

Die Entwicklung des Körpers zeigt einestheils eine zulnehmende Abgliederung der primären Anlagen, anderntheils gegenseitige Lageverschiebungen und fortgesetztes Wachsthum derselhen. Alle in der Keimscheibe vorhandenen Anlagen wachsen, aber ihr Wachsthum gesehieht nicht den urspriinglichen Grössenverhältnissen gemäss: die emen wachsen rascher, andere langsamer, die einen hören friiher, andere späiter zu wachsen anf, und indem so eine jede ihrem besondern Gesetze gemäss wächst, werden die spätern Organe nicht allein in Betreff ihrer gegenseitigen Lagerung von den primären differiren, sondern anch in Betreff ihrer relativen Massen und Maasse. Wir bezeichnen dies wichtige Princip als das des ungleichen Wachsthuns und werden später einlässlich auf dasselbe zurückzukommen haben.

Für die animalen Anlagen der Keimscheibe stellt sich nach 
dem, was wir im ersten Briefe gesehen haben, die allgemeine Topographie also: Was im Körper rechts liegen soll, liegt auch in der Keimscheibe rechts und nmgekehrt, dagegen fehlt noch der Gegensatz einer ventral- und einer dorsalwärts gerichteten Fläche. Von den in der Folge ventralwärts sebenden Theilen liegen einige vor, andere seitlich und wieder andere hinter den Anlagen der dorsalen Körpertheile und sie richten s:immtlich ihre freien Flächen nach aufwärts. Der Weg, auf welchem die ventralen Anlagen in die ilnen zukommende Lage iibergefiihrt werden, ist ein sehr einfacher. Es erheben sich auf der Gränze zwischen ihnen und den dorsalen Anlagen vier Falten, die $\mathrm{K}$ e imfalt en, wie wir sie nemen wollen : eine rordere, zwei seitliche und eine hintere. Nachdem die Falten eine gewisse Ausbildung erreicht haben, legen sich ihre Firsten um, und es kommt nun der eine, dorsale Faltenschenkel iiber den andern ventralen zu liegen (Figur 16). Dieser himwiederum liegt

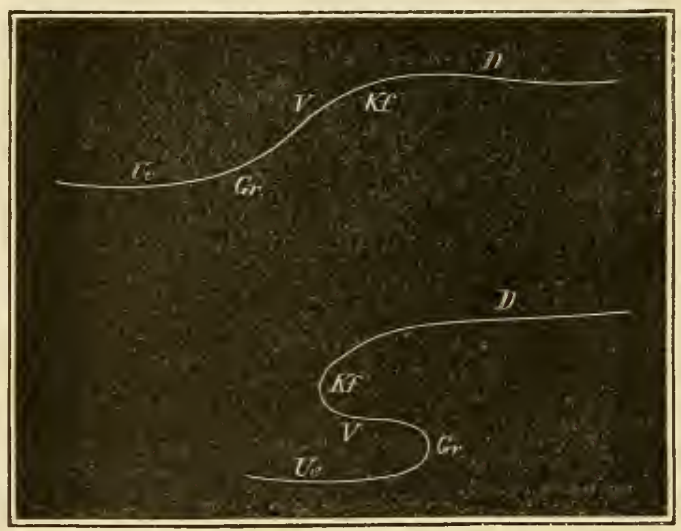

Fig. 16. Kf. Keimfaitenfirst.

D. Dorsaler Schenkel.

V. Ventraler

Gr. Grānzrinne.

Ue. Uebergangsstück.

iiber einem dritten Schenkel, ron dem er dureh eine rimnenförmige Biegung die Grïnzrinne, abgesetzt ist. Die friher flach ausgebreiteten Theile sind somit jetzt Sförmig zusammengebogen. Die gegen die Oberfliche convexe Keimfaltenfirst und die coneave Gräinzrinne sind die beiden Biegnngen des S. Seine drei Schenkel sind der dorsale, der ventrale und das Ueber- 
gangsstick. U ebergangsstï ck künnen wir nämlich den tief'stliegenden schenkel nennen, weil er der Uebergang zu dem ausserembryonalen Abschnitt der Keimhaut bildet. Torlïnfig magst Du die Rinne als Crinze embryonaler und ausserembryonaler Strecken ansehen, und die Modificationen, welche diese Regel stellenweise erleidet, unbeachtet lassen.

Die rentralen schenkel der beiden seitlichen Keimfalten trefien mit der Zeit in der Mittellinie zusammen und verWarhsen in einer langrgestreckten Nath. Der ventrale Schenkel der vordem und derjenige der hintern Keimfalte wachsen sich nicht entgregren, sie bleiben danernd durch einen weiten Abstand ron einander getrennt. Die vordere Gränzrinne entspricht dem spätern Boden der Mundhöhle, in die hintere Gräinzinne fällt der Ort füir die Schwanzspitze.

Ton den vier Keimfalten legt sich die rordere zuerst $u$, damn die beiden seitlichen und bei diesen schreitet die Umlegung ron vorn nach rïickwärts fort. Zuletzt geschieht die Unlegung der hinteren Falte. Diese Reihenfolge der Faltenumlegungen ist von Bedentung einestheils für die Conformation des resichts, anderntheils fiur diejenige des hintern Leibesendes. Um dies klar zu machen, muss ich Dir erst die firiheste embryonale Conformation dieser Theile beschreiben.

Das Gesicht eines Embryo ron der in Fig. 9 abgebildeten Stufe ist

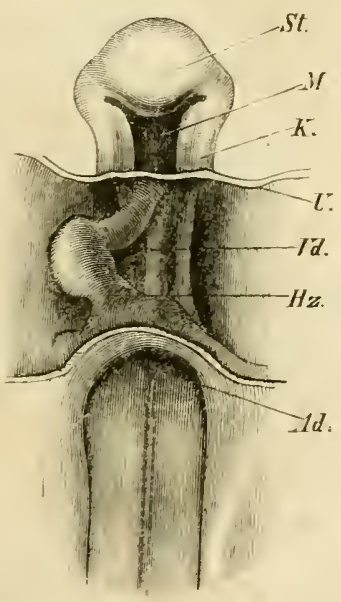
ausserordentlich einfach gestaltet. Es umfasst nämlich die ventrale Flïche des freien Kopfendes, und zeigt in seiner Mitte eine seichte viereckige Grube, die Mundbucht. Vor der Mundbucht liegt der Stirnwulst, durch das convex nach abwäirts hervor-

Fig. 17. Gesicht des Embryo von Fig. 9. 2umal vergrössert.

St. Stirnwulst.

M. Mundbucht.

K. hieferlejsten.

U. Umschlagsrand des animalen Blattes.

Vd. Vorderdarm.

Ad. Zugang zu obigem.

Hz. Herz, tretende Vorderhirn erzengt, neben ihr befinden sich die zwei longitudinal gerichteten K ieferleisten, und hinter ihr erfolgt der Umschlag der Gesichtswand in den unter dem 
Gesicht liegenden ansserembryonalen Theil des animalen Blattes. Die Grinzrime bildet somit den hintersten Abschinitt der Mundbucht und ihre Wand wird zu den Anlagen füir die ciebilde am Boden der Mundhöhle und für das Mittelstiiek des Unterkiefers. Hinter der schmalen, dureh die Umschlagsstelle gebildeten Brïcke siehst Du an der beistehenden Figur das, dem Hinterkopf angehörige, noeh breite vordere Ende des Leibesnabels und das zwischen seinen Rïndern hervortretende Her\%.

Ein Querschnitt dureh deu Gesichtstheil des Kopfes (Fig. 1S) zeig't neben der Mundbucht wiederum die beiden Kieferleisten, dariiber die niedrige Lichtung des Vorderdarms, damn die Chorda

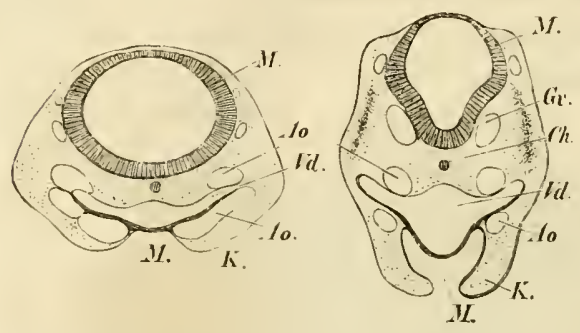

Fig. 1s. Querschnitt durch Fig. 19. Querschnitt durch den Kopf von Fig. 17. $41 \mathrm{mal}$ den Gesichtstheil d. Kopfes vergrössert.

M. Mundbucht.

K. Kieferleiste.

Vd. Vorderdarm.

Ch. Chorda dersalis.

H. Gehirnrohr (Mittelhirnl.

A0. aufsteigende und $a b$ steigende Aorta.

Gv. Gehirnvenen. dorsalis und das Gehirnrohr. Die iibrigen in der Figur weiss ausgesparten Stellen sind Durchselinitte der Blutgoefäisse, der auf- und der absteigenden Aorten und der Gehirnvenen. Ein Vergleich dieses Durchschuittes mit dem ron Fig. 11 zeigt dentlich, dass die Kieferleisten den Strecken der Leibeswand entsprechen, die dort unter der Wolffschen Leiste

liegren, d. l. den ventralen Schenkeln der seitlichen Keimfalte. Immer mehr bilden sich in der Folge die Kieferleisten aus, die Mundbucht wird zu einer Höhle rertieft, der noeh gemeinsamen Mund- und Nasenhöhle, oder primitiven Mundhöhle, wie man sie zur Unterscheidung von der definitiven nennen kann.

Die beiden Kieferleisten riicken sich in der Mittellinie entgegen und rerwachsen mit einander, theils direet, theils dureh Vermittlung eines vom Stirnwulst her kommenden Fortsatzes. Dureh ihre directe Vereinigung entsteht der grössere 'Theil des Gammens, durch ihre mittelbare Vereing'ung' die 
vordere Wand von Mund- und Nasenramm. Als offen bleibende Zug̈ange erhalten sich die Mundöffnung und die Nasenlöcher:

Mit anderen Worten sehen wir, dass an dem, durch Umleg'ung der vorderen Keimfalte entstandenen freien Kopfende zwei seitliche Falten als Fortsetzung der Wolff'schen Leiste entstehen, sich begegnen und theilweise rerwachsen. Die untere Fliche der vorderen Keimfalte bleibt mu in einem Theile ihrer Ansdehnumg frei, nämlich vorn und an den Seiten, das Mittelfeld wird ron unten her zugedeckt. Dic Bildung der Mundhöhle ist eine Folge der gekreuzten Faltenlegung.

Wir betrachten num anch das hintere Leibesende in der Zeit, wo es eben eine bestimmtere Gestaltmig gewomnen liat. Schon ans dem ersten Briefe hast Du entnommen, dass sich der verdickte Embryonaltheil der Keimscheibe mit seinem hintereǹ Abschnitt zu einer queren Falte erhebt, und dass diese weiterhin sich umlegt (Fig. 1 S. 3 und Fig. 5 S. 8). Die Ausbildung and Umleg'ung der hinteren Keinfalte erfolgt spaiter und weit langsamer, als die der vorderen. Nachrlem die Unlegung cimmal begomen hat, schärft sich noch während einiger Zeit der Biegungswinkel zu und der numgebogene Schenkel wird läinger. Du kamnst dies aus der Yergleichumg. der beistehenden Fig. 20 mit Fig. 2 sofort erkemen, mul- wirst Dich anch an den beiden Figuren iiberzengen, dass aus der First und aus dem ungebogenen Schenkel der Falte der Schwanz wird. Die freie Fläche des letzteren beschreibt sonit einen con-

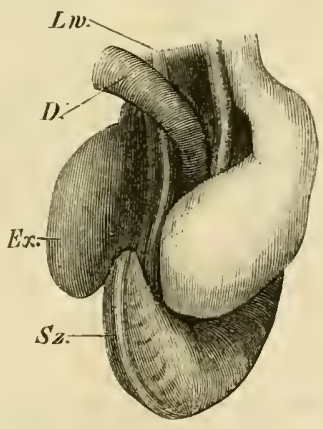

Fig. 20. Hinteres Leibesende eines Hühnchens rom 5. Bebrütungstag. Lw. Leibeswand.

Ex. Hintere Extremitäten.

Sz. Schwanz.

D. Darm. vexen Bogen und diesem folgen das Riickemmark und die beiden Reihen der Urwirbel. Am ungeschlagenen Sehwanzstiicke liegen das Riickenmark und die Urwirbel lings der unteren Fliche, die unvollkommen abgegliederte obere Fläche ist der Banchfliche des Rumpfes zugekehrt. Gleich wie der Grund der Mundbucht geht Anfangs das Schwanzende dureh ein Uebergangsstiick in 
den ausserembryonalen Theil der Keimhant iiber, dann aber lïst es sich ron diesem ab, und wird selbstständig.

Wären пu dic Verluältnisse in Betreff der Faltenlegung hinten dieselben wie vorn, so wiirden zwei Seitenfalten das umgeschlagene Schwanzstiick ron nuten umwachsen und dessen freie Fläche melı oder minder vollstindig decken. Statt dessen erscheint die Seitenwand des Sehwanzes firihzeitig nach oben eingezogen, und eine ron der Schwanzspitze nach riickwärts lanfende Furche trennt sie von der Seitenwand des Rumpfes. Der Schluss des Sehwanzes geschicht, von der Spitze zur Wurzel fortsehreitend, an dessen oberen Fliiehe. In der concaren Biegung vor der Schwanzwurzel bleilot eine Streeke mingesehlossen und wird zum Cloakenzugang.

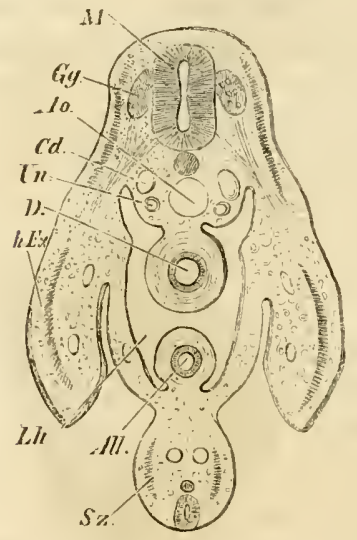

Fig 21. Schnitt durch das hintere Rumpfende eines Hühnchens vom 5. Bebrütungstag. iv mal vergrössert.

Sz. Schwanz.

M Medullarrohr.

Gg. Ganglienanlage.

Ao. Aorta.

h. Ex. hintere Extremitüten.

Bh. Bauch-resp. Beckenhöhle.

D. Darm.

Ail. Allantois.

Ur. Urnierengänge.

Cd. Cardinalvene.

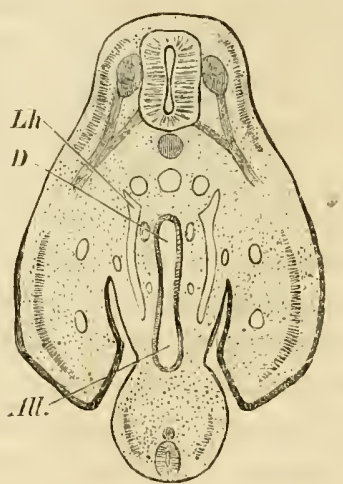

Fig. 22. Schnitt durch denselben Embryo, etwas weiter hinten. Dieselbe Buchstabenbezeichnung.

Im beistehenden Quersehnitt, Fig. 21, erkennst Du leicht das umgesehlagene, von der Rumpfwand erst unvollkommen getrennte Schwanzstiiek mit dem unten befindlichen Medullarrolne, der Chorda dorsalis und den Aortenfortsetzungen. Etwas 
weiter nach rom häite der Sehnitt den Schwanz ringsumher frei gezeigt, weiter nach riackwärts wird, wie rig. 22 zeigt, dessen Abgrenzung minder scharf.

Nach diesen Anseinandersetzungen wird es Dir nicht schwer werden, das in Fig. 23 mitgetheilte Schema zu verstehen. Es ist ein vereinfachter Längsschnitt des Körpers an welehem

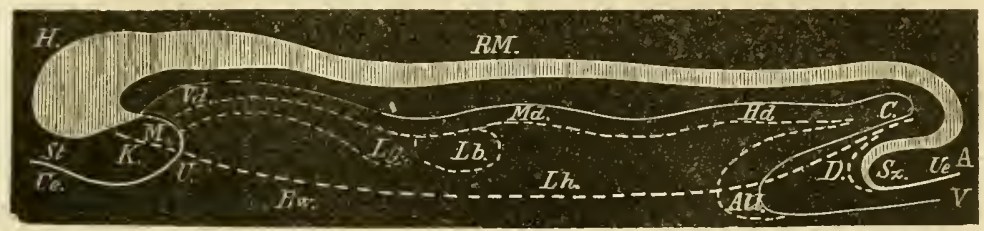

Fig. 23. Sclıematischer I ängsschnitt.

A. Animales blatt.

kir. Rückeninark.

Sz. Schwanz.

st. Stirnwulst.

if. Mundbucht.

K. Kieferleiste.

U. Umschlagsistelle, späterer lloden der Mundhöhle.

Ue. Uebergangsstūck.

Bw. Hals-, Brust- und Bauchwand.

Herz und $\mathrm{Zwerch}$ fell sind nicht eingezeichnet.

D. Damm.
Vd. Vorderdarm.

Id. Mitteldarm.

Hd. Hinterdarm.

C. Cloake.

All. Allantois

Lg. Lunge mit I uftröhre a. Kelilkopf.

Lb. Leber.

Lh. Leibeshöhle.

die Gebilde des animalen Blattes mit krättigen, die des regetativen mit zarten (ontouren angegeben sind. Die punktirten Linien sind die Linien der Verwachsmgsnithe. Die Ansdehnumg des Medullarrohres ist dureh einen senkrecht schraffirten Streifen dargestellt, seine Nathlinie nicht besonders bezeielmet.

Die umgelegte vordere Keimfialte ist in ihrem Scheitelstiicke vom Gehirn ansgefiult, das an der Gesichtsfliche den Stirnwulst erzengt. Hinter dem Stirnwulst folgt die Mundbucht, deren Grund rom vorderen Ende des Vorderdarms beriihrt wird. Die Seitenfalten des Vorderkopfes oder die Kieferleisten sind als punktirte Linien eingezeichnet. Als hinterer Absehluss der Mundbueht erseheint das Umsehlagsstiick U.

An der umgelegten hinteren Keimfalte siehst Du das Medullarrohr bis zur Schwanzspitze reichen. An letztere sehliesst sich das Uebergangsstiick des animalen Blattes an. Die Nathlinie des Schwanzes fällt in die Concavitait der Falte.

In unserem Schema ist auch der Primitiviarm mit einigen seiner Nebenanlagen eingezeichnet. Für jetzt betrachten wir nur seine beiden Enden. Das vordere Ende ist blind, erreicht 
mit semer Spitze die Gehimbasis und rult mit seiner meren Wand der Decke der Mundbucht mmittelbar auf.

Das hintere Einde dagegen erseheint als scharf geknicktes U-föminges Rohr, dessen miterer Schenkel, wie leicht ersichtlich ist, zum oberen in derselben Bezichung steht, wie der Sehwanz zum hinteren Ende des Rumpfes. Wir kömen den unteren Schenkel des Primitivdarms geradezu als Schwanzda r'm bezeichnen. Wie der Schwanz das umgesehlagene Stiick der animalen, so ist der Sehwanzdarm dasjenige der regetativen Rölıre. Das Bemerkenswerthe liegt num darin, dass der Sehwanzdarm nicht, wie der $R u$ u f'd a r m, ron der zugehörigen animalen Röhre umschlossen wird. Er kommt noch in die Röhre des Rumpfes zu liegen und del Schwanz sehliesst sich, olme irgend einen Absehnitt des vegetativen Rohres in sieh aufzunchmen. Der Schluss des Schwanzes und derjenige des hintersten Abschnittes der Rumpfwand erfolgt im Zwisehenramm zwischen dem Sehwanzdarm einerseits und dem Schwanzriekenmark mol seinen begleitenden Theilen andererseits.

Der Schwanzdarm ist die Anlage der Allantois und ihres Stieles. Seine Umbiegungsstelle in den Rumpfilarm bezeichnen wir als Cloake. Die Eröffnumg der letzteren gesehieht, gleich wie die des Vorderdarms, durch secundïre Spaltung.

In den beiden Querschnitten, Fig. 21 und 22, ist die urspriingliche Zusammengehörigkeit der Allantoisanlagen und des Schwanzes sehr deutlich zn erkennen, ebenso anch die Art und Weise, wie jene in die Vorderwand des Rmmpes hereinbezogen wird. Es wird Dir num verständlich sein, wie es kommt, dlass auf' dem Querselmitte von Fig. 21 zwei vegretative Röhnen liegen, deren eine mit der oberen, die andere mit der miteren Banehwand verbunden ist, mol dass in dem, der Umbieg'mogstelle näher liegenden linteren Sehnitte, Fig. 22, die beiden Rïhren mit einander zusammenhängen.

Eine Parallele zwischen Vorderkopf und Schwanz besteht in den allgemeinew Bedingungen der $\mathrm{Ab}$ shliederung: beide sind entstanden aus nmgeleggten Querfalten, vorn wie hinten kreuzen sich mit den Queralten die allgemeinen Lingstalten. ln der weitern Durchfiulurung aber sind die Abweichungen so gross, dass die beirlen Endabselnitte des Körpers in ilırer definitiren 
Gestaltung dies Gemeinsame ihrer Entstehung kaum meh" verrathen. Folgendes sind die Hauptunterschiede:

Torderkopf.

1) Feste Verbindung der Keimblätter bis zur Gränzrinne, Bildung einer einfachen, nach unten sich öffnenden Kopfdarmhöhle.

2) Das Medullarrohr erreicht die Gränzrimne nicht. Hinter dem Stirnwulst folgt die Mundbucht.

3) Schluss der Seitenfalten unter dem rentralen Schenkel der Querfalte; ebendaselbst Durchbruch der Rachenöfinung.

4) Mächtige Entwicklung des Medullarrohres, Bildung der Sinnesorgane.

Die Punkte, die wir als Endpunkte des Körpers ansehen, sind ans ungleichen strecken der Keimfalten herrorgegangen. Der vordere Endpunkt des Körpers, der Seheitel, geht ans der First der vorderen, der hintere Endpunkt, die Schwanzspitze, aus der Gränzrinne der hinteren Keimfalte hervor. Mit Riicksicht auf die Keimfalten entsprechen sich einestheils Seheitel und Schwanzwurzel, die aus den entgegengesetzten Keimfaltenfirsten, anderntheils Kinngegend und schwanzspitze, die in den entgegengesetzten Gräinzrinnen sich entwickeln.

Ein whema anderer Art als das ehen besprochene ist Fig. 24. In ihm namlich habe ich rersucht, die Topographie der animalen Anlagen zur Zeit ilıres flachen Nebeneinanderliegens wiederzugeben. Die dorsalen Anlagen sind dunkel gelassen, die ventralen schraftirt, und zwar ist der sich mmschlagende Theil der vorderen und der hinteren Keinfalte längsschraffirt, derjenige der seitlichen Falten runerschraffirt. Doppelte Schraffirmng haben die strecken, welehe in den Bereich zweier sich mulegenden Falten fallen. Die Längsausdehmung des Medullarrohres ist dureh einen dieken weissen Strich bezeichnet, die Firsten der vier Keimfalten sind dureh ansgezogene Linien, der Yerlanf der vier, die Körperanlage nmgehenden Grämrimen dureh punktirte Linien angedentet. 
Du kamnst das Sehema noch mehr vereinfachen, inden Du anf einem Blatt Papier die Linien, die hier gebogen verlaufen, gestreckt zeichnest. Brichst Du alsdam (las Papierblatt derart, dass die anscrezogenen Linien nach anfwärts, die punktirten nach abwiirts ihre Kante kehren, und legst Du es, den

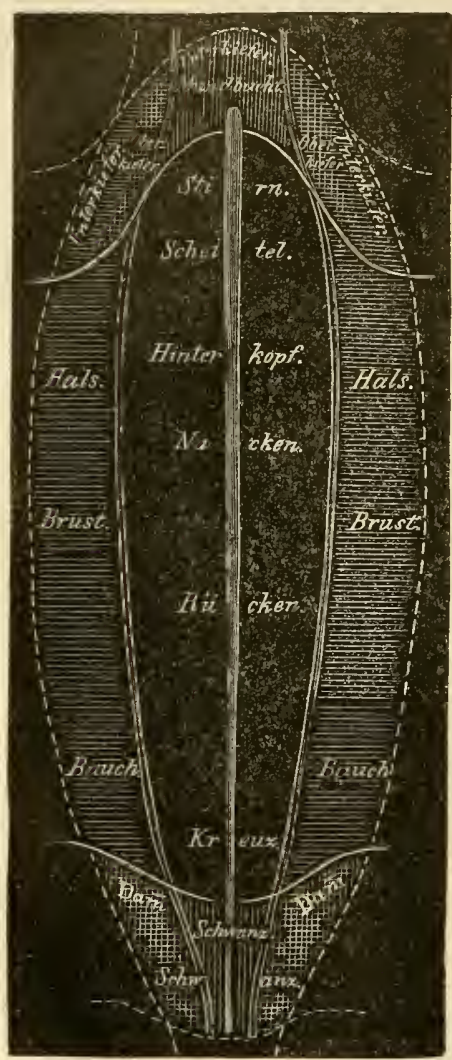

Fig. 24. gebildeten Falten entsprechend, zusammen, so dass zuerst dic vordern, damn die zwei seitliehen und endlich die hintere Falte umgelegt werden, so erhältst Du eine grobe Vorstellung von der Art, wie sich die Leibeswand zusammenfiigt. Hast Du das Papierblatt in der Weise beschrieben, wie es Fig. 24 angibt, so wirst Du nach erfolgter 'Zusammenlegung' jeden Theil am zugehörigen Orte finclen.

Die Hauptabweichung der Natur von einem solchen vereinfachten Schema liegt in dem bogenförmigen Verlante der verschiedenen Falten. Am auffälligsten ist die Kriimmmon der vorteren Keimfalte. Die axiale Strecke dieser Falte riiekt in Folge raseheren Waehstluums den Seitenstrecken weit roraus, diese sind daher nieht quer, sondern schräig gerichtet und krenzen sich unter stumpfen Winkel mit den Seitenfalten.

Ich lade Dich zum Schlnsse dieses Briefes ein, noeh einen Blick anf dic Uranlagen der 4 Extremitäten zu werfen. Bereits im ersten Briefe habe ich Dich darauf aufmerksam gemacht, dass die Anlagen der vorderen sowohl, als diejenigen der hinteren Extremititen von einer Leiste der seitliehen Leibeswand ansgehen, die wir dort die Wolff'sehe Leiste genannt 
haben. Aus den letzten Betrachtnngen wird Dir klar geworden sein, dass die Wolff"sehe Leiste identisch ist mit der First der seitlichen Keimfalte (rgl. Fig. 1). Der Ort der hinteren Extremitaten ist die Kreuzungsstelle der Wolff'schen Leiste mit der First der' hinteren Keimfalte. Der Ort der vorderen Extremitätenanlage wird, wie Du gesehen hast, durelı die Krenzung der Wolffschen Leiste mit einer schräg ron rorn her kommenden Falte bestimmt. Die Vergleichung der suceessiven Entwicklunggsstufen ron Fig. 15, 14 11), 9 und 5 ergibt, class diese sehräige Falte die mehr und "mehr zuriickgeschobene Seitenstrecke der vorderen Keimfalte ist. Die vier Extremitaiten entstehen sonach an den vier Kreuzungspunkten der beiden seitlichen mit den beidlen queren Keimfalten.

Indem die Seitenstrecke der vorderen Falte sich verschiebt,

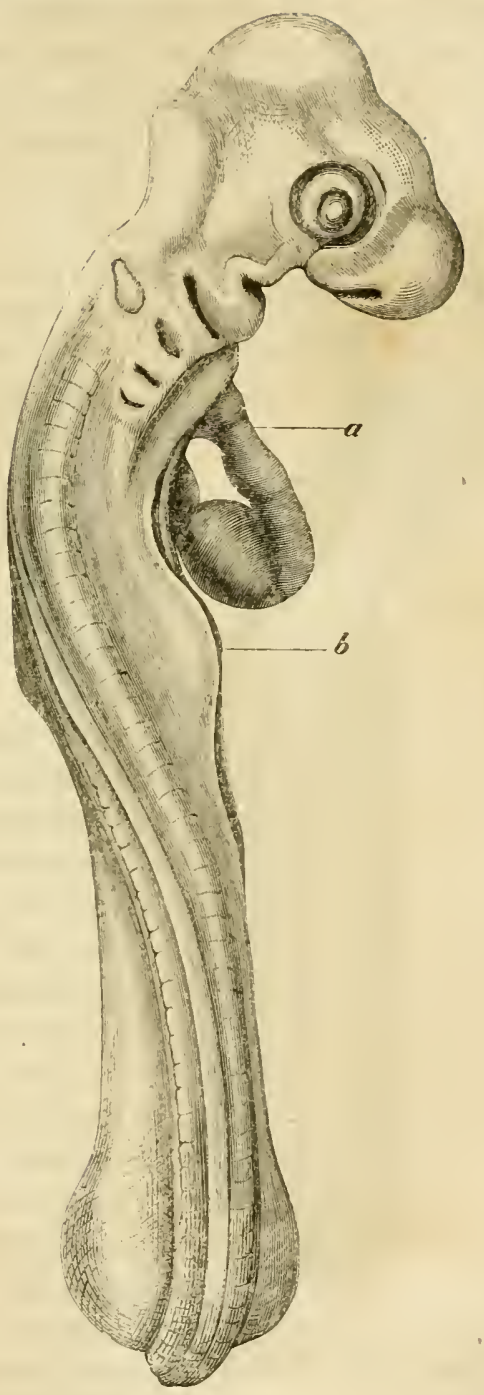

Fig. 25. (Fig. 1.) Hūbnchen vom rierten Tage der Bebrütung. 2umal vergrösserte Dorsalansicht. verschiebt sich auch ihr Kreuzungspunkt mit der Wolff'schen Leiste. Die vordere Extremitit entsteht nicht da, wo sich die 
beiden Falten zuerst, sondern da, wo sie sich zuletzt d. h. zur Zeit der seitlichen Faltenumlegung kreuzen. Wir stossen hierbei anf ein Dilemma in Betreff dessen, was wir als die Anlage der vorderen Extremitaiten bezeiehnen sollen. Sollen wir

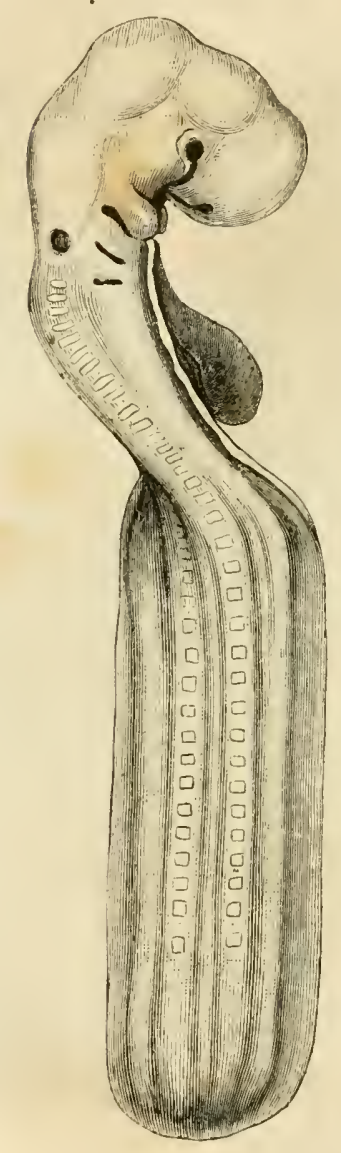

Fig. 26. (Fig. 5.) Hühnchen vom dritten Tage der Bebrütung. $20 \mathrm{mal}$ vergrösserte Dorsalansicht. die Kreuzungsstelle der beiden Falten so nenuen, ohne Riicksicht darauf, wo sie eben liegt, oder sollen wir den, Anfangs nicht genauer charakterisirten Abschnitt der Wolffsehen Leiste fiir die Anlage halten, an welchen die vordere Falte schliesslich stehen bleilst?

Wir kommen aus dem eben erwähnten Dilenma angenblicklich heraus, wenn wir die Unterseheidung machen zwischen einer Formanlage und einer Sulsstanzanlage. Falten, welche zur Abgliederung eines Organs fiiluren, sind wir unzweifelhaft berechtigt, als dessen Formanlagen zu bezeichnen. Nun zeigt sich aber an der Keimseheibe vielfach, dass deren Falten, älnulich wie die Falten eines zusammengeschobenen Papierstreifens, sich verschieben kömmen. Nach Art einer fortschreitenden Welle erreichen sie snecessive verschiedene Strecken der Scheibe, wobei sie ilıre Form zu verändern und, je nach den besonderen Bedingungen, ebensowohl an Höhe zu- als anch abzunchmen vermögen. Der oben erörterte Fall ist nicht das einzige Beispiel solcher Faltenwanderungen, anch die seitlichen und die hintere Keimfalte verändern imnerhalb gewisser Breiten ihren Ort, indem deren Gränzrinnen mehr und mehr auf das urvprimgliche Uebergangsstiick vorgesehoben werden.

Als Substanzanlage eines Organs diurfen wir natiirlich nul 
denjenigen Bezirk der Keimseheibe bezeichnen, der sehliesslich das Material zu dessen Bildung hergibt. Formanlage und Substanzanlage miissen sehliesslieh bei der Abgliederung des Organs zusammenfallen; für manehe Organe, wie z. B. fül das Medullarrohr, sind sie von Anfang an nie getrennt gewesen, für andere Organe aber, wie eben für die vorderen Extremitäten, entwickelt sich die Formanlage in grosser Entfernmng ron der Substanzanlage, und riickt dieser schrittweise näher. Die Formanlage der vorderen Extremität liegt Anfangs am Kopf, dann im Bereich des Halses und erreicht erst zuletzt die Gräinze des Brustbezirkes. Die Folgen dieser Verschiebung sind in der schrägen Verlaufsweise der Musculatur und der Nerren zeitlebens noch bemerkbar. 


\section{Dritter Brief.}

Die Schichten der Embryonalanlage. Keimblattlehre. Parablastische und archiblastische Anlagen.

Lieber Freund! Aus meinem rorigen Briefe hast Du wohl eine Vorstellung davon bekommen, wie sich iiberhaupt der Körper ans einer urspriinglich ebenen Platte zusammenfaltet, und wie er sich dabei von dem ansserembryonalen Gebiete der Keimhant abgliedert. Der klareren Darstellung halber hatte ich es vermieden, ron den sonstigen, in die Periode der Zalsammenfaltung fallenden Gliedernngsvorgängen zu reden. Hente wollen wir einen Theil des Versaiumten nachholen, und damit unsere Kenntnisse von der primitiven Anordnung der Organanlagen der Keimscheibe vervollständigen.

Zur leichteren Uebersicht stelle ich Dir noch einmal die Quersehnitte 27, 28, 30 und 31 unseres ersten Briefes zusammen, und fiige als Eröinzung zwei weitere Figuren 29 und 32 bei. Die Stufenfolge der seitlichen Zusammenschiebungen wirst Du nummehr mit einem Blicke ibersehen und, da alle Figuren bei derselben 40 maligen Vergrösserung' g’ezeichnet sind, erhältst anch eine ungefähre Orientirung iiber die allmählilige Griissenzunahme der einzelnen, auf dem Durchschnitte sichtbaren Gebilde. Die Schnitte stammen alle aus der unteren Hals- oder aus der Riickengegend; Fig. $2 S$ und Fig. 29 sind vom gleichen Embryo, Fig. 28 nämlich 5 bis 6 Urwirbelbreiten linter Fig. 29? entnommen.

Fassest Du für heute die Schiclitengliederung ins Auge, so faillt Dir sofort auf, dass die Tremnung einer animalen und einer vegetativen Schicht im gesammten Seitengebiete des Embryonalbezirkes friihzeitig und ausnehmend seharf vollzogen 

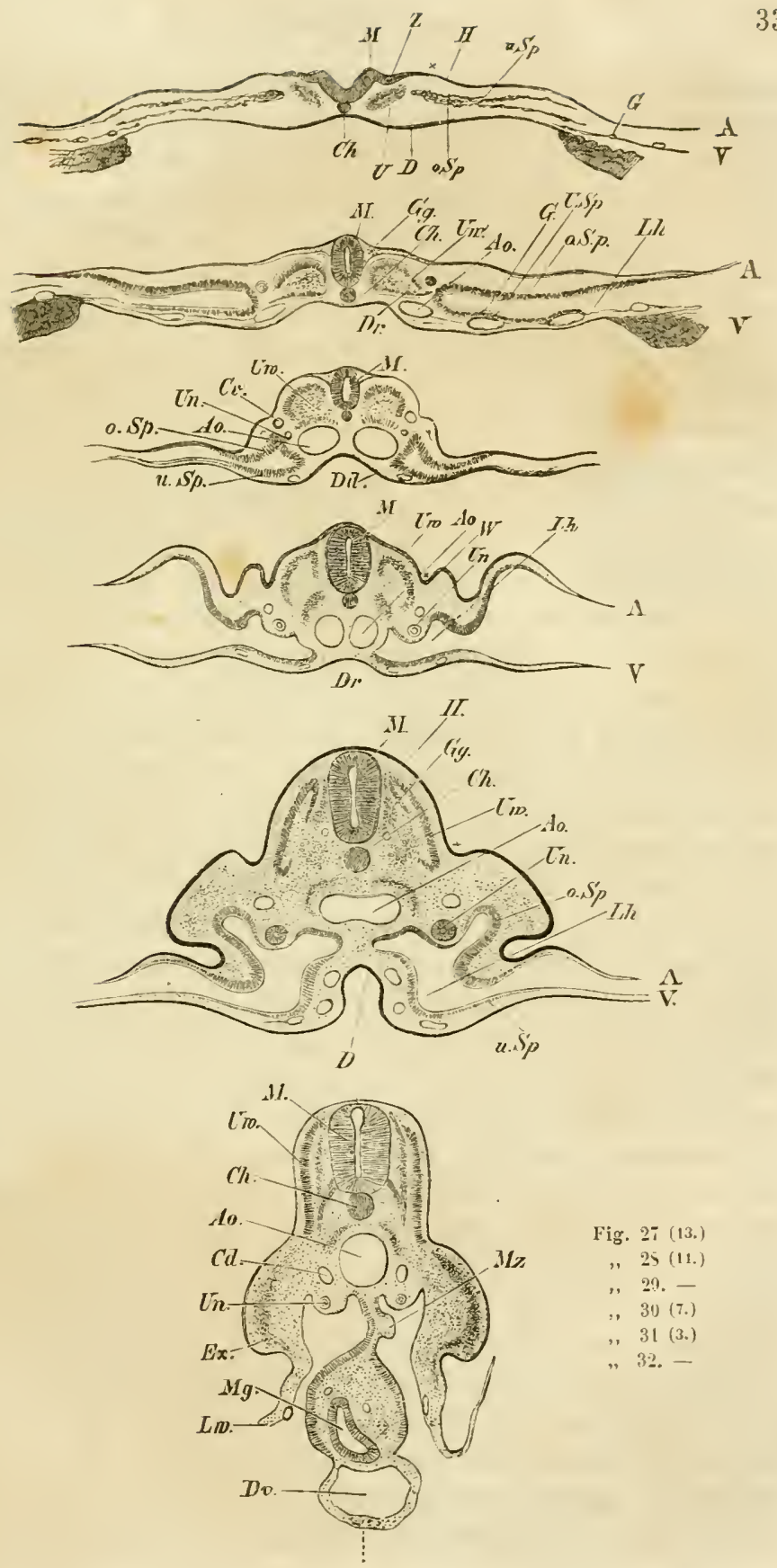

Fig. 27 (13.)

, 25 (11.)

, 29.

, $30(7$.

, 31 (3.)

, 32. - 
erscheint. Jede der beiden Schichten gliedert sich weiter, und zwar Anfangs, wie Dn an den oberen Figmen siehst, in 2 Blïtter, das Gränzblatt und die Muskel-oder Seitenplatte. In den unteren Figuren tritt, zuerst in der regetativen, dann in der animalen sehicht eme dritte zwischengeschohene Lagre, das Gefiissblatt hinzu. Keine der beiden Seitenplatten iiberschreitet den Embryonalbezirk. Nur das Horn- oder obere Gränzblatt einerseits und das Darmdriisen- oder untere Grinzblatt andererseits gehen in den ausserembryonalen Theil der Keimhant iiber. Jenes liefert späterhin die Wand des Annions und der sog. serüsen Hülle, dieses diejenige des Dottersacks.

Minder schart, als in der seitlichen oder parietalen Zone ist die Scheidung der regetatiren und der animalen sichicht in der Stammzone durehgefiihrt. Die spalte, welehe dort die beiden Schichten von einander trenut, hört an der (iräinze der Parietalzone anf, und jenseits derselben liegen an Rumpte die Urwirbel und deren Vorlinfer, die Lrwirbelplatten.

Die Urwirbel haben wir in unserem ersten Briefe ron der Fläehe her als kleine viereckige Felder kemen gelernt. Die ersten Spuren derselhen findest Du bei Fig. 14, wo sie mit ihrem äusseren Rande unter der Medullarplatte herrorsehen, ron der sie in Lebrigen grossentheils iiberdeckt sind. Frehon bei Fig. 10 liegen die Lrwirbel frei und in grösserer Zahl neben dem geschlossenen Theile des Medullarrohres. Eine noch längere Reihe bilden sie bei Fin. 9 und bei Fig. 5. In der hinteren Verlängerma der alogegliederten Urwirbel begegnest Dn allgemein einen ungegliederten lingsitreifen. dex Urwirbelplatte, und Du wirst geringer Leberleğmg bediurfen, um zu sehen, dass die einzehen Lrwirbel dureh Abtremung von diesen streifen entstehen miissen. Bei Fig. 2 endlich ist die quere Gliederung bis zur Sehwanzspitze vollendet.

Ein senkrechter Schnitt dureh die Lrwirbel in der ersten Zeit ihrer Entstehung, sei er in der Liings- oder in der Querrichtung durehgefïht, ergibt ein ziemlich charakteristisches Aussehen. Jeder Urwirbel nämlich zeigrt eine radiür streifige Rindenschicht und einen nicht gestreiften Kern. Diesem Bilde ist allerdings nicht zu entuehmen, ob der Urwirbel zur animalen oder zur vegetativen schicht zu zihlen, oder ob er 
üherhaupt einer der beiden Schichten ausschliesslich zuzuweisen sei. Dagregen erhältst Du die Entscheidung anf einer noch friiheren Entwicklungsstufe. Auch die 'Trennung nämlich der Scitenplatten ron den Lrwirbelplatten rollzieht sieh allnählig, und in der Zeit, weldhe der vollständigen Tremnung vorausgrelit, findet sich eine Periode, während welcher die obere Hälfte der Lrwirbelrinde mit der oberen, die untere Hälfte mit der unteren seitenplatte in fortlaufender Verbindung steht.

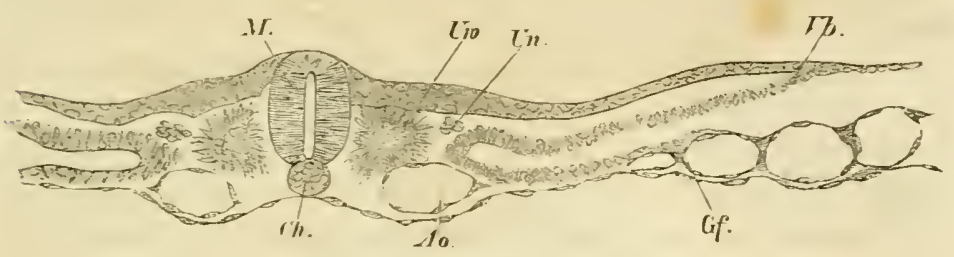

Fig. 33. Qnerschnitt von derselben Entwicklungsstufe wie Fig. 25. Vergr. Si. Bnchstabenbezeichnung wie frūher.

Darnach ist ron der Lrwirbelrinde die obere Hälfte zur animalen, die untere zur regetaticen Schicht zu rechmen. Die Verbindung beider Hälften ist nur eine 'voriibergehende, sie lïst sich nach einiger Zeit und zugleich erfahren die Lrwirbel eine ansgiebige Veränderung ihrer Lage.

Verfolgst Du die Figuren der Seite 33 von oben nach abwïrts, so sichst Du, dass eine den Urwirbel in seine beiden Hälften tremnende Linic hei Fig. 27 sehriig zu stehen kommt, so zwar dass deren medianes Ende nach abwärts sieht, bei Fig. 25 steht die tragliche Linie ambïhernd horizontal, bei Figr. 29 und noch mehr bei Fig. 30 ist das mediane Ende schräg nach aufwirts gerichtet und hei den untersten zwei Figuren endlich steht jene Linie fast rertical. Sie hat sich, während die stammzone des hörpers gleichzeitign immer mehr von den Seiten her zusammeugeschoben wurde, um etwa ein Drittheil cines Kreishogens gechreht. Schon bei Fig. 29 lockert sich dic Verhindung der beiden Rindenhälften der Urrwirbel. Die (h)ere behïlt ihr charakteristisch streifiges Aussehen bei, und ist durch alle nachfolgenden stufen hindureh dentlieh wieded zu erkemen. Ans iln wird später die Musculatur der Wirbelsäule. Die untere Pindenhälfte siehst Du um die Aorten sich herumlegen, und sie wird wohl völlig zur Bildung ron 
Getässmuseulatur verbrancht. Ihre selarfe Abgränzung vom Urwirbelkern und von den Producten der Gefïssblätter geht weiterhin verloren.

Die anfïngliche Lage der Urwirbelplatten miter der Medullarplatte (Fig. 27) zeigt, dass beide Gebilde derselben Längszone angehören: Die Medullarplatte ist urspringlich der Stammtheil des obern Gränzblattes, sie wird gegen den Parietaltheil durch die Zwisehenrinne abgegränzt. Zur späteren Decknng der Stammzone wird der imnere Absehnitt des bereits parietalen Hormblattes herbeigezogen.

Das Schema der Gliedermg ist somach folgendes:

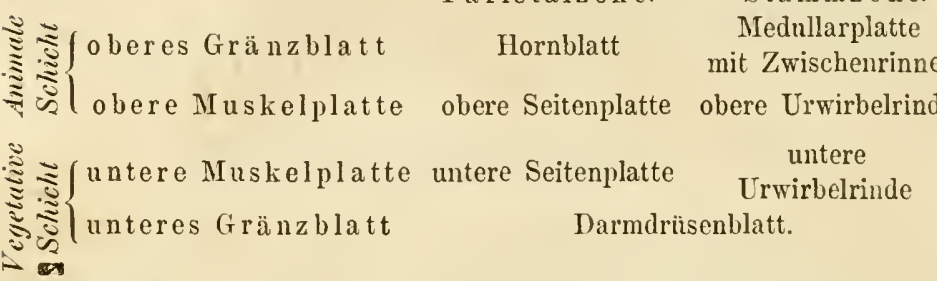

$$
\begin{array}{cc}
\text { Parietalzone. } & \text { Stammzone. } \\
\text { Hornblatt } & \begin{array}{c}
\text { Nedullarplatte } \\
\text { mit Zwischenrinne }
\end{array}
\end{array}
$$

Einen besonderen Ursprung hat die Kermmasse der Urwirbel. Sie stammt nïmlich ron keiner der beiden Muskelplatten, sondern von einem, zwisehen sie eingesehobenen Gebilde, dem Ax eustrang: Ehe noch die Urwirbelbildung begonnen hat, existirt lïngs der Mittellinie der Embryoualanlage ein unregelmässig umgrinzter Zellenstrang, welcher den Grund der Medullarrime mit der oberen Fläche des Darmdriisenblattes verbindet, und nach heiden Seiten hin einen Fortsatz

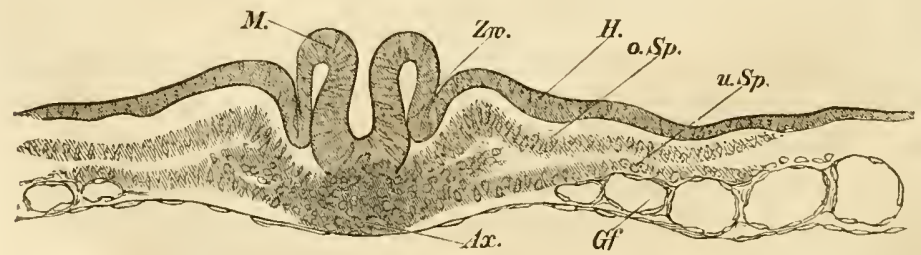

Fig. 34. Querschnitt etwas weiter hinten als Fig. 33 durch denselben Embryo geführt. Die Urwirbelscheidung hat noch nicht begonnen.

Ax. Axenstrang mit seinen seitlichen Fortsätzen.

0.MI. obere MIuskelplatte.

u. M. untere Muskelplatte.

Gf. Gefässschicht.

je zwischen die beiden Muskelplatten hinein entsendet. Die näheren, später nochmals zu erörteruden Beziehungen dieses 
Stranges zu Medullarplatte lassen es als mzweifelhatt erscheinen, dass ein grosser 'Theil seiner Zellen der animalen Schicht, und zwar speciell dem oberen Gränzblatt entstammt, anderentheils ist die Müglichkeit nicht zu beseitigen, dass er anch Zellen der vegetativen Schicht mit enthält, und so ist es vorläufig' am sichersten, den Axenstrang neben den beiden Grimzbliittern und den Muskelplatten besonders, d. h. als ungesonderten Rest aufzufiihren. Du ersiehst nun leicht, dass bei der Abtremung der Urwirbelplatten deren Kern ans dem Seitenfortsatz des Axenstrangs entstehen muss. Das Mittelstiick des Axenstrangs wird zur Chorda dorsalis. Auch nach Vollendung ihrer Abgränzung bleibt die Chorda in Verbindung. mit dem Medullarrohre sowohl, als mit dem Darmdriisenblatt; dann löst sich, an einigen Stellen friiher, an audern später, die letztere Verbindung, wïhrend diejenige mit dem Medullarrohre sebr lange und innig bestehen bleibt.

Die Unwirbelkerue sind wahrscheinlich nicht das ausserste vom Axenstrang abstammende Gebilde. Ein Theil des Seitenfortsatzes scheint noch in den Bereich der Seitenplatten sich zu erstrecken und hier das Zwisehenstiick zu bilden, das nach Waldeyer's Erfahrungen am Aufbau der Geschlechtsorgane sich betheiligt (die Regio germinativa). Auch den Unierengang glaube ich rom Seitenfortsaty des Axenstrangs ableiten zu niissen.

Die Scheidung der blattartigen Embryonalanlagen in zwei Hauptschichten stammt von Pander und ron K. E. v. Baer, deren in das erste Viertel unseres Jahrhunderts fallende Arbeiten überhaupt die wichtigsten Grundlagen der Entwicklungsgreschichte geliefert haben. Pander liess zwischen den zwei anfänglichen Schichten (seinem serösen und seinem Schleimblatt) als spätere Bildung eine dritte, seine Gefïssschicht anttreten. v. Baer, der die Bezeiehnungen animales und regetatives Blatt eingefiihrt hat, gliederte das erstere in Hautsehicht und in Fleischschicht, das letztere in Gefaissschicht und in Schleimhantschicht. ${ }^{1}$ ) Später sind verschiedene Versuche gemacht worden, die ältere Keimblattlehre zu modificiren, am meisten Beifall unter diesen hat sich derjenige ron $\mathrm{Remak}$ erworben, welcher drei blattförmige Uranlagen anuahm, ein oberes (sensorielles), ein mittleres (motoriseh germinatives) und 
ein unteres (Darmdriisen-)Blatt. Remak's oberes und unteres Blatt entsprechen den heiden Gränzblïttern, sein nittleres Blatt umfasst siimmtliche dazwischen liegenden Sehichten.

Die Kiemblattlehre, welehe gerade in nenester Zeit wieder viel discutirt worden ist, ist eines der dornigsten Gebiete der Entwicklungsseschichte. Schwierigkeiten der Beobachtung eompliciren sich mit Schwierigkeiten der Darstelhung und zu einer allgemeinen Verstindigm seheint rorerst wenig Aussicht. Fiir cine eingehende Discussion der verschiedenen Angaben und Ansichten wiirdest Du mir wohl wenig Dank wissen, dagegen möehte ich Dir doch die, lant meiner Ueberzengung, festen Punkte bezeichnen, welehe Dir als Anhaltspunkte zur Orientirmg dienen sollen.

Die Frage von der Zählung der Keimblaiter ist ron secmulärem lnteresse. ${ }^{2}$ ) Da, wo sich iberhaupt die Scheidung scharf durchtiilurt, d. h. in Parietalgebiet der Embryonalanlage und in sclwwangebiete, treten, wie wir oben sahen, vier Schichten, zwei Gräuzblaitter und zwei Muskelschichten auf. Diese vier schichten sind anf einer friiheren Entwicklungsstufe des Keims noch nicht von einander getrennt und wir haben somit: als Anfangsisstute $\left\{\begin{array}{l}1 \\ 2 \\ 3 \\ 4\end{array}\right.$

Jede der beiden mittleren Schichten hat sich von den beiden Nachbarschichten zu scheiden, und zwar zeigt die Erfahrung, dass die Scheidung nieht mit einem Male gesehicht. Einzehe Verbindmgen erhalten sich noch sehr lange, so siehst Du z. B. an den Fig. 28, 29, 30 und 31 das Hornblatt läng's der Gränzrime noch in fester Verbindum mit dem zugeschärrten Rand der oberen Muskelplatte; trotzlem dass beide Schichten in ilırem iibrigen Bereiche sehr ausgiebig und rollkommen sich getremnt haben.

Die ältere, von mir wieder anfgenommene Darstellung der Sehichtengliederung stiitzt sich auf das

$$
\left.\begin{array}{ll} 
& 1 \\
\text { Endergebniss } & 2 \\
3 \\
4
\end{array}\right]
$$


und auf' die friber erörterte physiologische Zusammengehörigkeit der Schichten 1 mit 2 und 3 mit 4.

Fiir die Ammanne eines besonderen mittleren Blattes lässt sich dagegen anfïhren das stellenweise Vorkommen einer

$$
\text { Uebergangsstufe }\left[\begin{array}{r}
1 \\
2 \\
3 \\
4
\end{array}\right]
$$

bei weleher 2 und 3 noeh weniger vollstiundig von einander getrennt sind, als von den anstossenden Griinzblättern. Auch lassen sich die, wie Du gesehen hast, etwas rerwickelten Verhältnisse im Axial- und im Stanmgebiet rascher und mit weniger Worten beschreiben, wenn die, hier urollkommen geschiedenen Bildungen einfach unter den Begriff eines mittleren Keimblattes subsumirt werden, das man zerfallen lässt in Chorda dorsalis, Urwirbel- und Seitemplatten.

Magst Du nun mit der Darstellungsweise der Schichtengliedermg Dich zufieden geben, welche ich im Bisherigen befolgt habe, oder magst Du eine solche wählen, welehe derjenigen von Remak näher steht, stets wirst $\mathrm{Du}$ auf eine Frage stossen, iiber welehe weder Remak noch seine Anhïnger einen befriedigenden, mit den Thatsachen vereinbaren Bescheid gehen und ron deren richtiger Beantwortung doch allein Klarheit in der Keimblattlehre zn erwarten ist. Woher stammen die Anlagen fuir die Gefäisse, fiùr das Bindegewebe und fïir den Kuorpel?

Betrachte Dir einmal Fig. 27 ron S. 33, so wirst Du innerhalb des eigentlichen Embryonalbezirkes die Medullarplatte und das Hornblatt, die Chorda, die Urwirbel und die Seitenplatten, sowie das Darmdriisenblatt sämmtlich derart getremt finden, dass je zwischen zwei benachbarten Gebilden ein mehr oder minder breiter Liickenraum liegt, der leer, oder riehtiger gesagt, aur von klarer Flissigkeit erfillt ist. Von Gefäissen ist da keine Spur und ebensowenig von einer Wandschicht, dureh deren Abspaltung dieselben entstehen kömnten.

Nun sieh Dir Fig. 25 an: Eine zusammenhängende Lage weiter Gefïssröluren, in ihrer Gesammtheit als das mntere Gefässblatt zu bezeiehnen, liegt zwischen der unteren Muskelplatte und dem Darmdruisenblatt, und die innerste dieser Röhren, 
als Aorta descendens anzusprechen, erfiullt den, sehon in Fig. 27 erkennbaren, geräumigen Liickenraum zwisehen Urwirbehn, unterer Seitenplatte und Darmdrisenblatt. Die iibrigen Räume sind noch leer, die Chorda von einem breiten hellen Raum umgeben, das Hormblatt dureh einen solehen von den Urwirbehn und von der oberen Seitenplatte geschieden. Dann sichst Du an der folgenden Fignr zartes Gewebe (das obere Gefässblatt) auch unter dem Hormblatt auftreten, und bemerkst speciell ein, Gefaiss, das an der Grimze der oberen Seitemplatte und der Urwirbel liegt, die Cardinalvene.

An dem Längsschmitt Fig. 12 (S. 14) begegnest Du einer Reihe von Gefässdurehsehnitten, die anch wiederum dem Darmdriisenblatt aufliegen. Jedes dieser Gefässe entsendet nach anfwärts zwischen die zwei dariiber liegenden Urwirbel einen Fortsatz, welcher zn einem V'erbindungsgef:iss zwischen der Aorta und der Cardinalvene bestimmt ist.

Späitere Stufen zeigen die Kette der zuerst rorhandenen weiten Gef aisse mehr und mehr verengt und nur einzelne Stämme, unter denen die Aorta der mächtigste ist, behalten iln grosses Caliber. Beide Aorten riicken sich unter der Chorda entgegen und versehmelzen mit einander, zugleich aber werden die bis dahin offenen Liickenrïume sucessive von einer zusammenhängenden Gewebsmasse ansgefiillt, die, wie die Beobachtung mit stärkeren Vergrösserungen zeigt, meist ans verzweigten Zellen besteht, welche mit der Wandung von Blutgefässen in Zusammenhang' stehen.

Die summarisehe Verfolgmug des Thatbestandes ergilut sonach Folgendes: Ehe Gefuisse in der Embryonalanlage auftreten, ist ein System freier Liieken vorhanden, entstanden dureh das Anscinanderweichen der Gebilde der Grimzblätter, der Muskelplatten und des Axenstranges. In diesen Liicken treten die Gefüsse nach einer ganz bestimnten Reihenfolge auf. Die Gefässe bilden sich ans Sprossen spindelförmiger und sternförmiger Zellen, und von ihrer Wand gehen nene solche Sprossen aus, die zum Theil wieder zu Gefäissen werden, zum Theil zur Bindegewebs- und zur Knorpelbildung Verwendung finden. Alles von den Gefiissen ausgehende Gewebe hängt unter sich zusammen, theils primär in Folge des baumartigen Hervorwachsens aus den zuerst vorhandenen An- 
lagen, theils secundiir in Folge nachtrïglich entstandener Verbindungen, und so bilden die Producte der beiden Gefässblätter sehliesslich eine durchgehende Ausfiillungsmasse dureh den gesammten Embryonalleib hindureh. Mit dem Eintreten der imnigeren Durchdringung werden anch die Gränzen zwischen den Producten der Gefässblätter und denjenigen der iibrigen Embryonalbestandtheile vielfach undeutlich, so dass nur auf dem Wege genauerer Untersuchung mit stärkeren Linsen entschieden werden kam, was dem einen und was dem anderen zukommt.

Keine von den friiher betrachteten Schichten, weder die Gräinzblätter noch die Muskelplatten, noeh auch der Axenstrang, sind bei der Gefiissbildmng irgendwie betheiligt. Die Quelle des ersten Bildungsmaterials fuir Gefässe liegt iberhaupt gar nicht im Embryonalbezirk der Keimscheibe, sondern ansserhalb dieses letzteren. Im Aussengebiete, im Bereiche des sog. Keimwalls und des den Embryo ungebenden durchsichtigen Hofes, sieht man zuerst gef:iss- und blutbildende Zellen in Strängen und in grösseren Haufen auftreten, und von diesem Aussengebiete her treten die ersten Sprossen längs der friher beschriebenen Bahn iiber dem Darmdriisenblatt weg in den Embryonalbezirk ein. Bei Fig. 27 siehst $D u$ solche primitive Gefäissanlagen mit einigen diimen Röhren am Rande der "Figur verzeichnet. Sind eimmal dic Gefisse und die von ihrer Wand abgehenden Zellenstrünge in den Embryo eingedrungen, so liegen sic Anfangs noch lose in den sie anfnehmenden Liicken, ohne Spur einer organischen Verbindung mit deren Wandung.

Du ersiehst aus dem Bisherigen, dass das Hereinwachsen der Gefässanlage in den Embryo und deren allmählige Ausbreitung in diesem ein Gegenstand directer und keineswegs schwieriger Beobachtung ist. Jene Anlagen und die aus ihnen hervorgehenden Gewebe (Bindegewebe, Knorpel, Knochen) treten durch diesen Entwicklungsmodus gegeniiber den aus den Gräinzblättern, den Muskelplatten und dem Axenstrang stammenden Anlagen in eine so besondere Stellung, dass es unter allen Umständen passend erseheint, sie mit einem gemeinsamen Namen zusammenzufassen. Ich bezeichne sic als Nebenkeim-oder als parablastische, die iibrigen als Hantkeim-oder arehiblastische Anlagen. 
Aus den arehiblastischen Anlagen entwiekeln sich: das Nervengewebe, das Muskelgewebe, die Epithelial- und Drisengewebe;

aus den parablastischen:

die Innenwand (Endothelwand) der saimmtlichen Gefäissräume, die Bhntzellen,

das Bindegewebe mit seinen versehiedenartigen Modificationen (Schleimgerrebe, adenoides Gewebe, Fettgewebe u. s. w.),

das Knorpelgewebe, das Knochengewebe.

Die Producte archiblastischen und diejenigen parablastisehen Ursprungs stehen zeitlebens in einem bestimmten Gegensatze zu einander. Olme die eigenartige Entwicklmngsweise zn kennen, haben die histologisehen Forseher die Zusammengehörig'keit der parablastischen Gewebe längst erkamnt, und deren scheinbar so verschiedenartige Bildungen unter der gemeinsamen Bezeichnmg der Bindesnbstanzen vereinigt. Denke Dir einen Angenblick alles Bhut, alle Gefäissauskleidung, alles Bindegewebe sowie allen Knorpel und Knochen ans dem Körper entfernt, so bleibt Dir ein zusammenhängendes Geriist iibrig, bestehend aus dem Gehirn mit dem Riickenmark, den Nerven, den Muskeln, den Driisenparenchymen und den epithelialen Bekleidungen der änsseren Hant mol der Schleimhäute. Denke Dir andererseits auf einen Augenblick alle archiblastischen Gewebe entfernt, so erhältst Du ein zweites, gleichfalls in sich zusammenhängendes Geriist, das wie der Ansgins ron jenem ersten sich verhält, mol das besteht aus dem Schäidel, der Wirbelsäiule, den Rippen und dem Brustbein, den Extremitätenknochen, den versehiedenen Knorpeln, den sämmtliehen Sehnen, Fascien, Bändern mnd lockem Bindegewebsmassen, dem Fette, fermer aus der Lederhant, ans der bindegewebigen Schicht der Sehleimhäute, den Hiillen von Gehirn, Rückenmark und Nerven, denjenigen der Driisen und der Muskehn und endlich aus einem weitverzweigten Astwerk von Gefäissrämmen mit dem darin enthaltenen Blut. Nicht nur im Ganzen und Grossen ist dies parahlastisehe Gewebsgeriist der Ausguss des arehi- 
blastischen, anch in Einzelnen für jedes Organ kehrt ein entsprechendes Verhältniss wieder, inden an jedem Mnskel, an jeder Driise, am Gehirn, am Riickenmark und an den sinnesorganen Bindegewebe nul Blutgefüisse eimmal die äusseren Hiillen bilden, und dann als verzweigtes Geriist ins Innere eindringen und diese Theile nach allen Richtumgen durchsetzen.

Betrachtest Du die Gewebe der beiden Grupuen nach ihrer physiologischen Bedentunę, so erkenust 1) sofort das herrorragende Uebergewieht der archiblastischen Gruppe. Sie vereinight die Gewebe, welehe dem Thierkörper sein besonderes Gepräige geben, das Nervengewehe, das Muskelwewebe und die Grundlagen der Simesorgane. Die parablastischen Gewebe dienen im allgemeinen mur als Stiitzen und als Terbindungsmitel der archiblastischen, sowie als Ernähumgsmittel für jene. Ihre Verwendung erscheint allenthaben der Leistmng von jelien untergeorduet und angepasst, und während Du nicht im Stande sein wirst, Dir einen lebenden Thierkörper zu denken ohne Nervensystem, ohne Muskehn und ohne Driisen, kannst Du Dir gar wohl einen solchen rorstellen, in welchem Bindegewebe, Knochen und Knorpel dureh anderes Material ron gleichen physikalischen Eigensehaften (dureh Leder, Hol\%, Leinwand u. s. w.) ersetzt sind und in dem selhst an Stelle des Bhutes eine Lösung bestimmter chemischer Stoffe kreist. ${ }^{3}$ )

Nach meinen am Hiihnerei gesammelten Erfahrungen habe ich mir die Ueberzengmg gebildet, dass die parablastischen Anlagen ans einer Quelle stammen, die man bis dahin gar nicht zum Keim gezählt hat, nämlich aus dem sog. weissen Dotter. Es ist diese Anschaumg von rerschiedenen Seiten her angefochten worden, und man hat rersucht darzuthun, dass anch die Gefässanlagen ans dem, bisher als Keim bezeichneten Theile des Eies herrorgehen. So interessant die Frage ron der eigentlichen Herkunft der parablastischen Anlagen nach andern Seiten hin ist, so hat sie doch keine direete Beziehung zu den Fragen der Formbildung, und da sie ohnedem nur mittelst monographiseher Behandlung durehgefochten werden kann, trete ich hier auf deren Disenssion nicht weiter ein. Nur das fiige ich zur Vermeidumg ron Missverstïndniss bei, dass ich weniger als je Grund habe, ron meiner bisherigen Ueberzengung abzulassen. ${ }^{4}$ ) 
Soll ich Dir nun nochmals resumiren, was Du vom Remak'schen mittleren Keimblatte zu lalten hast, so ist dies Folgendes: das Remak'sche mittlere Keimblatt umfasst die 'Theile, welche zwischen den beiden Gränzblättern liegen. Dieselben sind theils archiblastischen Ursprungs (die beiden Muskelplatten und der Axenstrang), theils parablastischen Ursprungs (die beiden Gefüssblätter). Letztere Anlagen treten nicht allein später auf, als erstere, sie sind iiberhaupt nieht in loco dureh Abspaltung von den iibrigen Anlagen entstanden, sonderu von aussen her lineingewachsen. Hältst Du es aus Griunden topographischer Beschreibung für zweckmäissig, die Theile zwischen den beiden Gränzblättern mit einem einzigen Wort zusammenzufassen, so magst Du sie etwa (im Ansehluss an eine ältere Bezeichnung von Reichert) Intermediärgebilde nenneu. Den Ausdruck „mittleres Keimblatt" rathe ich Dir deshalb ab, weil er zum Missverständniss einer" genetischen Zusammengehörigkeit von Gebilden Anlass giebt, die in Wirklichkeit nichts mit einander gemein habe'n. 


\section{Vierter Brief.}

Faltenbildung im Keim und deren Bedingungen.

Lieber Freund! Bei allen bisher besehrichenen Gestaltungsvorgängen hàt die Bildung von Falten eine Hauptrolle gespielt. Sie erseheint im Allgemenen als der einleitende Vorgrang, welcher den weitergehenden Tremnungen den Weg bezeichnet. Du kannst Dir, wie wir im zweiten Brief gesehen haben, die Keimselieibe als den flach ansgebreiteten Stoff rorstellen, ans welehem das Material für die einzelnen Organe des Körpers anszuseheiden ist. Znerst erfolgt die Seheidung in die zul verschicdener histologiseher Verwendung bestimmten Sehiehten. Dann aher wird der gesehichtete Keim ron einem System sich durehkrenzender Berg- und Thalfilten durehzogen, und jede dieser Falten, wo sie einmal anfgetreten ist, wird zur Gränzmarke eines grossen Hauptbezirkes des Körpers.

In der einfaehen Anlage von Fig. 15 findest Du schon den Grund gelegt fiir eine Reihe der wiehtigsten Scheidungen: das äussere System ron Rinnen trenut den Embryonalbezirk rom ansserembryonalen, ein darauf folgendes System ron Bergfalten die dorsalen Anlagen von den ventralen. Die Gränze von rechts und ron links wird dureh eine tiefe longitudinale, die von Kopf und Rumpf durch eine seielite quere Rime rorgezciehnet, und die wiehtige Trennung ron Stammzone und Parietalzone ist in Gestalt zweier leichter Lüngsfalten angedentet. Lougitudinale und quere Falten kreuzen sieh, jedes der hinter einander liegenden Quergebiete der Anlagen wird 
somit in eine Anzahl neben einander liegender Felder unterabgetheilt, d. h. wir begegnen am Kopf', am Rumpf und am Schwanz einer Stamm-, einer Parietal- und einer Anssenzone, und umgekelurt verfolgen wir die Stammzone und die Parietalzone dureh simmtliche hintereinander liegender Gebiete der Gesamminulage.

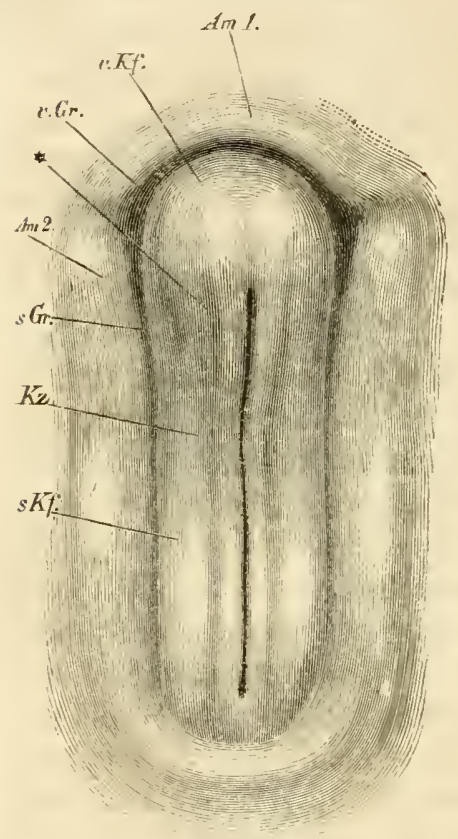

Fig. 33 (15). Embryonaltheil der Keimscheibe des Huhnes vom I. Bebiütungstag.

v. u. s. Kf. vordere und seitliche Keimfalte.

v. u. s. fir. vordere und seitliche Gränzrinne. hiz. Rime auf der Gränze von Kopf u. Rumpf.

* Falte an der Gränze von Stamm- u. ParietalAn 1. vordere und

Am 2. seitliche Amnionfalte.

Wir wollen das Prineip, wonach die primäiren Falten der Keimscheibe die Gräinzen grosser gemeinsamer Bezirke liefern, als das I'rineip der durchge henden Gränmmarken bezeichnen.

Die Läings- und die Querfalten, obwohl sie in der obersten Sehicht des Keims am schärfsten sich anspräigen, sind doch dieser Schicht nicht eigenthiimlich. Ein Blick anf die Querschnitte ron S. 33 oder auf den Lïngssehnitt Fig. 12 s. 14 zeigt Dir, dass im Allgemeinen alle Schichten an den Faltungsvorgängen Theil nehmen. Dabei sind allerdings stellenweise die Falten der vegetativen Schicht denen der animalen entgegengesetzt gerichtet. Bei Fig. 30 S. 33 7. B. siehst Dn die heiden Schichten in der Mitte der Parictalzone am weitesten auseinanderweichen, an deren

beiden Grïinen aber einander naheriieken.

Als Folge der Betheiligung der verschiedenen Schichten an der Faltenbildung ergiebt sich das Vorhandensein gleich abgegränzter Zonen in ihnen. So haben wir triher sehon die Medullarplatte und die drei verschiedenartigen Bestandtheile der. Unwirbelplatten als sich correspondirende Längshezirke 
kemnen gelerut. Weniger ummittelbar schliesst sich das Darmdriscnblatt in seinen Formbewegungen den iiberliegenden Schichten an.

Nicht jede ron Falten umgrïinzte Parcelle scheidet sich in der Folge zum gesonderten Organe aus. Wïhrend sich \%. B. der Stammtheil des oberen Gräinzblattes vom Parietaltheil als Medullarplatte be\% als Medullarrohr tremnt, bleibt der Kopptheil dieses Rohres mit dem Rumpftheile, und dieser mit dem schwantheile, d. h. das Gehirn mit dem Riiekemmark in fortlatufender Verbindung. Ebenso wenig kommt es zu einer Unterbrechung an der Gräinze der dorsalen und der rentralen Anlagen. - Damit auf die Bildmg einer Falte diejenige einer Spalte folge, ist nicht allein nöthig, dass die Falte einen gewissen Grad der Ausbildung erreiche, es miissen noch weitere Bedingungen linzukommen, wie die Einwirkung äusserer Zunkraifte, ein gewisser Grad ron Briichigkeit der zu trennenden schicht u. dergl., Bedingmgen, auf welehe wir bald zuriekkommen werden.

Wem wir uns vergegenwärtigen, wie zahlreich und wie versehiedenartig die Organe sind, deren Anlagen die Keintscheibe mufasst, wie ferner jedes Organ nicht allein nach seiner Grösse, sondern anch nach seiner histologischen Zusammensetzung dem späteren Bediurfniss des Gesammtorganismus und seinen Lebensbedingmugen angepasst ist, so muss uns die grossartige Einfachleit iblorasehen, mit welcher gleich in Anbegimn der Entwicklung Linien sich ziehn, deren jede fïr die gesammte Oekonomie der nachfolgenden Organentwickelung massgebend wird. Lass eine einzige dieser Falten ihre Lage verändern, so wird damit die Eintheihung der Zonen eine andere. Ganze Reihen von Anlagen werden, die einen vergrrissert, die anderen verkleinert werden, und ansgedehnte Verändermgen im Bane des sich entwickehden Organismus werden die Folge davon sein. Es enthält das Princip der durchgehenden Gränzmarken ein Motiv weitgreifender gegenseitiger Entwicklungsabh:ingigkeit der Theile, und gibt den Schliissel fiîr deren aus der Ziichtungslehre bekannte sog. Correlation.

Wir werden sjäter zu untersuchen haben, ob der Entstehung. von Falten auch bei späteren Bildungsvorgängen die einleitende Rolle znkommt, für hente wende ich mich sofort zur 
physiologisehen Frage: wie entstehen demn iiberhaupt Falten in der Keimscheibe?

Willst Du ein flach ansgebreitetes Papierblatt dazu bringen, Falten zu werfen, so stehn Dir natiirlich verschiedene Wege zu Gebote, eimmal kannst Du es ron den Rïndern her zusammensehieben, alsdann wird sich eine einzige, ziemlich regelmïssige Falte bilden, die um so höher sieh erhelt, je mehr Du die beiden Ränder einander näher riickst. Ein zweiter Weg steht Dir offen in Befeuchtung des Papieres. Machst Du es, um einen besondern Fall herauszugreifen, in seiner Mitte nass, so wird die genetzte Stelle anfquellen, sie wird sich ausdehnen und an dem, nicht sich dehnenden trockenen Rande des Papieres einen Ansdehnungswiderstand finden, der sie zu einer mehr odler weniger unregelmässigen Faltenbildung reranlasst. In beiden Fällen ist die Elasticitait des Papiers eine Grundbedingung des Faltenwurfes. Wäre das Papier absolut unelastisch (eine von der Plyssik bekanntlich keinem festen Körper zugestandene Eigenschaft), wiirde es mit andern Worten einer Aenderung seiner Form unter dem Einfluss äusserer Kräifte keinen Widerstand entgegenstellen, so wiirde es in dem einen, wie in dem anderen Falle zu einem Klumpen sich rerdicken. Eine sehr weiche Thon- oder Wachsplatte könnte ein Beispiel solchen Verhaltens gewähren.

Die Falten der Keimscheibe labe ich num wie diejenigen des Papierblattes als Falten einer elastischen Platte anfgefasst, weil eine andere Auffassung mir iiberhaupt physikalisch undenkbar erscheint. Dem gegeniiber bethenert Prof. II a eckel in mehreren während der letzten paar Jahre erschienenen Publicationen gleichlautend: „die Keimscheibe ist nicht elastiseh!" Anf welche Erfahrungen diese Bethenerung sich stiitzt, wird uns nicht mitgetheilt, und so wollen wir uns für diesmal erlauben, anstatt aus den Schriften von Prof. Ha eckel, unsere Belehrung bei einer wirklichen Keimscheibe zu suchen. Da kann ich Dir demn einige höchst einfache kleine Versuche angeben, die Dir tiber den Punkt keinen Zweifel mehr gestatten werden:

Du entleerst den Dotter eines frischgelegten unbebriteten Eies in eine Schaale, umschneidest den Keim mit der Scheere, hebst ihn mittelst eines trockenen Deckglases ab, und bringst 
ihn mitsammt dem Deckglase in eine unschädliche Flüssigkeit (Jodserum). Nun reinigst Du, immer unter Fliissigkeit, die Keimscheibe von der anhaftenden Dotterhaut und rom Dotter und erhäiltst sie als eine kreisrunde weisse Platte von etwa $31 / 2$ IIm. Durchmesser. Du kannst, wemn Du willst, die triibe gewordene Flissigkeit dureh klare ersetzen, und Du rersuchst num mit einer Sonde den Rand der kleinen Scheibe naeh der einen oder der andern Richtung hin umzulegen. Wofern Du sorgfältig verfïhrst, und die Gräinzen der Elasticität nicht iiberschreitest, wirst Du finden, dass der mimgelegte Rand jedesmal wieder in seine urspriingliche Stellung zuriickfedert. Dann kammst Du Folgendes vornehmen: Du lässt ein Ei während etwa 18 Stunden bebriten, die Keimscheibe dehnt sich dabei zu einem Durchmesser ron etwa S-12 Mr. aus. Tersuchst Du an der gut isolirten Scheibe mit der Sonde den Rand in radiärer Richtung einwairts zu drängen, so wird sich derselbe nach Wegnahme der Sonde wieder nach answärts bewegen. Schneidest Du aus der Scheibe Streifen von einigen Millimetern Durehmesser und schiebst sie, ähnlich wie frïher das Papierblatt, von den Rändern aus zusammen, so werfen sie Falten, die mit auf'hörenden seitlichen Drucke sich wieder ausgleichen. - Dur wirst leicht noch andere ahnliche Versuchsformen ausfindig machen kömnen, die Dich alle auf dasselbe Eudergebniss hinaustïhren werden, dass die Keimscheibe des Vogeleies schon in frïhen Stadien ihrer Entwicklung ein Körper von nicht unberlentender Biegungselasticitit ist.

Eine von aussen her auf' die Keimscheibe formverändernd wirkende Kraft läisst sich nun während der Periode der ersten Entwicklung nicht anlfinden, wohl aber ergeben sich im Verhalten der Keimscheibe selbst geniigende Bedinğnngen für deren Faltenbildung. Nur sehr im Vorbeigehen haben wir im Bisherigen des stetig ror sieh gehenden Wachsthums der Keimscheibe mo ihrer Gebilde gedacht, es ist an der Zeit, diese wichtige Function bestimmter ins Auge zu fassen.

Die unbebriitete Keimscheibe besitzt, wie Du soeben hörtest, einen Durchmesser von nur etwa $31 / 2$ Millimetern. Schon nach kurzer Bebritung macht sich eine Zunahme des Durehmessers bemerklich; stetig sehreitet diese roran, und die Seheibe, nach 24 Stunden gegen $1^{1}, 2 \mathrm{Cm}$. messend, wölbt sich ron da ab II is, Briefe. 
mehr und mehr als Halbkugel um den Dotter herum und unwächst diesen schliesslich vollständig. Währenddem legt sich die Embryonalanlage an, und wächst anch ihrerseits als Ganzes und in allen ilıren Theilen. Bei diesem stetigen Wachsthum der Keimscheibe sind nur zwei Möglichkeiten gegeben: entweder, die Ausdelmung ist in jedem gegebenen Zeitelement fuir alle Punkte der Keimscheibe dieselbe, oder sie ist fiir verschiedlene Punkte eine verschiedene. Im ersten Falle liegen im Wachsthum keine Bedingungen der Keimscheibenfaltung, in zweiten Falle ist die Faltung als nothwendige Folge rles ungleichen Wachsthums anzusprechen. Es ist dies leicht zu verstehen: Es sei z. B. eine elastische Platte ron beifolgender quarlratischer Gestalt mit je 18 Mu. Seite gregehen mud Du magst sie in die 9 Quadrate abe bis i eingetheilt denken. Diese Platte soll in ihrer ganzen Ansdehmung gleichmässig wachsen, so dass ihr Fliichenraum nach einer bestimmten Zeit sich vervierfacht. Jedes der 9 Quarlrate hat sich gleichfalls vervierfacht und fiir ein Herausgelien eines derselben aus der Ebene cler Uebrigen liegt kein Grund vor. Lass nun aber das Quadrat e sich verneunfachen, wïhrend die Uebrigen sich vervierfachen, so bilden letztere einen Rahmen, der fiur die Ausdebnung des Nittelquadrates einen Widerstand bildet. Letzteres wird, soweit seine physikalischen Eigeuschaften es gestatten, faltig sich hervorwölben, und auch der äussere Ralumen wird wegen des mach verschiedenen Richtungen mgleichen Widerstandes sich mehr oder weniger stark verziehen. Lass statt dessen das Quadrat e nach einer Richtung das dreifache, nach der andern das vierfache seines frihern Durchmessers gewinnen, so wird die Berlingung fïr Faltenbildung in einer Richtung ausgepriigter als in der andern; oder lass statt des Quadrates e die Quadrate e und h oder b, e und li sich rerneunfachen, so wirst Du wieder andere Berlingungen fïir den Faltenwurf bekommen.

Es ist, $11 \mathrm{~m}$ mich allgemeiner auszudriicken, in einer ungleichmässig sich ausdehnenden elastischen Platte dic Entstehung von Falten die nothwendige Folge der ungleiehen Austelunung, und die specielle Form des Faltenwurfes ist jeweilen eine Function des Gesetzes, welches fïr jerlen Punkt rler Platte und in einem jeden Zeitmomente die Ausdelnumg bestimmt. 
Sie ist uiberdies eine Funetion von der Vertheilung' der elastischen Kriifte in der Platte, eine $A_{\mathrm{l}}$ )lrängigkeit, von der wir vorerst abschen wollen.

Die ungleiche Vertheilung des Wachsthums in der Keimscheibe ist nicht schwer darzuthun. Ein erstes und am leichtesten zn verfolgendes Kriterium liefert die Dicke der Keimseheibe, vor allem die Dicke des oberen, von friih an durch seharte Contonren ausgezeichneten Gräinzblattes. Bevor die Entwicklung begomen hat, betrïigt die Dicke des oberen Grainzblattes in Mittel $20 \mu(0,02$ Im.), in (ler Mitte der Scheibe ist sie unbedentend stiirker als an Raude. Mit Begimm der Entwieklung ist es das zukiintige Embryonalgebiet, in dessen Bereich die Keimscheibe als Ganzes, und speciell das obere Grïinzblatt an Dicke rasch zumimmt, während in dem Randgebiete eine Verdiinnmg statt einer Verdickung und eine gleichzeitige Alplattung der ' Kellen eintritt. Die Verdickung' in Embryonalbezirk ist an bedeutendsten längs und neben der Axe, da wiederum am stairksten im zukiuftigen Kopftheile des Gebietes.

Vor vollständig erfolotem Schlusse des Medullarrohres ist an Querschnitten die Dickenzmahme vom Rand des Embryonalgebietes gegen die Vitte sehr sehön zu

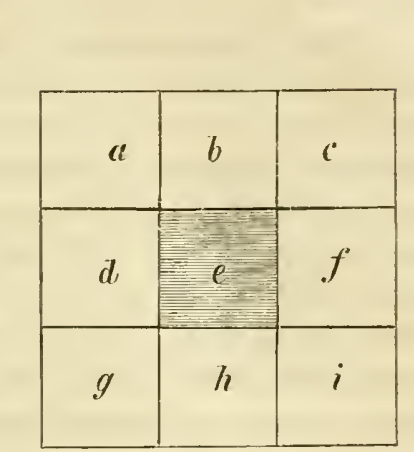

\begin{tabular}{|c|c|c|}
\hline$a$ & $b$ & $c$ \\
\hline$d$ & $e$ & $f$ \\
\hline$g$ & $h$ & $i$ \\
\hline
\end{tabular}
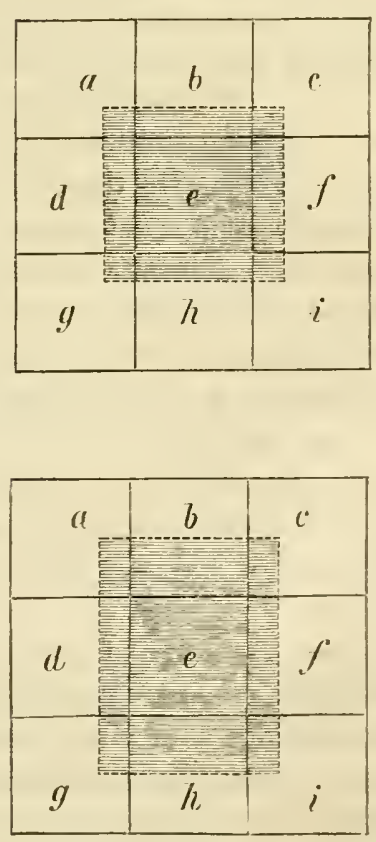

Fig. 31-39. 
verfolgen. Sie betrifft in erster Linic das Grünzblatt, dann aber anch die Muskelplatten, welehe beide am Rand des Embryonalbezirkes zugeschärft enden, und nur das Darmdriisenblatt zeigt sich lings der Axe gleich diimn, wie an Rande. Fig. 34 (S. 36) des rorigen Briefes kann Dir diese Dinge rergegenwärtigen.

Die Dickenabstufing von der Nitte gegen den Rand hin ist keineswegs in allen Schnitten dieselbe. Am Kopftheile ist die dicke Mittelzone breit und gegen den Rand hin erfolgt rasche Verjiing'ung; im Rumpfabschnitt ist die dicke Nittelzone schmaler und die Verjüngung gegen den Rand weit allmähliger. An Längsselmitten zeigt sieh das obere Gränzblatt im Kopftheile dicker als im Rumpftheil und seine Verjiingung am vorderen Rande erfolgt selır rasch. Die Dicke der Medullarplatte nach eben gesehlossenem Rohre bestimmte ich bei einem Embryo von der Stufe Fig. 10:

$\begin{array}{lr}\text { im Vorderkopf } & 45-45 \mu \\ \text { im Hinterkopf } & 35-40, \\ \text { im Halstheil des Rumpfes } & 35,\end{array}$

Embryo von der Stufe Fig. 9:

$\begin{array}{lr}\text { im Vorderkopf } & 50-60 " \text { " } \\ \text { im Hinterkopf } & 40-45 ", \\ \text { im Halstheil des Rumpfes } 35-40 ",\end{array}$

Das effective Wachsthum der Embryonalanlage in die Breite complicirt sich mit deren zunehmender Zusammenschiehmng. Letztere fiihrt trotz der Flächenzunahme der einzelnen Schichten Anfangs zn einem absoluten Selimalerwerden des Embryo. Es beträgt z. B. die Breite:

\begin{tabular}{|c|c|c|}
\hline Im Stadium & Im vorderen Drittheil & $\begin{array}{l}\text { In der Gegend } \\
\text { des 1. Urwirbels. }\end{array}$ \\
\hline Fig. 15 & $1,0 \mathrm{Mm}$. & - Mm. \\
\hline,$\quad 14$ & $0,5 \quad$, & $1,0 \quad$, \\
\hline$" 10$ & $0,7 \quad$, & $0,6 \quad$, \\
\hline 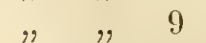 & $0,9 \quad$, & 0,5 \\
\hline
\end{tabular}

Durehgreifende Maassbestimmungen des transversalen Flächenwachsthums haben mit rerschiedenen Sehwierigkeiten zu kämpfen. Auf friiheren Entwickelungsstufen vor Schluss des Medullarrohres lassen sich feste zu Messungen geeignete Punkte nicht wohl bezeichnen, später, wenn die Organgränzen die 
Unsicherheit die Orientirung verringern, treten bald Complicationen ein, die in gegenseitigen Versehiebungen der, ursprüinglich im gleichen Querschnitt befindlichen Theile bestehen. In der kleinen Tabelle, die ich beifuige, sind für vier bestimmt charakterisirte Schnittstellen die Ausdehnung des flach ausgebreitet gedachten Medullarrohres (M) und des Hornblattes (H) eingetragen. Als Endpunkt fuir die Hornblattmessung gilt in den beiden unteren Rubriken der Ort seiner Verbindung mit der oberen Muskelplatte. Die in derselben Verticalcolonne enthaltenen Messungen beziehen sich auf Querschnitte eines und desselben Embryo. Aus den beigegebenen Verhäiltuisszahlen MI ersiehst Du: 1) das Uebergewicht des medullaren Wachsthums iiberhaupt, und 2) das, im Vergleich zum Riickenmarktheil, stiirkere Ueberwiegen desselben im Hirntheil.

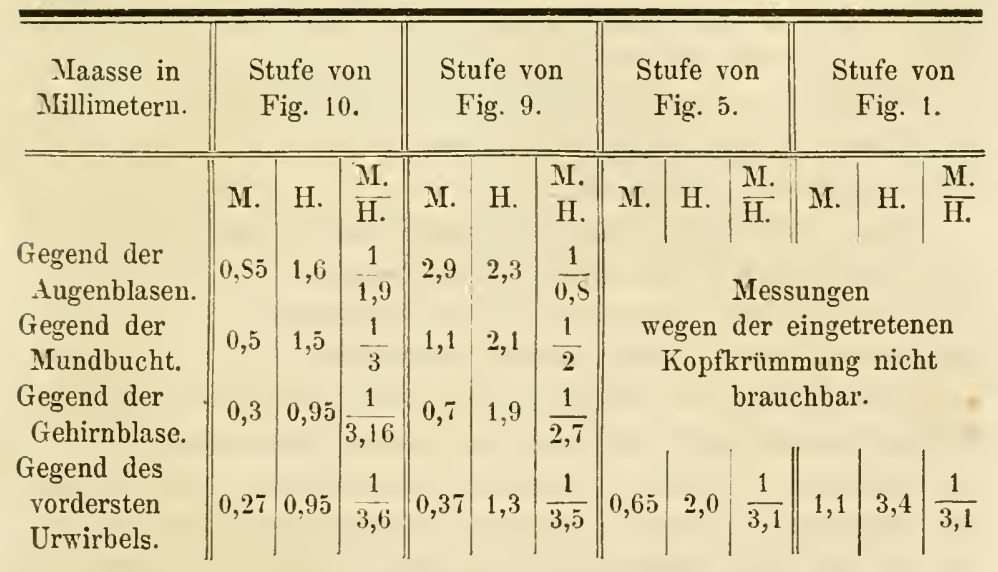

Auf das Voraneilen des cerebralen Wach sthums ist auch die Thatsache zurückzufiihren, dass alle Längsfalten im vorderen Theile des Embryo friiher und stärker sich entwickeln, als im hinteren.

Das starke Vorauseilen des Gehirns im Lïngswachsthum bedarf kaum eines besonderen Zahlenbeleges, Du brauchst nur die Figuren 1, 5, 9, 10 des ersten Briefes mit einander zu vergleichen, um Dich davon zu ïberzengen. Ein in Zahlen ausdriickbarer Vergleich zwischen dem Längswachstlıum des Rumpfes und des Gehirns lïsst sich mit Hïlfe der Urwirbel 
gewimmen. Die Länge der $\$$ vordersten Urwirbel (inel. Zwischenstreifen) beträgt zusammengenommen:

$\begin{array}{cccccc}\text { beim Embryo } & \text { Fig. } & 10 & 0,92 & \text { Mn. } \\ " & " & " & 9 & 0,92 & \\ " & \quad & " & 5 & 0,92 & " \\ " & " & , & 1 & 1,05 & "\end{array}$

Die Länge der hintereinander liegenden Abtheilungen des Gehirns (im Bogen gemessen):

$\begin{array}{cccccc}\text { beim Embryo } & \text { Fig. } & 10 & 1,4 & \mathrm{Mm} . \\ " & " & " & 9 & 1,55 & \\ " & " & " & 5 & 2,3 & " \\ " & " & " & 1 & 2,9 & "\end{array}$

d. h. während die Länge des vordersten Rumpfabschnittes 1 m etwa ${ }^{1}, 6$ zugenommen hat, hat diejenige des Gehirns un mehr als das Doppelte zngenommen. Es wird dies vorerst geniigen, Dich von der ungleichmässigen Vertheilung des Waehsthums in der Keimscheibe zu iiberzengen.

Da wir ums num dariiber klar geworden sind:

dass die Keimscheibe eine Platte ron nicht unbedentender Biegungselasticitit ist,

dass eine solehe Platte bei stattfindender ungleichmässiger Ausdehnmg in Falten sich werfen muss,

dass in der Keimscheibe das Wachsthum nach einem bestimmten Gesetze räumlich sich vertheilt,

dass endlich die Bildmo und erste Gliederung der Embryonalanlage durch Bildung von Falten sich einleitet,

kömnen wir das Ergebniss als feststehend betrachten, dass dic Bildung und erste Gliederung des embryonalen Kïrpers eine unmittelbare Function des Gesetzes ist, welches das Wachsthum der Keimscheibe nach Raum und nach Zeit bestimmt. 


\section{Fünfter Brief.}

Mechanik der Blätterspaltung. Einfluss der Kieimschcibenspannungen auf die Form der Zellen. Ueberschreitung der Elasticitäts- - und der Festigkeitsgräuzen, Bildıng des Axenstrangs und der Urwirbel. Bildung von Näthen.

Lieber Freund! In rorigen Briefe laben wir einen Angriffspunkt gefunden, ron wo aus das physiologisehe Studium der friihesten Formentwickelung sich nuternehmen lisst. Folgen wir hente dem angebahnten Pfade und mitersuehen wir, ob er mus zu noch weitergehenden Gesichtspunkten zu fiihren rermag!

Das Hauptergelnniss unseres letzten Briefes war folgendes: die Scheidung des Embryoulleibes von der iibrigen Keimhant und seine Gliederung in die fundamentalen Bezirke wird dureh Faltungen eingeleitet, welche ihrerseits die Folge sind nngleicher Vertheilung des Wachsthums in der Scheibe. Der raseher sich ausdehnende Embryonalbezirk findet einen Ausdehnungswiderstand an dem ihn numgebenden, ninder rasch wachsenden Randbezirk, und erhebt sich blasenartig iiber diesen. In ihm selbst sind wiederum Abstutingen der Wachsthmmsgeschwindigkeiten vorhanden, welche im Einzelnen mitbestimmend wirken auf die Form und auf die Reilenfolge der entstehenden Falten.

Nicht allein nach den versehiedenen Lïngen- nur Breitenbezirken stufen sich innerhalh der Keinscheibe die Wachsthumsgeschwindigkeiten ab, anch in verschiedenen Höhen dehnt sich die Scheibe ungleich rasch ans. An dem beistehenden (unvollständig wiedergegebenen) Durelıschnitte, Fig. 40, beträgt der gerade Abstand zwischen den beiden Anheftungsstellen del oberen Seitenplatten an das obere Grainzblatt $=107 \mathrm{Mm}$., was 
bei S5maliger Vergrösserung eine Breite von 1,26 Mm. ergielot.

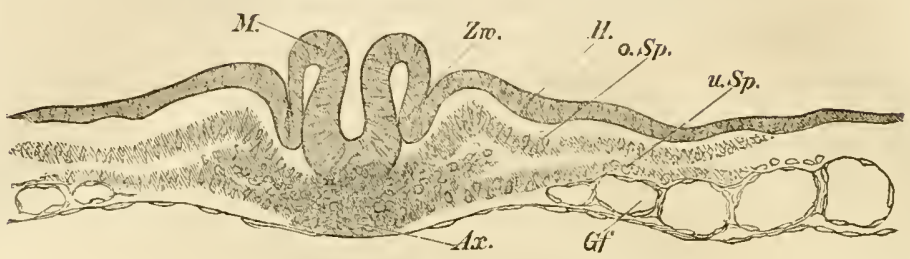

Fig. 40 (28). Querschnitt etwas weiter hinten als Fig. 27 durch denselben Embryo geführt. Die Urwirbelscheidung hat noch nicht begonnen.

Ax. Axenstrang mit seinen seitlichen Fortsātzen.

o. il. obere Miskelplatte.

u. M. untere Muskelplatte.

Gf. Gefāssschicht.

Beim Messen innerhalb dieser Breite entlang den Krümmungen resultirt als wirkliche Länge füir

$\begin{array}{lll}\text { das obere Griuzblatt } & 2,0 & \text { Mm. } \\ \text { die obere Muskelplatte } & 1,5 & \text { " } \\ \text { " untere Gü " } & 1,33 \quad " \\ \text { das mntere Gräublatt } & 1,3 & \text { " }\end{array}$

d. h. es ist das obcre Gränzblatt an der fraglichen Strecke und zu der gegebenen Zeit $1 \mathrm{~m}$ 1/3 breiter, als die obere Muskelplatte, und platte und als das Darmdriisenblatt. Auf friiheren Stufen sind die relativen Untersehiede geringer, aber in gleichem Simne vorhanden, beim unbebriiteten Keime sehliesslich gleichen sie sich völlig aus.

Die Ungleichheit in der Flächenansdehnung der versehiedenen Keimseheibenschichten ist der Grund der Blätterspaltung. Ueber diesen, im Bisherigen nur obenlin beriihrten Vorgang, wollen wir uns vorerst wiederum einige Ansehaumug verschaffen, und zwar nehme ich die Beschreibung beim Keim des unbebriiteten, frisch gelegten Eies auf.

Der Keim des umbebriteten Hiilnnereies ist, wie bereits früher erwähnt wurde, eine flache Seheibe von etwa $3^{1 / 2} \mathrm{Mm}$. Durehmesser. Der Rand der Scheibe ruht auf einem Ring: von weissem Dotter, dem sog. Keimwall auf, ihr Mittelfeld ist uiber einer, mit Fliissigkeit erfïllte Höhle, die K eimh öhle, ansgespamint. Die ersten sichtbaren Spuren des Embryo treten in diesem Mittelfelde auf, und zwar zwischen dem geometrisehen 
Mittelpunkte und dem einen, als hintern zu bezeichnenden Rande der Scheibe.

Die Keimscheibe besteht in der Zeit vor der Bebritung aus zwei Schichten, deren obere dicht und von scharfen Contouren umsäumt ist, während die untere aus locker verbundenen,

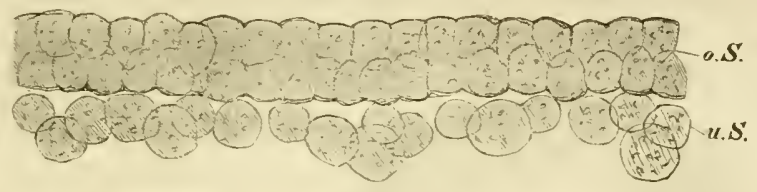

Fig. 41. Stück Keimscheibe des unbebrūteten Hūhnereies. 250mal vergrōssert in senkrechtem Durchschnitte.

0 . S. obere dichte Schicht.

U. S. untere lockere Schicht.

meistens kuglig gegen die Keimhöhle vorspringenden Zelien besteht. Einzelne Keimzellen liegen sogar, von der Scheibe getremnt, auf dem Boden der Keimhöhle. Eine eigentlich zusammenhängende Haut bilden die Zellen der unteren Sehicht noch nicht, sondern eine vielfach unterbrochene netzförmige Lage. Mit der oberen compacten Schicht hängen sie allenthalben zusammen, eine Verbindung, die sich von der Zeit der Furchung her noch erhalten hat.

Mit dem Beginn der Bebriitung gewinnt auch die untere Sehicht an Zusammenhang, die seitlichen Verbindungen mehren

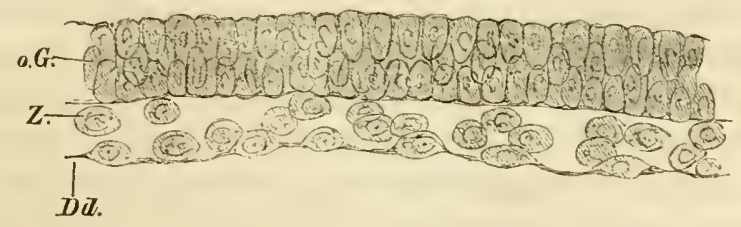

Fig. 42. Stūck Keimscheibe des Hühnereies nach 8 stūndiger Bebrütung. Senkrechter Durchschnitt, $250 \mathrm{mal}$ rergrössert.

o. G. Oberes Gränzblatt.

Dd. Darmdrủsenblatt

Z. Zwischenliegende Zellen.

sich, und es bildet sich eine tiefste blattartige Schicht, welche wir nummehr als Darmdriisenblatt bezeichnen dürfen, die oberste 
compacte Lage ist das obere Gränzblatt. Beide sind mit einander durch zwischenfiegende Zellen verbunden, welche in der Nähe der zukïnftigen Körperaxe am reichlichsten rorlanden sind. Dehmen sich num die beiden Gräinzblätter ans und bilden Falten, so ist zul einer Tremung ihrer Verbindtungen kein Grund vorhanden, so lange die Flächenausdehumg beider dieselbe ist. Dehnt sich aber das eine Blatt raseher aus als

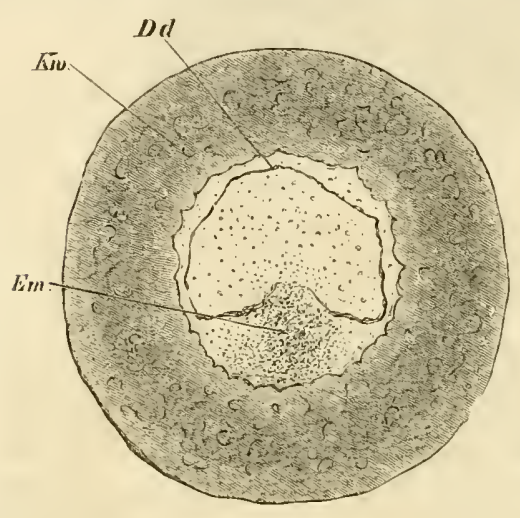

Fig. 43. Keimscheibe, 15 St. bebrütet. Vergr. 10mal.

$\mathrm{K}$ w. Keimwall (Ring von anhaftendem weissen Dotter).

Em. Erste siclitbare Spur der Embryonalanlage.

Dd. Rand des abgerissenen Darmdrüsenblatts. das andere, so werden sie bei ihrer losen Verklebung nothwendig' ron einander sich tremen mïssen. Die Trenumng wird da zuerst erfolgen wo die Verbindung am losesten, zuletzt da wo sie am imigsten ist. Sie erfolg't zuerst vor dem Embryonalbezirke dler Keimscheibe und in dessen Seitenabsehnitten, spiater im Stammgebiete, zuletzt liings der Axe. In beistehender Fig. 43 ist eine, wiihrend 15 Stunden bebriitete Keimscheibe in der Flïchenansicht dargestellt. Den Ort der Embryonalanlage erkemst Du an einem, in der hinteren Hälfte der Scheilse vorhandenen, unseharf begriuzten dunklen Streifen. Soweit dieser Streifen reicht, sind die beiden Sehichten noch ungeschieden, soweit die Scheibe hell, sind sie von einander getrennt. Forn und theilweise noch seitlich rom axialen Streifen ist der freie Theil des Darmdriisenblattes bei der Reinigrmg in grösserer Ausdehmung weggerissen worden und man sieht dessen scharfen Rand.

Treten um die beiden Gräinzblätter auseinander, so werden die dazwischen befindlichen Zellen theils dem einen, theils dem anderen Blatt folgen, oder sie werden, ilne Verbindung mit beiden anfgebend, eine mittlere Schicht bilden, die ihrerseits wieder in zwei zerfillt. Erstere Reihenfolge der Trennumgen tritt im Schwanz- und grossentheils im Parietalgebiet, 
letztere in stammgebiet in den Vordergrund. Dis Endergebniss ist, wie wir friiher schon sahen, die Bildung zweier Muskelplatten, deren cine den oberen, deren andere dem unteren Gräinzlulatt bleibend zugetheilt wird.

Alle die Trennumgen erfolgen nicht mit einem Male, sie leiten sich ein durch Zerrungen und fadenförmiges Ausziehen der verbindenden Zellen zwischen den am stärksten anseinander weichenden Strecken der Schichten, dam reisst die Verbindung: durch, die Zerrung lat mittlerweile nene, an Rand der Trennung liegende Strecken ergriffen, und so geht die Sache

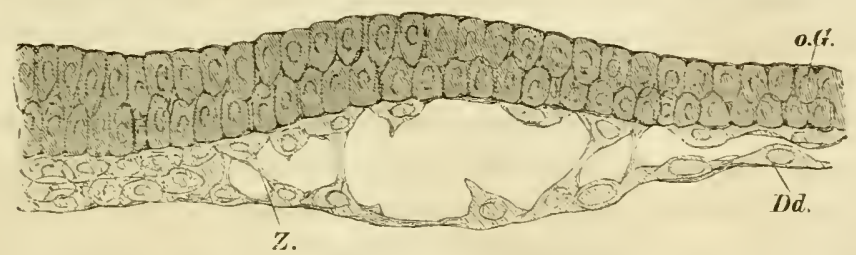

Fig. 44. Embryonalbezirk der Keimscheibe im Stadium der Blătterspaltung senkrecht durch-

o. G. oberes Gränzblatt.

Dd. Darmdrüsenblatt.

Z. Zwischenliegende Zellen zum Theil fadenförmig sich umspannend. Die dichtere Anhäufung links gehört dem Mittelbezirk der späteren Stammzone an.

ron bestimmten Stellen aus successive weiter. Das Ausspamnen fadenförmiger Terbindungen geht stets der vollständigen Lösung voraus. Wie lange und wie imnig an einzelnen Stellen die urspringhlichen Verbindungen sich erhalten, davon hast Du friiher schon Beispiele kemnen gelernt in der Verbindmug des Medullarrohres mit der Chorda dorsalis, und dieser mit dem Darmdriisenblatt, sowie in der Verloindung des ätusseren Randes der oberen Muskelplatte mit dem oberen Gränzblatt.

Gelist Du noch einmal die Schnitte durch, die ich Dir auf den letzten paar Seiten, bei stïrkerer Vergrösserung gezeichnet, mitgetheilt habe, so wirst $\mathrm{Du}$ anch bemerkenswerthe Verhältnisse in der Form der Zellen wahrnehmen. Terfolge zmäichst das obere Gräinblatt: bei Fig. 41, die unbebriitete Keimscheibe darstellend, findest Du dessen Zellen annähernd rundlieh, oder leicht oral mit Orientirung der grösseren Axe senkreeht zur Oberfliche. Schon bei Fig. 42 tritt die ein- 
seitige Verlängermng der Zellen mehr in den Vordergrund, noch mehr bei Fig. 40 sowie bei Fig. 44; und zwar wirst Du bei dieser letzten Figmr walrnehmen, dass die radiaire Verlïngerung der Zellen vom Rand der Embryonalanlage gegen die Mitte hin zunimmt, und dass sie in der Medullarplatte ihr Maximum erreicht.

Die Zellen der unteren Schichten haben Anfangs eine kuglige Gestalt, dann beginnt mit der Bildung des interen Gräuzblattes in dessen Zellẹ eine zunehmende Abplattung Platz zı greifen. In den Zellenschichten der Muskelplatten tritt im Verlaufe der Entwicklung, wie im oberen Gräinzblatte, radiäre Schichtung ein, auch hier in einem vom Scitenrand gegen die Axe hin zunehmenden Maasse.

Die Bedeutung dieser Eigenthiimlichkeiten ist unschwer zul verstehen. Wenn das obere Gränzblatt ans dem friiher angegebenen Grunde Falten bildet, so muss es als comprimirter Körper in seiner ganzen Breitenausdehnung im Zustande elastischer Spannung sich befinden. Jedes Theilchen drïickt vermöge seiner elastischen Kräifte auf die seitlich davon liegenden Nachbartheilehen, jede Zelle als Ganzes auf ihre Nachbarzellen. Die Folge davon wird sein, dass die einzelnen Zellen als weiche Körper in der Richtung geringsten Druckes, d. h. senkrecht zur Oberflïche sich ausdehnen, in der Richtung grösseren Druckes aber verkiirzen, sie werden spindelförmige oder prismatische Gestalten amehmen. Die Form der Zellen giebt uns also imnerhalb gewisser Gränzen geradezu ein Kriterium fiür die Grade der elastischen Spammung. Es ist num leicht verständlich, wie mit zunehmender Ausdehnung des oberen Gränzblattes die Spannung in ihm stets waehsen, und wie bei dessen iiberwiegendem axialen Wachsthum dieselbe gerade in der Medullarplatte ihr Maximum erreichen muss. Ferner ist aus den bekamnten Sïtzen ïber die Biegung fester Platten ersichtlich, dass am convexen Bogen der Falten die Spannung stets geringer sein muss, als am concaven und dass sie hier unter gerwissen speciellen Bedingmugen negativ sein wird. 1)

Fiir die Muskelschichten treten die Bedingungen einer Compressionsspammug viel späiter ein als fiir das obere Gränzblatt, im unteren Gränzblatt haben wir statt Spamungserscheinumgen Anfangs Erscheinungen del Dehnung; als deren Folge die fiur 
bestimmte Strecken friih eintretende Abplattung der Zellen aufgefasst werden muss.

Die Form einer Zelle kam, wie Du aus den eben besprochenen Erfahrungen ersiehst, nicht als eine durch die innere Organisation allein bedingte, somit specifische Eigenschaft angesehen werten, sie ist eine Function einestheils allerdings der Organisation, anderntlieils aber der auf die Zellen wirken. den :insseren Kr:ifte.

Es ist kaum nöthig, Dich darauf aufmerksam zu machen, dass die Analyse sämmtlicher Spannungsbedingungen für eine gegebene Stclle ein Problem äusserst rerwickelter Natur ist. Yon der Zeit ab, wo in der Keimscheibe Ungleichheiten des Wachsthums Platz gegriffen haben, entspricht ihre angenblickliche Form der jeweiligen Gleiehgewiehtslage eines ganzen Srstems elastischer Kräfte. Jeder Schnitt oder Riss wird das rorhandene Gleichgewicht stören und die Annahme nener Formen veranlassen, welehe zwar Gegenstand experimenteller Beobachtung, nieht aber derjenigen aprioristischer Toranssage sein können. Als Folge stärkerer Biegungen, Zerrungen oder Pressungen, welche die Schichten der Keimscheibe im Verlaufe der Entwicklunğ erfahren, können ferner stellenweise Ueberschreitungen der Elasticitätsgränze nicht ausbleiben, womit dann wieder nene Berlingungen in das ganze formbildende Kräiftesystem eingefiihrt werden.

Ein interessantes Beispiel ron der Entstehung neuer Gleichgewichtsbedingungen nach Ueberschreitung der Elasticitätsgränzen giebt die Geschichte des Axenstranges. Du erimnerst Dich der tiefen Rinne (Fig. 15), welche bald nach Entstehung der ersten Keimscheibenfalten das obere Gräuzblatt längs der Mittellinie bildet. Die Embryologen haben sie Primitivinne genannt, am Kopfe geht sie in eine scichte Furche iiber. Der die Rimne bildende Theil des Grinzblattes springt, wie die Quersehnitte zeigen, mit scharfer Kante gegen die unterliegenden Sehichten vor, die Muskelanlagen zur Seite drängend. Längs dieser scharf geknickten Kante nun hört die radiüre Streifung des oberen Gränzblattes auf, die Liicke zwisehen den beiden streifigen Seitenhïlften wird ron runden Zellen eingenommen. Dieselben sind bereits als Bestandtheile des Axenstranges anzusehen mol sie gehen ohne scharfe Gränze 
in die Zellenmassen iiber, welche die Verbindung mit dem Darmdriisenblatt herstellen, und die als Seitenfortsät\%e zwisehen die Muskelplatten treten.

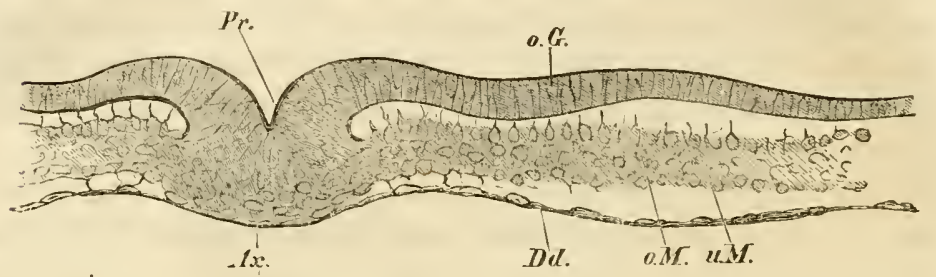

Fiğ. 45. Keimscheibe voı Hubn uach 26 stündiger Bebrütnng. Senkrechter Durchschnitt. Vergrösserung 150.

o. G. oberes Gränzblatt.

Pr. Primitivrinne.

Ax. Axenstrang.

o. H. obere und

v. M. untere Muskelplatte, von einander nicht geschieden.

Dd. Darmdrủsenblatt.

Wir haben hier einen Fall vor uns, wie er eintreten niisste, wem in einer dureh Zusammendricken gebogenen Gummiplatte der an stairksten gebogene Theil sich plötzlich in 'Thon, oder in eine andere, selu' wenig elastisehe Substanz verwandelte. Es wiirde diese Substanz aus der Fläche der Platte herausgetrieben werden und sich lings der Kante zu einem mehr oder minder unförmlichen Klumpen ansammeln.

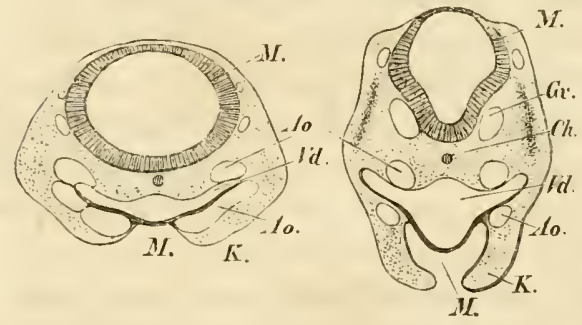

Fig. 46 (18), Querschnitt durch Fig. 47 (19). Querschnitt den Kopf von Fir. 17. tomal vergrössert.

I. MInndbucht.

K. hieferleiste.

Vd. Vorderdarm.

Ch. Chorda dorsalis.

H. Gehirnrohr Mittelbirnl.

Ao. aufsteigence und absteigende Aorta.

Gv. Gehirnvenel.
Du siehst jetzt, welchen Grund ich hatte zu der fribiher ausgesprochenen Behauptung, dass ein Theil der Zellen des Axenstranges aus dem oberen Gränzblatt stamme. Du wirst fermer leicht verstehen, dass wachsende Zellen aus dem Grinzblattantheile des Axenstranges leicht nach den Seiten him ausweichen können, 
und dass später, wenn das Medullarrohr und die Chorda im Uehrigen scharf sich isolirt haben, letztere doch noch wie ein Keil in ersteres kamn festgeklemmt sein.

Du wiirlest mich iibrigens missverstehen, wolltest Du glauben, dass alle Zellen des Axenstranges in der Weise dem oberen Ga:ainzblatte entstanmen. Das Autbrechen des olseren
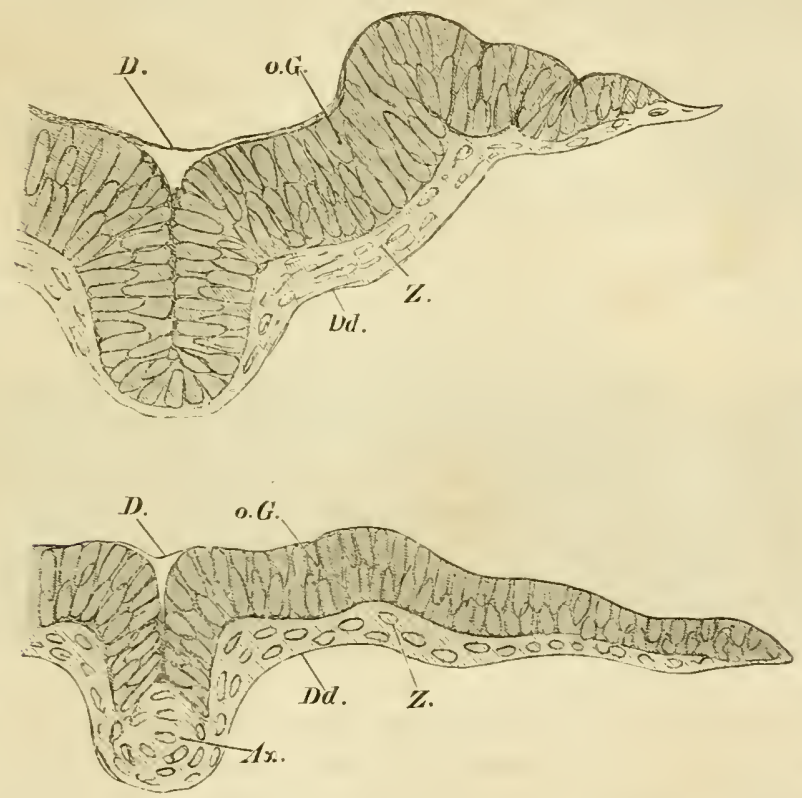

Fig. 48 nnd 49.

Querschnitt des Lachskeimes. S Tage p. foec. Vergrösserung 5.

o. G. oberes Grānzblatt.

D. Rinne, darüber liegende Deckschicht.

Dil. Darmdrũsenblatt.

Z. Zellenschicht zwischen den beiden Gränzblättern.

Grämzblattes erfolgt in Kopftheile nieht, hier bildet das Mledullarrolı eine anch in ihrem unteren Theile gleich dicke Platte mit durchgehender radiärer streifung. Gleichwohl fehlen der Axenstrang und die aus ihm hervorgehende Chorda im Kopftheile nicht, wie Du ans Fig. 15 und 19 trotz der ctwas schwachen Vergrösserung entnehmen kannst. Zur Verglleichung setze ich Dir anch 2 Querschnitte dureh die Kopfanlage eines Knochenfisches (Lachs) bei, deren eine, Fig. 38, 
die Gegend der Angenanlagen trifft, deren anderer, Fig. 49, diejenige des Hinterkopfes. An ersterem ist die Medullarplatte ununterbrochen, an letzterem siehst Du den zwischenliegenden Axenstrang eoncentrisch geschichtet.

Nicht allein die Elasticitätsgrränzen, anch diejenigen der Festigkeit werden bei den stattfindenden Umformungen der Keimscheibe vielfach iberschritten. Die oben besprochenen Blätterspaltungen gaben hierfiir ein erstes Beispiel, ein anderes, gleichfalls in frihe Perioden fallentes, giebt die Scheidung der Urwirbelplatten und diejenige der Urwirbel. Die Scheidung der Urwirbelplatten fällt in die Zeit vor der Erhebung der Medullarplatte, mit dieser hebt sich der durch zahlreiche Zellen ihrem Rande anhaftende Stammtheil der Inter-

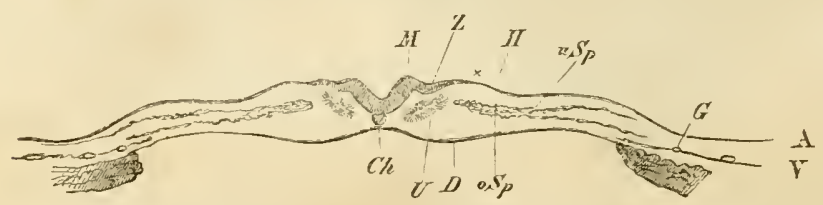

Fig. 50 (13). Querschnitt dureh den Embryo Fig. 10 bei a. 40 mal vergrössert. Dorsalansicht.

$$
\begin{aligned}
& \text { M. Medullarplatte. } \\
& \text { Z. Zwischenrinne. } \\
& \text { H. Hormblatt. } \\
& \text { U. Urwirbelplatte. } \\
& \text { S. Seitenplatte. } \\
& \text { D. Darmdrūsenblatt. } \\
& \text { Ch. Chorda dorsalis. }
\end{aligned}
$$

mediärgebilde. Die Verbindung des letzteren mit dem Parietaltheile wird erst ansgezogen und weiterhin getrennt. Die zurickbleibenden Zellenverbindungen der Urwirbel mit dem Hornblatt sind weiterhin anch der Grund, weshalb jene ron der Chorda seitwärts wegriicken und die Terbindnng mit ihr allmaihlig lösen.

Nit der Hebung der Urwirbelplatten hängt auch die Gliederung der Urwirbelplatten in einzelne hintereinanderliegende Stiicke zusammen. Dieser Scheidung geht nämlich eine, während des betreffenden Stadiums an Flächenbildern sehr auffällige Krïuselung voraus, die Du leicht verstehen wirst, wenn Du ins Ange fassest, dass die Körperaxe anch im Rumpftheile zu keiner 'Zeit gestreckt ist, sondern theils concave, theils convexe Ansbiegrungen macht. Fiir die sich aufstellende Medullarplatte und fuir die Urwirbelplatten sind somit die 
Bedingumgen dieselben, als wenn wir versuchen wollten, einen handartigen Leder- oder Stoffstreifen längs einer concaven Linie zu befestigen. Der Streifen wiirde sich mehr oder minder regehmaissig kräisseh. Am Medullarrohr sind, selbst nach vollendetem Schlusse, bei der Flichenansicht Ansbiegungen sichtbar, welche je in die Interstitien zwischen zwei Urwirbel fallen; in der lockeren Lrwirbelplatte aber bleibt es nicht bei den Kräuselungen, es kommt zur wirklichen Tremnung der sich faltenden Stiicke.

Etwas anders als in den eben betrachteten Fällen ist der Trennungsmechanismus bei der Scheidung der Leibeswand rom Ammion, der Darmwand von der Nabelblase, bei der Isolation des Herzens, und bei der 'Tremming des Ammion ron der serösen Hïlle. In allen diesen Fällen ist der frumdrorgan@ folgender: Zwei Falten begegnen sich mit ihren Firsten, mol sie

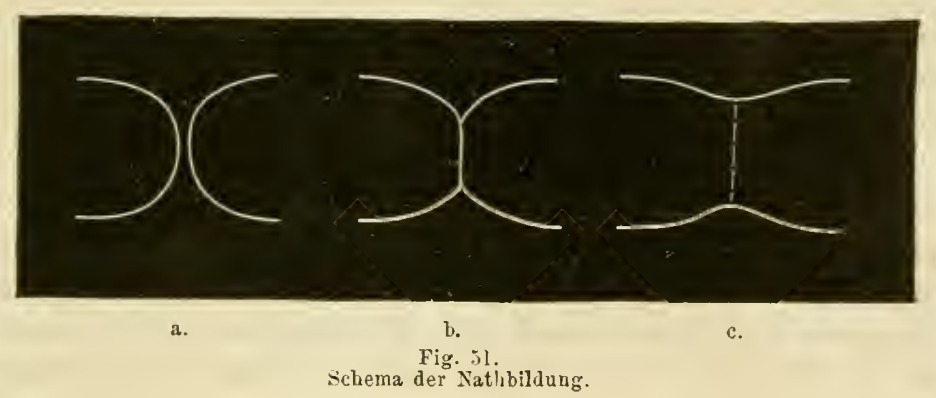

verwachsen mit cimander. Der obere schenkel der einen bildet mit den oberen der anderen eine zusammenhängende, Aufangs noch rimnenförmig vertiefte Platte, ebenso die unteren Schenkel. Das gleichfalls zur Verlöthımg grelangte 'Zwischenstiick verjiingt sich bei der, mit der Zeit murermeidlich eintretenden spamung, und dam zerreisst es, ohme merkliche Reste zu hinterlassen. Nach älmlichem Princip) greschehen eine Anzahl sogen. Abschnirungen der naclufolgenden Entwicklungszeit, wie die Abschniirmng der Linse, diejenige der Gehörblase u. a., deren Verstaindniss einer aufmerksamen Betrachtung keine Schwierigkeiten in den $\mathrm{Weg}^{\mathrm{T}}$ legt. 


\section{Sechster Brief.}

Allgemeinheit des Faltungsprincipes bei der Bildung von Organanlagen. Bildung von Herz, Luftröhre, Lungen, Leber, Schilddrüse, Magen und

Milz.

Lieber Freund! Die Ungleichheit des Wachsthums verschiedener Keintheile und die Bedeutung derselben als formbildendes Prineip haben sich als das feste Ergebniss der in den letzten beiden Briefen mitgetheilten Beobachtungen und Messungen herausgestellt. Wir wissen nunmehr, dass jene Ungleicheit im Wachsthum nicht allein die Bildung der den Keim abtheilenden Falten bedingt, sondern dass sie mittelbar auch die Ursache ist fïr die Scheidung der Keimblätter, fuir die Abspaltung der Urwirbelplatten und der Urwirbel, für die Trennung der Chorda dorsalis, kurz für die gesammte Gliederung des Keimes, soweit sie in den ersten Perioden der Entwicklung sich vollzieht.

Es erheht sich nun, wie $\mathrm{Du}$ siehst, die Frage, ob es möglich ist, unter Zugrundelegung desselben Prineipes auch die weitergehenden Organabgliedermingen, die Bildung des Herzens, der vegetativen Organe und der Sinnesorgane abzuleiten, oder ob es dazı der Herbeiziehung neuer Principien bedarf. Diese Frage hängt innig zusammen mit einer andern, ob der Gang des Wachsthums einem Gesetze einfacher zeitlicher und räumlicher Abstufing folge, oder ob derselbe bei Bildung besonderer Organe anch zu besonderen Anläufen oder Spruingen sich erhebe.

Die friberen Embryologen hatten bereits die Erfahrung gemacht, dass die Bildung mancher Organe von bestimmten Flächen ausgeht. Die Bildung des Herzens, der Luftrölure und 
Lungen, der Schilddriise, sowie diejenige der Leber und des Pankreas wurden in Beziehung zur Gesehichte des Primitivdarmes gebracht, die Bildming der Linse, der Gehörblase und diejenige der Hautdrïsen wurden als sogen. Absehnürungen des Hornblattes aufgefasst. Immerhin ging man dabei von der Voraussetzung aus, dass da, wo ein solehes Organ sich zu bilden lıabe, die Substanz in einem gegebenen Augenblicke zu wuchern begimne. Es sollte die Bildung des Organs das Ergebniss eines ans dier Ordnung der Nachbarsehaft heraustretenden localen Wachsthumsprocesses sein. Nun ergiebt aber die Beobachtung der frïheren Stadien keine solchen localen Wucherungen. Von den, in den Ort des späteren Gehirnes fallenden Streeken maximalen Wachthums aus stuft sich, soweit aus dem vorhandenen Material erkennbar ist, das Wachsthum stetig nach allen Richtungen hin ab, raseh nach vorn, langsamer und symmetrisch nach den beiden Seiten, am langsamsten nach rïckwärts. Ebenso findet sich Abstufung in der Wachsthumsgeschwindigkeit von den obcren zu den tiefen Sehichten der Keimscheibe. Mit Riicksicht auf die histologische Bestimmung der Anlagen heisst das: es wächst im Beginn der Entwicklung am rasehesten die Anlage für das Nervengewebe, langsamer diejenige für die quergestreiften, noch langsamer die fïr die organisehen Muskeln, und am langsamsten (wenigstens gilt dies vom Darmdrisenblatte und vom Rande des Hornblattes) die Anlagen für Epithelien und für driisige Theile.

Wir gelangen somit zu folgender Alternative: entweder berechtigen uns die Erfahrungen iiber Bildung bestimmter Organe zum Schlusse, dass an gegebenen Stellen und zu gegebenen Zeiten locale Wucherungen auftreten, oder aber es müssen sich alle bei Organanlagen in Betracht kommenden Substanzanhäufungen als durch Faltenbildung bedingte $\mathrm{Zu}$ sammendrängungen auffassen lassen.

Ist ersteres der Fall, dann miissen wir uns von vornherein sagen, dass das Gesetz, welehes das embryonale Wachsthum beherrseht, unmöglich einen einfachen Ausdruck haben kann, in letzterem Falle aher wird es wahrscheinlieh, dass dieser Ausdruek ein verhältnissmässig einfacher sei. Es ist nämlich alsdann zu vermuthen, dass anch im weiteren zeitlichen Ver- 
laufe der Entwickelung die Wachsthumsgeschwindigkeit fiir irgend eine der gegebenen Anlagen nieht sprungweise, sonderu nur in allmähligen Abstufungen sich ändert. An und fiir sieh empfiehlt sieh, wie Du siehst, diese Annahme durch ihre grösstmögliche Einfachheit, auch erlaubt sie, wie ich Dir später zeigen werde, iiber das Wesen der Zeugung und der erblichen Uebertragung Vorstellungen zu formuliren, welche sich ungezwungen dem Rahmen mechaniseher Naturvorstellungen einreihen.

Die Beobaehtung hat bis dahin kein Organ antgedeekt, dessen Bildungsgesehiehte zur Amuahme localer Wucherungen nöthigt. Fiir einige wenige Organe, wie für die Nieren und die Nebennieren, ist unsere Kemntniss der erstẹn Anlagen noch unvollkommen. Fiir die grosse Mehrzahl der iibrigen ist der Nachweis von deren Bildung durch Faltumgsvorg:inge unmittelbar zu fïhren. Fiir einige Hauptorgane werde ich Dir das beziigliche Material vorlegen, und ich beginme mit der Gesehiehte des Herzens.

Wir haben in friiheren Briefen dic doppelte Gliedermng. der Muskelanlagen, einmal in Stammtheil und Parietaltheil und dann in die obere, oder animale und in die nutere, oder vegetative Platte, besprochen. Fiir den Kopf' erleidet dieses Gliederungsehema einige Modifieationen. In Vorderkopf sind an und fîr sich die Muskelanlagen unbedentend, und die Gliederung in Stamm- und Parietaltheil tritt nur unvollkommen ein. Im Hinterkopf dagegen sind die Muskelanlagen heträehtlieher, und es ist ihre Scheidung in Stamm- und Parietaltheil bestimmt ansgeprägt. Der Parietaltheil ist zu imnerst eine einfache Platte, dann spaltet er sich in zwei Sehichten (s. Fig. 52), von welehen die untere breiter und unverhältuissmässig viel dicker ist, als die obere. Aus der unteren Schicht entwickelt sich die Musenlatur des Herzens, des Pharynx und des Diaphragma. Es sind dies lauter quergestreifte Musculaturen, und als ummittelbarer Ausdruek der Thatsachen ergiebt sich somit, dass am Kopf die vegetative Platte als selbststïndige Anlage fehlt, die animale dagegen in zwei Sehiehten von ungleicher Stärke, eine schwächere obere und eine stärkere untere, gespalten ist. Die untere Platte lässt sich bis zum vordersten Absehnitte des Halses verfolgen, hier legt sie sieh an die obere an. Dahinter gestaltet sich 
die Schichtung so, wie ieh Dir sie friuher als typiseh beschrieben habe. Die spaltförmige Leibeshöhle besteht demgemäss aus einem vorderen, beiderseits von animaler Mnseulatur ungr:iuzten Raume, und aus einem hintereu, dessen eine Wand dureh animale, dessen andere dureh vegetative Musenlatur gebildet wird. Ersterer ist die Anlage der Brust- und letzterer die der Bauchlı̈̆hle. Die Abgräinzung beider ist die mit der Herzanlage verbundene Anlage des 'Zwerchtells. Unter den umstehenden Zeiehnungen sind es Fig. 58 und Fig. 64 und 65, welche die Verbindung der beiden animalen Schiehten auf dem Quersehnitte zeigen; Fig. 57 ist der Stufe Fig. 9, die beiden andern sind der Stufe Fig. 5 entnommen. ${ }^{1)}$

Es darf Dich nicht betremden, dass hier von einer Brusthöhlenanlage am Kopf; von einer Zwerehfell- und einer Bauchhöhlenanlage am Halse die Rede ist. Auch das Herz bildet sich, wie Du sehon aus den Figuren des ersten Briefes entnommen hast, an Kopf; wnd wandert, indem es das Zwerehfell mitnimmt, erst später in seine definitive Lage. Darin liegt anch der Grund, weshalb das Herz ron einem Kopfnerven, das Zwerchfell von einem Halsnerven imervirt ist. ${ }^{2}$ )

Die Bildung des Helzens hängt in imniger Weise mit derjenigen des Vorderdarms zusammen. Der Vorderdarm schliesst sich durch das mediane Zusammenwachsen der zwei seitlichen Falten des Darmdriisenblattes (Fig. 52 11. Fig. 55). Nachdem die beiden Falten sich erreicht und vereinigt haben, isolirt sich die neugebildete untere Wand des Vorderdarms auf die, im vorigen Briefe besprochene Weise. Mit den zwei Falten des Darmdriiseublattes bewegen sich gleichläufig' die unteren animalen Platten, und unter dem sich sehliessenden Vorderdarm begegnen sich, der Zeit naeh etwas später, anch sie. Wiirden die Muskelplatten dem Darmdriisenblatt durchweg genau anliegen, so wiirde der Vorderdarm zwar eine musculöse Wand bekommen, ein Herz indess käme dabei nicht zu Stande. Die Bildung des letzteren ist davon abhängig, dass jederseits die Muskelplatte, breiter als das zugehörige Darmdrisenblatt, von diesem sich faltenartig abhebt. Die der innern Faltenflïehe entsprechende Rimne der Muskelplatte ist die erste Andentung eines Herzratmes, die Wand der Faltenrinne wird zum Muskelsehlatche des Herzens. 

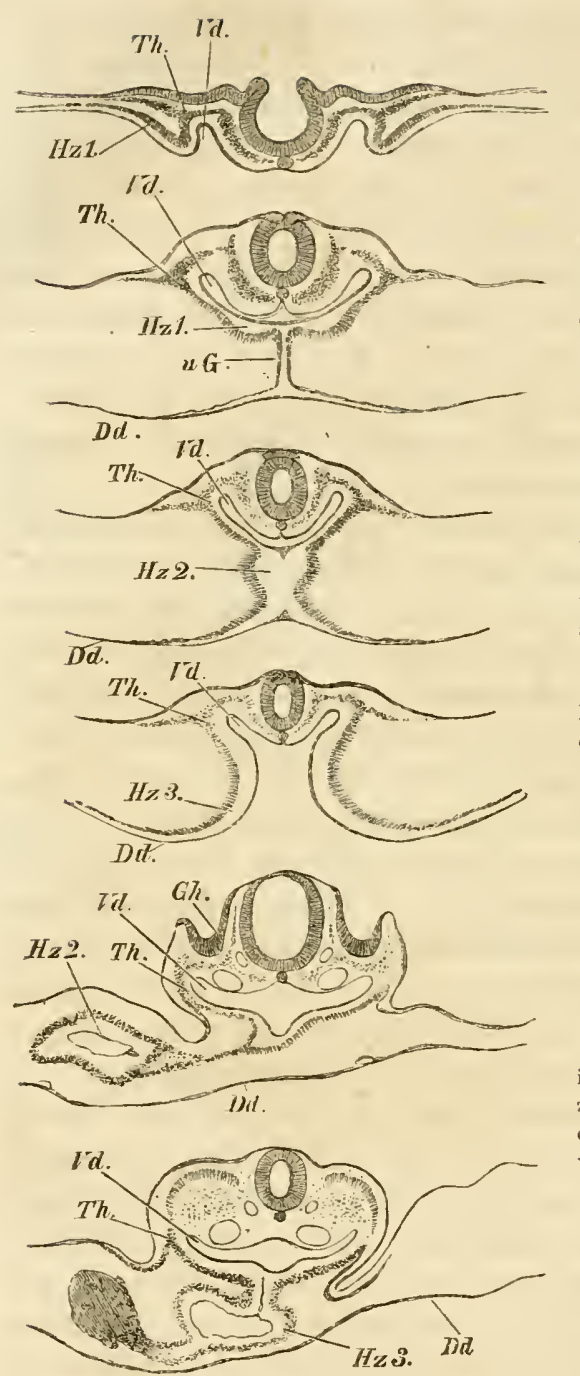

Fig. 52-5i

Querschnitte zur Bildungsgeschichte des Herzens, 6ämmtlich $40 \mathrm{mal}$ vergrössert.
Fig. 52 entstammt einem Embryo der Stufe 14 (S. 16), Fig. 53-55 einem und demselben Embryo von der Stufe 10 (S. 12) and Fig. 56 and 57 einem Embryo ron der Stufe 9 (S. 12).

Fig. 52 ist durch die Gegend des späteren Herzbuibus geführt, die Herzbildung hat noch nicht begonnen. Der Ort Hz. I bezeichnet die Spalte, welche später zum Bulbustheil wird.

Bei Fig. 53--55 ist der Bulbustheil und der vordere Ventrikeltheil angelegt, die hintere HerzhäIfte noch uicht.

Fig. 56 zeigt den Ventrikel-, und Fig. 57 den vorderen Vorhofstheil eines bereits pulsirenden Herzens.

Th. Theilungsstelle der animalen Muskelplatte in die obere und untere Schicht.

Hz. 1. Iferzanlage, Bulbustheil.

Hz. ". $\quad$ " Ventrikeltheil.

Hz. 3. " Vorhofstheil.

Vd. Vorderdarm.

Dd. unterer (ausserembryonaler) Theil des Darmdrüsenblattes.

Gh. Gehörgrube (Fig 5).

Bei den unteren zwei Figuren ist der Endocardialschlauch eingezeichnet, bei den Fig. $53-55$ ist er der Kleinheit der Figuren halber weggelassen.

Die Art und Weise, wie sich die beiderseitigen Rinnen zu einander und zum Vorderdarm verhalten, ist nicht in der ganzen Länge der Herzanlage dieselbe. In dem, zuerst sich 
ahlegenden rorderen Herzdrittel kehren die Rimmen ihre Convexität nach abwärts, ihre offene Seire nach aufwärts, letztere wird ron oben dureh die Wand des Vorderdarms, d. h. durch das Darmdriisenblatt geschlossen, oder richtiger gedeckt (Fig. 53). Im mittleren Herzdrittel kehren beide Rimnen ihre Höhlung der Medianebene, somit einander gegenseitig zu (Fig. 54). Der urspriunglich dazwischen liegende rerticale Theil des Darndriisenblattes wird binnen Kurzem durehrissen. - Im hinteren Herzdrittel gelangen die Rinnen mit ihrer Höhlung. auf die untere oder Uebergangsplatte des Darmdriisenblattes, letzteres schliesst auch wiederum den Kanal, aber diesmal ron unten her. Gleich nachdem das Herz in seiner ganzen Lïnge angelegt ist, lassen sich,

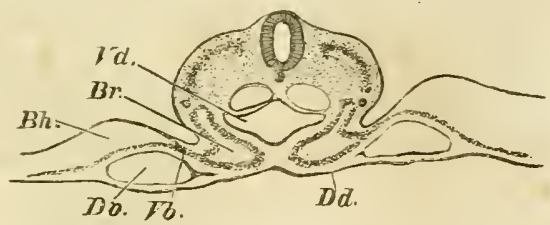

Fig. 5s. Schnitt rom gleichen Embryo wie Fig. 56 und $5 \%$, etwas weiter hinten. Vergr, 41.

u. Mf. hinteres Ende der unteren animalen Muskelplatte, bei

Vb. sich mit der oberen verbindend.

Dr. die in das hintere Herzende tretende Dottervene. Br. Anlage der Brusthöhle.

Bh. Anlage der Banchhōhle. dem Gesagten zu Folge, drei Abtheilungen unterscheiden, die drei späteren Hauptabtheilungen entsprechen, es sind dies der Bulbustheil, der Ventrikeltheil und der Vorh of stheil. Von diesen dreien ist nur die mittlere Abtheilung ron Anbeginn an einfach, die vordere und die hintere Abtheilung sind gablig gespalten, und nur nachträglieh riieken deren Seitensehenkel in der Medianebene zusammen, und schliessen sich melı' und mehr zu einem selbstständigen Rohr mit rings umgreifender Muskelwand. Mit Bezug auf die Lage der drei Herzabtheilungen magst Du Dir auch noch einmal den Längssehnitt Fig. 59 ansehen, an welchem der sehräge Verlauf des, als Falte angelegten Herzens und seine Beziehung zum Vorderdarm deutlich hervortreten.

Nach der Art seiner Entstehmo muss das Herz sowohl nach oben als nach abwärts mit einer medianen Platte, einer Gekrösplatte, wie wir sie nemen können, rersehen sein. Das obere Herzgekrïse fehlt im Bulbustheil und entwickelt sich hier später (Fig. 60). In Ventrikeltheil ist es von Anfang an vorhanden, reisst aber frühzeitig durch, im Vorhofstheil bleibt es kurz. - Das untere Gekrïse ist im Bulbustheil gut 
ausgebildet (Fig. 52) und verliert sich selion im Ventrikeltheil, es ist von sehr voriibergehender Existenz. - Vom oberen

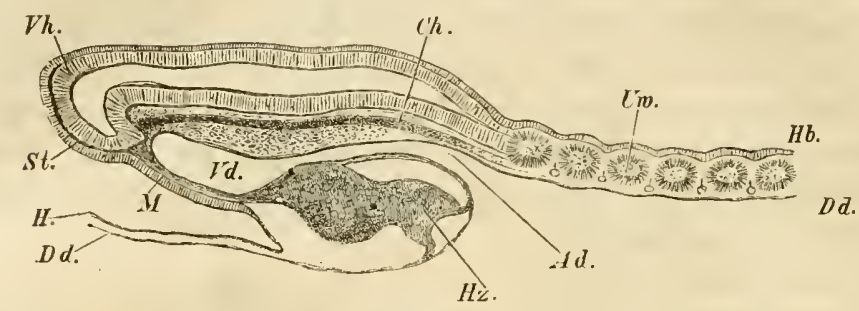

Fig. 59 (12). Längsschnitt durch eineu Embryo vom zweiten Bebrütungstage. 41/mal vergrössert.

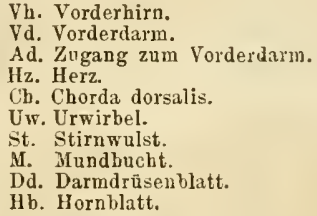

Gekröse erhält sich ein Rest im Bulbus- und im Vorhofstheil, dort ist er der Träiger der aus dem Bulbus hervorgehenden Arterien, und hier wird er zum Leitband fiir die in den Vorhof

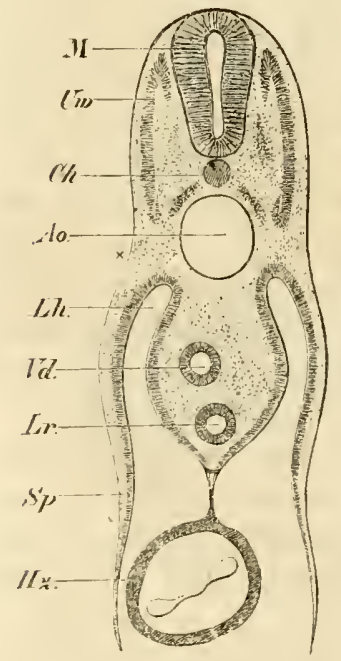

Fig. 60 (4). einmiindenden Venen.

Das Her' ist, wie Du aus Fig. 10 s. 12 siehst, urspriinglieh ge streckt und symmetrisch gestellt; so bleibt es aber nieht lange, es biegt sich mit seinem frei werdenden Ventrikeltheil zur Seite (nach reehts). Spaiter riicken sich, nach der, in den Lehrbichern besehriebenen Weise, Bulbus- und Vorhofstheil entgegen, wobei ersterer melır nach vorn und rechts zu liegen kommt als der letztere.

Der Schlauch, dessen erste Bildungsgesehichte ich Dir soeben beschrieben habe, ist die Muskelwand des Herzens, er ist nicht ummittelbar zur' Aufinalnme des Blutes bestimmt. 
In seinem Innern bildet sieh aus parablastischen Anlagen jederseits eine Gefäissrölıre von Bau der Aorten, oder anderer primitiver Gefässe. Beide Röhren versehmelzen zuerst im Ventrikeltheil mit einander, und ihr Inneres wird in der Folge von rothem Blute durehströint. Zwisehen diesen Endoeardialröhren, wie wir sie nemnen wollen, und der Muskelwand bleibt ein ziemlich breiter Zwischenraum, nur von klarer Fliissigkeit erfullt, uibrig. Später verliert sich dieser Raum mehr und mehr dadureh, dass die Wandungen des museulösen und des endocardialen Her'zsehlanches sich entgegenwachsen und theilweise durehdring'en. ${ }^{3}$ )

Sowie das Herz gebildet ist, fiingt es anch an rhythmisch sich zusammenzuziehen. Die Fliissigkeit im innern Schlanche

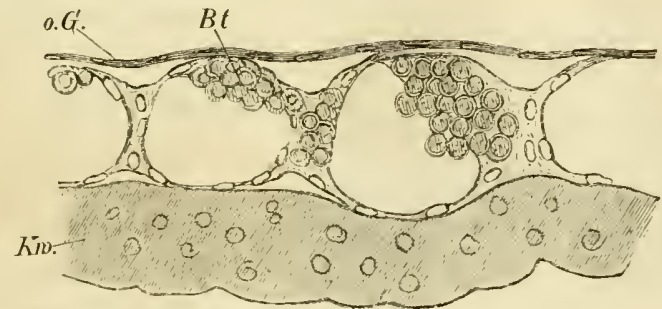

Fig. (j1. Querschnitt aus dem Aussenbezirk der Stufe Fig. 9. Vergr. $250 \mathrm{mal}$.

Bt. Blutgefăss $\theta$ mit den in der oberen und Seitenwand sitzerden Blutinseln.

o.G. oberes Gränzblatt.

hw. Keimwall.

ist Anfangs noch klar, später mengen sich rothe Blutkörper in wachsender Zahl bei. Dieselben sind, wie die ersten Gefaissanlagen, ausserhalb des Embryonalleibes, in den sogen. Blutinseln entstanden. Man hat, ehe man die Geschiehte der Blutgefisse genaner kannte, oft geglanbt, die letzteren als Folge der Herzwirkung ansehen zu miissen, als Kanäle, die das rom Herzen ansgepresste Blut sich gebildet habe. Diese Annahme ist völlig unhaltbar; denn ehe ein Herz da ist, sind, weit ausserhalb des Embryonalbezirkes, schon Blutgefässe angelegt, und deren Höhlung sehreitet in centripetaler, nicht in eentrifugaler Richtung vorwärts. Die eben erwähnten Blutinseln sind Zellenanhäufungen in der Wand der äıssern Blutgefässe, deren Zusammenhang allmählig sich lockert, und 
deren Bestandtheile dureh den sich bewegenden Blutstrom aus den urspriingliehen Lagern entfernt werden.

Wir werden später wieder anf cinige Punkte der Her'zentwicklung zuriiekkommen, für diesmal rerlassen wir das Organ und werfen einen kurzen Blick auf die Entstehungsgesehichte anderer, in Verbindung mit dem Primitivdarm sich

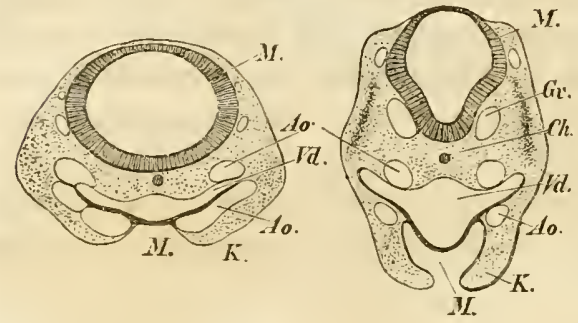

Fig. 62 (18). Querschnitt durch Fig. 63 (19). Querschnitt den Kopf von Fig. 17. $40 \mathrm{mal}$ vergrössert.

II. Mnndbucht.

K. Kieferleiste.

Td. Vorderdarm.

Ch. Chorda dorsalis.

M. Gehirnrohr (Mittelhirnl.

A. anfsteigende und absteigende Aorta.

Gv. Gehirnvenen. entwickelnder Organe, zinächst auf diejenige der Luftröhre und der Lungen.

Aus einer Anzahl bereits mitgetheilter Querschnitte fFig. 62, 63 11. Fig, 53-57) hast Du ersehen kömen, dass der Vorderdarm ummittelbar nach erfolgtem Sellusse eine flache Spalte von nicht unbetriiehtlieher Breite ist. Seine Gestalt auf dem Quersehnitt ist

halbmondförmig, die obere eoneare Wand sehmiegt sich den Stammgebilden der animalen Schieht und den Aorten an, stellenweise bis zum Hornblatte herausreichend, die untere conrexe Wand ist im Gesicht der Mundbucht, am Hinterkopf der Herzanlage zugekehrt.

Je mehr die Abplattung des Körpers sieh geltend macht, um so mehr versehmailert sieh der Vorderdarm und es vertieft sich die convexe Ausbiegung seiner rorderen Wrand zur schmalen Rinne. Dass es sich dabei wirklich um ein seitliches Zusammengedrücktwerden handelt, zeigen nieht allein die Bilder, sondern auch die Zahlen:

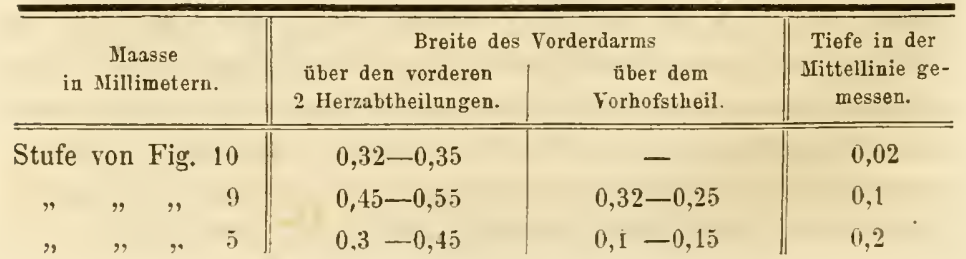


Das Rohr verliert an absoluter Breite, was es an Tiefe gewinnt. Die mediane untere Rinne wird zur Luftröhre und zum Kehlkopf (Fig. 64 und 65 .

Folg'st Du nun in den Reihen der Schnitte der fraglichen Rinne ron rorn nach riickwärts, so triffst Du bei der Entwicklungsstufe ron Fig. 5 dicht hinter dem Vorhofstheil des Herzens auf eine Stelle, wo. die Rinne doppelt ist, d. l. Du gelangst zu den Anlagen der beiden Lungen (vergl. Fig. 65); noch weiter zuriek ist der Primitivdarm offen, nnd Du überzeugst Dich, dass die rinnenförmigen Anlagen der Lungen in die friher (S. 10) erwähnten seitlichen Rinnen des Mitteldarmes sich fortsetzen. Die nach einem Modell gezeichnete Fig. 66 kann Dir dieses Verhältniss klar maehen. Die zwei auf dieser Stufe noeh offenen, dreieekigen Seitentheile schliessen sieh bald darauf gleichfalls, und werden zu den paarigen Anlagen der Leber.

Die Lichtung der Luftröhren- und der Lungenanlage trennt sich weiterhin ron derjenigen des Verdauungsrohres, und wir finden

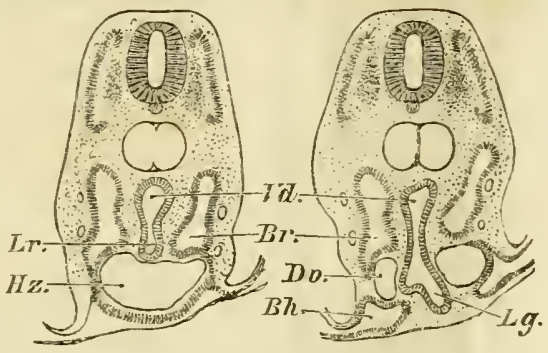

Fig. 61 und 15.7 .
Querschnitte durch einen Embryo von der Stufe Fig. 5. 4)imal vergrössert.
Vd. Verdanungsrohr.
Lr. Luftröhrenanlage.
Lg. Lungenanlage.
Br. Brustaöhlenanlage.
Bh. Bauch öhlenanlage.
Hz. Vorhofstheil des Herzens.
Dr. Dottervene. nunmehr eine, bez. zwei vordere und eine hintere, ron Epithel ausgekleidete Röhren (s. Fig. 60 S. 72), die noch von einer gemeinsamen Muskel- und Gefässwand umgeben sind. Erst später, mit zunehmender Ausdehnung der Röhren vollzieht sich auch äusserlich ihre Seheidung.

Aus der unteren Wand des Vorderdarms, und zwar aus den, seitlich von der medianen Rinne gelegenen Strecken gehen auch die Anlagen für die einzelnen Abtheilungen der Sehilddriise herror. Umstehende Zeichnung (Fig. 67) giebt Dir in sehematiseher Darstellung 1) die Bildungsweise der Luftröhre, 2) der Luftröhre nebst Schilddrise, und 3) der Lungen. 
Wir gehn zu den, weiter nach rückwïrts liegenden $A b_{\text {- }}$ schnitten des Prinitivdarms über, und ich lade Dich ein,

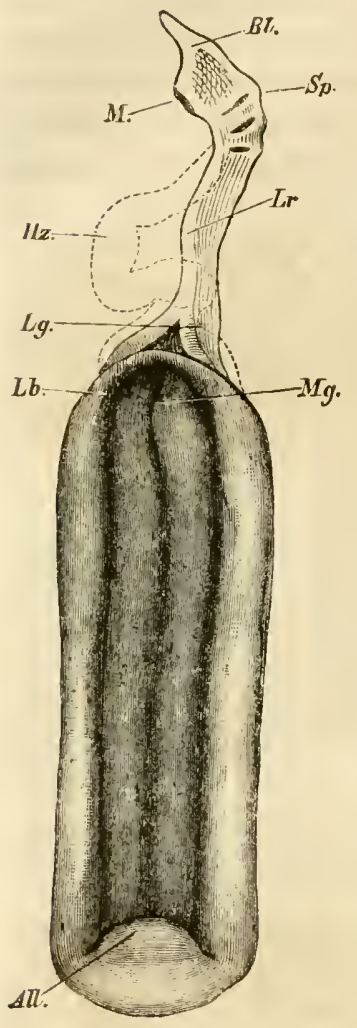

Fig. $66^{2}(8)$. Primitivdarm des obigen Embryo. 20mal vergrössert. Die pnnktirte Linie zeigt die Lage des Herzens.

B1. Blindes mit dem Hirn verbundenen Ende des Vorderdarms (sog. Rathkesche Tasche).

M. Berührungsstelle des Vorderdarms mit dem Grund der Mundhöhle.

Sp. Schlundspalten.

ifb. Herz.

Lr. Luftröhrenanlarge.

$\mathrm{Lg}$. Lungenaulage.

Lb. Ort der Leberanlage.

Mg. Ort der Magenanlage.

All. Ort der Allantoisanlage. einen nochmaligen Blick auf die Schnittzusammenstellung des zweiten Briefes (S. 33) zu werfen. Du wirst bemerken, dass der, zum eigentlichen Verdaungsrohr bestimmite mittlere Theil des Darmdriisenblattes Anfangs keine musculöse Bekleidung hat. Dann riicken (Fig. 29 u. f.) von der Seite her die unteren Seitenplatten medianwïirts vor, und erreichen sich nahezu in der Mittellinie. Das Verdaunngsrohr elhält sonach seine Muskelwand nicht vom Stammtheile, sondern vom Parietaltheil der unteren Muskelplatte.

Die Darmanlage kann, wenn sie von den Seitenplatten erreicht wird, von der Aorta und der Chorda dorsalis sich bereits ein Ende entfernt haben, alsdann bilden die einander begegnenden Platten im Zivischenranme ein unpaares Gekröse, wie Dir solches die unterste Figur jener Znsammenstellung vor Augen fithrt.

Hat man sich fïr verschiedene Embryonen fortlaufende Reihen von Querschnitten angefertigt, mind misst man an denselben die Höhe zwischen dem Darmdriisenblatt mol der Chorda dorsalis, so iiberzengt man sich, dass sie sclron in ziemlich frither Zeit (bei der Stufe von Fig. 9) einem gesetzmässigen Wechsel unterworfen ist. An bestimmten Stellen ist der Abstand zwischen dem Darmdriisenblatte und der Chorda grösser, an anderen kleiner.

Die Unterschiede nehmen noch zu in den späteren Entwicklungsperioden. In Fig. 65 habe ich den Gang dieser Be- 
wegungen verzeichnet. Im vorderen Halsalsschnitte erreicht die Entfernung des Primitivdarms ron der Chorda und rom Medullarroln ein erstes Maximum, damn folgt weiter hinten cin Minimum, ein nenes Maxim!m us. s. w. Es sind diese Bieg'ungen der Darmaxe deshalb von Wiehtigkeit, weil sie cinestheils die spätere Gliederung des eigentliehen Verdauungsrohres bestimmen und weil sie anderntheils fiir die Tren-

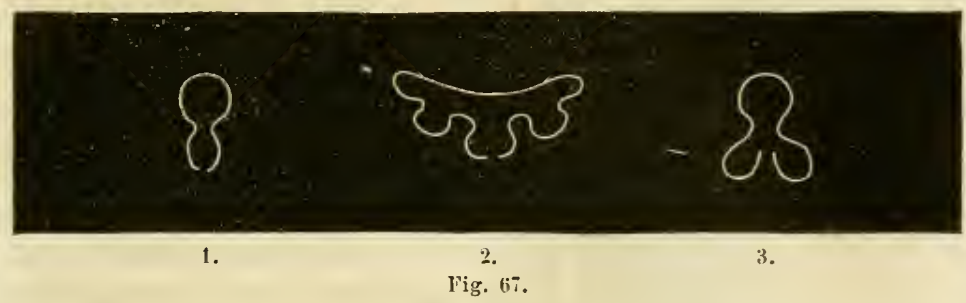

nung der hinter cinander liegenden Nebenorgane des P'rimitivdarmes entscheidend sind.

In den Ort der unteren ersten Ausbiegung faillt die Bildungsstelle des Magens mit seinem ziemlieh beträehtliehen Gekröse. Die nach abwïrts gerichtete Convexitiit der Biegung bestimmt als einspringende Querfalte die Gränze zwischen der Lungen- und der Leberanlage. An der mit Md bezeichneten Stelle minimalen Abstandes zwisehen Darm und Chorda

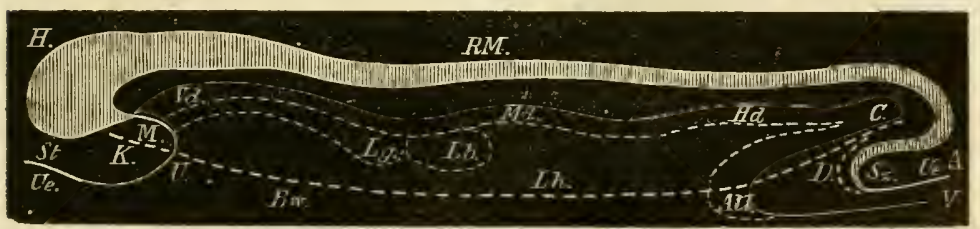

Fig. lis (23).

billen sich das Duodenum und das Pankreas; der nachfolgende, mit breiter Gekrösanlage versehene Abschnitt liefert den iibrigen $\mathrm{D}$ iinndarm, und hinter der mit $\mathrm{Hd}$ bezeiehneten Stelle folgt die Anlage des Diekdarms.

So lange der Körper noeh völlig gestreekt ist, liegen die Gebilde des Primitiodarmes symmetriseh zu einer dureh die Axe gelegten Mittelebene, das Herz weicht zuerst aus der symmetrisehen Stellung zur Seite. Erfolgt nun aber jene Seit- 


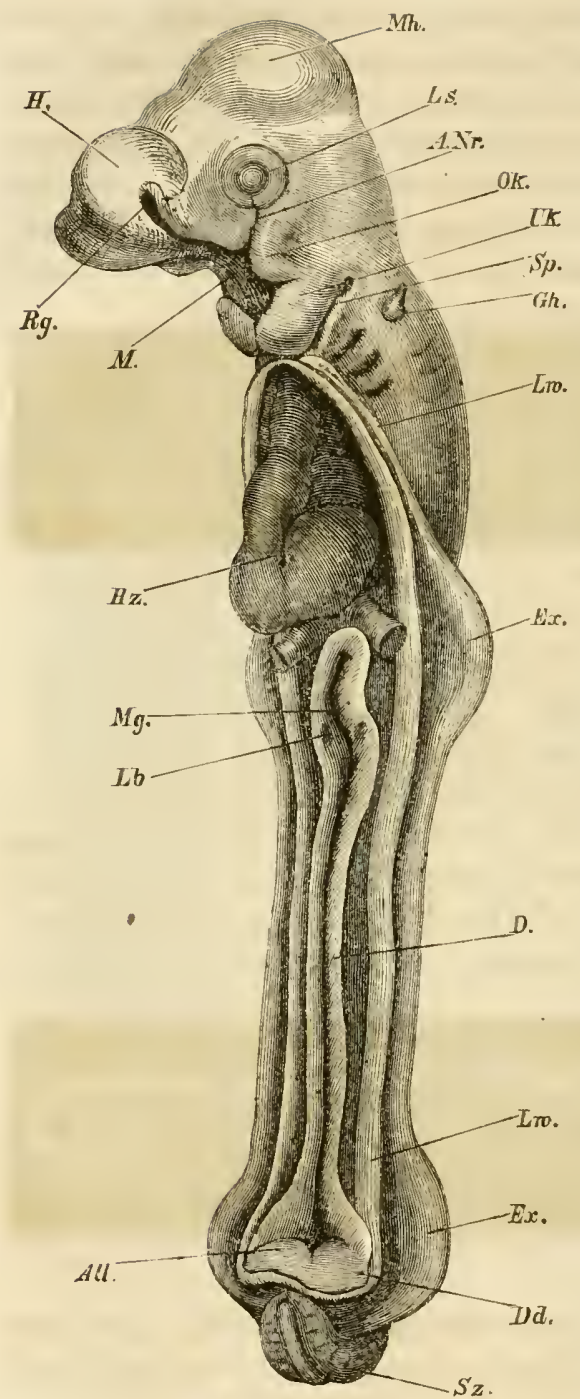

Fig. 69 (2).

Mg. Magenanlage.

Lb. Leberanlage.

wärtslegung voll Kopf und von Hals, welelie Du von Fig. 5 und 6 her kennst, so treten anch im Bereich des Primitivdarmes Störumgen der Symmetrie auf. Nach erfolgter Seitwärtslegung wird eine den Körper halbirende Flïche windschief sein. Verliefe der gesammte Primitivdarm symmetrisch, so miisste er anch jetzt noch von der windschiefen Flïche seiner ganzen Länge nach halbirt werden. Dies trifft aber nicht zu: mit seiner mittleren, vor den Buchstaben Md des obigen Schema liegenden Strecke weicht er stellenweise nach rechts, stellenweise nach links ab. Mit Hiilfe von Schnittreilien lässt sich der Gang dieser Kriimmmigen leicht feststellen und $\mathrm{D} u$ findest sie sowohl in Fig. 66 als in Fig. 69 verzeichnet: erst Abweichung der Darmaxe nach rechts, dann wieder nach links und dann wieder nach rechts (vergl. auch den

Schmitt Fig. 70). Du wirst keine Muihe haben, Dich zu überzeugen, dass mit jener Axenkrïmmung die Abgliederung des M a gens eingeleitet ist. 
Zu derselben Zeit und wohl aueh aus denselben Ursachen, bildet sieh im Gekröse des Magens eine kleine, längsgerichtete Falte, die Du an Fig. 70 auf dem Quersehnitt wiedergegeben findest. Es ist diese Falte die Anlage der Milz. ${ }^{1}$ )

Du ersiehst aus der obigen Darlegung, wie anch die Gliederung des Verdaumgsrohres und der vegetativen Organe in friihester Zeit schon vorbestimmt wird durch einge einfache, in ihrer Entstehung unter einander rerkniipte Faltumgen, theils longitudinalen, theils queren Verlaufes.

Fassest Du die Lage ins Auge, welche die rom Darmdrisenblatt gelieferten Anlagen zu einander einnehmen miissen, so lange dieses flach und ausgebreitet ist, so siehst $\mathrm{Du}$, dass alle zum eigentlichen Verdauungsrohr einbezogenen Strecken unmittelbar neben der Axe liegen. Aus

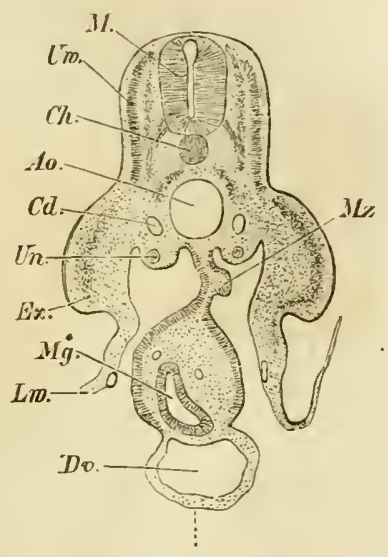

Fig. $70(32)$.

Mg. Magenanlage.

diz. Milzanlage.

mehr seitwärts liegenden Strecken bilden sich die Anlagen für die Luftröhre, für die Lunge und für die Leber. Ich stelle Dir beifolgend eine sehematische Uebersicht zusammen. Der verticale Strieh bedeutet die Axe, die beiden ausgezogenen queren Striehe den Ort der vorderen und der hinteren Keimfalte, die punktirten den der beiden Gränzrimnen. In der vorderen Körperhälfte wird eine weit grössere Strecke des Darmdriisenblattes zur Organbildung einbezogen, als in der hinteren Hälfte und der Grund davon ist unsehwer zu erkennen, wemn man sich die röllig verschiedenen Bedingmuen vergegenwärtigt, unter welehen der Schluss des Primitivdarmes in der vorderen und in der hinteren Körperhälfte gesehieht. Siehst Du die Figuren 52-55 S. 70 dureh, so bemerkst Du, dass der Vorderdarm zu einer Zeit sich schliesst, wo die Leibeswand noch flach ausgebreitet ist. Breit legt sich das, ron den Muskelanlagen noch unvollkommen getremute Darmdriisenblatt um die iiberliegenden Gebiete und erstreekt sich beiderseits bis zur Gränze der Stammzone. Zur breiten oberen 


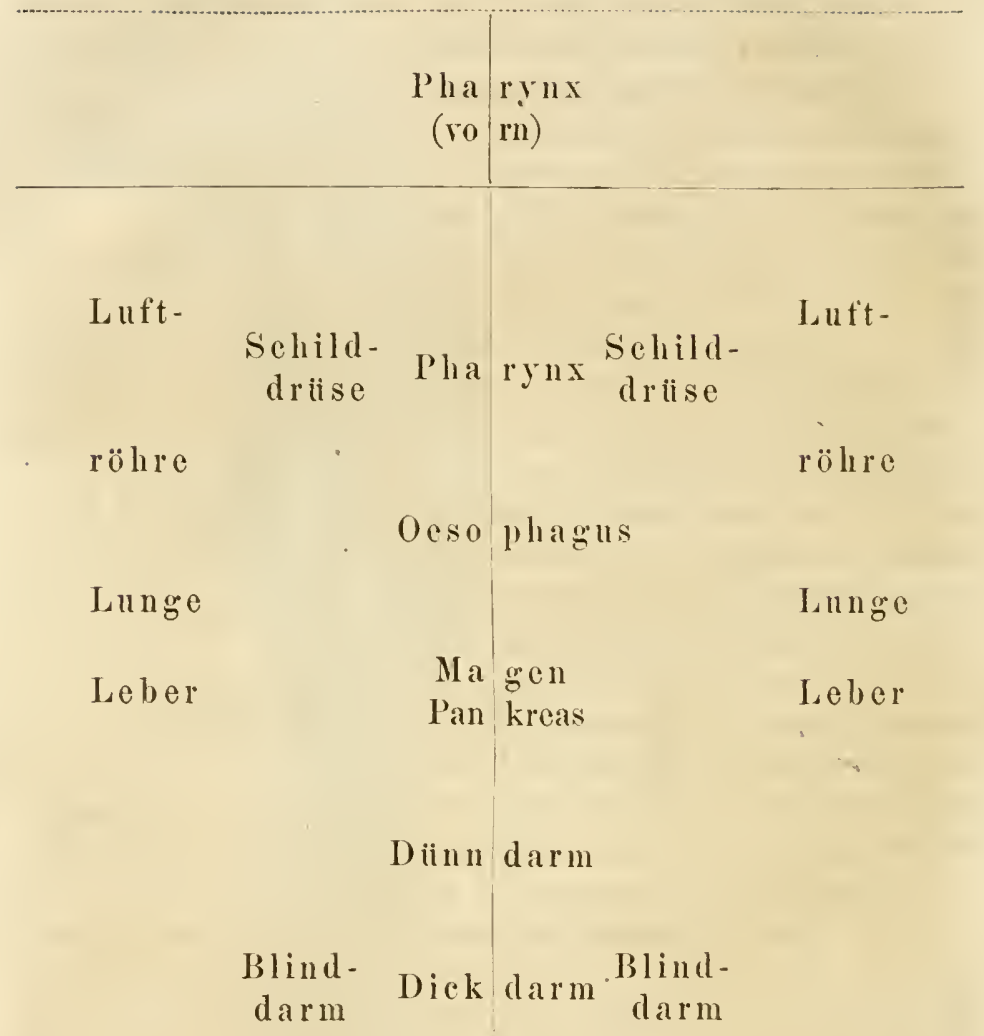
Clo ake

Allan tois 
bildet sich eine, nicht minder breite untere Wand des Vorderdarms. Tritt alsdann die Compression des Körpers ein, so wird ein bedentender Theil der unteren Schlauchwand für die Bildung von Nebenorganen verfiigbar, welche durch Längsfalten vom Hauptrohr sich abgränzen.

In der hinteren Körperhälfte hat sich dagegen das Darmdruisenblatt von der Chorda und von den übrigen Stammgebilden getrennt, lange bevor der Darmschluss beginnt. Während die seitliche Zusammenschiebung der äusseren Körperwand schon im Gange ist, liegt das Darmdriisenblatt noch ziemlich flach ausgebreitet (Fig. 30 S. 33). Mit der zunehmenden Verengung des Leibesraums werden auch die Bedingungen ungünstig für die Anlage eines breiten, zu weiteren Abschnürungen Material bietenden Rohres. Nur die beiden Blinddärme werden aus mehr seitwärts liegenden Streeken der vegetativen Schicht als Anfangs kurze, stumpfe Kegel herausgeschnitten.

Was die Leber anbetrifft, so entsteht sie, wie früher schon erwähnt wurde, aus jener dreieckigen, taschenförmig gestalteten Strecke des Darmdrüsenblattes, welche in der Verlängerung der Lungenanlage liegt (Lb Fig. 66). Indem sich die Wandungen jener Tasche aneinanderlegen, entsteht jederseits eine hohle Platte. Beide Platten umfassen den in das hintere Herzende eintretenden, Anfangs doppelten, weiterhin einfachen Venenstamm, und vereinigen sich in der Folge zu dem einen gemeinsamen, rou Gefässanlagen bald auf das reichlichste durchsetzten Organe. 


\section{Siebenter Brief.}

Iie weiteren Folgen vom Princip ungleichen Wachsthums. Die Folgen der Abflachung des Körpers; Umbildung des Gesichtes.

Lieber Freund! Bis dahin hat uns das einfache mechanische Princip der, als Folge ungleichen Wachsthnns auftretenden Faltungen den Schliissel zum Verständniss einer Reihe von fundamentalen Entwicklungsvorgïngen an die Hand gegreben. Allein wie stellt sich, so fragst Dn mich, die Sache, wenn eimmal eine gewisse Summe von Organen sich abgegliedert, und zu selbstständigen Massen gesammelt hat? Entzieht sich nicht von da ab die Formbildung des Organes jeder ferneren mechanischen Betrachtung?

Die Antwort hierauf wird sich ergeben, wenn Du Dir die Grundbedingung klar machst, nu die es sich bei jeder ferneren Körperentwicklung handelt.

Jede Organanlage führt, nachdem sic vom Gesammtkeime sich abgelöst hat, fort zu wachsen und sie vergrössert sich, sei es rascher, sei es langsamer, bis sie ihren Endtermin und ilır Endvolım erreicht hat. Zwar steht (worauf ich schon oben hingewiesen habe) der Gang des Wachsthums, den das alogegliederte Organ befolgt, in bestimmten gesetzmässigen Beziehungen zum Wachsthum des betreffenden Keimscheibenbezirkes vor eingetretener Abgliederung, sowie auch zu demjenigen der aus früheren Nachbarbezirken hervorgegangenen Organe. Allein von derartigen Bezichungen wollen wir fïr jetzt absehen und uns an die empirisch gegebene Thatsache halten, dass jeder Theil seinem partialen Gesetz des Wachsthums gemäss zunimmt. Die ummittelbare Beobachtung ergiebt 
Verschiedenheiten jener Partialgesetze für versehiedene Organe. In gleiehen Zeiten nimmt ein Theil in stärkerem Verhältniss zu, als ein anderer, und daraus folgt mit Nothwendigkeit, dass die zur Zeit der Organablüsmng vorhandenen Lagebezichungen mannigfach sich ändern miissen. Ein wachsendes Organ wird an einer Stelle Druck, an einer anderen Zerrung' ant seine Nachbartheile ausiiben. Sind in ihm selbst Abschnitte verschieden raschen Wachsthums vorhanden, so enthält es in sich die Bedingungen neurer, sei es mehr, sei es minder tiefgreifender Gliederungen. Die Gestaltung; die das Organ schliesslich annimmt, ist daher abläingig von dem Gesetze seines eigenen Wachsthums, von seinen r:iumlichen Beziehungen zu Nachbartheilen und ron dem Wachsthume dieser letzteren.

Das Princip ungleichen Wrachsthums behält dem Gesagten zufolge auch im weiteren Verlaufe der Entwickelung seine Bedeutung als formbestimmendes Princip. Allerdings verwickeh sich nit fortschreitender Gliederung des Körpers anch vielfach die speciellen Bedingungen der Formung, und es wachsen damit die Schwierigkeiten mechanischer Erklärıng. Ohne grosse Sorgfalt und ohne umsichtige Beriicksichtigung aller concurrirendeu Verhältnisse wird man den Irrwegen willkiihrlicher Deutungen nicht entgehn, und die grösste Gefahr liegt jedenfalls darin, zu vorzeitig Alles erklären zu wollen. Nach meinen bisherigen Erfahrungen ist es am sichersten, aus der Summe der vorkommenden Umgestaltungen diejenigen heranszusuchen, deren Mechanismus einfach genug ist, um jedes Missverständniss auszuschliessen. Die Zahl solcher Fälle ist grösser, als man vou Anfang an erwartet, eine Reihe scheinbar verwickelter Umbildungen erhält ihre Erklärung durch den Vergleich mit richtig gewälalten Paradigmen. Der Fall der nach der Kante gekiimmten Platte, derjenige des geknickten Schlanehes, und ähnliehe mehr, kehren in ihren elementaren Bedingungen häufig wieder, und der Wiederkehr gleicher Bedingungen entspricht durchweg das Zustandekommen gleichartiger Gestaltungen. Durçh Vorfiihrung einiger Beispiele wird es mir, wie ich denke, gelingen, Deinen Sinn für mechanische Auffassung so zu schärfen, dass Du beim Blick auf organische Formen Dir selbst rom innern Zusanmenhang Rechensehaft giebst, welcher deren verschiedene Einzelnheiten umfasst. 
84
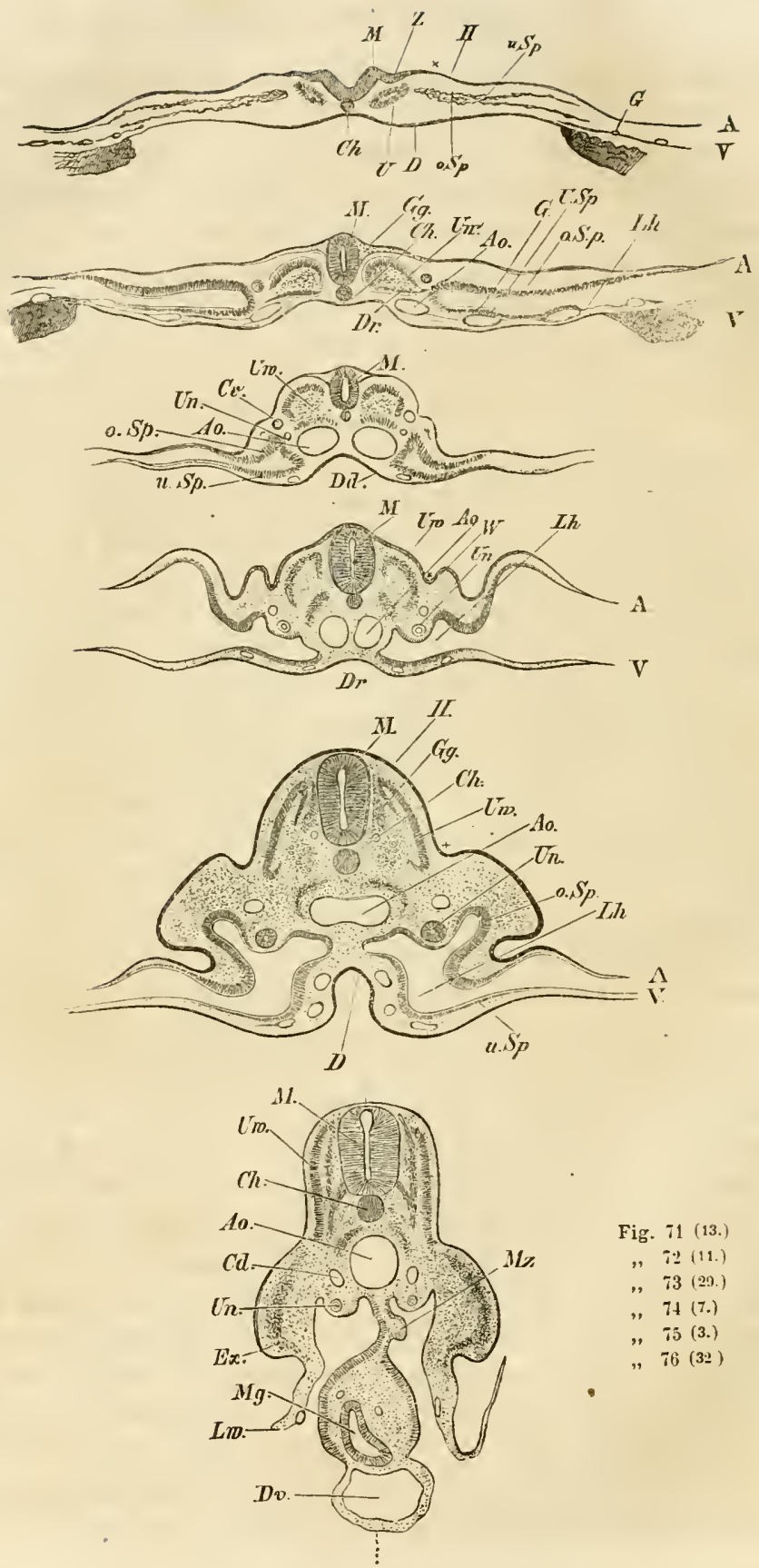

Fig. 71 (13.)

", 让 (11.)

, 73 (20.)

74 (7.)

, 75 (3.)

, 76 (3:) 
Umlagerung der primitiven Organe bei zunehmender Abflachung des Körpers. Ich habe Dir im dritten Briefe eine Zusammenstellung von Quersehnitten annähernd derselben Körpergegend bei versehieden entwickelten Embryonen mitgetheilt, und Dich auf die, während einer gewissen Zeit mit der Entwickelung fortsehreitende Abflachung des Körpers aufinerksam gemacht. Der Körper wird, während er an Breite abnimmt, höher, gerade so, wie die durch Zusammensehieben eines Papierstreifens entstehende Falte mit zunehmendem Zusammenschicben der Ränder an Höhe gewinnt, was sie an Breite verliert. Währenddem num aber diese allgemeine Aenderung der Gestalt vor sich geht, erfolgen im Einzelnen eine Reihe von Umlagerungen, welehe sich saimmtlich als Theilerscheinungen jenes einen Grundrorganges herausstellen. Ich komme micht zurück auf die Unlegung der seitlichen Keimfalten und auf die Annäherung der Gränzrinnen an die Mittellinie, als auf friber erledigte Dinge. Von den Veränderungen in der Stellung der Urwirbel und von der Trennung ihrer versehiedenen Bestandtheile habe ich Dir friher glciehfalls schon gesprochen. Du wirst bei einem nochmaligen Blick auf die Abbildungen selbst wahrnehmen, dass ihre Umlagerung eine nothwendige Folge von der allgemeinen Abflachung der Stammzone ist. Die Muskeltafeln der Urwirbel stellen sich mehr und mehr vertical, d. h. in die Lage, welehe den geringsten Breitenraum beansprucht. Die iibrigen Bestandtheile der Urwirbel, der Kern und die untere Rinderihälfte werden in die Tiefe gedrängt, und breiten sich im Raume ans nnterhalb des Medullarrohres. Es löst sich nämlich, in gleichfalls leicht verständlicher Weise, das Darmdriisenblatt von der Chorda los, und durch seine Entfernung von ihr wird der in der Breitenausdehmung verlorene Raum wieder eingebracht, wobei eine Reihe von Gebilden sich beiderseits gegren die gebildete Liieke vordrängen. Ausser den ebenerwähnten tiefern Bestandtheilen der Urivirbel nimmt diese zunächst die absteigenden Aorten auf, welche, ursprünglich auf der Gränze von Stamm- und Parietalzone liegend, erst unter die Urwirbel und von da aus unter die Chorda geschoben werden, und die schliesslich hier zu einem gemeinsamen Rohre verschmelzen. Ferner rïcken sich, wie ich Dir im vorigen 
Bricfe gezeigt habe, noch unterhalb der Aorta die unteren Seitenplatten entgegen, und liefern so dem Primitivdarm seine obere Wand. Als eine weitere Folge der zumelimenden Abplattmng erseheint die Verschiebung der Umierenanlagen und der Cardinalvenen. Diese Theile, mrspriinglieh auf der Gräinzo zwisehen Urwirbeln und Seitenplatten und unterhalb des Hornblattes entstanden, riieken in die 'Tiefe und treiben das Verbindungsstiick der oberen mit der unteren Seitenplatte ror sich her, anf diese Weise die Urnierenleiste bildend. Es ist diese Leiste, wie Du ans Fig. 74 und 75 ersiehst, die untere First einer Längsfalte, an deren Bildung die Leibeswand in ihrer gesammten Dicke 'Theil nimmt. Ihr entspricht an der Oberfliche eine seitwairts von den Urwirbehn liegende Rimne, welehe

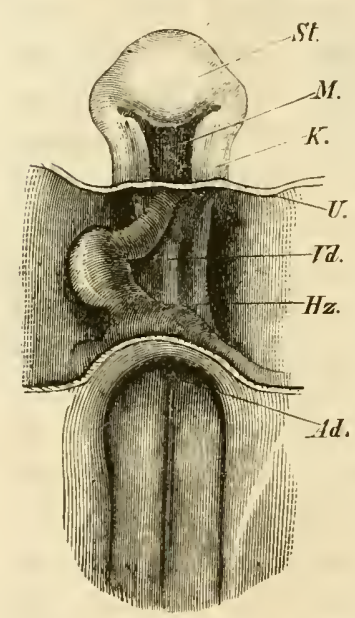

Fig. 77 (17). Gesicht des Embryo von Fig. 4. 2umal vergrössert. St. Stirnwulst.

M. Mundbucht.

K. Kieferleisten.

U. Umscblagsrand des animalen Blattes.

Vd. Vorderdarm.

Ad. Zugang zu obigem.

Hz. Herz.

in der Folge sich mehr rerwischt, während durch das Wachsthum der Urnieren die Leiste an Maichtigkeit stetig zumimmt.

Dass endlieh anch die Umbildung des Primitivdarmes mit der seitlichen Compression des Körpers in ursäehlichem Zusammenhange stehe, das ist Dir in vorigen Briefe entwiekelt worden.

Umbildung des Gesielites. Als ein zweites Bcispiel tiefgreifender Umgestaltung unter einfachen mechanisehen Bedingungen wähle ich die Gesehichte des Gesiehtes. Du hast im zweiten Briefe die einfache Form kennen gelernt, welehe dem Gesicht zur Zeit seines ersten Bestehens zukommt. Es bedarf einiger Einbildungskraft, $u$ aus der wiedergegebenen Flaiche das herauszulesen, was später daraus wird; wogegen Du ohne sonderliehe Mithe in der Physiognomie Dich zurceht finden wirst, welche Figur is abgebildet ist, und noeh besser natiirlich in derjenigen ron Fig. 79. Und doch ist zwischen der Entwicklumgsstufe ron Fig. 77 und der- 
jenigen ron Fig. is ein geringer zeitlicher sipung. Es bedarf höehstens eines halben Tages, mu die eine in die andere iiberzufïhren.

Nehmen wir erst eimmal das entwickelte Gesicht ron Fig. is dureh: Seine Mitte wird von der Mundhöhle eingenommen, deren Zugang" eckig ron Gestalt und nuverhältnissmässig weit ist. Die lintere Gräinze bildet der, in der Nitte winklig gebrochene Unterkieferfortsatz, seitlich daron liegen, als cinwairts gebogene Leisten, die zwei $O$ berkieferforts ittze, rom ist der mächtige, die Ebenedes Hundzuganges weit iiberragende stirnwulst. Vom rorderen Theil der Mundhöhle gehen jederseits zwei Rimnen ab, deren jede in einer vertieften Endgrube blind endigt. Die eine dieser Rinnen, die Nasenrinne, rerliuft an Stirnwulst selbst und endigt an ihm als Riechgrube, die andere liegt zwisehen Stimwulst und Oberkieferfortsatz, ihre Endgrube ist die Linsengrube, sie selbst heisst die $A u$ gennasenrinne. Ans der Linsengrulue nämlich bildet sich dureh Erhebung. des Bodens die Linse des Auges, als ein Produet des Hornblattes. Die Angemnasenrinne, noch während laingerer Zeit offen bleibend, schliesst sich späiter zum Augennasenkamale.

Am Stirnwulst wird in friilıerer Zeit das Vorderhirn ron seinen Hiillen (dem Hornblatt, den parablastischen und erent, den Muskel-

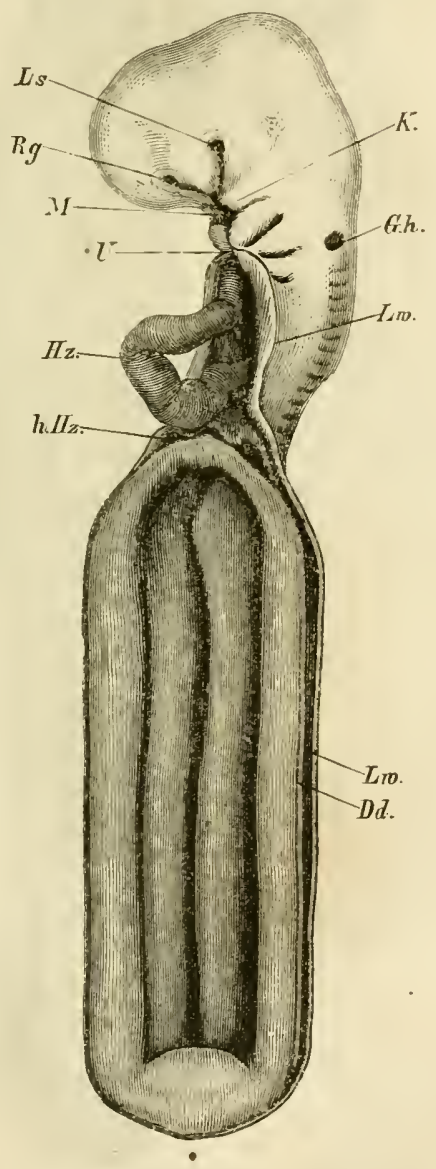

Fig. is (i). Dasselbe in der Ventralansicht. R. Riechgrube.

Ls. Linsengrube.

Gh. Gehörgrube.

II. Mandhöhle.

(1.) Oberkieferfortsatz.

U. Unterkieferfortsatz.

Hz. Herz.

h. $\mathrm{Hz}$. Hinterer Herzschenkel.

I.w. Lmschlagsstello der Leibeswand in das Amnion.

Dd. Darmdivisenblatt. 


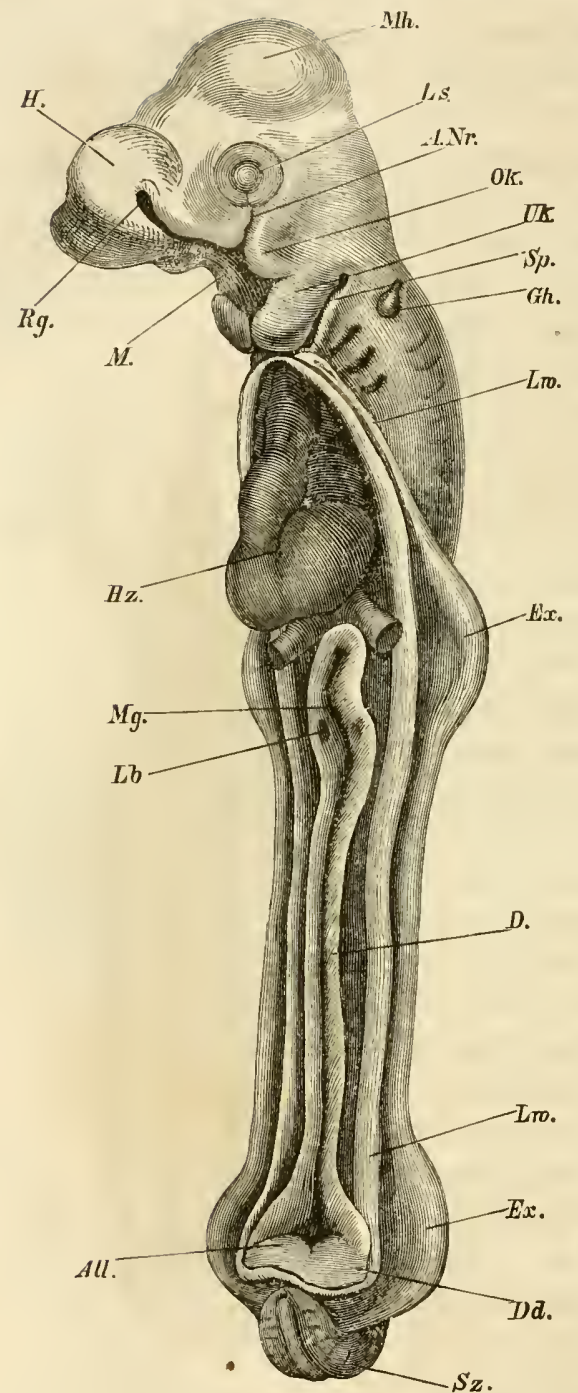

Fig. 7912). 11ühnchen in der Ansicht vou d. Bauchseite Rg. Riech grube.

H. Hernisphäre.

Mh. Mittelhirn.

Ls. Linse

Ok. Oberkieferfortsatz

Uk. Unterkieferfortsatz.

M. Mundhöble.

Gh. Gehörblase.

LW. Umschla der Lib. Schwanz. das Amnion.

Dd. Umschlagsstelle des Darmarüsenblattes. anlagen) knapp umschlossen. Damn aber falten sich diese im Zwischenraum zwischen den beiden Augenanlagen selbstständiger hervor, und entwickeln sich zur vorderen Bedeckung des primitiven Mundraums. Es entstehen so der mittlere und die beiden seitlichen Stirnforts ätze; ersterer erhebt sich im Raume zwischen den beiden Nasenrinnen, letztere drängen sich jederseits als dreieckige Keile in die Liicke, welche seitlich ron der Nasenrinne, zwischen ilır und der Linse nebst Augemnasenrinne iibrig bleibt. Die drei Stirnfortsätze liefern das Material fiur den mittleren Theil des Gesichts, beim Hiihnehen fiir den Schnabel, beim Sängethier und beim Menschen fiir die Nase und den mittleren Theil der Obcrlippe (bez. den Zwischenkiefer). Du wirst die versehiedenen, die Mundhöhle umrahmenden Fortsätze nielit allein an Fig. 79 , sondern auch an dem etwas weiter entwickel- 
ten Gesicht von Fig. S0 wiedererkennen. Auch wirst Du beachten, dass dieselben im Umfang der betreffenden Gruben und Rinnen mehr und mehr wulstartig sich emportreiben.

Hinter dem Unterkieferfortsatze liegt die Reihe der in das Imnere des Vorderdarms miindenden SehIundspalten (Anfangs 3, später 4), welehe dorsalwärts strahlig divergiren. Ueber der \%weiten Spalte befindet sich die, bei Fig. 6 noeh offene Gehör.mrube, deren Querschnitt Du an Fig. 55 des vorigen Briefes kemen gelernt last.

Vergleiehst Du nun dieses Gesicht mit dem primitiven ron Fig. $7 \bar{i}$, so erkennst Du in der Mundhöhle die stark verticfte Mundbueht wieder, im mittleren freien Theile des Unterkieferfortsatzes die Umbiegungsstelle $\mathrm{U}$ der animalen Schicht, in dessen mit den Oberkieferfortsätzen verbundenen seitlichen Streeken und in diesen Fortsätzen selbst die winklig verbogenen und höher gewordenen Kieferleisten.

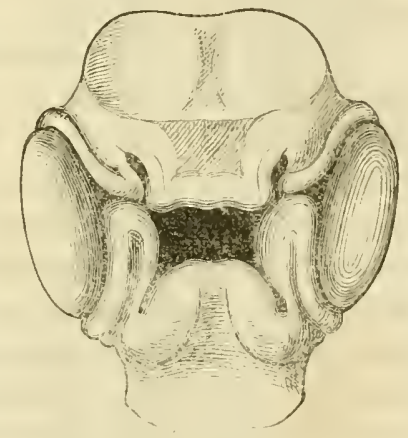

Fig. So Gesicht eines Hühnchens nach staigiger liebrütung. Smal vergrōssert. Am Stimwulst sind die Riechgruben nebst den Nasenrinnen neu aufgetreten, oder, richtiger, dureh die seitliche Compression des Kopfes aus einer unscheinbaren zu einer scharf abgegränzten Bildung geworden. Dagegen ist die Angennasenrime als seichte, die Kieferleisten rom Stirnwulst tremmende Furehe schon auf der Stufe des primitiven Gesichtes vorhanden.

Die wesentlichen Untersehiede des secundären ron dem primären Gesicht sind somit:

1) Vertiefung der Mundhöhle und Verengung ihres Zuganges,

2.) Vertiefung der Augennasenrinne und scharfe Ausprägung der Linsengrube,

3) winklige Biegung und Einwärtsdrängung der Kieferfortsïtze,

4) Auftreten der Nasenrinne und der Riechgruben, und

5) starkes Herrortreten des Stirnwulstes.

Betrachtest Du die Köpfe im Ganzen, so siehst Du, dass 
diejenigen ron Fig. 78 und 79 sich von dem von Fig. 77 bez. Fig. 81 in einem Hanptpunkte sehr wesentlich unterseheiden. Nicht allein sind sie seitlich stark abgeplattet, sondern sind sie mehrfach im Winkel gebrochen. Das friiher am meisten nach vorn gerichtete Ende sieht nach abwïts (oder correctererweise nach rechts) und der Theil, der friiher an höehsten lag, ist jetzt der vorderste geworden. Diese winkligen Biegungen zeichnen sieh besonders seharf im Verhalten der einzchen Hirnabtheilungen ab, worauf ich in einem späteren Briefe zurïckzukommen gedenke.

Alle die oben aufgez:ihlten Untersehiede des seeundären rom primären Gesieht, d. h. also die Vertiefung der Mundbncht zur Mundhöhle, die Verbiegung der Kieferleisten, die Ausbildung der Linsengrube und Vertiefung der Angennasenrimne und endlich das starke Vornibertreten des Stimwulstes, sind in ihrer raschen Entwickelung bedingt durch die mit deren Alpplattung sich combinirente Axenkrimmung des Kopfes. Sollte die blosse Ueberlegmng nicht geniigen, Dir diesen Znsammenhang klar zu machen, so magst Du Dir die Sache mit Hiilfe eines Wachs- oder Thonklumpens veransehaulichen. Giebst Du einem solchen Klumpen die allgemeine Gestalt des Kopfes ron Fig. $7 \overline{7}$, fassest Du ihn alsdann an seinen vier Seiten mit den vier Fingern einer Hand, und driiekst diese raseh zusammen, so wird der complimirte Klumpen alle wesentliehen Charaktere des Gesiehtes von Fig. 7s ammehmen.

Woher kommt num aber die so rasch mul stark sich entwiekelnde Kriimmung des Kopfes? Wir müssen, um dies zu verstehen, den Bezirk der eigentlichen Embryonalanlage verlassen und uns die Verhältnisse im Anssengebiet etwas näher ansehen :

Auch ausserhalb des Embryonalbezirkes bilden sieh quere und longitudinale Falten, und zwar in derselben Reihenfolge, wie im Embryonalbezirke. Eine bogenförmige Querfalte tritt znerst auf, später jederseits eine Liingsfalte, und in der Folge auch eine lintere Querfalte. Du findest diese Falten in den Figuren 15, 14, 10 mol 9 des ersten Briefes verzeichnet. Fiir sie gilt in umgekehrtem Sim dasselbe, was yon den Keimfalten. Sie erheben sich bis zu einer gewissen Höhe und legen sich dann gegen den Embryo um, zuerst die rordere Querfalte, 
dann der vordere Abschnitt der Seitenfalten, später anch die hintere. Dureh ilure Verwachsumg, ror Allem dureh die longitudinale Verwachsung der beiden seitlichen Längsfalten wird jene sehon friilıer erwälnte Hiille um den Embryo gebildet, welche als A mnion den Embrrologen seit altester Zeit bekannt ist.

In Fig. $\$ 1$ haben wir die Stufe, welehe die Umlegung der vordern Amuionfalte zeigt: Capuzenartig beginnt die nmgelegte Falte das freie Kopfende zu decken. Hat erst diese Ueberlagerung begonnen, dam folgt rasch die Bildung der Lïingsnath.

Embryonen der Stufe von Fig. is sind in ihrer vorderen Hiilfte, die der stufe von Fig. 79 vollstaindig von Amuion umhiillt. Es tiallt die Ueberlagerung der vorteren Ammionfalte iiber das freie Kopfende zeitlich zusammen nit der begimnenden Periode der Kopfkriimmung. Beide stehn in einer unmittelbaren cansalen Beziehung. Dureh jene dem Kopt' iibergeschobene C'apuze erfahrt die fernere Längrsansdehnung des Koptes einen kräiftigen Willer- Fig. \$I (9). Hühnchen zwischen dem zweiten stand, der vom wachsenden und dritten Bebrütungstag. Zumal vergrosserte Kopfe nicht iiberwunden wird, sondern dem dieser sich dadureh aupasst, dass er sich kriimmt. Mittelbar ist anch die Seitwiirtslegung des Embryo, sorrie die spätere Kriimmung des gesammten Rumpfes auf dieselbe Be-

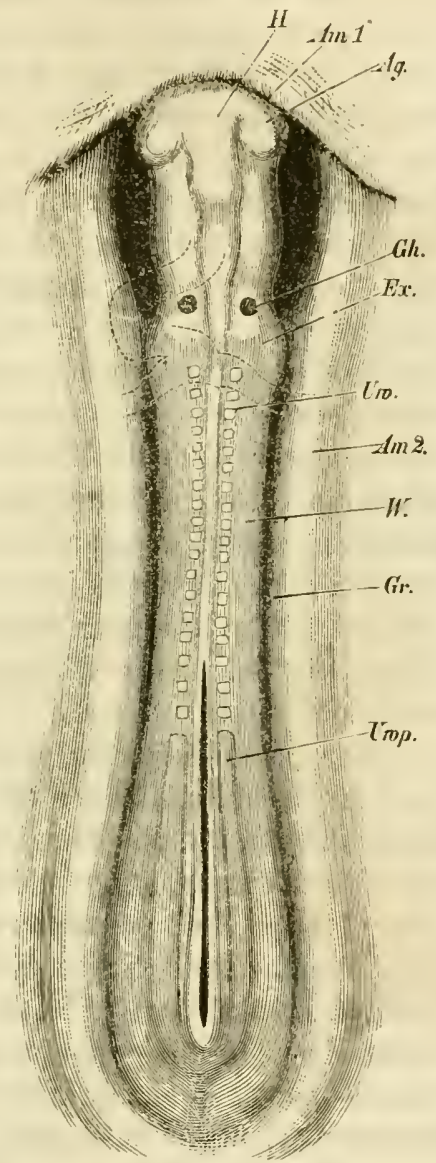
H. Hirn, in Vorderhirn, Mittelhirn und Hinterhirn sich gliedernd.

Ag. Augeublase.

Gh. Gehörblase.

Ex. Formanlage der vordern Extremitäten.

IV. Wolffsche Leiste.

s. Gr. Seitliche Grānzrinne.

Uw. Urwirbel.

Uwp. Urwirbelplatte.

Am. 1. Yordere Amnionfalte.

"2. Seitliche

G." Grube nnter dem "freien Kopfende. Die muntirte Linie bezeichnet den urt des Herzens. 
dingung des neu anfgetretenen longitudinalen Ausdehnungswiderstandes zuriiekzufiihren.

Eine entseheidende Controlle dafiur, dass wirklich das Amnion die Ursache der entstehenden Kopfkrimmung ist, liefert die vergleichende Embryologie. Die eharakteristisehe Kopf'kriummung finden wir bei den Sängethieren, Vögeln und den Reptilien, sie fehlt den Fisehen und den Amphibien. Jene drei Klassen sind es aber allein, bei welehen der Embryo von einem Amnion umhiillt wird, aueh kommt bei ihnen allein die temporäre Zusammenkriimmung des gesanmten Körpers vor, von weleher der, absichtlieh gestreekte Embryo Fig. 1 nur eine sehwache Idee giebt. Ueberall finden wir ferner, soweit bis jetzt exacte Beobaehtungen reiehen ${ }^{1}$ ) bei den höheren drei Wirbelthierklassen, dass der Eintritt der Kopfkriimmung, sowie derjenige der nachfolgenden Kriimmungen des Rumpfes, zeitlieh genau an die dichte Umschliessung dureh die Amnionanlage geknipft ist. Wir haben hier eine jener Formabhängigkeiten zwisehen Bildungen seheinbar ganz differenter Natur, für welehe ieh Dir später noeh fernere Beispiele werde anfiibren können.

Nur im Vorbeigehen gedenke ich noeh der oben erwähnten Sehlundspalten. Aneh die Gesehichte dieser vielbesproehenen Bildungen ist physiologiseh höehst einfach. Sie sind nämlich ihrer Entstehungsgesehiehte naeh Fältelungen der seitlichen Wand des Vorderdarms, dadureh bedingt, dass diese Wand, ähnlich wie früher die Urwirbelplatten, nach der Kante gebogen wird. Ibre Riehtung entsprieht den Krimmungsradien des betreffenden Bogens. Ganz nnter denselben Bedingungen entstehen anch die Kiemenspalten der niedrigen Wirbelthierklassen. Die Faltenberge der Vorderdarmwand stossen auf das Hornblatt, indem sie die zwischenliegenden Muskelanlagen verdrängen, und brechen alsbald zur Oberfläehe dureh. 


\section{Achter Brief.}

Das embryonale Gehirn. Formen einer sich biegenden elastischen Röhre.

Ableitung der ersten Gehirnformen.

Lieber Freund! Wir wenden uns hente zu der im Bisherigen etwas stiefmiitterlich behandelten Anlage des Centralnervensystems, speciell zu derjenigen des Gehirns. Aus dem ersten Briefe weisst Du bereits, dass der Zeit nach das Gehirn unter allen, aus der Keimscheibe sich abgliedernden Organen, die erste Stelle eimnimmt, und dass es, gleich dem, mit ihm fortlaufend verbundenen Riickenmark, durch Einrollen einer langgestreckten Platte, der Medullarplatte, entsteht. Beide bilden nach vollendeter Abscheidung eine zusammenhängende Röhre von nicht unbeträchtlicher Lichtung.

Die Breite des eben geschlossenen Gehirns nimmt, wic Du aus der Fig. 10 (S. 12) ersiehst, von hinten nach vorn zu, und erreicht ihr Maximum unweit vom vorderen Ende. Die Zunahme ist indess keine gleichmässige, es wechselu ausgebanchte Strecken mit Einschnirungen, wodurch das Gehirn in mehrere Hauptabschnitte zerfällt. Von Anfang an sind drei hintereinanderliegende Anschwellungen vorhanden, welche nach v. Baer's Vorgang als primäres Vorderhirn, Mittelhirn und Hinterhirn bezeichnet werden. Die hintere Anschwellung entspricht zwei späteren Hirnabtheilungen, dem Hinterhirn kurzweg und dem Nachhirn, deren Gränze in die grösste Breite der Anschwellung fällt, und im Grunde sofort bestimmbar ist. Aus dem primären Vorderhirn gliedern sich beiderseits die A u ge n blasen ab. Dieselben sind, unmittelbar nachdem das Gehirn sich geschlossen hat, als seitliche Vor- 
wölbungen angelegt und ihre selbststïndigere Ablösung erfolgt weiterhin durch cine Furche, welche von oben herab zwischen sie und das iibrige Vorderhirm einsehneidet. Nach erfolgter Abgliederung der Augenblasen zeigt sich die vordere Ilälfte des letzteren von der hinteren durch eine Rinne getremnt; die hintere Hälfte des primären Vorderhirns heisst nunmehr Zw ischenhirn, die vordere Vorderhirn kurzweg, oder Hemisphäenhirn. Wir haben somit folgendes Schema der Gliederung:

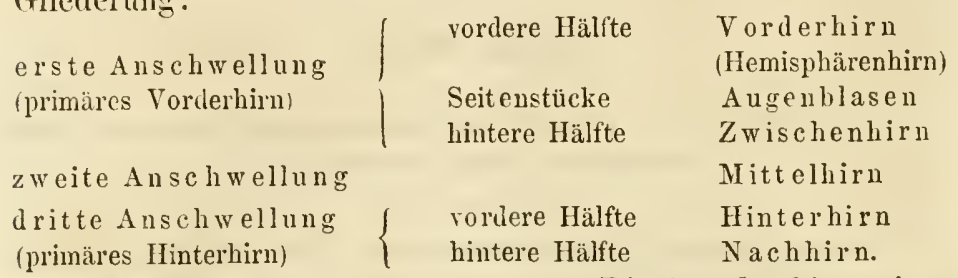

Die Axe der lintereinan-

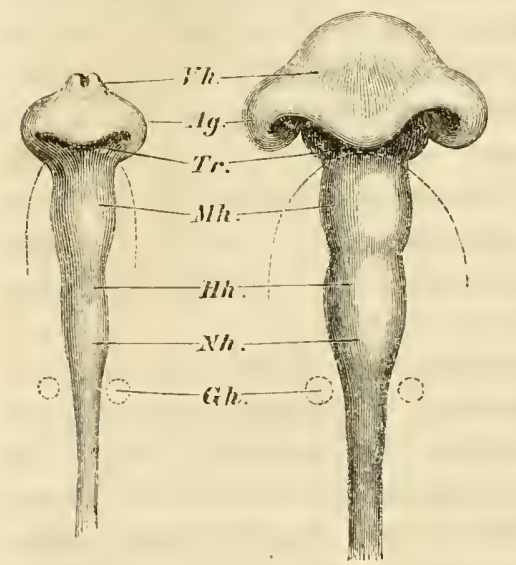

Fig. 82. Gehirn eines ilühnchens von der Stufe Fig. 10, von der Basis her gesehen. Vergr. 41).

Vh. Vorderhirn.

Ag. Angenblase.

Mh. Mittelhirn.

Hh. Hinterhirn.

Die punktirte bogenförmige Linie bezeichnet

die vordere Gränze des Vorderdarms.
Fig. 83. Gehirn eines Hühnchens von der Stufe Fig. 9, von der Basis her gesthen. Vergr. 30.

Nh. Nachhirn.

Gh. Ort der Gehörblase.

Tr. Trichterfortsatz. der liegenden Abtheilungen des Gehirnes beschreibt einen flachen, S-förmigen Bogen. Concav im Hinterkopf, wird diese Linie beim Uebergang auf den Vorderkopf convex und biegt sich mit ilren vordersten Schenkel hakenförmign nach rüickwärts. Wir nennen diese drei Kriummungen Briickenkriimmung, Nittelwölbung

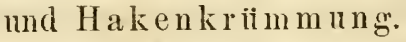

Das hakenförmig zu-

riickgebogene Stuick der Axe reicht bis hinter die $\mathrm{Ab}$ angsstelle der Augenblasen. An der Basis ist die Endstelle dureh einen spitzen Vorsprung bezeichnet, den

Triehterfortsatz. Zu ihm tritt von jeder Angenblase her eine scharfe Leiste, welche eine an deren unterer Fläche befindliche Grube begränzt. 
Zu den oben genamnten drei primären Hirnkrïmmungen kommt als vierte die zwischen Riickenmark und Nachhirn sich entwickehnde Nackenkrii mm nng (dorsalwärts eonvex). Sie ist beim Hühnehen Anfang's sehr schwach angedentet. Secundär, als Theilerseheinung der allgemeinen Kopf krimmung treten in der Folge an den Gränzen des Mittelhirns die zwei Scheitelkrii mmugen auf, durch deren Ausbildung das Mittelhirn zur vordersten von sämmtlichen Gehirnabtheilungen wird.

Das Medullarrohr, sowie es znerst sich anlegt, besteht ausschliesslieh ans Zellen. Ans diesen werden später die Elemente der grauen Substanz ron Hirn und Riickenmark; ein kleiner Theil derselben liefert anch die Epithelien der Adergeflechte. Bedentend spaiter, als die Anlage der grauen Substanz und Anfangs nur als diunner Anflug. der letzteren entwickeln sich die ersten Spuren weisser Substanz. Ihre Fasern sind, wie dermalen kein Histologe bezweifelt, als Anslïufer aus den vorhandenen Zellen hervorgewachsen, und sie sind Anfang's ansserordentlieh fein und zart. Wie lange die

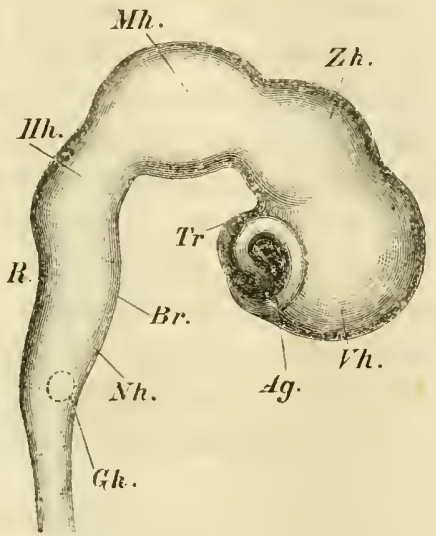

Fig. 34. Gehirn eines Hühnchens ron der Stufe Fig. 5. 311mal vergrössert.

R. Ort der Rautengrube

Zh. Zwischenhirn.

Br. Brŭckenkrümmung

Uebrige Buchstaben wie bei Fig. 8: u. 53.

Bildung nener Fasern und die Verlängerung sehon gebildeter andanert, das wissen wir nicht; soviel ist sicher, dass die Massenzunahme der weissen Substanz sehr allmählig fortschreitet. Erst mit der reichlicheren Entwicklung der weissen Substanz wird das Gehirn aus einem dimnwandigen Hohlkörper zul einem eompaeten Organe.

Es ist nöthig, ron der spätern Entwicklnng der weissen Substanz Notiz zu nehmen, weil dadurch die Frage ron der Formbildung des Gehirns und des Riiekemmarks in verschiedene besondere Aufgaben zerfüllt. Zuerst nämlich sind die verschiedenen grauen Substanzmassen des ausgebildeteu Gehirns zuriickzufïhren auf die einzelnen Wandstrecken des ur- 
sprünglich gegebenen Rohres, eine Aufgabe, die anf dem directen Wege der Beobaehtung gelöst werden muss, und die für einige Hirntheile sehr geringe, fuir andere dagegen sehr bedeutende Schwierigkeiten darbietet. Hand in Hand mit dieser empirisehen Ableitung hat die Erforsehung der mechanisehen Bedingungen zu gehen, welehe der Gliederung des primären Rohres zu Grunde liegen. Vüllig davon getrennt bleibt dann zum Sehlusse die Aufgabe iibrig, die Gesetze der Bildung und Vertheilung weisser Substanz zu suchen.

Es ist nieht mein Zweek, Dir eine volle Entwicklungsgesehichte des Gehirns zu geben, ich besehränke mich anf das Herausgreifen einiger Absehnitte, aus welehen Du Dir Dein Urtheil iiber die Anwendbarkeit und die Tragweite unserer bisherigen Betrachtungsweise bilden magst. Wir werden dabei von der Thatsache ausgehen miissen, dass das Gehirn auf seiner Anfangsstufe ein Sehlauch mit mässig elastischer Wandung und mit einer verhältnissmässig weiten Lichtung ist, und es wird gut sein, wenn Du Dir von vornherein die Formen in Erimmerung rufst, die ein solcher Schlauch in einer Reihe besonderer Fälle annimmt. Jeder beliebige, nicht allzu dickwandige Gummisehlanch kann Dir dazn die Mittel an die Hand geben.

1) Wenn Du den Sehlanch biegst, so bildet sieh' (je naeh der relativen Wandstärke bald friiher, bald später) an der stärkst gebogenen Stelle eine Knickung. Die geknickte Stelle wird breiter als das iibrige Rohr, der Quere nach abgeplattet, und an ihrer Concavitait bildet sieh eine Rimne. Diese Rinne ist in der Mitte am tiefsten, der äussere Rand des Rohres nimmt an ihrer Bildung keinen Theil, er iiberragt sie als ohrförmig gebogene Wulst. Der raseheren Verständigung halber wollen - wir seinen vortretenden Theil geradezu als das $\mathrm{Ohr}$ der Kniekung bezeichnen.

2) Fixirst Du eine Randstelle des Schlauehes mit Huilfe einer starken Pincette oder eines Zwirnfadens, und suchst Du nun denselben in der Richtung der Fixationsstelle zu versehieben, so wird er sich im Allgemeinen etwas vorwölben und zugleich in der Nähe seines vorderen Endes einknicken, so zwar, dass der vordere Rand beider Ohren als schräge Leiste zur Fixationsstelle sich zuriekbiegt und die dahinter liegende, 
bis zu ihrer unteren Fliiche reichende Furehe abgränzt (siehe Fig. S6).

3) Du schlitzest das Rohr eine Strecke weit der Länge nach auf, oder noch besser, Du schneidest einen spindelförmigen Riemen aus seiner Wand heraus, und biegst dasselbe in einem nach abwiirts convexen Bogen, Fig. ST, so werden die Ränder klaffen. Die Röhrenlichtung weitet sich aus zu einer flachen rantenförmigen Grulse, deren grö̈sste Breite in den Ort der stärkster: Biegung fillt.

4) Du schiebst das gesehlitzte Rolır ron seinen Enden her zusammen, so wird in Bereich der geschlitzten Stelle ein Theil unter den anderen sich vorschieben, und Du erhailtst an der betreffenden Stelle eine Reihe characteristischer Configurationen, welche rascher zul ithersehen als zu beschreiben sind (s. Fig. S9).

5) Du hiegt das aufigeselilitzte Rolne in anfwärts conrexem Bogen (Fig. SS), so flacht sich sein Boden gleichfalls ab, und erhebt sich an der Stelle der stärksten Bie-

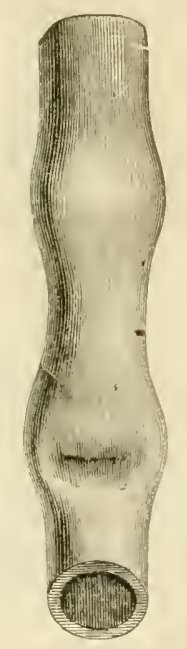

Fig. 5. Gummischlanch Fig. *6. Gummischlauch oben convexunten con- dersen oberes Ende cav şebogen.

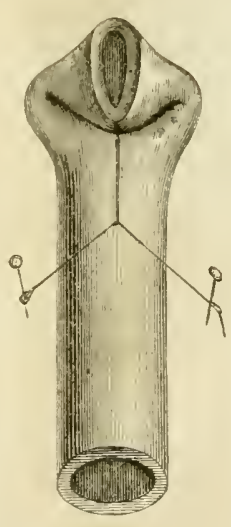

durch einen eingesetzten Zwirufaden zurückgezogen ist. gung zu einem queren Sattel.

Diese Stelle erreicht die gröisste Breite; ron illr ans eonvergiren nacl rorn sownhl, als nach riickwirts die Ränder des Rohres.

Schon im Beginn, und noch während der Periode der Schliessung begegnen wir am Medullarrohre roria bergehenden Eigenthimlichkeiten seiner Gestalt, welche als Illustrationen eben anfgezählter Fälle dienen kïnnen. Ein Beispiel fiil den dritten Fall giebt Dir die Answeitung des Medullarrolures in Fig. 14 Seite 16, welche dem Orte nach zusammenfällt mit der rimnenförmigen Einbiegung zwischen Kopf und Hals. Noch viel bemerkenswerther aber ist die spindelfürmige Verhreiterung. 
der Medullarplatte hinter den eben gebildeten Urwirbeln der Stufe von Fig. 90. Diese Verbreiterung hat schon von friih

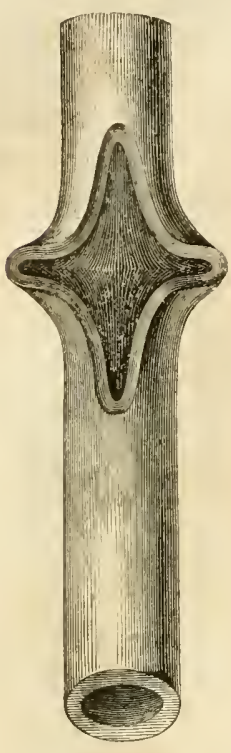

Fig. 6\%. Geschlitzter Gummischlauch mit concaver Biegung.

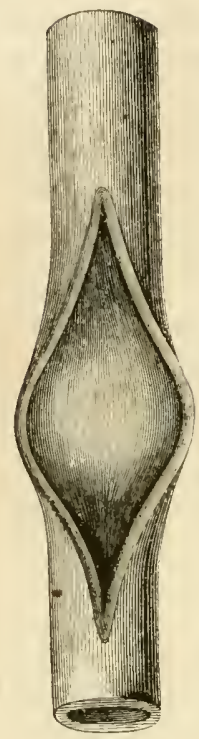

Fig. 8\&. Geschlitzter mischlauch mit convexer Biegung. an die 'Aufmerksamkeit der Beobachter auf sich gezogen, und in der Regel hat man sie für die Anlage des sog. Sinus rhomboidalis desVogelriickenmarkes angesehen. Das ist sie num keinenfalls: einmal findet sich wïhrend der betreffenden Entwicklungsstufe dieselbe Ausweitung der Medullarrinne anch bei Säugethierembryonen ; ${ }^{1}$ ) sodann lässt sich durch Zählung der davor liegenden Urwirbel leicht zeigen, dass sie in den Bereich der Rückenzone faillt, während der Sinus rhomboidalis dem Sacralmark angehört, und endlich ist jene Ausweitung eine durchaus voriibergehende Bildung, welche bereits auf der nächstfolgenden Stufe von Fig. 9 geschwunden ist. Ihr temporäres Vorhandensein hat seinen Grund in der convexen Bie-

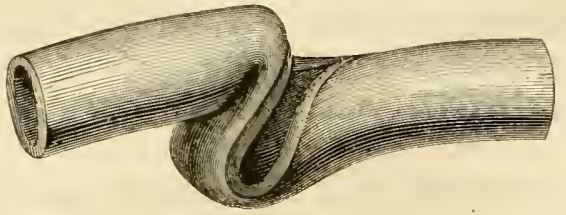

Fig. 59. Geschlitzter und der Länge nach zusammen gestossener Gummischlanch.

gung, welche die Körperaxe im Dorsaltheile beschreibt, und iiber deren Existenz Längsschnitte und Flächenansichten gleich ïberzeugende Bilder geben. Ihre Bedingungen sind diejenigen des vierten unserer oben betrachteten Fälle, und alle Einzelnheiten der Configuration, denen wir dort begegnen, finden 
wir hier auf das vollständigste wieder. Fül mich persönlich kniipft sich das Interesse an dies besondere Beispiel, dass ich an ihm zuerst auf den Zusammenhang aufmerksam geworden bin, welcher zwischen einer entstehenden Form ind den mechanischen Berlingungen ihrer Entstehung vorhanden ist.

Was mun das Gebirn anbetrifft, so entsprechen seine drei primären Krimmungen den drei hintereinanderliegenden Ausweitungen seiner Seitenwand, die Hakenkriimmung derjenigen des Vorderhirns, die Mittelwölbung der des Mittelhirns und die Briickenkriimmung der Verbreiterung auf der Gränze des Hinter- und des Nachhirns. - Das Vorhandenscin der primären Gehirnkriimmumgen kniipft sich an dasjenige der ersten Querfaltungen der Keimscheibe. Die Merlullarplatte beschreibt jene Krimmungen schon bevor sie sich schliesst; späterhin nehmen sie aber, wie die Beobachtung zeigt, sämmtlich zu, eine Zunahme, welche in nachweislicher Abhängigkeit von den Beziehungen zwischen der animalen und der vegetativen Keimschicht steht. Schon wiederholt ist in früheren Briefen der Verbindung gedacht worden, welche durch den Axenstrang, und später durch die aus ihm entstandene Chorda dorsalis zwischen der Mfedullarplatte und dem Darmdriisenblatte längs der Mittellinie unterhalten wird. Du weisst auch, dlass diese Verbindung

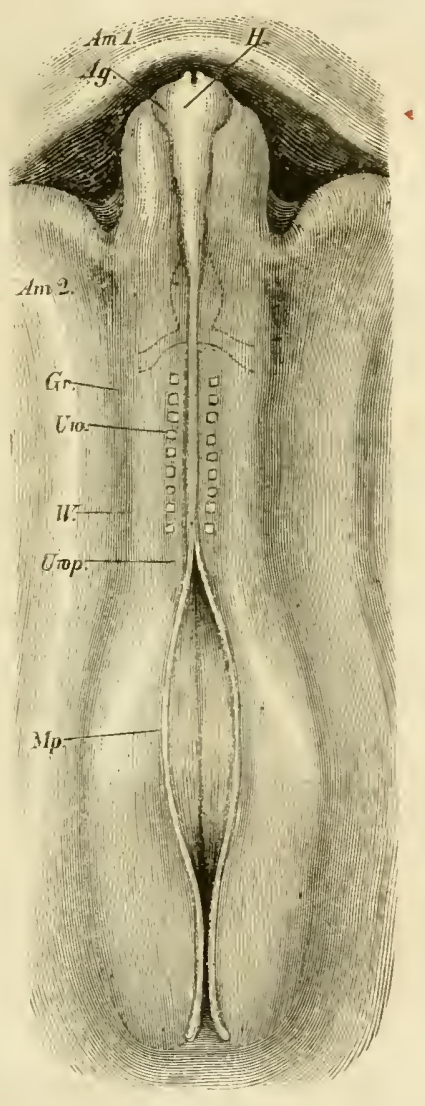

Fig. 90 (10). Hiuhnchen vom zweiteu Bebrütungstag. 20mal vergrösserte Dorsalansicht.

H. Hirn, in Vorderhirn, Mittelhirn nod Hinterhirn sich gliedernd. Ag. Augenblase.

WV. Wolffsche Leiste.

s. Gr. Seitliche Gränzrinne.

Uw. Urwirbel.

Uwp. Urwirbelplatte.

Am. 1. Vordere Amnionfalte.

An. 2. Seitliche

G. Grabe unter dem freien Kopfende. Mp. Offener Theil des Medu llarrohres. Medullarplatte.

Der Ort des Herzens ist durch pnnktirte Linien angegeben, das Herz ist noch gestreckt. 
in der Folge sich lïst, indem zuerst das Darmdrisenblatt von der Chorda, und, viel später, diese rom Medullarrohre sich entfernt. Am imnigsten ist die Verbindung dureh zwisehengelagerte Masse zwischen dem ursprünglieh rordersten Rande der Medullarplatte und dem vorderen Eude des Vorderdarmes. Die Verbindmo ist hier eine so imnige, lass, wenn in sehr später Zeit der Vorderdarm rom Gehim sich tremnt, die Tremmung nicht im Verbindungsstiicke gesehieht, sondern in der Continuität des Vorderdarmes selbst. Ein kleines Stiiek ron diesem bleibt als rorderer Lapuen der Hypophysis in danernder Verbindung mit dem Gehinn. Es wäichst aber das Medullarrohr, und speciell das Gehirn raseher in die Länge als der Vorderdarm; da es nieht zu einer Tremung beider Theile kommt, so muss der lingere Theil sich krimmen, und miissen ferner die unmittelbaren Folgen der 'Zerrung' in den mit einander verhundenen Strecken des Vorderdarms sowohl, als des Medullarrolures zu Tage treten. Beides trifft in sehr prïgnanter Weise ein: nieht allein erhebt sich das Medullarrohr iiber dem Vorderdarm in wachsendem Bogen, sondern es ziehen sich an beiden Theilen die rerbundenen Enden triehterförmig ans, wir bekommen auf die Weise am Gehirn den oben betrachteten Trichtertortsatz, am Vorderlarm die aus Fig. 91 bekamnte sog. Rath ke'sche Tasehe.

Fiir den vorderen Abschnitt des Gehins wird dureh die Verbindung mit dem Torderdarm jene Bedingung hergestellt, welche wir oben heim Gummisehlaneh als zweiten Fall elörtert hatten, der Vorderdarm spielt hier die Rolle des fixirenden Fadens, und die Form, welehe das vordere Gehirnende amimmt, ist genan jenem Paradigma entsprechend. Du brauchst in der That nur die Fig. S2 mit der Fig. S6 zu rergleiehen, 111 die grösstmöglichste Uebereinstimmung in allen wesentlichen Punkten wiederzufinden. Die fixirte Spitze des gehogenen Schlanches findest Du in dem Triehterfortsatz, seine beiden Ohren in den zwei Angenblasenanlagen wieder; ebenso sind die beiden schräigen Leisten ron der Fixationsstelle zu den Ohren und die dahinter liegende Rimne rorhanden, letztere an der unteren Fläche der Angenblasen endigend. Noeh viel sehärfer treten diese Dinge bei Fig. S3 herror, nur hat hier schon die Abgliedermg der Augenblasen rom Vorderhirn be- 
gonnen, ein Vorgang, der auf ein anderes Moment zurlickzufiihren ist, auf die Wirkumg nämlich des zur Seite gerickten Zwisehenstranges. Dies Gebilde, aus der Wandung der Zwischenrimne entstanden, liegtam Kopf urspringlich iiber der Schlussstelle des Medularrohres. Damn aber verschiebt es sieh, wohl in Folge der dasselbe treffenden Längsspannung zul Seite, und kommt neben das Hinterhirn und das Mittelhirn zu liegren. Am Vorderhirn aber schneidet es zwischen den eigentlichen Gehirntheil des Rohres und die Angenblase ein, auf Querschnitten als 3kantiger Keil sich darstellend. Aus dem Zwvischenstrang entstehen die Anlagen der spinalen Ganglien des Kopfes (Trigeminus-, Aeusticus-, Glossopharyngeusund Vagusganglien). Aus demselben Materiale stammt die Anlage der Gehörblase. Dieselbe tritt stets an derselben Stelle neben dem Nachhim, etwas hinter der Rautengrube auf, d. h. an der Kreuzungsstelle der Zwischenrime mit der, ant der Grämze des Hinterkopfes befindlichen Querrinne, und sie leitet sich, soweit ich einsehe, davon ab dass an dieser Stelle die Rinne sich als offene Grube erhält und erst später in gesonderter Weise sehliesst.

Von nicht geringerem Interesse als die Verhältnisse im Berciehe der Hakenkriimmung sind die im Bereiche der Briekenkriimmung. Es ist zwar gerade das Hirn des Vogelembryo wegen der nur mässigen Ausbildung

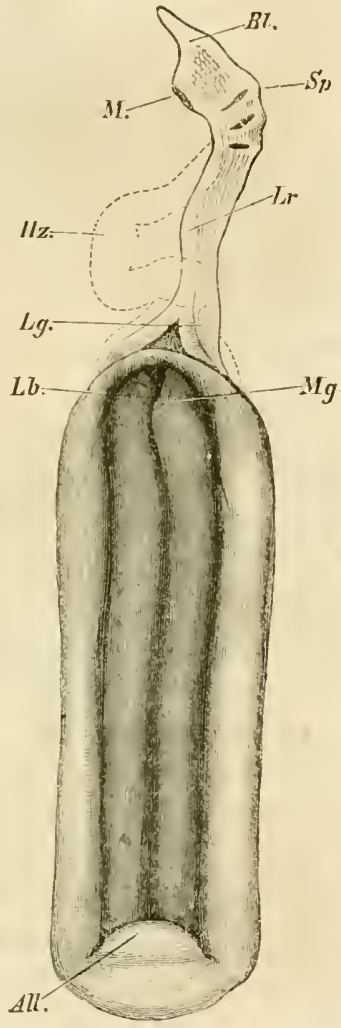

Fig 91 (8). Primitivdarm des obigen Embryo. 2umal vergrössert. Die punktirte Linie zeigt die Lage des Herzens.

BI. Blindes mit dem Hirn verbundenen Ende des Vorderdarms. (sog. Rathkesche Tasche).

II. Berührungsstelle des Vorderdarms mit dem Grund der Inndhöhle.

sp. Schlundspalten.

He. Herz.

Lr. Luftröhrenanlage.

Lg. Lnngenanlage.

Lb. Ort der Leberanlage.

VI. Ort der Magenanlage.

Ali. Ort der Allantoisanlage. jener Krimmung kein sehr schlagendes Object. Dagegen stossen wir aut sehr ausgepräigte Verhältnisse am Gehim der Knochen- 
fische und damn wiedertum an demjenigen des Mensehen und einer Anzahl von Säugethieren. Nehmen wir zunächst als Bei-
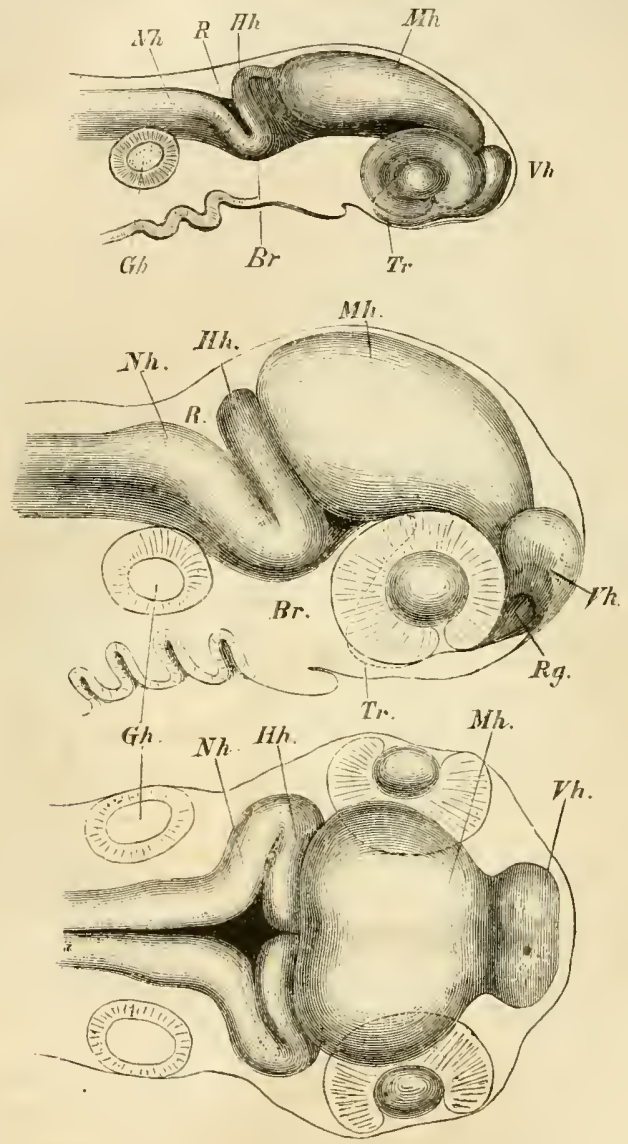

Fig. 92. Gehirn eines Hechtembryo. 3 Tage $p$. foec. Vergrösserung 30 . Buchstabenbezeichnung wie oben.

Br. Brīckenkrümmnng. Der Trichterfortsatz ist in punktirten Linien ein-

Fig. 93. Gehirn eines Forellenembryo. 4 Wochen p. foec. im Profil gesehen. Vergrösserung 30.

Rg. Riechgrube.
Fig. 94. Dasselbe vou oben gesehen. gezeichnet.

spiel das Gehirn eines Hechtenbryo vom 3. Tage, oder dasjenige eines Forellen- oder eines Lachsembryos von etwa 14 Tage nach der Befruchtung. Ein solches (s. Fig. 92) besitzt eine wohl ent- 
wickelte Hakenkrümmung mit starkem Trichterfortsatz und ein langgestrecktes Mittelhirn. Besonders aber zeichnet es sich aus durch eine scharf ausgebildete Briickenkrimmung, welcher an der oberen Fläche ein tiefer Einschnitt entspricht. Weit treten an dieser Stelle die Rïnder des Rohres zur Seite, genau nach dem Falle des geschlitzten und scharf eingeknickten Gummischlauches. Die auf diese Weise entstehende breite Grube ist die Anlage einer Rautengrube; ans den hinteren divergirenden Rändern der Grube werden die Verbindungsstiicke des Markes mit dem Kleinhim (Corpora restifornia), die rorderen convergirenden Rïnder aber und ihr, hinter dem Mittelhiru liegendes Verbindungsstiick liefern das Material zur Bildung des Kleinhirns.

Folgen wir dem ehen betrachteten Gehirn auf die etwas vorgeriickte Stufe Fig. 92 und 93, so begegnen wir einer zunehmenden Entwicklung der verschiedenen Krimmungen. Durch die wachsende Zusammenschiebung der Theile ist der hintere Hirnabschnitt, oder das Nachhirn unter die daror liegende Anlage des Kleinhirns, und diese unter diejenige des Mittelhirns geschoben worden. Wie ein Klappdeckel legt sich nunmehr die Kleinhirnanlag'e, oder der urspriinglich rordere Rand der Rautengrube iilser diese weg, und rerengt ihren Zugang. Dies Verhältniss nimmt in dem Maasse zu, dass bei einem Fische ron etwa $2 \mathrm{Cm}$. Länge das Kleinhirn beinahe

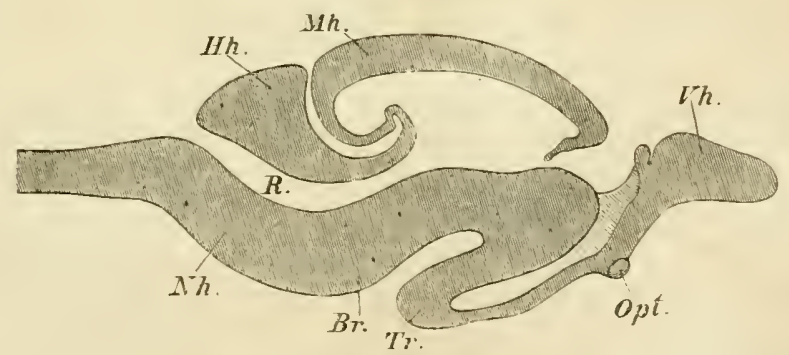

Fig. 95. Hirn eines Salmenembryo von 2 Ctm. Länge im Längšschnitt. Vergr. 20. Bezeichnung wie oben.

ganz unter das Mittelhirn geriickt erscheint und nur mit einem mittleren Lappen frei nach hinten vortritt, und so finden wir die Sache auch am Hirn des ausgewachsenen Thieres. ${ }^{2}$ ) 
Eine auffallende Uebereinstimmung in dem Verhalten dieser hinteren Abschnitte finden wir beim Gehirn des Menschen. Ich lege Dir einige nach Photographien entworfene Zeichnungen bei. Die Betrachtung der iibrigen Unterschiede zwischen diesem und dem embryonalen Fischhirn vorerst bei Seite lassend, mache ich Dich darauf aufmerksam, wie enorm stark auch hier die Briickenkrimmung entwickelt ist, und wie weit zugleich das Nachhiru miter das Hinterhirn, und dieses muter das

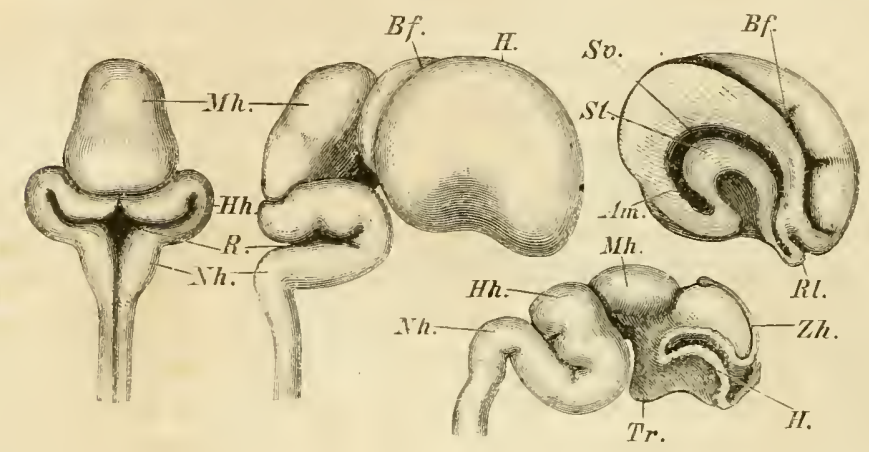

Fig. 96. Hirn eines menschlichen Fötus von ca. $;$ Wochen. Die Vorderhirnlemisphären sind mit Ausnahme ihres Wurzelstückes entfernt, man sieht das blossliegende Zwischenhirn $(\mathrm{Zh})$ und den Trichterfortsatz (Tr). Buchstabenbezeichnung wie oben.

Fig. 97. Hirn eines 10wöchentlichen menschlichen Fötus in der Seitenansicht. H. Hemisphäre.

Fig. 98. Dasselbe von hinten her gesehen.

Fig. 99. Mediale Fläche der abgetragenen Hemisphäre.

St. Streifenhügel

Sv. Seitenventrikel.

Am. Anlage des Ammonshorn.

Bf. Bogenfurche.

Mittelhirn geschoben ist. Entsprechend dieser starken Entwicklung der Brickenkriimnmug findest Du auch eine sehr breit angelegte Rautengrube.

Wenn Du Dich an obigen Beispielen von rer Abhängigkeit iiberzengt hast, in welchen die Gehirngliederung ron den anftretenden Longitudinalbiegungen des Organes steht, so wird es Dich interessiren, nach der Richtung eine kleine vergleichende Umschau zu halten, und eine solche gedenke ich Dir im nächsten Briefe rorzuführen. 


\section{Neunter Brief.}

Bedentung der Brückenkrümmung für die Entwicklıng des Kleinhirns und der Medulla oblongata; Hemisphären des Grosshims und deren Umbildung. Anftreten der weissen Substanz.

Lieber Freund! Nach den Auseinandersetzungen des letzten Briefes werden Dir keine Zweifel geblieben sein iiber den causalen Zusammenhang zwisehen der primäiren Gliederung' des Gehirns und seinen primären Krimmmgen. Wie jene Gliederung, so kommen anch die Kriummungen dem Gehirn sïmmtlicher Wirbelthiere zu. Andentungen davon seheinen, soweit man aus den $\mathrm{K}$ ow a lew sk y'schen Abbildungen schliessen kann, in friiher Lebensperiode selbst dem Amphioxus nicht ${ }^{1}$ ) zu fehlen. Die Gehirnkrimmungen sind indess bei Vertretern verschiedener Wirbelthierordnungen auf gleicher Entwicklungsstufe ungleich stark ausgeprägt, und anch ungleich über die Gesammtlinge des Hirmrolnes vertheilt. In diesen Ungleiehheiten liegt ein Grund für späitere Versehiedenheiten des Gehimbatres, und es ist leicht verstaindlieh, wie eine einzelne Abweichung, sei es im Grade einer Kriummung, sei es im Orte derselben, ihren Einfluss stets auf einen ganzen Complex von Hirntheilen erstrecken wird. Wo z. B., wie beim Fischhirn, dureh die langoestreckte Mittelwölbung eine lange Mittelhirnanlage abgesteckt wird, da wird nothwendig in einer anderen Anlage (hier in derjenigen des Vorderhirns) eine entsprechende Verkiirzung eintreten, und diese erste Feststellung: der Proportionen wird auch dureh secundaires Wachsthum nieht wieder ausgeglichen. Eine gegenseitige Entwicklungsabhängigkeit besteht fiur die Theile des Gehims gleichermaassen, wie für die grossen Districte des Gesammtkeimes. 
Die zuletzt erörterte Brïckenkriimmung mag uns sofort als Beispiel des Einflusses dienen, welehen die Ausbildung einer gegebenen Kriumnung anf die Entwicklung der umgebenden Theile ansiibt.

Der Ort der Briickenkriummmng bestimmt, wie wir das letztemal gresehen haben, denjenigen der Rantengrube; letztere ist die, dureh die Knickung verbreiterte Röhrenlichtung. Je stärker die Knickung, um so breiter wird unter iibrigens gleichen Bedingmengen die Grube sein, und um so grösser die Längenausdehnung ihrer anseinanderweichenden Ränder. Die grösste Breite der Rantengrube bezeichnet die Grinze zwischen dem Nachhirn und dem Hinterhim, oder mit den bleibenden Namen, zwischen dem rerlängerten Marke und dem Kleinhim.

Das Kleinhirn zerfällt, wie die Anatomie zeigt, bei den meisten Abtheilungen der Wirbelthiere in ein Mittelstiick, den sog. Wurm, und zwei durch eine Furche davon abgesetzte

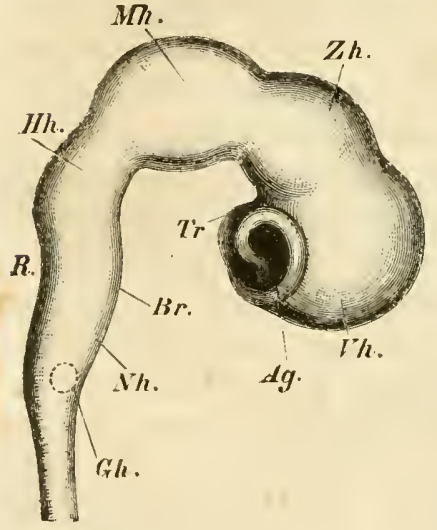

Fig. 100 (8i). Gehirn eines Hühnchons ron der Stufe Fig. 5. $30 \mathrm{mal}$ vergrössert. R. Ort der Rautengrube. Zh. Zwischenhirn.

Uebrige Buchstaben wie bei Fig. \$2 n. \$3. Seitenstiicke. Das erstere bildet sich ans den in der Mittellinie rereinigten Streeken der oberen Röhrenwand, d. h. aus solchen Substanzmassen, die hinsichtlich der primitiven Lagerung vor den Anlag'en der Seitenstïcke befindlich waren. Beim Vogelembryo ist, wie Du aus der Fig. 100 ersiehst, zwischen dem Mittelhirn und dem rorderen Rande des Rautengrubenznganges ein ziemlieh langes ungeschlitztes Stiick rorhanden, aus welchem der gleichfalls langgestreckte Wurm entsteht. Wo ein solches Zwischenstiick urspriinglich geringere Entwicklung besitzt, da kann durch secundïres Znsammenschieben der Seitentheile gleichwohl ein starker Mitteltheil des Kleinhirns sich entwickeln, wofiir die Knochenfische ein Beispiel liefern. Im Uebrigen bilden sich aus den offenen Vorderwäinden der Rautengrube die Seitenstiicke des Kl cinhirns. 
An der, basalwärts rorspringenden Querleiste der Brickenkrimmung entstehen bei Säugethieren die Querfasern der Briicke, ferner brechen an ihr samz allgemein die Wurzeln des N. trigeninus dureh. Daran und theilweise an der Vorwölbung kann man noch an ansgebildeten Gehirn den Ort jener Leiste erkennen. Allerdings wird dureh die an der Hirnbasis anftretenden weissen Substanzmassen die Schürfe der Anfangsformen vielfach rerwiseht, und die Orientirung wesentlich erschwert. Wie die iibrigen Himkriummungen, so pflegt auch die Brickenkriimmmg im Lanfe der Entwicklung zuzunehmen, bei dem einen Geschöpf mehr, bei dem andern weniger, und je stärker die Zunahme ist, um so mehr schieben sich die hinteren Hirntheile unter die mittleren.

Aus den allgemeinen Beding'ung'en des sich knickenden Schlanches haben wir sonach folgende Abhängigkeiten zu erwarten:

Schwache Briickenkriimmung: Schmale. Rantengrube, kleines Cerebellum, wenigstens kleine Seitentheile desselben.

Geringe Vorsehiebung der Briickenkriimmung: Weit offener, rom Cerebellum unrollständig gedeckter Zngang zur Rautengrube; Cerebellum hinter dem Mittelbirn liegend, Austrittsstelle des N. trigeminus noch unter dem offenen Theile der Rautengrube, und nahe an deren breitester Stelle.

Starke·Briickenkriimmung: Breite Rantengrube, starkes Cerebellum, insbesondere starke Seitentheile desselben.

Starke Vorschiebung der Brïckenkriimmung: Enger, rom Cerebelhm bedeckter, und schräg verlaufender Zugamg zur Rautengrube; Cerebellum rom Mittelhirn iiberlagert; Austrittsstelle des N. trigeninus iiber die breiteste Stelle der Rautengrube nach roln geriickt.

Um zu sehen, inwieweit diese Ableitungen mit den Thatsachen stimmen, betrachten wir einmal die anf gleichen Entwicklnngsstnfen befindlichen Gehime des Hiihnchens Fig. 101 und des Hechtembryo Fig. 92 (S. 102) und figen ihnen dasjenige des Froschembryos Fig. 102 bei. Alle 3 Zeichnungen sind bei derselhen Vergrösserung aufgenommen, und es tritt 
Dir darans die bemerkenswerthe Thatsache entgegen, dass alle drei Gehirne in ihren ahsoluten Maassen sich schr nahe stehen. Es ist diese geringe Grössensehwankung des sich formenden Rohres, wie $\mathrm{Du}$ siehst, neben dem Vorhandensein der primäien Kriimmungen ein neues Moment zur Erklärung des ailmlichen Ganges der Crlierlermg.

In Vorbeigehen mache ich Dich anch anf die Länge des in der Hakenkrimmung zuriickgebogenen Stiickes beim Fisch - und beim Froschhirn gegeniiber dem des Hiihnchens aufmerksan, sowie auch anf die bedentende Lïnge des Mittelhirns beim ersteren.

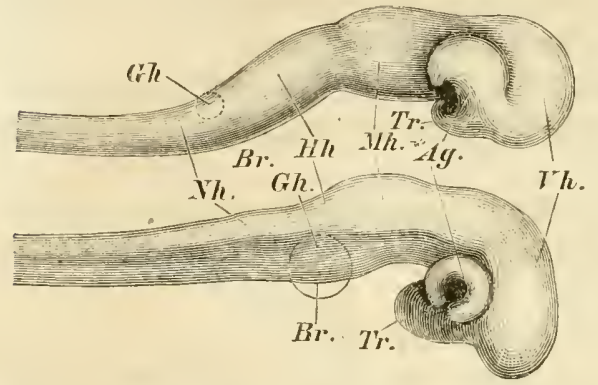

Fig. 101. Gelirn des Hühn- Fig. 102. Gelim des Froschchens, Profilansicht von

Fig. 9.3 . 30mal vergr.

Was num speciell die Briickenkriimmung anbetrifft, so ist diese beim Froschembryo sehrunbedeutend, beim Hiihnehen etwas erheblicher, beim Fischembryo ausnehmend stark ausgebildet. Bei letzterem nimmt sie, wie Du ans dem vorigen Briefe weisst, nocli erheblich zu, und fiilnrt zu einer weitgehenden Vorschiebung* der hinteren Hirntheile unter das Mittelhirn. Auch beim Hiihnehen nimmt die Krimmung noch etwas zu; und es geschieht eine, obwohl geringe Vorriickung (vgl. Fig. I S. 3). Beim Frosch dagegen hleibt die Kriimmung gering und schiebt sich auch kanm in merklicher Weise vor.

Der starken Entwicklung der Brickenkrïmmung beim Fischlirn entspricht die starke Entwicklung des Cerebellum und eine weite Vorlagerung der Austrittsstelle des N. trigeminus. Anders liegen die Dinge beim Vogelhim. Das Cerebellum besitzt zwar, ans den friilıer erörterten Grinden, einen ziemlieh starken Wum, dagegen sind dessen Seitentheile sehr sehwach und nieht iiber die Rautengrube zuriiekgebogen. Das Maximum del basalen Wölbung liegt ziemlich weit hinten und auch der 'Trigeminusanstritt f'illt um weniges vor' den Eingangsschlitz der Rautengrube. 
Ausnehmend schwach bleibt bekamntlich das Cerebellum beim Frosch; es ist hier eine diimne, nur das vordere Ende der Rautengrube iiberbrickende Lamelle. Seiner geringeren Entwicklung entsplicht eine, gleichfalls geringe, weit hinten liegende basile Vorwölhung, an welcher, noch unterhalb des
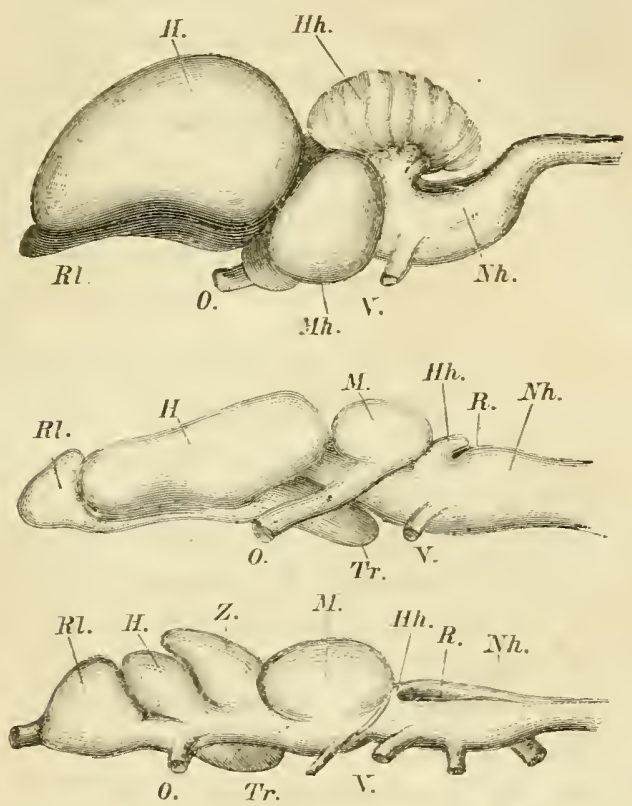

Fig. 103. Gehirn des erwachsenen Huhnes. 2mal vorgr.

Fig. 101. Gehirn des Frosches. 5mal rergr.

Fig. 105. Gehirn von Petromyzon fluviatilis (nach Joh. Müller.

R. Eingang zur Rautengrube.

5. Nervus trigeminus.

Br. Brücke.

Lebrige Buchstabenbezeichnung wio oben.

offenen Theiles der Rautengrube, der $\mathrm{X}$. trigeminus hervortritt. In noch höherem Grade zeight das Gehirn ron Petromyzon diesen Complex ron Eigenthiimlichkeiten.

Säugethierhime laben in Allgemeinen eine wohl entwickelte Briickenkriimmung; in Grade der Ausbildung bestehen erhebliche Lnterschiede. Am Ende der Reihe steht in der Hinsicht das mensehliche Him und es erklärt dies die Mächtigkeit seiner Keinhimhemisphären, sowie die starke Vorschiebung seiner Briicke und seines Trigeminusaustrittes. Da- 
gegen erreicht beispielsweise bei einem unserer, embryologisch beststudirten Hanssängethiere, dem Kaninchen, die Briickenkriimmung nur einen mässigen Grad, und dasselbe gilt von den Seitentheilen seines Kleinhirns.

Unter den versehiedenen primären Absehnitten des Gehirnrohres erfillurt das Mittel hirn im Laufe der weiteren Entwicklung die unbeträichtlichsten, das Vorderhim aber die bedeutendsten Abweichungen von der anfänglichen Grundform. Aus dem primäen Vorderhirn gehen nämlich bei der successiven Abgliederung hervor:

das $Z$ wischenhirn, oder die Umgebung des dritten Ventrikels (Sehhügel, Zirbel und Boden des Ventrikels bis zum Infundibulum);

die Angenblasen, oder Anlagen der Netzhant und der Pigmenthaut;

die Grosshirnhemisphären einschliesslich der Streifenhügel;

die Vorderwand des dritten Ventrikels,

das Gew ölbe, und

die Riechlappen.

Die Verfolgung dieser Abgliederung im Einzelnen und die Anfsuchung ihrer mechanisehen Bedingungen wïrde ein ziemlich tiefes Eingehen in die Gehimanatomie verlangen, wozu mir lier nieht der Ort seheint; anch sind bei der Complication der Verhällnisse eine Reihe von Punkten noch des weiteren Studiums bediuftig. Dagegen kamn ich mir nicht versagen, auf eins von den Gliedern des Vorderhirms, und zwar auf das bedentendste und zugleich das bedeutsamste einzugehen, auf dịc Hemisphären und deren Entwicklung bei Singetlieren.

Unmittelbar nachdem, zugleich mit der scharfen Abglicderung der Augenblasen, die Furehe zwischen dem Zwischenhirn und dem secundairen Vorderhirn anfgetreten ist, ist letzteres noch unpaarig und enthiilt eine einzige Höhle als Fortsetzung der Höhle des Zwivischenhirns. Bald jedoch tritt an ihm, vom vorderen Ende der Basis ansgehend, eine Furche auf, welche in seine vordere und in seine obere Wand einschneidet, und welche dann an der Gränze des Zwischenhirns in zwei seitliche Schenkel auscinander weicht. Dureh diese Furche wirl eine Theilung des Vorderhirns in die zwei Hemisphären angebahnt. Die Höhlung der letzteren oder die Seitenventrikel 
sind Anfangs Divertikel der medianen Vorderhirnhöhle. Je tiefer aber die tremnende Furche einschneidet, Im so mehr reducirt sich das Mittelstiick der Höhle, und $n \mathrm{~m}$ so enger wird der Zugang' zn den Seitenventrikeln.

Fiir die Ursache der, das Vorderhirn spaltenden Furehe, halte ieh den in der Mittellinie wirksamen longitudinalen Zug, der rom Triehterfortsatz ansgeht. Mit dem Vorhandensein eines solchen Zuges wiirde anch die Verdiinnmg der Hemisphärenwand im Bereiche der Furehe in Uebereinstimmung zu bringen sein.

Jede Hemisphärenanlage ist dem Fig. 106. Horizontalschnitt durch Obigen zufolge ein blasenartiger Körper, weleher an der Hirnbasis mittelst einer breiten flachen Wurzel festsitzt, nach rom, nach oben und nach hinten hin aber seine Wurzel frei iiberragt.

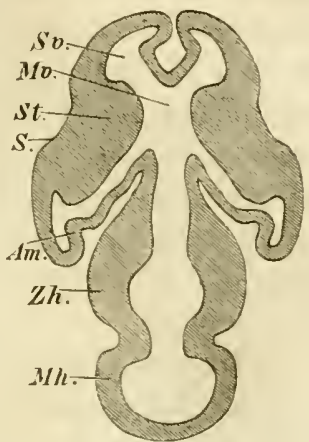
Sv. Seitengentriker.

II. Mittelventrikel des Vorderhirns.

S. Sylvische Grube

St. Streifenhügel.

An. Anlage des Ammonshorns.

Zh. Zwischenhirn.

3lh. Mittelhirn. Es bestehen zur Zeit des ersten Auftretens manche Uebereinstimmungen in Verlalten der Hemisphärenblasen und der

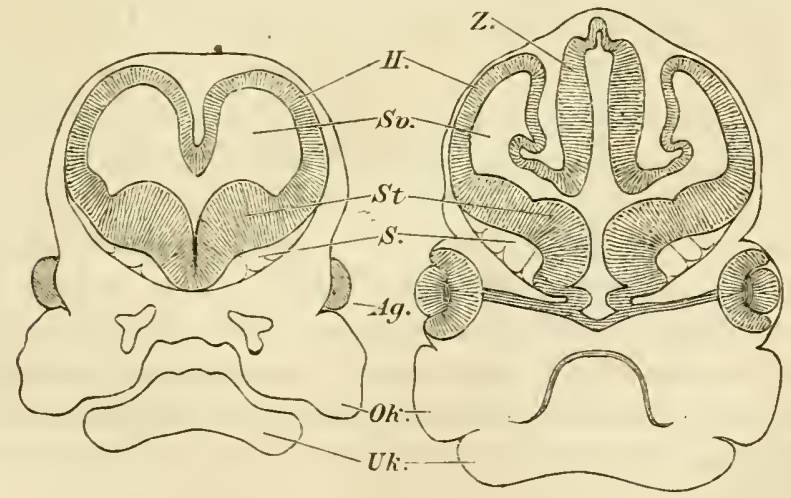

Fig. 107. Frontalschnitt durch den Kopf eines Kaninchenfötus (14 täg. p. f.) $10 \mathrm{mal}$

Fig. 10s. Schnitt etwas weiter hinten, das vergrössert. Der Schnitt fällt vor die Gränze des Zwischenhirns.

$$
\begin{aligned}
& \text { Ag Ange. } \\
& \text { ok. Oberkiefer. } \\
& \text { Uk. Unterkiefer. }
\end{aligned}
$$


Angenblasen, und am Him des Hiihnchens nehmen sich jene Anfangs geradezn aus wie eine vordere Wiederholung der letzteren. Constant ist das Vorhandensein einer, an der Aussenwand befindlichen Grube, welche von der Basis ans sich an die Wurzel und ron da ans noch ein Stiiek weit auf den freien Theil der Hemisphären erstreekt. Diese Grube ist die Fossa Sylrii. Ihr entspricht an der Imnenfliche des Hemisphärenraumes ein wulstiger Vorsurung, die Anlage des Streifenli iigeIs (s. Fig. 106, 107 und 10s). Den frei vortretenden Theil der Hemisphärenblase ptlegt man in der Anatomie als Hirnmantel zu bezeichnen.

Von anssen betrachtet, hat jede Hemispluäre cine anuähernd bohnenförnigge Gestalt: die der Wurzel angehörige Fossa Sylvii wird ron dem rorgewiilhten Mantel in convexem Bogen umspanut. Mit Ausnahme der Fossa Sylvii und einer nachher zu betrachtenden Furehe am hinteren Ende pflegt Anfangs die Hemisphäre an ihrer Aussenwand keine Furchen oder Vertiefungen, wenigstens keine von bleibender Bedentung zu zeigen. Anders die mediane Wand. Diese ist, soweit meine Erfihrmangen reichen, zu keiner Zeit völlig glatt, sondern stets von einer bogenförmigen, nud zu einer bestimmten Zeit auch ron einer Anzahl radiärer Furehen durchzogen. Letztere sind meistens voribergehender Natur, die Bogenfurehe dagegen ist, wie wir theihweise schon ans den Arbeiten ron Arnold mol ron Fr. Schmidt wissen, ron durehgreifender Berlentung für die späitere Organisation des Gehirns. Sie erzengt einen in die Hirnhöhle rorspringenden logenförnigen Wnlst, dessen hinterer 'Theil zum $A \mathrm{mmonshorn} \mathrm{wird,} \mathrm{während} \mathrm{der} \mathrm{mittlęre}$ und der vordere die Bildung des Gewölbes bedingen. ${ }^{2}$ ) Das vordere Ende der Bogenfurehe länft in den vorderen Rand der Hemisphäre aus und eine Zweigfinche begränzt den darunter liegenden Riechlappen. Am hinteren Hemisphärenrande iiberschreitet dic Furchc, auch beim menschlichen Fötus, anf' friiheren Entwicklungsstnfen den Rand, und ist ron anssen her noch eben sichtbar (Fig. 97).

Weshalb gerade an der medialen Hemisphärenwand Faltungen zuerst anftreten, ist nicht schwer zu verstehen. Nicht allein ist dieselbe diumer als die änssere, sondern dureh das Zusammentreffen in der Mittelehene wirken ja wlie beiden 
Hemisphären gegenseitig raumbeschränkend anfeinander; anstatt bauchig sich vortreiben zu können, sind sie genöthigt, sieh der ebenen Begränzungsflüche zu adaptiren.

Es ist Dir bekannt, wie die Gehirne der Sängethiere und speciell dasjenige des Menschen, dureh hervorragende Hemisphärenentwicklung sich auszeichnen, und wie die einmảl hervorgewölbten Hemisphären der Reihe nach das Zwischenhirn, das Mittelhirn und das Hinterhirn nebst dem Nachhirn zu iiberdecken vermögen. Wir bleiben zunächst beim mensehlichen

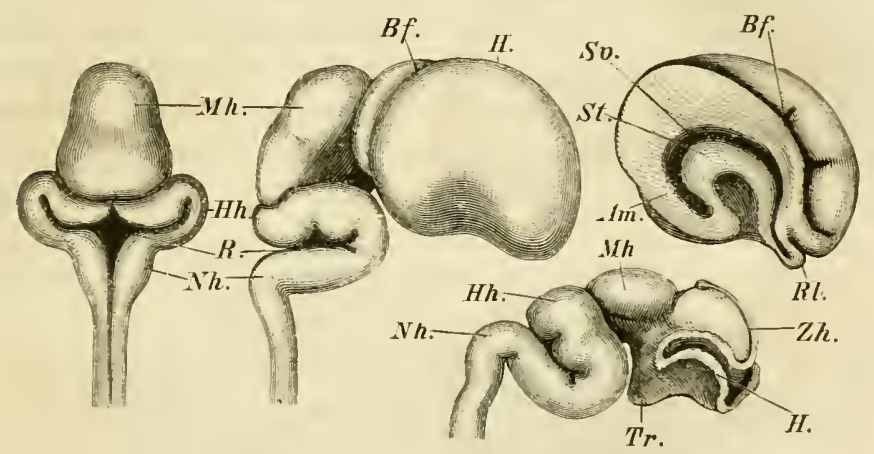

Fig. 109 (96). Hirn eines menschlichen Fötus von ca. 7 Wochen. Die Vorderhirnhemisphären sind mit Ausnahme ihres Wurzelstückes entfernt, man sieht das blosliegende Zwischenhirn (Zh) und den Trichterfortsatz. Buclistabenbezeichnung wie oben.

Fig. $110(97)$. Hirn eines 10wöchentlichen menschlichen Fötus in der Seitenansicht. H. Hemisphäre.

Fig. 111 (98). Dasselbe von linten her gesehen.

Fig. 112 (99). Nediale Fläcle der abgetragenen Hemisphäre.

St. Streifenhügel.

Sv. Seitenventrikel.

Am. Anlage des Ammonshorn.

Bf. Bogenfurche.

Gehirn stehen, bei welchem die Ueberlagerung dahinter liegender 'Theile den höchsten Grad erreicht, nul wir betrachten kurz die Hauptphasen der Hemisphärenversehiebung.

Es besitzt der, rom Hemisphärenmantel beschriebene Bogen, wie Du aus Fig. 110 siehst, Anfangs eine ziemlich gleichmässige Wölbung, und nur um weniges ist er hinten höher, als vorn. Damn aber :indert sich dies Verhältniss. An dem fist gleichmäissigen Bogen entsteht in der hinteren Hälfte eine, erst stumpte, dann spitz werdende Ecke, welehe nach hinten iberhäingt, und zugleich etwas medianwïrts sieh ein- 
biegt. Es wird diese Ecke zum sog. Hinterlauptslappen des Grosshirns. Nit der Schrägschiebung des Hemisphärenbogens stehn eine Reihe von weiteren Veränderungen in Zusammenhang: Die an der Aussenfliche befindliche Fossa Sylvii nimmit, wie der Hemisphäreumantel, eine winklige Gestalt an, und verlängert sich in eine nach rïckwärts sehende Spitze. Der zuvor bogenförmige Seitenventrikel wird zu einer dreizipf-

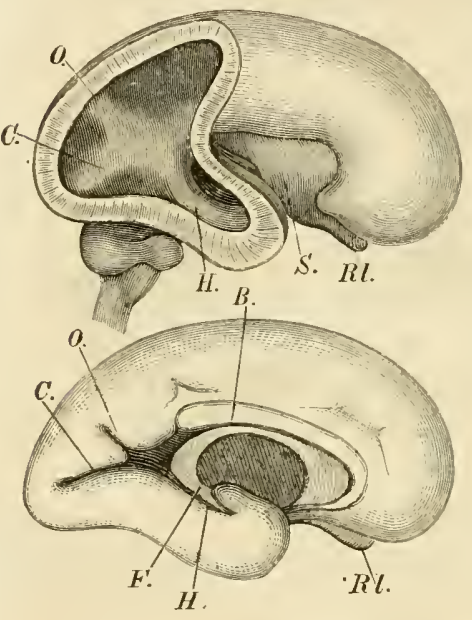

Fig. 113. Gehirn eines ca. $4 \frac{1}{2}$ monatl. menschlicben Fötus ron Aussen her gesehen. Ein Theil der Hemisphărenwand ist weggenomnen, um die Fin. inneren Falten zu zeigen.

Dieselbe Hemisphäre von der medialen Fläche.

F. Fornix mit Sept. pell.

c. Fissura calcarina

0 . Fiss. occipitalis

Hi. Riechlappen.

H. Balken.

H. Fissura bez. Pes Hippocampi.

ligen Höhle, deren neи auftretender Zipfel als sogen. hinteres Horn eben dem Hinterlauptslappen angehürt. An der merlialen Wand aber macht sich der Einfluss jener Hemisphärenumlegung dadurch geltend, dass die Bogenfurehe in zwei sich kreuzende Schenkel auseinandergelit, deren einer als Verlingerung des rorderen, der andere als Terlängerung des unteren Theiles der Bogenfurche auftritt. Jener bildet die sog. Fissura calcarina der Anatomen, dieser die innere $\mathrm{Oc}-$ cipitalspalte. Beide Furchen können bei ilırem ersten Auftreten sieh wohl derart stören, lass zuerst nur die eine oder die andere zur Ausbildnng gelangt, und man findet fötale Gehine aus dem 5. Nonate, an welchen auf der einen Seite nur die Fissura calcarina, auf der anderen nur die $\mathrm{F}$. occipitalis vorhanden ist.

Suchst. Du nun nach der Ursache, welche jener starken Versehiebung der Hemisphäiren zu Grunde liegen mag, so findest Du folgende: Durch die starke Briickenkrimmung ist die Anlage des Kleinhirns und der Briicke beim menschlichen Embryonalhirn sehr weit nach rorn geriickt. Es dauert. 
daher nicht lange, his die sieh ausdehnende Hemisphäre mit dem hinteren Rande ihres Bogens an jene Theile anstösst, und nunmehr sind die Bedingungen für das weitere Hemisphärrenwaehsthum rerändert. Die sich ausdelmende lintere Hemisphärenhälfte weieht, da ihr unten ein Widerstand geboten wird, nach dem Raume aus iiber dem Cerebellum und dem Mittelhirn, und gewinnt dabei eben jene dreizipflige Gestalt. Die Bildung des Hinterlappens und des Hinterhornes, sowie der Fiss. oecip. int. und ealcarina sind daher: mittelbare Folgen der stark entwickelten Briickenkriimmung.

Ein vergleichenden Blick auf andere Sïugethierhirme griebt dieser Ableitung ilnre Bestaitigung. Die oben erörterten Eigenthümlichkeiten kommen in voller Aushildung nur dem mensehlichen Gehirne und dem Gehirn höherer Affen _zu, sie

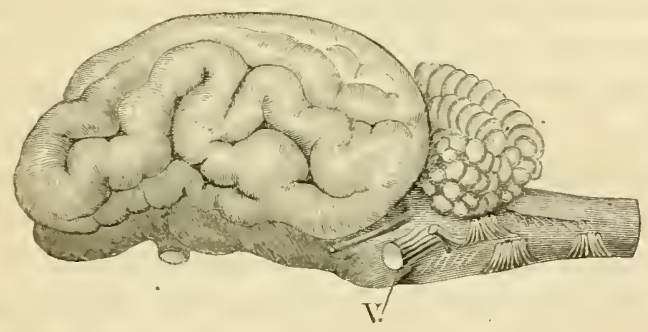

Fig. 115. Gehirn des Schafes (nach Leuret auf $3 / 5$ reducirt).

fehlen dagegen oder sind nur sehwach vorhanden bei denjenigen anderer Säugethiere. Du magst, um Dich dariber zu unterrichten, den schönen Hirnatlas von Leuret, oder allenfalls anch die Copien daraus von $\mathrm{Huguenin}{ }^{3}$ ) durehblättern, durchweg findest $\mathrm{Du}$ die Riiekwärtsschiebung der Hemisphären genan der Beriihrung entsprechend, welche zwischen ihnen und dem vorderen Rande des Cerebellum und der Brïcke vorhanden ist.

Als Beispiel lege ich Dir die Copie eines Sehafhirnes bei, an welehem die Zuriicklegung der Hemisphäre nahezu null ist, und die Fossa Sylvii die Gestalt einer verticalen Spalte besitzt.

Ich habe Dir im Obigen einige Gruben und Furehen der Hemisphärenoberfläehe namhaft gemacht, welehe mit einander das gemein haben, dass sie frihe auftreten und dass sie 
Falten der gesammten Wand sind. Jeder derselben entspricht somit ein imnerer Wulst oder Vorsprung. Wir können diese Furchen als Primärfurehen, oder noch passender vielleicht als Totalfalten der Hemisphärenwand bezeichnen. Es sind, $111 \mathrm{~m}$ sie nochmals mit den entsprechenden inneren Vorspriingen anfzuzïhlen :

Furche:

Fossa Sylvii

Bogenfurche, vordererTheil

Bogenfurche, hinterer Theil oder Fiss. Hippocampi

Fissura calcarina

Fissura occipitalis
Vorsprung:

Streifenhügel

Fornix

Pes Hippocampi

Calcar avis

Convexität des Hinterhornes,

endlich kann noeh genannt werden, die mit der Fiss. ealcarina und F. Hippocampi parallel anftretende Fissura collateralis, weleher im Ventrikel die Eminentia collateralis entspricht.

Eine Anzahl von Totalfalten hauptsiichlich radiären Verlaufes, welehe in frither Zeit (3 Monat) vorhanden sind, gleichen sich mit zunehmendem Wachsthum wieder ans, und hinterlassen keine bleibenden Spuren.

Die Dieke der Hemisphärenwandung nimmt, besonders durch Entwicklung ron weisser Masse, rom fiunften Monate al, erheblich zu, und die Ventrikel erfahren eine entsprechende Verengung. Gegen das Ende des fiunften Monats tritt beim Mensehen jenes nene System von Furchen auf, welches der Hemisphäre ihre bleibende Configuration ertheilt. Zn diesen Furehen gehören einige, die sich durch erhebliche Tiefe und dureh die Constanz ilures Anftretens auszeichnen (wic die Centralfurehe, die Stirnfurchen, die Sehläfenfurchen, die Interparietalfurche 11. s. w.); allein bei alle dem nehmen sie eine ganz separate Stellung ein gegeniiber den friilier betrachteten. Konnten wir dort von Totaltalten der Hemisphärenwand reden, so haben wir es hier nur mit Rindenfalten zu thum, d. h. es ist blos die grane Rinde in Falten erhoben, und nur sehmale Fortsäitze der weissen Sulıstanz dringen den Raum ausfïllend, in deren Basis ein. Keinerlei Eigenthiimliehkeit der Ventrikelwand spiegelt das Vorhandensein dieser ausseren Bildungen wieder. Auch in der Art ihres ersten Auftretens unterscheiden 
sich diese secundïren, oder Rindenfalten von den Totalfalten. W:ihrend diese gleich in seharfer Auspräigmg anftreten, entwickeln sich jene almuihlig, zuerst als seichte Vertiefungen, deren Ansdehnmng und 'Tiefe nach und nach sich vergrössert.

Es ist klar, dass bei den durchans rerschiedenen Eigenschaften der prinären und der secundiiren Furehen und bei der so rersehiedenen Art ihres Auftretens, beide nicht auf dieselben Entstehungsbedingungen zurïckgefïhrt werden kömen. Hatten wir es dort mit Faltungen einer verhältnissmäissig diumwandigen Blase zu thun, bei welcher nachweisbar äussere Momente mitbestimmend waren, so handelt es sich hier $1 \mathrm{~m}$ Veränderungen an einer dicken, ans zwei Schichten bestehenden Wand, bei welchen nur die eine, äussere Wandschicht direct betheiligt ist, und bei welchen auch nicht an Kräfte gedacht werden darf, die ron aussen her wirken. Lnter diesen Umständen kann man kaum im Zweifel dariiber sein, dass nur das relativ stärkere Flächenwachsthum der äusseren (grauen) Wandschicht der Grund ist, weshalh diese iiber ihrer Unterlage sich erhebt und sich in Falten wirft.

Nur wenige Worte fiige ich noch bei iiber das Anftreten der weissen Substanz, einen Gegenstand, den man kaum angefangen hat zu bearbeiten. Du hast frïher gehört, dass die weisse Substanz sehr langsam sich entwickelt, und dass ihre Fasern als Anslïufer der friher vorhandenen Nervenzellen anzusehen sind. Eine Reihe höehst interessanter Fragen thut sich num dabei auf. Wenn die Fasern ron einem Endpunkte auswachsen, wie gelangen sie zu ihrem anderen Endpunkte hin? wie entwickeln sich die secundären Faserverbindungen immerhalb der Centralorgane? wie kommt es, dass jede Muskelfaser, oder dass jeder Hautbezirk ihre Nerrenfasern, jene motorische, diese sensible erhalten u. s. w.? Es sind dies Fragen, zu deren Beantwortung bis jetzt fast alle Angriffspunkte fehlen. Nur in Betreff der gröberen Vertheilung weisser Substanz liegt einiges Material vor. Darnach ergiebt sieh der höchst einfache Satz, dass die weisse Substanz da auftritt, wo sie Raum hat. Um Dir diesen Satz zur völligen Ueberzeugung. zu bringen, miisste ich Dir ein ziemliches Detail vorfiihren, ich begniige mich statt dessen mit einigen kurzen Hinweisen. An den Gross- und Kleinhirnhemisphären, welehe von 
ihren Hïllen knapp umschlossen sind, sammelt sich die weisse Sulsstanz an der innern, der Ventrikelhöhle zugewendeten Flaiche; am Riickenmark, wo der enge Kanal wenig Raum bietet, bilden sich die Strä̈nge aussen ; an der Hirnbasis sehmiegen sich die weissen Substanzziige in die einspringenden, Anfangs nur von schwammigem, wasserreichem Bindegewebe a usgefiillten Winkel und Rinnen der Oberfläche. Die peripherisehen Nerven folgen, meist mit den Gefäissen laufend, den offenen Liieken zwischen den Muskel- und sonstigen Anlagen des Körpers u. s. w. Eines der hiibschesten Beispiele findet sich am Boden der Rautengrube. Hier liegt beim dreimonatlichen mensehlichen Fötus eine tiefe offene Kreuzfurche, der Längsschenkel des Krewzes wird spïter von der Raphe, der Querschenkel ron Fasem der Striac acusticae ansgefiillt.

Wir miissen zwar die weissen Substanzziige als grosse Strassen ansehen, welehe von Fasern der verschiedensten Bestimmung durchmessen werden können, immerhin kann der Umstand, dass seheinbar äussere Bedingungen, wie das Vorhandensein von Liicken und Rimnen jenen Massen den Weg. vorschreiben, fiir die eigentliche Organisation des Systems nicht bedentungslos sein. Wir haben sehliesslich keinen Grund anzunehmen, dass besondere Anziehumgskrätte eine Faser nothwendig zu diesem oder jenem Endpunkte hinziehen, und es liegt zum Mindesten ebenso nahe, sich zu denken, dass jede auswachsende Faser schliesslich da endigt, wo ihr natiirlicher Ausbreitungsweg sie hinlenkt, und dass eben in der primären Anordnung dieser Wege die Grundbedingmg der Organisation enthalten sei. 


\section{Zehnter Brief.}

Das Wachsthumsgesetz; räumliches und zeitliches Wachsthumsgefälle und deren Bedeutung für die schliessliche Ausbildung des Körpers.

Liebel Freund! In meinen letzten Briefen bin ich wohl etwas tiefer in anatomisches Detail hineingerathen, als dem urspriinglichen Plane entsprechen mochte, und es erscheint an der Zeit, dass wir wieder zu den Fragen allgemeinerer Natur zuriickkehren.

Ueber folgende Punkte bist Du jetzt eines mit mir geworden: eimmal, dass der erste Faltenwurf der Keimscheibe und deren primitive Gliederung durch die ungleiche Vertheilung ihres Wachsthmms bedingt wird, und dass fermer die nach erfolgter Abgliederung eintretende Umformung der Organanlagen vom Wachsthume dieser Anlagen selbst und ron demjenigen der iibrigen Körpertheile abhaingt. Allgemein gefasst lautet unser Ergebniss also:

Es ist bei gegebener Anfangsform des Keimes die Form des, aus demselben hervorgehenden Körpers eine abgeleitete Folge der räumlichen und zeitliehen Vertheilung des Keimwaehsthums.

Die Vertheilung des Wachsthums nach Raum und nach Zeit folgt fül jedes Geschöpf einem gegebenen Gesetze, dessen Bestimmung Sache der empirischen Forschung ist. Wir bezeichnen die auf Zeit- und auf Masseneinheit bezogene Massenzunahme eines Keimbezirkes als dessen Wachsthumsgesehwindigkeit. Da das speeifische Gewicht des Keimes iiberall nahezu gleich gesetzt werden kann, so ist in continuirlichen Theilen desselben jener Werth zugleich als Maass des Volumwachsthums anzusehen. Du weisst bereits aus friheren Briefen, dass beim Beginn der Entwickelung das Maxi- 
mum der Wachsthumsgeschwindigkeit in die Anlage des Gehims fällt, dass sie in der Anlage des Riickemmarkes etwas geringer ist, dass sie, von einer, jene Anlagen halbirenden Linie ansgehend, nach beiden Seiten hin symmetrisch sieh abstnft, sowie sie auch nach der Tiefe hin almimmit. In gleicher Weise zeigt die Erfahrung, dass die Wachsthumsgeschwindigkeit immerhalb einer gegebenen Anlage mit der Zeit sich ändert.

Das Wachsthumsgesetz, dessen Kemntniss für jedes Geschöpf besonders anzustreben ist, hat die Wachst humsgeschwindigkeiten aller einzelnen Pnnktedes Keimes als eine Funetion der Lage, der Zeit nnd der äusseren Bedingungen auszudriicken. Haben wir uns frîher den eben befruchteten Keim in eine Anzahl organbildende Bezirke zerlegt gedacht, so kïmmen wir hente einen Schritt weiter gehen, und sagen, dass imerhalb eines jeden dieser Bezirke den Theilen eine Wachsthumserregung imnewohnt, die sie bei ihrer Ablösung rom Gesammtkeime als Mitgift mit sich nehmen. Die urspriughliche Anstehnung des organbildenden Keimbezirkes einerseits und die seinen Theilen innewohnende Wachsthumservegmug andererseits, sind die beiden ron Anfang al, gegebenen Factoren, deren Verhalten die späitere Entwicklung des entstehenden Organes bestimmt. In der gesetzmässig geordneten Erregung zum Wachsthum liegt iiberhampt der ganze Inhalt erblieher Uebertragung, nnd das Problem der Zeugung, sowie ich es verstehe, löst sich auf in die Frage: Wie wird die Wachsthumserregung anf das Ei iibertragen, und welches ist der Antheil der beiden Erzenger an dieser Uebertragung?

Die Zeugungsfrage wird uns später nochmals besch:iftigen, bleiben wir vorerst bei Besprechung des Wachsthums stehen: Da die Wachsthumsgesehwindigkeiten in versehiedenen Bezirken des Keimes verschieden sind, so werden wir von einem gegebenen Punkte aus zu Punkten anderer, sei es grösserer, sei es geringerer Wachsthumsgeschwindigkeit fortschreiten. Ton der, im Wachsthm voraneilenden Gehirnanlage ansgehend, gelangen wir durehweg nach Punkten geringerer Wachsthumsgeschwindigkeit, in allmähligem Abtalle nach der einen, in rascherem nach einer anderen Richtung. 
Denken wir uns auf einer, der Keimscheibe entsprechend eingetheilten Horizontalebene ein System ron Senkrechten errichtet, deren Jängen je proportional sind den Wachsthumsgeschwindigkeiten der betreffenden Oberfläehepunkte im Beginne der Entwicklung, so werden die freien Enden der Ordinaten eine Fläche bilden, deren Gestalt der angenblickliche geometrische Ansdruck der Wachsthumsvertheilung ist. Eine solche Fläelıe wird sich demmach im Gebiete der Gehimanlage am höchsten iiber dic Hurizontalebene erheben, in den ausserembryonalen Bezirken aber wird sie sich dieser letzteren rings herum nähern, und annähernd parallel mit ihr verlaufen. Der Uebergang aber rom Erhebungsmaximum zu den peripheriseh liegenden Minima wird nach verschiedenen Richtungen ungleich steil, und mit mngleicher Wölbung geschehen. Wir wollen die Aenderung des Geschwindigkeitswerthes von einem Punkte zum näichstfolgenden als dessen räi $u$ mliches W a chsthumsgefälle bezeichnen. Legst Du einen Verticalschnitt, sei es in der Längsaxe selbst, sei es in einer zu ihr senkrechten Ebene dureh die Fliiehe, so selmeidet er diese in einer gekrimmten Linie, deren Gefälle in versehiedenen Strecken selbstrerständlich zu weehselı rermag. Jede solehe Linie driickt aus, wie in der betreffenden Zone die Wachsthtmmsgeschwindigkeiten rom Ort eines Maximums zu demjenigen eines Minimums sich abstıfen. Dic Wölbung del Gesammtfläehe ist der Ausdruek aller der Einzelnverhailtnisse. Wofern num das Gesetz, nach welchem im Beginn der Entwicklung die Wachsthumsgeschwindigkeiten iiber den Keim vertheilt sind, ein einfaches ist, so muss auch jene geometrische Wachsthumsfläche cine gleichmässige Wölbung mit lanter rermittelten Uebergängen besitzen. Wo nicht, wird ihr Niveau unruhig sein, und, je rerwickelter das Gesetz der räinmlichen Wachsthumsvertheilung, um so mehr sind plötzliche Gruben, umvermittelte Buckeln, oder scharfe Eeken in ihr zu erwarten.

Zur Construction einer solchen Fläche fehlt uns das nöthige empirische Material, immerhin kömen wir uns iiber einige ihrer Eigensehaften ein Urtheil bilden an der Hand dessen, was wir uiber die Abstufungen der Keimscheibendicke beobachten. Zwar ist es nicht zulässig, die, fiir verschiedene Punkte weehselnden Dicken einer Keimscheibenschicht ein- 
fach den betreffenden Wachsthumsgeschwindigkeiten proportional zu setzen, allein beide Wertle miissen, so lange keine Zerrungsbedingungen mitspielen, stets in gleichem Sime sich ändern. Grössere Wachsthumsgeschwindigkeit einer Stelle wird grössere Dieke im Gefolge haben, und umgekehrt. Da uns nun die Beobachtung von Querschnitten zeigt, dass sowohl das obere Gränzblatt, als die beiden Muskelplatten von der Mitte gegen die Peripherie hin an Dieke stetig abnehmen, und da entsprechende Erfahrungen anch für Längsschnitte sich wiederholen, so sind wir zu der Aussage berechtigt, dass auch die geometrische Wachsthumsfliche keine Spriinge in ihren Gefuillen hat, dass diese letzteren auf einer jeden Strecke ron einem Maximum zu einem Minimum durchweg absteigend verlanfen und dass ihre Wechsel stets durch Uebergänge vermittelt sind. Es ist mit andern Worten das Gesetz der räumlichen Vertheilung des Wachsthums im Beginn der Entwicklung ein verhältnissmässig einfaches zu nemen.

Eine geometrische Fläche, wie wir sie uns oben construirt dachten, ist für eine gegebene Sehicht des Keimes nur der momentane Ausdruck der Wachsthumsvertheilung, die Wachsthumsgeschwindigkeiten variiren auch nach der Zeit. Wollten wir für einen einzelnen Punkt des Keimes etwa für einen Punkt der Gehirnanlage die zeitliehen Aenderungen des Wachsthums graphisch verzeichnen, so wïrden wir wiederum eine gekriimmte Linie bekommen, deren weehselnde Gefaille nunmehr als zeitliche Wachsthumsgefälle wiirden zu bezeichmen sein. Wollten wir aber, ähnlich wie oben, eine Fläche der rïumlichen Wachsthumsvertheilung fiir die aus einer Sehicht lıervorgegangenen Theile in einer späteren Entwicklungsperiode construiren, so wären zunichst die einzelnen Punkte nach bestimmten Grundsätzen auf eine Horizontalebene zu projiciren, und dam wielerum ein System von Ordinaten proportional den betreffenden Wachsthumsgeschwindigkeiten zu errichten. Solehe für versehiedene Zeitpunkte construirte Flächen wiirlen in ihren Formen nicht iibereinstimmen und ihre Abweichungen von der Anfangsform wiurden voraussichtlich wachsen mit der Länge der zwisehenliegenden Zeit. Ob eine jede solche Fläehe, und ob auch die für einzelne l'unkte des Keimes construirten zeitlichen Wachsthumscurren unter allen Umständen nur sanft 
gesehwumgene Formen beibehalten, oder ob in ihren Gef:illen grïssere Springe auftreten, dariber darf man sich kaum bedingungslos aussprechen. Wenn ich geneigt bin, regelnässige Abstufungen anch im zeitlichen Ablaufe des Wachsthums für wahrscheinlich zu halten, so bestimmt mich dazu der Umstand, dass mir bis jetzt keine, einer solchen Voraussetzung: widersprechende Erfahrung bekannt ist, und ich nach einem bekamnten Grundsatze der Naturforschung der einfachen Voraussetzung bei gleiehen Anspriichen den Vorzug for der verwickelten gebe. ${ }^{1}$ )

Der Gang des zeitlichen Wachsthumsgefailles ist im Allgemeinen ein absteigender, oder, was dasselbe besagt: alle Theile nehmen in späteren Entwicklungsperioden an Masse relativ weniger zu, als in friiheren; sehliesslich hören sie überhaupt auf zu wachsen. Diese absteigende Richtung scheint, soweit sich ersehen lässt, schon in friheren Perioden sich geltend zu machen. Es ist nicht leicht, letzteren Punkt fiur die allererste Periode mit völliger Schärfe festzustellen, weil Gewichts- oder auch nur Volumsbestimmungen an ganz jungen Keimen nicht möglich sind. Man ist somit zunäichst auf die Bestimmung einzelner Dimensionen angewiesen, und anch da wird die Unzurerlaissigkeit der Zeit als Entwickelungsmaassstab bei höheren Wirbelthieren zu einer schwer zu ungehenden Fehlerquelle. Ich habe, um einen Anlaltspunkt zu haben, bei $2+$ Hiihnerembryonen die Länge der sichtbaren Embryonalanlage gemessen und daraus fiir 3 Gruppen ron je S Stiick die beziiglichen Mittelwerthe bereehnet. Vor Ablanf der ersten 24 Stunden lassen sich Messungen nicht sicher ausfiihren, weil der Keimwall das hintere Leibesende deckt. Als Maximum der Anfangsläugre kann der halbe Durchmesser der Keimscheibe gesetzt werden, weil vor Beginu der Bebritung die Embryonalanlage nach rorn nur um Weniges die geometrische Mitte der Scheibe iiberschreitet. Die Körperlainge habe ieh von der Zeit ab, da die Kopf- und die Rumptkriummungen eingetreten sind, im Bogen gemessen. Die erste Columne der kleinen Tabelle enthält die mittleren Bebriitungszeiten, die zweite die mittleren Längen der Embryonen, die dritte Columne die absoluten, die letzte die proportionalen stïndlichen Längenzuwachse. 


\begin{tabular}{l|c||c|c}
\hline $\begin{array}{c}\text { Mittlere } \\
\text { Bebrütungszeit. }\end{array}$ & $\begin{array}{c}\text { Mittlere Länge } \\
\text { des } \\
\text { Embryonalkörpers. }\end{array}$ & $\begin{array}{c}\text { Absoluter Zuwachs } \\
\text { in } \\
\text { einer Stunde. }\end{array}$ & $\begin{array}{c}\text { Proportionaler } \\
\text { Zuwachs in } \\
\text { einer Stunde. }\end{array}$ \\
\hline \hline 0 Stunden & $1,75 \mathrm{Mm}$. & $0,05.5 \mathrm{Mm}$. & $3,1 \%$ \\
31,25 & 3,47 & 0,17 & $2,9 \%$ \\
$77,-$ & 5,15 & 0,11 & $2,1 \%$ \\
70,5 & 7,61 & &
\end{tabular}

Der Gang in den beilen letzten Colummen ist, wie Du siehst, kein stetig gleichgerichteter, und es muss ausgedehnteren Bestimummen vorbehalten bleiben zu entscheiden, ob das Verhältniss des voriibergehenden Ansteigens mit nachfolgendem Abfalle der heiden Werthreihen ein gesetzmässiges ist. Soviel ist ersichtlich, dass das absolute Längenwachsthmm in der allerersten Zeit am greringsten ist, und später etwas zunimmt, während vom relativen Wachsthum das umgekehrte zu gelten scheint.

Ansgedehntere Erfahrmngen als iiber das Längenwachsthmm des Hiihuchens, besitze ich iiber dasjenige des Lachsembryo. Bei diesem hält sich der absolute Tageszuwachs während einer Reihe von Wochen ziemlich auf derselben Höhe zwisehen 1/4 bis 1:3 Mm., um dann, etwa vom zweiten Monat, ab zu sinken; $d$. h. es findet von ziemlich friiher Zeit ab eine gleichfalls stetige Abnahme der mittleren Geschwindigkeit des Längenwachsthums statt, welche später sogar in eine absolute Abuahme des Wachsthums iibergeht.

Die eintretende Abnahme der Wachsthumsgeschwindigkeit macht sich nicht fiir alle Producte der urspriinglichen Keimscheibe in gleichem Maasse geltend. Eine bekamnte Erfahrung zeigt uns, dass unter den Hauptorganen des Körpers das Gehiru und das Riickenmark zuerst zu wachsen anthören. Länger als diese Theile wachsen die Muskeln, am läugsten die epithelialen Theile. Letztere hören iiberhaupt gar nicht auf zu wachsen, wie das Längerwerden unserer Haare und Nägel, die Abschuppung unserer Epidermis und andere ähnliche Erfahrungen mehr bezengen. Diejenigen archiblastischen 
Gewebe, deren Wachsthumsgesehwindigkeit ron Anfang ab die bedentendste war, erschöpfen ihren Wachsthumserregung zuerst, die ron Anfang an am wenigsten rasch wachsenden, wachsen am lïngsten fort. Graphiseh veranschaulicht sich dies Verhiiltniss dureh drei iibereinandergezeichnete Curven, deren eine, das Nerrenwachsthum $(\mathrm{N})$ bezeichnend, am höehsten beginnt und an friilıesten abfaillt; die zweite, die Curve des Muskelwachsthums (M), weniger hoch begimt und später al)fällt; die dritte endlieh, die Epitheleurve (E), den niedrigsten Gipfel, aber auch das geringste Gefaille lat.

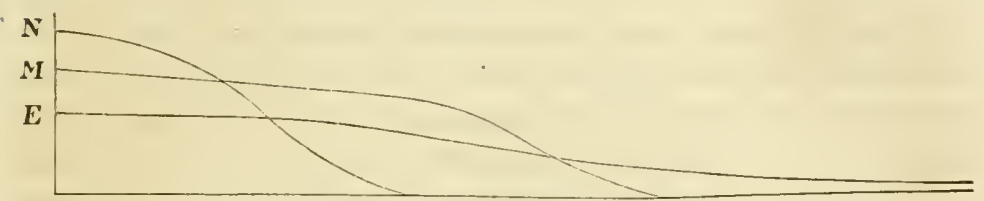

Fig. 110 .

Bedeutsam ist die Beziehung zwischen diesen Wrachsthumsverhältnissen und der physiologischen Stellung der gebildeten Gewebe. Das Nervengervebe, das Du hinsichtlieh seiner physiologischen Bedeutung sicher an die Spitze aller iibrigen stellen wirst, wäichst Anfangs an rasehesten, hört aber an fribesten zu wachsen auf, während ron den epithelialen Geweben nach beiden Richtungen das Umgekehrte gilt. Das Wachsthum der physiologisch tiefer stehenden Gewebe iiberdanert somit dasjenige der höher stehenden, und erreicht mit der Zeit immer mehr das Uebergewicht iiber diese.

Der bedeutende Vorsplung, welchen auf friheren Entwicklungsstuten die Anlage des Centralnervensystems gegenüber allen iibrigen Embryonaltheilen besitzt, fiihrt sich zunäehst zuriek auf die Grösse des bei der primïren Gliederumg ihr zugetheilten Urbezirkes, und damn auf ihre griossere Wachsthumsgeschwindigkeit. Dank der letzteren ändert sich das Verhältniss während einiger Zeit noch mehr und mehr zu ihren Gunsten, dam aber tritt der Punkt ein, wo ihre Wachsthumsintensitait unter diejenigen der iibrigen Anlagien sinkt, und ron da ab wird ihr Antheil an der Gesammtmasse des Körpers relativ immer geringer, der der Nuskeln- und der epithelialen Anlagen dagegen stetig grisser. 
Du siehst ans Obigem, wie wichtig bei Beurtheilung der schliesslichen Massenvertheilung im Körper die Berieksiehtigung der zeitlichen Wachsthumsverhältnisse ist. Nicht blos die relative Grösse des organbildenden Keimbezirkes, anch nicht blos die Höhe, bis zu welcher das Wachsthmmsmaximum Anfangs sich erlrebt, sind fiir die Massenentwicklung des Theiles von Bedentung, sondern vor Allem das Gefälle der zeitliehen Wachsthumseurve: Je steiler in Allgemeinen dies Gefälle, um so kleiner wird der Theil absolut und relativ verbleiben und umgekelırt.

Vergleiehst Du z. B. in friiheren Entwicklungsperioden den Embryo eines Knochenfisches mit demjenigen eines Vogels oder eines Sängethieres, so findest Du anf gleieher Entwicklungsstufe bei jenem die Gehimanlage absolut eben so gross, relativ, wie es seheint, noch grösser als bei diesem. Allein sehr frïh schon lıört das Fischhiru zu waehsen aut, während die Muskeln fort und fort zumehmen, und so wird im Laufe der Zeit das Missverhältniss immer grösser, bis schliesslieh bei grossen Fisehen das Hirn nur noeh nach Zehntansendsteln (ler iibrigen Körpermasse sich bemisst. ${ }^{2}$ )

Die Zeit, ïher welche sich das Gesammtwachsthum des Körpers erstreckt, beträgt bekanntlich neistens Jahre und bei manehen grüsseren Thieren Jahrzehnte. Dem gegeniiber vollzieht sich die erste Gliederung des Keims in Fristen, welche nur nach Tagen, oder höchstens nach Wochen zu zählen sind. Das Hïlnchen von fiinftïgiger Bebritungsdaner ist schon im Besitze aller semer Hanptorgane, und nur untergeortnetere Abgliederungen, wie diejenigen der Horngebilde, der Federn und Klanen, sowie die der kleineren Driisen der Hant und der Sehleimhäute fallen in spätere Perioden der Entwicklung. Aehnliches gilt von Fisch-oder Sängethierembryonen, und es geht daraus hervor, dass fiir die grmondlegende Eintheilumg des Körpers die Wachsthumsverhïltnisse der allerersten Zeit die entscheidenden sind. Die in diesen ersten Zeiten vorhandene räumliche Vertheilung des Waclssthuns bestimmt das typische der gesammten Organisation. Das spätere, dureh lange Zeiträume sich erstreckende Wachsthum beherrscht die besondere Ausbildung der Organe und deren Massenentwicklung.

Der Kürze halber können wir das, der Organabgliederung 
vorausgehende Wachsthum als das primäi e, das spätere als das seeundäre bezeichen. Wem das primäre Wachsthm die typische Gliederung des Körpers bedingt, so liegen im seeundïiren die Motive für die zahllosen generellen, specifischen und individuellen Differenzirungen. Alle Untersehiede in der ersten Gliedlerung des Keimes, mögen sie auch noch so unscheinhar sein, bedingen eine gewisse Divergenz der Entwieklungsrichtung, deren Folgen um so präignanter in Erseheinung treten werden, je weiter iiberhaupt die Entwieklung fortschreitet. Ueberdies zeigt die rergleichende Entwicklungsgeschichte, dass die Verhältnisse des seenndären Wachsthums in viel grösseren Breiten schwanken, als diejenigen des primäiren. Eis gilt dies sowohl von der Daner des Gesammtwachsthums, als auch von dem Verhäitniss, in welchem neurales, museuläres und epitheliales Wachsthum zeitlieh sich abstufen. Soeben labe ich Dich auf das frithe Aufhören des Gehirnwachsthums beim Fisch aufmerksam gemacht, dem als entgeg'engesetztes Extrem das langdanernde Wachsthum desselben Organes beim Mensehen und bei einigen höheren Sïugethieren gegeniiber gestellt werden kamn. In den am liingsten fortwachsenden Gebilden epithelialen Ursprunges aber, in der Behaarung, Befiederung, Bezahmung u. s. w. stellt sich in Laufe der Zeit ror allen Andern jener Reichthmm ron Variationen her, weleler der besehreibenden Zoologie ilne lBände fiullt. Anch die Entwicklung sexueller Charactere failt vorzugsweise in den Bereich secundiiren Wachsthums, wie sclıon ans dem späten Erscheinen von vielen derselben sich ergiebt.

Daraus, dass im Obigen nur von netralem, museulärem und epithelialem Wachsthum die Rede gewesen ist, ersielıst Du, dass ich bei den letzten Betrachtungen nur die Bildungen arehiblastischen Ursprungs im Auge gehabt habe. In der That liisst sich nur für diese von einem eigenthimlichen Gesetze des Wachsthumes reden. Alle parablastisehen Gewebe, Gefaissröhren, Bindegewebe, Knorpel, Knochen, sind in ihrer Entwieklung abhängig von den archiblastisehen und zwar in mehrfacher Weise: Fürs erste sind sic daranf angewiesen, die Räume auszufüllen, welehe zwischen jenen ansgespart bleiben, und sie werden dadureh in ihrer Gesammtvertheilung von jenen bestimmt. Sodann aber steht auch ihre histologische Gliede- 
rung unter dem Einfluss archiblastischer Anlagen. Die parablastisehen Anlagen maehen nämlich naehweislich ein Stadimm der Indifferenz durch, während dessen es durch äussere Umstainde bestimmt wird, ob ihre Zellen zur Gefässbildung, zur Knorpelbildung oder zur Bindegewebsbildung Verwendung finden. ${ }^{3}$ ) Dabei zeigt die Beobachtung, dass allenthalben, wo parablastische Anlagen an archiblastische direct anstossen, dichte Netze von capillaren Blutgefäissen sich bilden, wo dies nicht der Fall ist, entsteht faseriges Bindegewebe oder Knolpel. Bindegewebe entsteht da, wo ungleichmässiger Druck oder Zug Seitens der Nachbartheile auf die parablastischen Massen wirkt, Knorpel da, wo dies nicht der Fall ist. Demgemäss bereiten sich das wachsende Ange, das wachsende Hirn, die wachsenden Driisen ilıre fibrüsen Kapseln, es bereiten sich ans im Anfang indifferenten Anlagen die Mnskeln ihre Sehnen und ihre Fascien, und deren Faserung ist stets parallel dem stattfindenden Zuge, oder senkrecht zu dem stattfindenden Drucke gerichtet.

Anch die morphologische Gliederung des festeren Skeletts, des, dem Knochengeriist voransgehenden Knorpelgeriistes ist nur aus dem bestimmenden Einfluss der Muskelanlagen zu verstehen. Wo eine verknorpelnde Anlage von Muskeln abwechselnd, bald in einer, bald in der entgegengesetzten Richtung: bewegt wird, da bildet sich Anfangs eine erweichte Stelle, weiterhin eine wirkliche Gelenkspalte. Die Endform der Gelenkflächen hängt ron der Tertheilung der einwirkenden Muskeln ab. Es schleifen sich, wie man dies ausgedriickt hat, die Muskeln ihre Gelenke, und es crklärt sich darans, warum die Beweglichkeit eines Gelenkes stets der mmgehenden Musculatur genau angepasst ist, und weshalb Muskeln nic zwischen Punkten desselben Skelettsticks sich ausspamen. Die Entwicklung des parablastisehen Körpergeristes ist cine mittelbare Folge des Gesetzes, nach welehem der, die archiblastisehen Gewebe liefernde Keim wäelist.

Bei der, alle Form- und Massenentwicklung beherrschenden Bedeutung des Wachsthumes muss, wie Du sichst, die physiologische Entwicklumgsgeschiehte ror allem darauf ansgehn, für eine gewisse Summe ron Geschöpfen den Gang die- 
ser Function genau festzustellen. Wo wir jetzt allenfalls noch im Wege der schätzung den allgemeinen Gang des Wachsthums, seine $\mathrm{Zu}$ - oder seine Abnahme eonstatiren, da ist eine strengere Forschung genïthigt, ansgedehnte Zahlenreihen und deren methodische Terkniipfung zu rerlangen. Noch sind grossentheils die Messmethoden erst zu schaffen, und es läst sich jetzt schon roranssehen, dass unter den verlangten Zahlenreihen manche mur das Ergebniss jahrelanger gewissenhafter Arbeit sein kamn. Allein die Menge der zu iiberwindenden Schwierigkeiten dart uns da am wenigsten entmuthigen, wo ler Weg klar rorgezeichnet ist. - In endloser Ferme steht die Möglichkeit, dereinst die Wachsthumsgesetze organischer Wesen in Formeln niederzuschreiben, und solchei Anssicht gegeniiber tritt einem allerding's unwillkiihrlieh der Spruch v. Baer's ror die Scele: „Die Wissenschaft ist ewig in ihrem Quèll, unermesslich in ihrem Umfang, endlos in ihrer Aufgabe, merreichbar in ihrem Ziele." 


\section{Elfter Brief.}

Die Theorien der Zeugung.

Lieber Freumd! Deu Begimn des gesetzmässigen Keimwachsthums, aus dem alle nachfolgende Formung sich ableitet, mitssen wir auf die Zeî́ verlegen, da Samen und Ei zusammentreffen, da letzteres von jenem befiruchtet wird. Es fïhlurt uns die riiekläufige Verfolgung von den Aufangsbedingmngen jenes Gesetzes zu dem alten, so viẹl und so lebhaft discutirten Räthsel der gessehleehtliehen Zengung. Die Gesehichte der Zengungs- und Entwieklungstheorien reieht bis an die Grä̀nzen des historisehen Alterthums hinan, und nach jeder Riehtıng bildet sie eines der interessantesten Kapitel der Gesehiehte der Wissensehaften. Von bescheidenen Anfängen aus ist der Betrag an grundlegenden thatsiichlichen Kemntnissen, erst langsam, damn, seit den letzten zwei Jahrhunderten, raseher mon in steigender Progression angewachsen, und wir bereits stehen einer Summe von Lirfahrungen gegeniiber, deren Ueberbliek der Einzelne mit Miihe zu erwerben vermag. Wemn nun aber bei alle dem sieh herausstelt, dass iiber das Wesen des Zengungsvorganges hente dieselben grundsätzlichen Differenzen bestehen, welche schon vor 2000 Jahren bestanden haben, mögen wir versucht sein zu glauben, dass ein nach der Riehtung gehendes Streben iiberhaupt hoffinungslos ist, und dass wir am besten thun, dasselbe röllig aufzngeben.

Ein genaneres Studium jedoch der Frage zeigt, dass zu soleh verzweifelnder Haltung noch kein Grund vorliegt. Das dermalen erreichbare Ziel liegt allerdings kanm höher, als in 
einer richtigeren Fragestellung. Allein haben wir eine solche, damn besitzen wir iiberhaupt die Handhabe zur Einordnung des Zengungsvorganges in die Reihe anderer, unserem Verständnisse offener daliegrender Naturvorg̈̈uge.

Eine einl:̈ssliche, auf' die Quellen zuriickgreifende Geschichte der gesehlechtlichen 'Zengungstheorien habe ich vor einigen Jahren in Archiv tüir Anthropologie veröffentlicht, wo Du sie, wem der Gegenstand Dich interessirt, im 4. u. 5. Bande vorfindest. Beilüufig gesagt, wirst Du aus jenen Aufsuitzen entuehmen, dass die, häufig mit scharfen Tendenzhieben versetzten Darstellungen neuerer Handbiicher und populärer Schriften ein durchaus verzerrtes Bild der stattgehabten Kämpfe und vor Allem derjenigen des verflossenen Jahrhunderts geben. Während uns z. B. A. v. Haller nenerdings kurzweg als ein zelotischer Eiferer dargestellt wird, welcher mit seinem tyrannischen Nachtworte Andersdenkende riicksichtslos erdrickt hat, so lerust Du ihn, falls Dir der tief humane Sinn des grossen Hamnes nicht anderweitig schon bekannt sein sollte, gerade in seiner Stellung zur Zengungstrage als ernsten und gewissenhaften Forscher hochschïtzen, welcher immer und immer wieder neue Versuche zu einer, befriedigenden Lösung des iln bearbeitenden Räthsels unternimmt, und welcher auch nicht sich schent, friher verfochtene Meinungen wiederholt zu verlassen, sobald sie ihm mit den Thatsachen nicht mehr vereinbar erscheinen.

Meine Aufgabe in diesem Briefe geht iibrigens weder dalin, historische Gerechtigkeit zur Geltung zu bringen, noch auch dahin, Dir eine Aufzählung der Zengungstheorien nach ihrer zeitlichen Reihenfolge zu geben. Wohl aber wïnsche ich mit Dir die principiellen Standpunkte durchzngehen, die in diesen Fragen eingenommen worden sind, und zu untersuchen, welche derselben iiberhaupt vor unserer hentigen naturwissenschaftlichen Einsicht Stand halten.

Die Zeng'ungstheorien lassen sich, wenn wir auf die, bald dunkel, bald bewusst ilmen zu Grunde gelegten Leitgedlanken zuriickgehen, ziemlich ungezwungen in vier Gruppen unterbriugen. Die den vier Gruppen angehörigen Theorien können wir mit abgekiirzten Bezeichnungen zusammenfassen als : 
Extracttheorien,

Präformationstheorien,

Theorien der , formgestaltenden Kräfte", und

Theorien der iibertragenen Bewegung.

1) Extract he orien. Die Ursache der besondern Form, welche der erzeugte Organismus amnimmt, wird in die Herkunft des zur ersten Bildung verwendeten Stoffes verlegt. Nach dieser Vorstellungsweise lieferm alle Organe des Körpers an die Sexualorgane ihren Beitrag ron entsprechend gearteten kleinsten Bestandtheilen, und im Zusammentreffen dieser letzteren liegen die Bedingungen fiir die Bildmg und fiir die besondere Formung des neuen Kïrpers. Es ist der jugendliche Organismus ein Extract der elterlichen Organismen und darum diesen ähnlich.

Dieser Versuch einer Erklïrung gehört zu den ältesten, die wir kemnen, er findet sich bei Hippoerates selbst, und in psendohippoeratischen Schriften. In der bekamnten, von den Langköpfen unter den Skythen handelnden Stelle der Schrift "iiber Luft, Lage und Wasser" behaupitet Hippoerates, es sei clie, Anfangs künstlich erzengte Langköpfigkeit schliesslich erblich gerrorden, und begriundet dies mit folgenden Worten: „Der Same strönt nämlich ron allen Theilen des Körpers her, mul ist gesund oder mgesund, je nachdem die Theile gesund oder ungesumd sind. Wem num ron Kahlkïpfigen, ron Blanäugigen und Sehielenden ebenfalls Kahlkïpfige, Blanaingige und Sehielende herkommen, und dasselbe anch ron der iibrigen Körperbildung gilt, warum sollte von einem Langkopf nicht anch ein Langkopf entstehen?" - Systematisch durchgefiihrt wird derselbe Gedanke in dem meehten hippoeratischen Buch „de Genitura", dessen Argumente Du am angegebenen Orte nachlesen magst.

In viel späterer Zeit hat sodam B uffon mit seiner Theorie der immeren Nodel (théorie des monles) die Annahme von der Bildung des Embryo ans einem Extracte der elterlichen Organismen wieder anfgenommen. Jeder Thierkörper ist nach ihm ein imerer Model, worin die als Nahrung eingetretene organische Materie geformt wird. Nicht allein formt der Körper als Ganzes, sondern anch jeder seiner Theile, je nach seiner Weise und Gestalt. Der aufgenommene Stoff wird nach An- 
passung an den Hodel nit dessen Substanz identisch und bewirkt dessen Wachsthum. Nach dem Abschluss des letzteren aber bleibt der Ueberschuss nicht mehr in den Organen; sondern wird nach gewissen sammelstellen zuriickgetrieben, und hier bilclen mumehr die organischen Ioleciile kleine Körper ähnlich dem Gesammtkörper. „Denn", sagt Bnffon, „wemn alle Theile des organisirten Körpers organische Theile zuriiekschicken, ähnlich lenen, woraus sic selbst bestehen, so muss aus deren Vereinigurmg nothwendig cin dem Ganzen :ihnlicher Körper entstehen." Die Unmögliclıkeit, sich dies mechanisch zu erklïren, gibt Buffon ausdriicklich zu, allein er hält ein Streben nach mechanischem Verstindniss organischer Formbildung iiberhaupt für eine umnöthige Beschränkung unseres geistigen Horizontes, da ja die organisehe Natur ihre eigenen, ihrer besonderen Substanz zukommenden Krïtte hat.

Die neneste Wiederaufnahme einer solchen Vorstelluugsweise findet sich in der "provisorischen Hypothese der Pangenesis" von Charles Darwin. Den Weg zu seiner Hypothese findet Darwin gleichwie Buffou in der Erfahrung iiber die ungeschlechtliche Fortpflanzung durch Knospung, und im Uebrigen schliesst er an die bekannten Lehren der Zellentheorie an. "Es wird fast allgemein zugegeben", so sagt er, ,dass die Zellen oder Einheiten des Körpers sich durch Theilung oder Proliferation fortpflanzen, wobei sie zunächst dieselbe Natur beibehalten, und sehliesslich in die verschiedenen Gewebe und Substanzen des Körpers verwandelt werden. Aber ausser dieser Vermehrungsweise nehme ich an, dass die Zeilen vor ilırer Umwandlung in völlig passive oder "gebildete Substanz" kleine Körnchen oder Atome abgeben, welche durch den ganzen Körper frei circuliren, und welche, wemn sie mit gehöriger Nahrung versorgt werden, durch Theilung sich vervielfaltigen, und später zu Zellen entwickelt werden können, gleich denen, von welchen sie herriihren. Diese Körnchen könneu der Deutlichkeit halber Zellenkörnchen genanut werden, oder, da die Zellentheorie nicht vollständig begriindet ist, einfach Könchen. Es wird angenommen, dass sie roin den Eltern den. Nachkommen iiberliefert und meist in der Generation, welche ummittelbar folgt, entwickelt, aber oft in cinem schlummernden Zustande viele Generationen hindurch 
iiberliefert und dann erst entwickelt werden. Es wird angenommen, dass ihre Entwicklung ron der Vereinigung mit anderen theilweise entwickelten Zellen oder Körnchen ahhängt, welche ihnen in dem regelmässigen Verlaufe des Wachsthums roransgehen. Es wird ferner angenommen, dass Körnchen nicht blos an jeder Zelle oder Einheit wïhrend ihres erwachsenen Zustandes, sondern wïhrend aller Entwicklungszustiinde derselben abgegeben werden. Endlich nehme ich an, dass die Körnehen in ihrem schlummernden Zustande eine gegenseitige Verwandtschaft zu cinander haben, welche zu ihrer Aggregation entweder zu Knospen oder zu den Sexualelementen fiihrt."

Darw in iiberträgt demzufolge in seiner Hypothese das Prineip der Erblichkeit aus dem, mnseren Sinnen zugänglichen Gebiete griberer Formen in das, nur dem Gedanken zugängyliche Gebiet der Moleciile, anf welchem Bodeu wir immer wieder der Nothwendigkeit einer Erkliirung gegeniiberstehen. Allein wollten wir davon absehen und wollten wir selbst die Möglichkeit zugeben, jede Ganglienzelle bilde ihre Ganglienzellenkeime, und gebe je nur einen an cinen nenen Gesammtkeim $a b$, und dasselbe grelte ron jedem andern unserer Elementarbestandtheile, so bleibt stets noch sicher, dass eine Summe von diminutiven Theilrepräsentanten oder von Organsplittern nicht ein diminntives Ganzes liefern wird, sondern ein regelloses Gemenge, das anf den Namen eines Organismns keinen Anspruch machen darf.

Es wird Dich interessiren die Kritik zn lesen, welche auf die ähnliche Hypothese semer Zeitgenossen Aristoteles geschrieben hat, und ich theile Dir einige der hauptsächlichsten Sätze daraus mit: "Erstens", so sagt er in seiner Schrift ron der Erzengung der Thiere, ,. ist die Aehnlichkeit kein Beweis dafür, dass der Same rom ganzen Kïrper herkommt, da die Abkïmmlinge auch in der Stimme, den Nïgeh, Haaren und in der Bewegung ähnlich sind, von welchem allen doch Nichts herkommt. Manches haben anch die Eltern noch nicht zu der Zeit, wo sie erzengen, z. B. die granen Haare oder den Bart. Ferner gleicht man den Grosseltern, ron welehen niehts hergekommen ist. Demn die Achnlichkeiten pflanzen sich durch mehrere Geschlechter fort, wie dies in Elis bei einen Mäd- 
chen der Fall war, welche mit einem Mohren Ungang hatte, indem nicht ihre Tochter, sondern der Sohn der letzteren von schwarzer Farbe war. Dasselbe Verhältniss zeigt sich anch bei den Pflanzen, bei denen ja offenbar der Same auch von allen Theilen herkommen wiirde. Viele Pflanzen haben aber manche Theile gar nicht, manche kann man hinwegnehmen und manche wachsen nach. Ferner kamn anch der Same nicht von den Fruchthiillen herkommen, und doch zeigen auch diese dieselbe Gestalt. Feruer muss man fragen, kommt der Same nur ron einem jeden der Gewebe (gleichartigen Theile), als da sind Fleisch, Knochen, Sehnen, oder kommt er auch von den Organen (ungleichartigen Theilen), z. B. dem Gesicht und der Hand? Demn nimmt man an, dass er nur von jenen kommt, so gleiehen die Abkömmlinge doch gerade mehr in letzteren den Eltern, in Gesicht, an den Händen und Fiissen. Riihrt also die Aehnlichkeit in den Organen nicht davon her, dass der Same von allen Bestandtheilen kommt, so ist nichts entgegen, dass anch die Aehnlichkeit in den Geweben nicht davon herriihrt, dass der Same vom ganzen Körper herkommt, sondern von einer andem Ursache. Nimmt man aber an, dass er nur von den Organen herkommt, so gibt man zu, dass er nicht von allen Bestandtheilen herkommt. Richtiger wäre, dlass er von den Geweben herkommt, dem jene sind friiher rorhanden, und die Organe sind aus den Gerveben zusammengesetzt, und die Achnlichkeit im Gesicht und in den Händen ist nicht ohne die in Fleisch und in den Nägehn. Nimmt man aber drittens an, der Same komme von beiden Ordnungen von Bestandtheilen, wie sollte damn die Erzeng'ung stattfinden? demn die Organe sind ans den Geweben zusammengesetzt. Küime also der Same von diesen, so lhiesse dies so riel, als dass er ron jenen und ron ihrer Zusammensetzung herkomme. Man rergleiche den Ḱörper mit einem Namen, kommt etwas ron dem ganzen Namen, so kommt es ron jeder Silbe, und kommt es ron diesen, so kommt es auch ron den Buchstaben als den Elementen der Silben, und ron deren Zusammensetzung. Wenn also Fleisch und Knochen ans den Elementen bestehen, so wiirde man bis anf clie Elemente znriickgehen miissen, denn wie wäre es möglich, dass der Same aus der Zusammensetzung herkäme? und doch kïnnte olme 
diese keine Aehnlichkeit stattfinden. Wenn aber irgend ein Späteres die Znsammensetzungewerkstelligt, so wird dieses die Ursache der Aehnliehkeit sein, nicht aber dass der same rom ganzen Kïrper herkommt."

2) Präformationstheorien. Die Forn wird als das von vornherein Gegebene und nicht weiter zu Erklïrende angesehen. Das vorgebildet angenommene junge Wesen bedarf zum Wachsthum nur der Erweckung zum Leben durch einen passenden Reiz und durch cine entsprechende Nahrumg. Dieser Gedanke bildet, wie Du weisst, den Kern der von S' wammerdam zuerst ansgesprochenen Evolutionstheorie, der allgemeinst verbreiteten Theorie des vorigen Jahrhunderts; in entspreehend veränderter Gestalt kehrte er anch in einigen der Spermatistentheorien wieder. Es ist iiber diese Theorien und speeiell iiber die Evolutionstheorie so oft und streng der Stab gebroehen worden, dass wir uns ersparen kömnen, anch unsererseits mit ihnen ins Gericht zu gehen. Wenn wir iiberdies wahrnehmen, dass gerade die hervorragendsten embryologischen Beobachter, ron Swammerdam und M alpighi ab bis auf $\mathrm{Hallel}$ und Spallanzani Evolutionisten gewesen sind, so muss uns dies in minerem Urtheile zur Vorsicht stimmen. Und in der That zeigt sich bei genanerer Analyse der beziiglichen Arbeiten, dass dic Beobachtung des, der Mutter entstammenden Keimes den thatsïchlichen Boden aller evolutionistischen Vorstellungen bildet, und dass eben dieser Berbachtung die letzteren den bedentenden Vorsprung verdankt haben vor allen epigenetischen, den Embryo aus flissigem Material erzeugenden Theorien. Die Auffassung des Keimes als einer zwar organisirten, aber morphologiseh noch ungeglierlerten Anlage des zuliunttigen Wesens lag den Forschem jener Perioden fern, und so glaubten sie da, wo sie den präiexistirenden Keim auftanden, sofort auch seiner rerwickelten Gliederung gewiss zu sein. Den Berobachtungen von C. Fr. Wolff war es rolbehalten, nachzuweisen, dass die Entwicklung des Körpers nur durch die Stufen grober Anfangsskizzen hindurch zu denjenigen feinerer Ausbildung fortschreitet. Mit dieser Erkenntniss hat Wolft den wichtigsten Grund zur Keimlehre grelegt. Auch ihm ist es jedoch nicht gelungen, im gleichen Wurfe 
der Frage ihre lüsende Fassung zu geben. Erst mit den Arbeiten ron Baer's und mit Schaffung der 'Zellentheorie ist dic Formel gefunden worden, welehe iiber diese Klippe hinweggeholfen hat.

3) Die Theorien "formgestaltender Kräfte". In minder klaren Anfängen mögen wohl schon bei Aelteren hieher gehörige Anschaumugen aufzufinden sein. Scharf ausgesprochen findet sich die Annahme formgestaltender Kräfte zuerst bei einigen Epigenesisten des vorigen Jahrhunderts, vor allen bei Maupertu is und bei Turberville Needham.

Die geistreichen Anfsätze des Ersteren verdienen auch in unserer Zeit alle Aufmerksamkeit, denn nicht allein enthalten sie interessantes Material zur erl)lichen Uebertragung von Abnormitäten, sondern es entwickelt in ihnen M a upertu is sehon in sehr klarer und nicht zu missverstehender Weise das Princip der Speciesbildung anf dem Wege natïrlicher und kiinstlicher Ziichtung, wobei die geschlechtliche Zuchtwahl ausdrücklich mit hereinbezogen wird. Als feiner Hofmann weiss er die Darstellung seiner Anschaumgen in ein Compliment auf Friedrich den Grossen und auf die Entwicklung Prenssens auslaufen zu lassen. In speciellen Sachen der Zengungstheorie war Maupertu is vor Allem ein Gegner der Erolutionslehre, und als soleher hat er nach einem Auswege gesucht zur Erklärung organiseher Formbildung ohne Präformation. Er sucht ihn in einer Parallele mit Krystallisationsverhältnissen und besonders mit der zierlichen Formbildung des sog. Dianenbaumes. Er denkt sich in dem Gemenge männlicher und weiblicher Samenfliissigkeit wie in der Krystallisationslange eine Kraft wirksam, nnverständlich zwar in ihrem Ursprung, aber doch vor unseren Angen thätig, welche als anziehende je die Theile zusammenfiihrt, welche zur Bildung eines Organs zusammengehören. Dabei ist er allerdings genöthigt, den in der Fliissigkeit enthaltenen Theilchen noch besondere Verwandtschaft zu den gleichartigen Theilchen zuzuschreiben. Jene enthält daher sich gegenseitig' anziehende 'Theilchen zur Herzbildung; solche zur Kopfbildung, zur Eingeweidebildung u. s. W., womit im Grunde an die Stelle der einen formbildenden Kraft eine Reihe besonderer Anziehmingkriafte gesetzt wird.

Bei Maupertuis' Zeitgenossen, dem englisehen Jesuiten 
T. Needham, tritt der Gedanke in den Vordergrumd, cinen, der organischen Materie inhärirenden, wechselnder Steigertung fähigen Wachstlumstrieb als formbildendes Princip einzufiihren. Needham's Conceptionen, obwohl nicht ohne entwicklungsfähige Gesichtspunkte ${ }^{1}$ ), haben geringen Einfluss gewommen, weil sie ron ihrem Urheber zu wenig klar durchgearbeitet worden sind.

In die Kategorie formgestaltender Kriatte fällt anch die Vis essentialis ron C. F. Wolft. Als solche bezeichnet Wolff eine, in ihren Wirkungen determinirte kraft, welche nach ihm fortwährend die Excretion nener Theile aus bereits vorhandenen veranlasst. Durch die Vis essentialis wird nämlich vorhandenen Theilen neuer Saft zugefïhrt, dieser wird an der Oberfläche als Tropten ausgesehieden, erstarrt sodann, und ist num seinerseits wieder zur Ausscheidung nener Theile befähigt. Wenn Du Wolff' gewöhnlich als Epigenesisten autgefiihrt findest, so darf'st Du doch die Khuft nicht iibersehen, die ihn vỏn den meisten iibrigen Epigenesisten trennt. Denn während diese den Körper in der Regel frei in einem fliissigen Gemenge organischer Materien haben entstehen lassen, setzt seine Theorie vom Ei zum Organismus und rom Organismus wiederum zum Ei eine geschlossene Kette aneinander gereihter Wachsthumsrorgäinge roraus. Wo lff hat iibrigens in späterer Zeit auf seine Vis essentialis offenbar kein Gewicht mehr gelegt, dem in seiner wichtigsten Schrift, , ïber die Bildung des Darmkanals", gedenkt er derselben ebensowenig, als seiner Excretionstheorie, welch letztere mit seinen neuen Beobachtungen anch in der That nicht mehr in Uebereinstimmung zu bringen war.

Unter der Bezeichnung Bildungstrieb oder $\mathrm{X}$ isus formatirus hat gegen Ende des rorigen Jahrhunderts J. Fr. B I ume nbach ein formbildendes Princip) in die Zengrungslehre eingefiihrt, und damit rlen iiberlebten Präiformationstheorien gegeniiber solchen Erfolg erzielt, dass ihm der äussere Rulm von deren Besiegung zuf:̈llt. Für die damalige Zeit war das nene Prineip in der Thai ein grosser Fortschritt, und man wiirde Blumenbach ungerecht beurtheilen, wollte man ron ihm die Schärfe phýsiologischer Auftassung verlangen, wie sie erst als Frucht nenerer Arbeiten möglich geworlen ist. Seine 
Ueberzengung spricht er also aus: "dass in dem rorher rohen ungebildeten Zeugungsstoffe der organisirten Körper, nachdem er zu seiner Reife und an den Ort seiner Bestimmung' gelangt ist, ein besonderer, damn lebenslang thätiger 'Trieb rege wird, ihre bestimmte Gestalt Anfangs anzunelimen, dam lebenslang zu erhalten, und wenn sie je etwa rerstimmelt worden, wo möglich wieder herzustellen." Es ist bemerkenswerth, dass Blumenbach das Wort ,Trieb" anstatt des, von Andern soviel missbrauchten Wortes "Kraft" angewendet hat. Der Grund, den er dafiur latte, war indess nicht derselbe, aus welchem wir heute rermeiden von einer Lebenskraft zu spreehen. Ausdriicklieh bezeichnet er den Bildungstrieb als zu den „Lel,enskräften " g’ehörig, deren er noch mehrere Arten, die Contractilität, Irritabilitait und Sensibilität aufzählt, und er hat sein Wort nur deshalb gewählt, um das bildende Princip der organisehen Natur von den auch den unorganisehen Natur zukommenden, die oft so zierlichen Krystallformen erzengenden "Bildungskräitten" zu unterscheiden.

Der Kampf um die Existenz oder Nichtexistenz einer Lebenskraft ist in unser Aller Erimnerung und, wenn wir ihn nicht mehr mitgek:impft haben, so sind wir doch noch grossentheils dessen Zengen gewesen. Gegeniiber der Einfuihrung selıarfer physikalischer Begriffe in die Physiologie hat wenigstens der Name einer Lebenskraft nicht Stand zu lialten vermocht; ob ron dem friiheren Inhalte des Begriffes Einiges unter sehärferer Fassung und unter zeitgemässer Benenuung wiederbelebbar ist, mag vorerst unerörtert bleiben. Mit der' Lebenskraft sollten, wie man erwartet, anch die formgestaltenden Kräfte aus der Literatur geschwunden sein, da sie als Theilkräfte mit ihr stehen und fallen mussten. So rasch jedoch klären sich die Begriffe nicht, und Du begegnest pietätvollst gehegten Reliquien des Vitalismus, wo Du sie dem Aenssern nach am wenigsten suchen wiirdest. So meint einer unserer thäigsten juingeren pathologischen Anatomen, dass im Keime , immanente, dureh Züchtung erworbene formgestaltende Kräfte rorhanden sind, welche, auch unter ungiinstigen äusseren Bedingungen, wemn auch in modificirter Form, die Entfaltung desselben zur typisehen Bildung des Organismus bedingen. " ${ }^{2}$ ) .

Was will der Verfasser mit solchem Satze sagen? Er 
richtet sich speciell gegen diejenigen, welehe organische Formen mechanisch abzuleiten versucht haben, und so beabsichtigt er vielleicht anszudriicken, es sei dies noch nicht durchweg grelnugen. Gut! weshalb wird uns denn aber unter dem Schein einer Erklärung von "formgestaltenden Kräiten" gesprochen, da doeh das Wort "Kraft" liingst seine ganz bestimmte Verwendung in der theoretischen Mechanik gewonnen hat, und da es hier nie etwas Anderes, demn ein gegebenes Element der Rechnung bedentet. Ans der Mechanik herausg'enommen, zur Erklailung eines beliebigen dunkeln Vorgangs verwendet, bei dem uns alle Elemente der Rechnung, Grössen, gegenseitige Abstände und Geschwindigkeiten der bewegten Massen unbekannt sind, rerliert das Wort seine wissensehaftliche Bedeutung. Dic angebliche Erklärung besagt alsdann gerade nur, dass der dunkle Vorgang seme Ursachen hat.

Von „formbildenden Krïtten " orler von "Gestaltungskrätten "spricht in seinen verschiedenen Publicationen auch der gelehrte Verfasser der natiurlichen Schöpfungsseschichte. Er unterscheidet eine "imnere Gestaltungskraft", die Erblichkeit, und eine "äussere ", die Anpassung. Immerhin lässt er es nicht bei dieser Bezeichnung bewenden. Er fiihrt uns die Erblichkeit und die Anpassung anch ror als die ,formbildenden Funetionen der Organismen", oder als deren "Bildungstrieb", und dann wiederum als ihre "fundamentalen Lebenserseheinungen ", als ihre "plyysiologischen Grundeigensehaften", stets aber" als die "Cansae efficientes oder die wahren Ursachen organischer Körperform." - Wo die Anstriicke also sprudeln, dass sie auf' derselben Seite, oder selbst im gleichen Satze sich dräingen, da erscheint es wiinschbar, den Grundbegriffen nachzngehen, welche sich der Verfasser rom Wesen des Lebens und von seinen gestaltbildenden Leistungen grebildet hat.

"Geist" und "Seele", so ruft er uns am Schlusse seiner" soeben erschienenen Anthropogenie zu, sind nur höhere und combinirte, oder differenzirte Potenzen derselben Function, die wir mit dem allgemeinsten Ausdruek als „Kraft" bezeichnen, und die Kraft ist eine allgemeine Function aller Materie. Wir kennen gar keinen Stoff, der nicht Kraitte besissse, und wir kemnen umgekehrt keine Kriifte, die nicht an Stoff gebunden sind. Wenn die Krifte als Bewegnng in Erscheinmo treten, 
nemen wir sie lebendige (aetive) Krifte oder Thatkrïte; wemn die Kräfte lingegen in Zustand der Ruhe oder des Gleiehgewichtes sind, nemmen wir sie ge b un d e ne (latente) oder Spannkräte. Das gilt ganz ebenso ron den anorganischen, wie ron den organisehen Naturkörpern. Der Magnet der Eisenspä̈hne anzieht, das Pulrer das explodirt, der W' asserdampf der die Locomotiven treibt sind lebendige Anorgane; sie wirken ebenso durch lebendige Kraft, wie die empfindsame Mimose, die bei der Beriuhrung ibre Blätter zusammenfaltet, wie der ehrwiirdige Amphioxns, der sich im Sand des Neeres rergrähbt, wie der Mensch der denkt."

.:Unsere Anthropogenie hat uns zu dem Resultate gefiihrt, dass auch in der gesammten Entwicklungsgesehichte des Henschen, in der Keimes-, wie in der Stammesgeschiehte keine anderen lebendigen Kräfte wirksam sind, als in der iibrigen organischen und unorganischen Natur. Alle die Kräfte, die dabei wirksam sind, konnten wir zuletzt auf das Wa chsthum zuriickfiihren, anf jene fundamentale Entwickelungsfunction, durch welche ebenso die Formen der Anorgane, wie der Organismen entstehen. Das Wachsthum selbst beruht wiederum anf Anziehung und Abstossung gleichartiger und ungleichartiger 'Theilchen. Dadureh ist ebenso der Menseh, wie der Affe, ebenso die Palme, wie die Alge, ebenso der Krystall, wie das Wasser entstanden. Die Entwicklung des Menschen erfolgt demgemäss nach denselben .. ewigen ehernen Gesetzen ", wie die Entwicklung jedes andern Naturkörper's. Dureh die definitive wissenschaftliche Begriundung dieser monistischen Erkemntniss thut unsere Zeit einen unermesslichen Fortschritt in der einheitlichen Weltanschaumg u. s. w."

$\mathrm{Wo}_{0}$ in aller Welt, so fragst sicherlich anch Du, ist im Jahre 1874 das Publicum zu finden, welehes in diesem Wortschwall des Herm Häekel Sim zu finden rermag? Wo die Gebildeten denen die "höher combinirte und differenzirte $\mathrm{P}_{0}$ tenz der Kraft" als tiefsimnige Lösung des uralten Räthsels rom Wesen des Bewusstseins imponirt? Wo die angehenden Naturforseher und Vediciner, welche man im Unklaren dariber gelassen hat, ob im Weltall andere Bewegungsrorgäinge vorkommen, als solehe die auf Anzielıungen und Abstossungen ron Massentheilchen sich zuriickfiilnren, und denen Haickel's 
Anziehungen und Abstossungen gleichartiger und ungleichartiger Theilchen tiil eine meehanische Erklärung des Wachsthums und der organischen Formbildung geiten diirfen?

Und nun gar die Erörterungen uiber "l le ben di g e Kr äfte"! Bei keinen Geringeren als bei Helmholtz hat Verfasser, seinem Citat zufolge, iiber dies Wort sich unterriehtet, und num stellt er uns sofort im Palver und im Wasserdampt "lebendige Anorgane" vor, "welche ebenso durch lebendige Kraft wirken, wie die emptindsame Mimose und wie der ehrwiurdige Amphioxus." Es ist dies ein Wortspiel, so zierlich, dass man an einen Scherz zu glauben versucht ist. Oder sollte es wirklich Herm Häekel mbekannt sein, dass die "lebendige Kraft" der theoretisehen Mechanik $\left(\begin{array}{c}m v^{2} \\ 2\end{array}\right)$ mit der Erklärung der Lebensvorgäinge niehts zu thun liat, da sie das Maass bedeutet, nach welchem das Arbeitsvermögen bewegter Mássen gemessen wird, ğleiehgiltig. welches im Uebrigen die Ursache der Bewegung gewesen sein mag??

Folgen wir unserm Autor einen Schritt weiter und untersuehen wir seine Stellung zu der Frage von der Uebertragung elterlicher Eigenschaften auf den Keim! „Wir haben zu unterseheiden", so heisst es im aehten Vortrage seiner natiirliehen Schöpfungsgesehiehte, „zwischen der Erblichkeit und der Vererbung. Die Erblichkeit ist die Vererbungskraft, die Fäh i goke it der Organismen ihre Eigenschaften auf ihre Nachkommen durch die Fortpflanzung zu ïbertragen. Die Vererbung bezeiehnet die wirkliche Ausiibung dieser Fähigkeit, die thatsächliche Uebertragung." Es wird uns nun an Beispielen die Wirkung der "Vererbungskraft" klar gemacht, wir erfahren von der Vererbung der Sechsfingrigkeit, von der Familie der Stachelsehweinmenschen, von der Erbsünde, dem Erbadel u. s. w., nehmen in einem folgenden Absehnitte die Erörterung der neun, theils conservativen, theils progressiven "Vererbungsg'esetze" entgegen, als da sind: das Gesetz der ununterbroehenen, der unterbrochenen, der sexuellen, der amphigonen, der abgekiirzten, der angepassten, der befestigten, der homochronen und der homotopen Vererbung: Unsere Aehtung vor dieser Reihe wird allerding's etwas herabgestimmt, wemn wir erfahren, dass einzelne dieser "Gesetze", mit andern "g'ewisser- 
maassen in Widerspruch stehen." Bedenken wil iiberdies, dass kein einziges dieser Gesetze uns im concreten Fall eine bestimmte Voranssage des eintreterden Zengungserfolges gestattet, so sagen wir uns, dass Häckel sicherlich besser gethan hïite, seine sogen. Vererbungsgesetze als blosse, durch die Erfahrung ermittelte Modalitïten der Vererbung zu bezeiehnen. Er liätte es alsłann der Zukunft iiberlassen diürfen, die Gesctzmässigkeit in den Bedingungen ihres Anftretens festzustellen, und uns damit die noch unbekannten Gesetze der Vererbung zu enthiillen.

Nicht bei den Gesetzen allein verbleibt es indess bei Häckel, er gibt uns anch ohne alle Schwierigkeit eine Erklärung der Vererbug. Es wird uns zunïchst am Beispiel der einzelligen Organismen gezeigt, dass sie durch Theilung: sich fortpflanzen. .. Wenn Sie nun zunïchst diese einfachste Form der Fortpflanzung, die Sellsttheilung betrachten, so werden Sie es gewiss nicht wunderbar finden, dass die Theilproducte des urspriinglichen Organismus dieselben Eigenschaften besitzen, wie das elterliche Indiridum. Sie sind ja Theilhälften des elterlichen Organismus, und da die Materie, der Stoff in beiden Hailften derselbe ist, da die beiden jungen Individnen gleich viel mul gleich besehafiene Materie ron dem elterlichen Oruanismus iberkommen laben, so finden Sie es gewiss natuirlich, dass auch die Lebenserscheinungen, die physiologischen Eigenschaften in beiden Kindern dieselben sind. In der That sind in jeder Beziehmug, sowohl hinsichtlich ihrer Form und ihres Stoffes, als auch hinsichtlich ihrer Lebenserscheinmgen die beiden Tochterzellen nicht ron einander und von der Mutterzelle zu muterscheiden. Sie haben von ihr die gleiche Natur" geerbt."

Non werden die rerschiedenen Formen ungeschlechtlicher und geschlechtlicher Zeugung in eine Reihe gestellt und schliesslich fiü alle der obige Schluss wiederholt, "In allen Fällen ditrfen wir daher ron rornherein schon erwarten, dass die kindlichen Individnen, die ja, wie man sich ausdriickt, Fleisch und Bein der Eltern sind, zugleich immer dieselben Lebenserscheinungen und Formeigenschaften erlangen werden, welche die elterlichen Indiriduen besitzen. Immer ist es nur eine grössere oder geringere Quantitiit ron der elterlichen Materie 
und zwar ron dem eiweissartigen Protoplasma, welehe auf das kindliche Individum uibergeht. Mit der Materie werden aber auch deren Lebenseigenschaften, die molecularen Bewegungen des Plasma iibertragen, welehe sieh dann in iluer Form äussern."

Nach Molière's mrerfänglichem Zengnisse hat einst bei der Frage iber die Ursache der schlaferzengenden Eigensehaften des Opiums ein Doctorand das höchste Lob seiner Facultait erworben dureh die Antwort:

Quia est in eo

Virtus dormitiva,

Cujus est natura

Sensus assoupire!

Heute geht die Frage nach der Ursache der form- und ähnlichkeiterzengenden Eigenschaften des Keimprotoplasmas, und aus dem Kreise der Facultätsdoctores selbst erfolgt die Antwort:

\section{Quia est in eo \\ Virtus formativa. \\ Cujus est natura \\ Formam recreare!}

Wie clamals der Chorus der Doctores, so hat jetzt, ob der gliicklichen Erklärung, derjenige der Scholares in das fieudige Bene, bene, bene! einzustimmen. All jene Worte, welche ein wissenslurstiges Her'z zu stärken vermögen: elterliche Materie, moleeuläre Bewegung'en, Lebenseigenschaften, Eiweiss, Form und Protoplasma kommen zur Verwendung. "Misee, fiat explicatio!" so lautet das erkenntnissbringende Recept unseres greschickten Doctors, und auf cinen Schlag eröffnet es die Angen fiir alle Geheimisse der Zengug und des Lebens. 


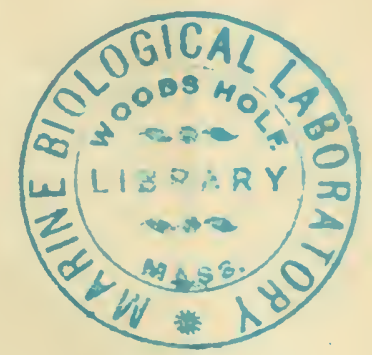

\section{Zwölfter Brief.}

Die Theorien der übertragenen Bewegung.

Lieber Freund! Dic Vorstellungen über die Ursachen organischer Formbildung, welche in meinem letzten Briefe besprochen worden sind, haben sich sämmtlich als unhaltbar erwiesen. Bei weiterer Y'erfolgung filhrt uns jede derselben unrettbar in eine Sackgasse hinein, und in Widerspriiche mit den allerersten Elementen naturwissenschaftlicher Einsicht. Zum Theil erweisen sie sich geradezu als Wortspielereien, die nicht verdienen, dass man sie iiberhaupt Hypothesen nennt, da sie nur darauf ansgehen, klingende Worte an die Stelle einer Erklïrung zu setzen. Sehen wir zu, ob nach einer andern Richtung ein Ausweg winkt, und betrachten wir hente

die Theorien der übertragenen Bewegung, zu welchem Zwecke wir etwas weiter anszuholen haben.

Wo nur unser Auge dem Naturlaufe mit Aufmerksamkeit folgt, da begegnet es Vorgängen von Bervegung, die unter sich derart verkniipft sind, dass Bewegung an Bewegung sich anschliesst, und die gesanmte Kette ron uns nicht anders, demn als eine einheitliche Erschcinung wahrgenommen, und bezeichnet wird. Wenn wir von einem Strome, oder von einer Flamme sprechen, da rerbinden wir mit dem Worte die Vorstellung gewisser Sinneswahrnehmungen, die das fliessende Wasser, oder die bremnende Kerze in uns erregt; nur ausnahmsweise, und jedenfalls nur durch das Bediirfiniss wissenschaftlichen Denkens gedrängt, geben wir uns Rechenschaft von der Summe verwickelter Bewegungen, welche das eine wie das andere Wort zusammenfasst. Oder wenn wir von einer Welle sprechen, so denken wir zunächst an die sanftgeschwungene Form, welche 
die Oberflache einer bewegten Wasserflïche darbietet, an das allmählige Weiterschreiten der Form von dem Punkte der ersten Entstehung zu immer entlegeneren Punkten hin, an das Plätschern des an das Ufer anschlagenden Wassers u. s. f., allein der Gedanke an die, der Zeit nach sich ablösenden Bewégungen der einzelnen Wassertheilehen, an die vou ihmen durchlaufenen Bahnen, oder an die Zu- und Abnahme ihrer Geselıwindigkeiten liegt mus ferne, und auch hier gelangen wir mur auf dem weiten Umwege physikalischer Untersuchung zur Erkenntniss dieser Grundvorgainge. In allen diesen Fällen folgt die Verkniipfung der Bewegung irgend einem, ihren Fortgang ausdrickenden Gesetze. Wir haben sonach Gesetze doppelter Art zu mnterscheiden :

1) fimdamentale Gesetze, welche bis jetzt der einfachste Ausdruck sind fiir das Wesen der Krïfte (Newton'sches Gravitationsgesetz).

2) Specialgesetze, welche die Regelmässigkeit ausdriicken der, dureh irgend welche jener Fundamentalkräfte erzengten Bewegungsvorgïinge (Fallgesetz, Gesetze der Wellenbewegung II. S. W.).

Einen Beweg"ungsvorgang, welcher einem solchen Speeialgesetze folgt, wollen wir mit dem allgemeinen Namen Process bezcichnen. Proeesse einfacherer kümnen zu solchen verwickelter Art sich combiniren, fiir welche eomplieirtere Gesetze Platz greifen. Die Zahl der in der Natur ablaufenden Processe ist unendlich gross; auch das organische Leben ist solch ein Process, und zwar ein soleher eomplicirtester Art. Als dessen näehste Glieder können wir die Processe der Athmung, der Ernährung, des Wachsthums u. s. w. ansehen.

Wie nach dem Grade der Verkniipfing; so kömnen auch nach der Art ihres zeitlichen Ablanfes Processe in das Unendliche variiren. In einer grossen Zahl von Fällen ist ihr Ablauf der Art, dass während längerer Perioden die Bewegung fortwährend anf neue Theilehen sieh iiberträgt, die nun ganz denselben Process durehmachen, wie diejenigen, an deren Stelle sie getreten sind. Eine ruhig bremnende Flamme gibt Dir ein Beispiel eines solchen gleiehmässig fortlanfenden Processes. - Oder, es bringt die Verkniipfung der Bewegungen mit sich, dass in bestimmten, unter sieh gleichen Zeitabsehnitten 
gleiche Bewegmugsvorginge wiederkehren. Dies gilt von den verschiedenen Arten ron Wellenbeweg'ung' und bekamntlich heissen die hierher gehörig'en Processe periodische.

Fíl uns ist es nun ror Allem wichtig, uns die Beziehungen klar zu machen zwisehen Process und Form. Lnter Form verstehen wir, dem urspriinglichen Wortsimn zufolge, die unseren Sinnen (zunächst dem Auge und weiterhin dem Tastsinu) wahmelmbare räimuliche Anordnung der Theile eines Gebildes. Bildlich wird das Wort allerdings noeh weiter ausgedehnt, so spricht der Philosoph von der Form einer Vorstellung, der Mathematlker von der Form einer Gleichung. Es sind dies die iibertragenen Anwendungen des Wortes, welche, wie andere ähnliche Uebertragungen, abstracte Verhältnisse durch sinnliche Veranschaulichung unserem Verständniss nahe zu bringen suchen.

Ein jeder Process als massenbewegender Vorgang ist insoweit formerzengend und formverändernd, als dic von ihm herbeigeführte Anordnung von Massen von unseren Simnen, und zwar speciell von unserem Auge können wahrgenommen werden. Nur mittelbar und in groben Ziigen gibt uns die Form Auskunft iiber die ihr zu Grunde liegenden Proeesse. Den arbeitenden Telegraphendrath halten wir fiir eine ruhende Masse, und selbst die brennende Flamme kann uns das Bild einer feststehenden Form gewähren. Im ersteren Falle läuft der Process im Gebiete moleculären Gesehehens ab, und lässt die, unserem Ange allein zugüngliche gröbere Massenanordnung unver:indert; im zweiten Falle werden zwar fortlaufend nene Massen in den Proeess hereingezogen, allein gleichmässig. läuft der letztere $a b$, und erhält eine constante Anordnung zum Leuehten erhitzter Theilcheı. Es ist, um einen Vergleich zu bratehen, die Form einc Uebersetzung aus der uns unleserlichen Sprache des wirkliehen Gesehehens in unsere Sprache der Sinneswahrnehmung, eine Uebersetzung mannigfach verzerrt, und jedenfalls in hohem Grade unvollständig, welche das Wesentlichste in vielen Fällen auslässt, um Unwesentliches mit vordraingender Breite zu behandeln.

So ist denn unsere eigene Körperform die äusserliche Kundgebung eines zusammenhängenden, gesetzmässig ablaufenden Proeesses. Mit allen Hiilfsmitteln mechanischer und opti- 
scher Technik suehen wir die Formen und deren zeitlichen Veränderungen bis in ihr feinstes Detail festzustellen, um daraus soviel, wie nn1 immer möglich, von dem Lebensprocesse selbst herauszulesen, und doch bleibt unsere Ausbente ein diurftiges Stückwerk gegenüber dem von uns erstrebten Ziele. Wir sehen die Bewegungen unserer Gliedmassen, wohl auch die Verkiilzung der einzelnen, das Glied bewegenden Muskeln, wir sehen aber nichts von dem der Muskelverkiirzung zu Grunde liegenden Vorgange. Wir sehen die Bewegung des Blutes in den Adern, wir sehen aber nichts von jenen umfangreichen Stoffbewegungen, welche wir unter der Gesammtbezeichnung der Errährungsvorgänge zusammenfassen. Wir sehen die äusseren Formen des Gehirns und des Riickenmarkes, die Form der in ihnen vorhandenen Zellen und die Verlaufsrichtung. ihrer Fasern; allein dabei fehlt uns jeder Einblick in die materiellen Vorgänge einfachster Nervenleitung, geschw eige denn in diejenigen, welche mit dem Ablaufe unserer Gedanken verkniipft sind. Als ruhende Massen, wie der Telegraphendrath, oder richtiger vielleicht wie die stätig brennende Flamme erscheinen uns die Gewebe unseres Körpers, in ihren Formen Nichts von dem Stoffstrome verrathend, dem sie Dasein und Dauer verdanken.

Eine Kategorie von Vorgängen hebt sich durch ihre äusserlich wahrnehmbaren Folgen ans der Reihe der iibrigen hervor, es sind dies die Vorgänge des Wachsthums. Wir kennen das Wachsthum nur aus seiner Aensserung, der Massenzunahme; seine inneren Bedingungen, seine Beziehungen zu anderen Lebensprocessen, speciell zu denjenigen der Ernährung kennen und verstehen wir nieht, und werden wir auch sobald nicht verstehen. Das Wachsthum als Theilprocess des Gosammtlebens ist in keiner Weise eine formbildende Kraft, wohl aber ein formbildender Process, auf den wir immer und immer wieder behufs Ableitung der Form zuriickzugreifen haben. Wenn der Keim als Ganzes wächst, wenn die aus ihm abgegliederten Organanlagen zu wachsen fortfahren, erst rasel, dann langsamer, bis sie nach abgemessener Zeit ein abgemessenes Maass erreicht haben, so haben wir darin die Aensserung eines Processes vor uns, welcher im miitterlichen Ei begimmend, und durch die Befruchtung rasch gesteigert nach streng 
geordneten Gesetzen abläuft, gleich der ïber den Wasserspiegel sich erhebenden Welle. Da wie dort sind es die Anordnung der zu bewegenden Massen und die Modalitäten der ersten Erregung; welche das Gesetz des gesammten Herganges bestimmen. Ich sage der Erregung und nicht des Anstosses, denn wenn wir unter Stoss die einfache in einem Zeitelemente geradlinig' wirkende Kraftwirkung verstehen, so bediurfen wir eines Wortes, welches, entsprechend dem Worte Process, eine, laut bestimmtem Principe nach Raum und nach Zeit geordnete Summe von Stössen umfasst. Dafür scheint mir unter den noch verfuigbaren Worten das Wort Erregung das passendste zu sein. Es bedarf kaum eines besonderen Hinweises darauf, wie das Gesetz, dem die Erregrung folgt, fiir den Hergang des nachfolgenden Processes bestimmend ist. Ein einfacher Stoss auf eine Wasserfläche, wie er rom fallenden Steine ausgeht, gentigt zur Erzengung einer Welle, und Du erhältst in dem Falle eine einfache, gleichmässig (nach dem Gesetze des zuund abnehmenden Winkelsinus) an- und absteigende Form. Allein Du bist im Stande eine beliebig anders gestaltete Wellenform ron verwickeltster Gestalt zu erzeugen, wemn Du, anstatt eines einzigen Steines deren viele hineinwirfst, so zwar dass Du Art, Ort und Zeit des Hineinwerfens in ganz bestimmter Weise l'egelst. ') Wolltest Du einem Plysiker das Problem aufgeben in einem geniigend tiefen und ausgedehnten Wasserbecken an bestimmter Stelle und zu bestimmter Zeit eine beliebig von Dir hingezeichnete Wellenform entstehen zu lassen, so wiirde er auf dem Wege der Rechnung ermitteln, an weleher Stelle, zu welcher Zeit, ron welcher Höhe die Steine (die der Einfachheit halber alle gleich schwer diirften genommen werden) hinein $\mathrm{zu}$ werfen wäiren.

Nach Erörterung dieser nothwendigen Vorbegriffe kehren wir zu unserem eigentliehen Gegenstande, zur Frage der Zeugung zuritck. Dieselbe erledigt sich, wenigstens nach ilrer allgemeinsten Auffassung, nunmehr mit wenigen Worten: Das Leben eines jeden Individuums ist ein Process, $d$. h. eine Summe gesetzmässig unter einander verknuipfter Bewegungsvorgänge. Die formbildende Aeusserung des Lebensprocesses ist das Waehsthum. Die Frage nach der Erzeugung des Individuums fällt somit zusammen mit der Frage nach der Er- 
regung: und den Bedingungen des Lebens, speciell nach derjenigen des Wachsthums. Wissenschaftliche Theorien der Zeugung können keine anderen sein, als Theorien der iibertragenen Bewegung:

So einfach und so selbstverständlich dies erscheinen mag, so ist doch nach dieser Richtung am seltensten die Lösung gesucht worden. Klar hat indess anch hierin schon Aristoteles gesehen. Vom Mam geht nach ihm bei der Zeugung

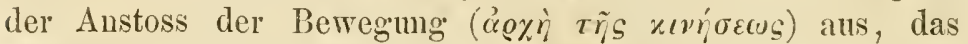
Weil, liefert den Stoff. "Und es muss gleich Anfangs 'der eine Theil des Stoffes beisanmen sein, ans welehem der erste Keim gebildet wird, der andere Theil aber fortwährend hinzukommen, damit die Frucht wachse." "Indem der Same eine Ausscheidung ist und sich in der Berregung befindet, kraft welcher das Wachsthum durch die Vertheilung der letzten Nahrung geschieht, so formt er, wenn er in den Uterus gelangt ist, und setzt die im weiblichen Körper vorhandene Ansscheidung in die Bervegung, in der er sich befindet; denn anch jene ist eine Ansscheidnng und sie enthält das Vermögen zur Bildung sämmtlicher Theile, nicht aber die Theile in Wirklichkeit." An einer anderen Stelle bespricht Aristoteles die successive Bildung der Organe und erklärt, dass die rom Samen ansgehende Bewegung fortwïhrend newen Theilen sich iiberträigt. "Es ist aber der Fall, dass ein Erstes ein Zweites berregt, und ein Zweites cin Drittes, wie bei den wunderbaren Antomaten. Die ruhenden Theile der letzteren besitzen nämlich eine gewisse Fähigkeit, und wemn eine aiussere Kraft den ersten Theil in Bewegnng setzt, so wird sofort der nächste in thätige Bewegung rersetzt. So wie nun bei den Automaten jene Kraft gewissermassen bewegt, olne zur Zeit irgend einen Theil zu berithren, nachdem sie jedoch friiher einen beriihrt hat, auf ïhuliche Weise wirkt anch das von dem Samen Kommende, oder was den Samen bereitet hat, so dass es zwar einen Theil beriihrt hat, num aber nicht weiter beriihrt.... Der Same aber ist ein solehes Wesen, und hat ein solches Bervegungsprincip, dass, wenn der Anstoss ;er Beweging aufhört, ein jeder Theil und zwar als ein beseelter wird." Ueber diese allgemeinsten Gesichtspunkte hinaus und bis in die Details Aristoteles zn folgen ist nicht möglich. 
Eine, den einzelnen Verhältnissen gerecht werdende Theorie der 'Zengung anfzustellen, rermag man hente nicht, und hat man damals noch riel weniger rermoeht.

In gleich dentlicher Wrise hat Keiner der Späteren den o oigen Grundgedanken wieder ausgesprochen, obwohl Anklänge daran in mehreren der spaiteren Theorien sich wiederfinden. Ich spreche hier nicht ron den verwickelten Vorstellungen Galens, in welchen u. A. anch der gestaltenden Kratt des Samens ein Antheil zugewiesen ist. Dagegen kann auf Harvey hingewiesen werden, bei welchem in zahlreichen Ausspriichen der richtige Begriff des Keimes Ausdruck findet, und welchem anch derjenige einer Bewegungsibertragung nieht fremd geblieben ist. "Primordium regetale" nennt er das Ei. Er stellt Zengung, Waehsthum und Ernährung als kaum zu tremnende Vorgainge in eine Linie. „Orum itaque est corpus naturale, so sagt el u. A., virtute animaii praeditum, principio nempe motus, transmutationis, quietis et enservationis. Est denique ejusmodi, ut, ablato omni impedimento, in formam animalis abiturum sit." Er rergleicht die Zengung mit der Wirkung ron Gährungserregern, und nennt den Samen geradezu ein Contagium, wobei er allerdings die Vorstellung hegt, dass dessen Contactwirkumg in die Entfernung sich fortpflanze.

Anch dic mechanischen Theorien ron Descartes diurften, so roh sie sind, hier erwähnt werden. Sie gehen ebenfalls ron dem Gedanken ans, dass in der Zengung ein Gährungsprocess rorliege. Enter den neueren Forschern hat Th. Bischoff die Parallele mit der Gährungserregung wieder aufgegriffen, im Anscliluss an Liebig's bekannte Theorie der Fermente.

C. E. r. Baer hat sich meines Wissens nie speciell ïber die Generation ausgesprochen, seine leitenden Grundgedanken iiber das Wesen der Entwicklung liegen indess in rielen rorziiglichen Aensserungen theils seines Hauptwerkes, theils seiner kleineren Anfsätze zu Tage. Wenn er sagt, "dass nicht das Körperliche rorgebildet ist, wohl aber das Unsichthare, der Gang der Entwicklung:"; wenn er sich reiter ausspricht, .. dass das Wesen des Lebens eben nur der Lebensproeess, oder der Verlanf des Lebens sein kann, dass fiir einen organischen Körper das Beharen nur ein Schein, das IT erden aber 
das Wesen und das B l e i b e nde ist ", so tritt in solehen Sïtzen auf das prägnanteste hervor, wohin der grosse Forscher den Schwerpunkt der Frage verlegt.

Das befruchtete Ei träigt in sich die Erregung zum Wachsthum, so zwar, dass letzteres bei vorhandenen Entwicklungsbedingungen fortschreiten wird, bis sein Maass und seine Zeit erfiillt sind. In der Wachsthumserregung aber liegt, wie Du schon friher gesehen hast, der gesammte Inhalt erblicher Uebertragung von vïterlicher sowohl, als von mütterlicher Seite. Nicht die Form ist es, die sich iberträgt, noch der specifisch formbildende Stoff, sondern die Erregung zum formerzengenden Wachsthum, nicht die Eigenschaften sondern der Beginn eines gleichartigen Entwickelungsprocesses.

Ist nun die Form eine abgeleitete Folge des Wachstlıums, sind ilıre Verwickelungen denkbar bei einem verhältnissmässig. einfachen Grundgesetze des letzteren, so ist aueh die, einer Zeugungstheorie gestellte Aufgabe in hohem Grade vereinfacht. Es bedarf nicht des Suchens nach besonderen Einrichtungen, un dieses oder jenes Merkmal, 1 m die Farbe des Haares, die Gestalt der Nägel, oder die Warze am Kinn zu iibertragen. Zu übertragen ist der gesctzmässig geordnete Anfang des Processes, und daraus muss das Uebrige, bei Vorhandensein der guinstigen äusseren Entwicklungsbedingungen, als nothwendige Folge hervorgehen.

Folgende Grundsätze lassen sich, wie mir scheint, als fest jetzt schon aufstellen, da sie theils der Ausdruck direkter Beobachtung, theils unmittelbare Folgen allgemein giiltiger Principien sind:

1) Der miitterliche Keim, oder das Ei im engeren Sinne des Wortes ist eine zum Wachsthum erregbare Substanz.

2) Unter bestimmten, vorerst nicht allgemein feststellbaren Bedingungen kann, wie die Parthenogenesis zeigt, das Ei seine Wachsthumserregung aus inneren Ursachen bekommen, und demgemäss sich entwickeIn ohne vorangegangene Befruchtung.

3) Wo keine Parthenogenesis besteht, da bedarf das Ei, damit es zu waehsen beginnt, des Contactes mit männlichem Samen.

4) Das Wachsthum, als ein nach Raum und nach Zeit 
normirter Vorgang setzt voraus, dass auch die Wachsthunserregung eine Function von Raum und ron Zeit ist.

5) Soll eine erbliche Uebertragnng durch Vermittlung des Samens möglich sein, so muss die Wirkung, die der Same auf das Ei ausibt, eine Function von Raum und rou Zeit scin.

6) Wenn das Ei die Bedingungen miitterlicher Uebertragung enthält, so kann dessen Substanz keine durchweg gleichartige sein. Es muss dessen Wachsthumserregbarkeit, sei es in Folge ungleicher Massenvertheilung; sei es in Folge verschiedener Constitution, an verschiedenen Stellen eine verschiedene sein. Es muss die Wachsthumerregbarkeit des Eies eine Function des Raumes sein.

7) Ist für die einzelnen Samenfäden das Gesetz gegeben, nach welehem ihre erregende IVirkung zeitlich und räumlich sich ausbreitet, ist ferner Ort und Zeit ihres Eintrittes in das Ei gegeben, und fïr das Ei das Gesetz, nach welchem seine Erregbarkeit räumlich sich vertheilt, so bestimmt die Combination dieser gegebenen Bedingungen das Wachthumsgesetz des Keimes, und damit dessen gesammte nachfolgende Entwicklung:

Um Dir an einem Beispiele die Sache zu veranschanlichen, nehme ich den oben besprochenen Fall wieder auf von der Erzengung einer verwickelten Wellenform durch zeitlich und räumlich geordnetes Hineinwerfen von Steinen in ein Wasserbecken. Hiebei liegt im Werfen der Steine die Erregung zum wellenbildenden Processe, und wir vergleichen dies mit der Summe der erregenden Stösse, welche der Same dem Ei ertheilt. Würdest Du die Steine nach derselben Ordnung, anstatt in ein Wasserbecken, in ein solches geworfen haben, welches mit Oel, oder mit Alkohol, oder mit irgend einer anderen, vom Wasser durch grössere oder geringere Zähigkeit, und durch grösseres oder geringeres specifisches Gewicht sich unterscheidenden Fliissigkeit gefuillt war, so wäre in jedem dieser Fälle die Form der Wellen eine andere geworden, als im ersten. Es ist also die Form der Wellen nicht allein abhängig von dem Gesetze der Erregung, sondern auch von der Zähigkeit und dem specifischen Gewicht der wellenbildenden 
Fluissigkeit. Die zähere Fliissigkeit wird gregeniiber der minder zähen niedrigere Wellen bilden, und dasselbe gilt von der specifisch sehwereren gegeniber ron der leichteren. Jene besitzen, um das Wort zu brauchen, eine geringere "Wellenerregbarkeit" als diese.

Denke Dir nun, Du rermöchtest eine Fliissigkeit zu schaffen (in gewissen Gränzeṇ wäre dies durch ungleiche Erwärmung zu leisten), worin an versehiedenen Stellen die Zähigkeit und das specifische Gewicht versehieden wilren, und Du wiirdest dabei irgend ein Gesetz der Abstufung zu Grunde legen, so hättest Du ein Motiv gefunden zu speeifiseher Beeinflussung der Wellenformen. Du hïttest ein Beeken, dessen Inhalt an rerschiedenen Stellen verschiedene Wellenerregbarkeit besitzt. Bei jeder anderen Vertheilung dieses Werthes wiirden wieder andere Wellenformen entstehen. - Es entspricht soleh ein Beeken mit specifiseh rertheilter Wellenerregbarkeit dem miitterliehen Ei mit seiner speeifisehen Tertheilung der Wachsthumserregbarkeit. Eine ungleiche Vertheilung der Wellenerregbarkeit in Deinem Becken künntest Du Dir, bei sonst gleichartiger Fliissigkeit anch daron abhüingig denken, dass die Erregung die Fliissigkeit nicht ruhend, sondern bereits in irgend einem Bewegungstorgange begriffen rorfindet.

Die obigen Sätze, speciell die Siitze 5- $\bar{\imath}$, enthalten nicht eine Theorie der gesehlechtlichen Zengung, wohl aber enthalten sie die Bedingmugen, welchen eine solche Thenrie geniigen muss, und ich sehe nicht ein, wie davon etwas abgehen kann. Theorien, welehe, wie dic älteren Gährungstheoricn die räımliehe Normirung der Samenwirkung ausser Betraeht lassen, helfen ums nicht iiber den formenden Einfinss derselben hinweg. Beim gegenwärtigen Stand unseres Wissens, da ums bekannt ist, dass der Same geformte Elemente, die Spermatozoen enthält, und dass diese durch eine besondere Oeffnung ins Ei cindringen, lassen sich die zu einer Zeugungstheorie hinfïhrenden Fragen schärfer präcisiren als dies frither möglich war. Die genaueste Untersuchung der Einzelheiten, als da sind: Form und Grösse der Samenfäden, Form und Grösse der Nikropyle, Stellung der Mikropyle zum Keim, Ort des stärksten Wachsthums des letzteren bezogen anf den Ort der Mikropyle 1 . $(\mathrm{ggl}$. mehr muss die Elemente liefern, ans welchen die Theorie sich 
aufbaut. Wiirde z. B. die Beobachtung ergeben, dass die Mikropyle gross genug ist, un rielen Spermatozoen zugleich den Eintritt zu gestatten, so wiirde die Theorie anders zu gestalten sein, als wenn (wie ich dies beim Lachs und bei der Forelle in der That constatirt habe) nur ein Spermatozoon auf einmal im Kanale Platz hat. Wiirde sich heransstellen, dass das eintretende Spermatozoon zuerst auf einen excentrischen Punkt der Keimscheibe stösst, so wïre damit wieder ein Element gregeben zur Ableitung des anfainglichen Wachsthumsmaximums II. s. W. Ich trete in solche Einzelnheiten nicht weiter ein, weil es zwecklos ist, dieselben ohne ein breites Beobachtungsmaterial zu discutiren. Ich habe Dir in meinen vorigen Briefe nur rersprochen, die Richtung der Fragestellıng' zu bestimmen, und das glaube ich im Obigen geleistet zu hahen. 


\section{Dreizehnter Brief.}

Vermittelung erblicher Uebertragung. Die Descendenzlehre und die Beziehungen der Morphologie zu derselben.

Lieber Freund: Wir wollen uns heute einmal vorstellen, wir besiissen eine durchaus befriedigende Theorie, welche uns bei gegebenen ïnsseren Entwicklungsbedingungen (Temperatur, Materialznfuhlr u. s. w.) in allen wesentlichen Punkten die Processe im befruchteten Keim aus den Eigenschaften der Spermatozen einerseits, ans denjenigen des unbefruelteten Eies andererseits, lund aus der Art ihres Zusammentreffens abzuleiten gestattete. Nit alle dem wären wir nicht zu Ende; denn es würde zunächst die weitere Frage an uns herantreten: wie es denn kommt, dass die Spermatozoen iiberhaupt specifische und individuelle Eigenschaften des Vaters oder eines väterlichen Ascendenten, das Ei solche der Mutter, oder eines ilurer Aseendenten dem erzcugten Wesen iibertragen kamn? - Nicht um diese Frage zu beantworten, wohl abcr, um auch hier wiederum eine klare Fragestellung anzubahneu, gehe ich mit einigen Worten darauf cin.

In der Regel ist man, wie dies speciell in den Extracttheorien ausgesprochen ist, geneigt, einen verwickelten Zusammenhang zwischen der Organisation des Vaters oder der Mutter einerseits, und derjenigen der Spermatozoen oder des Eies andererseits anzunchmen; der Art, dass die Eigenthiimlichkeiten eines jeden Organes, oder Organtheiles in irgend einer räthselhaften Wcise auf die betreffenden Keimstoffe zuriickwirken, in ilınen reproducirt, oder, wenn Du lieber willst, repräsentirt werden. 
Es ist klar, dass eine derartige Voranssetzung keine absolute Berechtigung hat. Sehen wir zunächst ab von aller Möglichkeit der Uebertragung erworbener Eigenschaften, so ist aus den Erörterungen unseres letzten Briefes klar, dass zur Erzengung eines gleichartigen Entwicklungsganges nicht das Vorhandensein irgend welcher verwickelter Uebertragungsmechanismen nöthig ist, sondern ïberhaupt nur ein gleichartiger Anfang. Fangen zwei, in ihrem weiteren Ablaufe keiner Hemmung unterworfene Processe gleich an, so werden sie auch gleich ablaufen, mag im Uebrigen der Anfang derselben durch noch so einfache Motive bedingt sein. Wirfst Du ein paarmal nach einander Steine genan in derselben Weise in ein ruhendes Wasserbecken, so entstehen stets übereinstimmende Wellenformen. Wenn der Entwicklungsprocess bei Erzenger und Erzengtem in gleicher Weise begonnen hat, so muss er in seinem weiteren Verlaufe dahin führen, dass auch beim Erzengten Keimstoffe entstehen, denen gleich, welchen er sein eigenes Dasein rerdankt. Die Bildung der Keimstoffe ist ja nur ein Theilvorgang des gesammten, in der Zeugung geregelten Entwickelungsprocesses. Oder mit anderen Worten: es muss, weun für zwei Individnen der Entwickelungsgang gleichartig begonnen hat, die Aehnlichkeit entstehender Organisation, wie in der Form des Gesichts, oder in der Farbe der Haare so auch in Beschaffenheit der Keimstoffe wiederkehren.

Es liegt kein Grundror, eine nnmittelbare Einwirkung der Theilgebilde des elterlichen Organismus auf diespecifischen Eigenschaften der entstehenden Keimstoffe anzunelimen.

Es sollen sich nun aber auch erworbene Eigenschaften iibertragen, und da entsteht allerdings die Frage, ob dazu eine specifische Abhängigkeit des Keimstoffes ron den einzelnen Theilen des Erzeugers erforderlich ist? Dies wäre unbedingt der Fall, wenn Eigenschaften sich rererben wiirden, welche während des individuellen Lebens erworben sind, wie Verstïmmelungen ron Gliedmassen, oder erlernte Fähigkeiten.

Erfahrungen der ausgedehntesten Art erlauben uns die Entscheidung uiber diesen Punkt: Seit Jahrtausenden stehen und gehen wir in derselben Weise, seit Jahrhunderten sprechen unsere Vorfahren dieselbe Sprache, und schreiben dieselbe 
Sehrift, und doch mussten wir selbst, und miissen unsere Kinder diese Fähigkeiten jedes wieder einzeln erlernen. Seit Jahrtausenden iiben ferner gewisse Völkerschaften die Circumeision, olme dass der, immer wieder von nenem abgetragene Theil dureh Vererbung versehwunden wäre. Solchen Erfahrungen gegeniiber kann die Handvoll Aneedoten, welche man zu Gunsten der Vererbung individuell erworbener Eigenschaften angefiihrt hat, ${ }^{1}$ ) nicht aufkommen. Ohmedem erimert ihre Beglaubigung lebhatt an die Beweise für das "Versehen Sehwangerer", und auf wissensehaftliche Beachtung diurfen sie zum Mindesten keinen Anspruch machen. Bis zum Eintritt besserer Beweise halten wir an dem Satze fest, dass die im individuellen Leben erworbenen Eigenschaften sieh nicht vererben.

Mit dem Namen "erw or bene Eigense ha fte n" bezeichnet man nun aber auch solche, die im Laufe von Generationen durch kiinstliche oder natiirliche Ziiehtung zur Ausbildung gelangt sind, oder Eigenschaften, die, wie die Sechstingrigkeit, bei irgend einem Individuum aus innern, nicht näher bestimmbaren Entwicklungsgriinden anftreten, und dam sich weiter fortpflanzen. In beiden Fällen ist der Ausdruck "erworben " offenbar uneigentlich, und wiirde der Klarheit hatber lieber vermieden. Jene kömnte man vielleicht als erzii ch tete, diese als eingesprengte Eigenschaften bezeichnen. Weder fiur die eine noch für die andere Kategorie ist die Annalıme verwickelter Beziehungen der Organe zum Keimstoff erforderlich; demn beide erscheinen nur als der Partialausdruck des allgemeinen Entwickelungsprocesses, und treten in diesem wesentlichen Punkte nicht aus der Reihe der iibrigen erblichen Eigensehaften heraus.

Setzen wir nun voraus, es sei uns bekannt:

die Eutstehung des organischen Wesens aus dem Keim, die Entwicklungserregung des Keimes in Folge des Zusammentritts der beiden Keimstoffe,

die Abhängigkeit der Organisation der Keimstoffe ron der Organisation der Erzengenden,

so haben wir allerdings den Entwickelungsprocess erkannt in seinem Fortgange rom Erzengten zum Erzeugenden und ron da wiedertum zum Erzengteu. 
Nicht zum geschlossenen Ring fiigen sich indess die gleichnamigen Enden unserer Reihe zusammen, sondern jedes schliesst an an vorausgehende, oder an nachfolgende Reihen. Der Entwickelumgsgang des Individuums ist das einzelne Glied eines ins Unermessliche fortlaufenden periodischen Processes, des Entwickelungsprocesses der Grenerationen. Keimstoffe und Keim sind die sehmalen Substanzbriicken, mittelst deren neue Glieder in gesetzmïssiger Folge den vorangehenden sich anfiigen. "Aeternitatis periodus", so heisst der Keim ja schol bei Harvey, , inter parentes et liberos, inter eos qui fuerunt, et qui futuri sunt, media via sive transitus."

In rereinfachtem Bilde erscheint der Entwickelingsprocess der Generationen als eine unermessliche Wellenlinie, worin die einzelne Welle dem Wachsthumsgange des einzelnen Individums entspricht. An- und Absteigen seines Gesammtwachsthums finden in deren besonderer Form ihren Ausdruck. Ganze Strecken der Linie stimmen in der Form der einzelnen Wellen derart iberein, dass die Eigenthiimlichkeiten der Biegung, welehe in der einen rorhanden sind, in den rorausgehenden und in den nachfolgenden wiederkehren. Eine jede einzelne Welle ist die Trigerin ron Eigensehaften, die nicht iln eigenthiimlich, sondern grossen Strecken der Wrellenreihe gemeinsam sind. Eine absolute Periodicitat existirt nun aber, das lehrt uns die tägliche Erfahrung, in keiner solehen Reihe. Kinder derselben Eltern weichen bald in mincler, bald in mehr anffiilliger Weise ron einander, und ron ihren Eltern ab, Eigensehaften frïherer Glieder können mit Ueberspringung der dazwisehen liegenden in späteren wiederkehren u. s. w.

Die Möglichkeit ist denkbar, dass die vorkommenden Schwankungen um die gemeinsame Mittelform auf Rechnung der wechselnden äusseren Entwicklungsbedingungen (Ernährung u. s. w.) kommen. Es wäle dies rergleichbar dem Fall eines regelmässigg arbeitenden, eine Wellenlinie anfzeichnenden Apparates, welcher an einer Zeichnungsflache von umregrelmässig wechselndem Widerstande arbeitet. Dabei wiirden in der Form der aufgezeichneten Curven Schwankungen gleichfalls unvermeidlich sein, und es könnten Formeneigenthiimlichkeiten in späteren Gliedern wicderkehren, die in irgend einem früheren 
vorhanden waren, in den dazwisehen liegenden aber gefehlt hatten.

Das accidentclle Moment äusserer Entwicklungsbedingungen, zngleich mit dem Princip der sexuellen Kreuzung möchten möglicherweise genügen, uns die Schwankungen verständlich zu machen, welche die Generationsreihen lebender Wesen in den von uns nnmittelbar verfolgten Strecken darbieten. Erweitern wir indess unseren Blick iiber die Zeitspanne hinaus, in welcher wir leben und iiber welche menschliche Urkunden reichen, so erfahren wir, dass unsere mitlebenden Reihen mit ihren, um gegebene Mittelwerthe oscillirenden Gliedern sich nicht vom Unendlichen her dnrch die Zeiträume fortgepflanzt haben, dass friiheren Erdaltern andere, allem Anschein nach oft an gewisse Epochen gebundene, und mit den Epochen wechselnde Formen lebender Wesen eigenthimlich gewesen sind.

Nachdem uns durel Darwins schöpferische Arbeiten die Angen geöffnet worden sind fuir die unter unseren Augen fortwährend vor sich gehenden Nenbildungen organischer Formen, nachdem wir im Princip der natiirlichen Zuichtung einen weitgreifenden Schliissel in dic Hand bekommen haben zum Verständniss der Ausbildung und Fixirung besonderer Formen, ist das Problem des genetischen Zusammenhanges der Geschöpfe verschiedener Erdalter mit viel grösserer Wucht als je zuvor in den Vordergrund getreten. Mit der grössten Wahrscheinlichkeit lässt sich behaupten, dass die, nnter nnseren Angen sich entwickelnden Generationsreihen die directen Fortsetzungen sind jener älteren, von den unsrigen vielfach abweichenden Reihen, von welchen uns die Geologie Kenntniss gibt. Mit der grössten Wahrseheinlichkeit ergibt sich ferner, dass jeweilen die hochorganisirten Fornen aus einfachen Grundformen herrorgegangen sind, dass, um beim Bilde der Wellenlinie zn bleiben, die Anfangs kurzen und flachen Wellenglieder mehr und mehr sich erhoben, gestreckt und in ihrer Gestaltung rerwickelt haben. Es sind diese Wahrscheinlichkeiten so ausserordentlich viel grösser als Alles, was wir uns sonst zur Zeit iiber den Zusammenhang der organischen Schöpfung ausdenken können, dass wir vollauf berechtigt sind, sie als vorläufig sichere Basis zu betrachten, als Basis, auf welcher iiber Menschenalter hinaus die Wissenschaft ruhig 
weiter bauen kann, gleiehgiltig ob der fortschreitende Entwickelungsgang der Generationsreihen im Wesen des Entwicklungsprocesses selbst begriindet, oder ob er, wie die consequente Anwendung des Ziichtungsprincipes dies verlangt, jeder besonderen Reihe durch die äusseren Lebensbedingungen aufgedrängt sein mag.

Mit Anerkennung des allgemeinen Prineipes del Deseendenz ergibt sich sofort die Aufgabe seiner speciellen Durchfiihrung. Die Lebhaftigkeit, womit die hentige Zoologie an dieser Aufgabe sich betheiligt, ist um so gerechtfertigter, als sie dabei unter allen Umständen nur gewinnen kann. Die auf den speciellen Nachweis der Deseendenzverhältnisse gerichtete Arbeit kommt der längst vorhandenen Aufgabe natiirlicher Systematik zu Gute, und miisste, wenn auch die Descendenzfrage hinwegfiele, grösstentheils in genau derselben Weise geleistet werden.

Gegenstand und Methode der pliylogenetischen Forsehung, wie sie sich nummehr nennt, sind durehaus andere als diejenigen 'der von mil bearbeiteten physiologisehen Entwicklungsgesehichte des Individumms. Die eine Forschung f'ingt da an, wo die andere aufhört, und die eine arbeitet mit Begriffen, deren die andere nicht bedarf. Insofern könnte ich es hier unterlassen, mich iiber phylogenetische Arbeitsweise irgendwie auszusprechen. Die Sache liegt indess so, dass die Ausscheidung der Gebiete noeh keinesweg's erfolgt ist. Nicht allein wird entwieklungsgesehichtlichen und iiberhaupt morphologischen Erfahrungen in phylogenetisehen Fragen eine Beweiskraft zugemessen, deren Berechtigung vielfaeh anfechtbar ist, sondern es wird ron einigen Seiten her geradezu behauptet, dass supponirte phylogenetisehe Verbände an und fiir sich schon alle Erklärung individueller Entwicklungsrorgänge in sich enthalten. Hier thut eine Verständigung iiber das, jeder Forschung zukommende Gebiet, und thut vor Allem auclı Kritik der angewendeten und anzuwendenden Methoden dringend noth, und ich darf nicht unterlassen, das Meinige zur Klärung der Begriffe beizutragen.

Der historische, auf die eigentlichen Urkunden zuriickgreifende Beweis für die genetische Verwandtschaft organischer 
Wesen fällt der Paläontologie zu. Sie vermag zu zeigen, wie in den anfeinander folgenden Erdepochen die Formen jedes gegebenen Kreises sich ununterbrochen modificirt haben, und wie heutige Formen in vielen Fällen durch schrittweise veränderte Zwischenstufen den abweichenden Formen weiter zurickliegender Epochen sich anreihen. Paliiontologisehe Stammbiiume, wie sie z. B. auf Grund reichhaltigster Forschung L. Rüti: meyer für die Wiederkäuer, fiur die pferdeartigen Thiere und nenerdings fiir die Schildkröten aufgestellt hat, scheinen mir die eigentlichen Grundpfeiler einer wissenschattlichen Descendenzlehre zu sein, welchen sich als kaum minder wichtige Stiitzen die Nachweise anschliessen iiber die Gruppirung verwandter Formen der Jetztzeit um bestimmte geographische Mittelpunkte herum, also Arbeiten wie die von Alfr. Walla ce iiber die Fama des Malayischen Archipels, und die ron L. Riitimeyer über die Herkunft unserer Thierwelt.

Es sind num aber die Urkumden der Palïontologie liickenhaft und wenig Aussicht ist vorhanden, dass gerade die entscheidensten Uebergangsbriicken sich mit ilırer Hiilfe so bald werden schlagen lassen. Die wichtigsten Uebergangsgesehöpfe haben wir, wegen der Natur ihrer Körpersubstanz, gar keine Hoffnung als Petrefacten je zu finden. Da liegt demn der Gedanken nahe, auf den reichen Gefilden der rergleichenden Anatomie und Entwickelungsgeschichte die Ausbente zu suchen, welehe uns die Paliiontologie so muihsam und mit so karger Hand gewährt.

Die Formen organischer Wesen sind in wechselndem Grade unter einander ähnlich; von Formen der einen Gruppe zu solchen einer anderen sind in der Regel Uebergänge, oft in sehr allmähliger Abstufung vorhanden; Formen, die in ilnem ausgebildeten Zustande von einander differiren, kömnen in ihren embryonalen Phasen sich sehr nahe stehen; reife Formen einer Art können mit den embryonalen einer anderen wesentlich iibereinstimmen.

Bereits die Classificationsbestrebungen der älteren Zoologen haben diesen Erfahrungen Rechnung getragen, und sie im Interesse des Systems verwerthet. Allein durch dic Descendenztheorie sind sie in ein weit helleres Licht geriickt worden. Wem Formen unter sich älnlich sind, so ist lie Möglichkeit 
gegeben, dass sie unter sich auch genetisch zusammenhïngen. Lïsst sich der gesammte Formenreichthum der organischen Welt nach den, in ausgebildeten, oder in embryonalen Zustainden vorhandenen Aehnlichkeiten in baumförmig unter sich zusammenhängenden Reihen anordnen, der Art, dass an der Wurzel des Baumes die einfachsten Formen sind, in dessen auseinander weichenden Wipfelzweigen die complieirtesten, zwisehen den einen und den anderen aber eine fortlaifende Stufenleiter von Zwischenformen, so drängt sich der Gedanke auf, dass dieser, nach der Formähnlichkeit entworfene Baum des Systemes zugleich der Stammbaum der genetischen Verwandtsehaft ist.

Liegen aber die Dinge wirklich so, ¿lass die morpholngische Verwandtsehaft unter allen Umstimden die g'enetische beweisen muss? Es wird dies jetzt so rielfach angenommen, dass manche Schriftsteller andere Möglichkeiten geradezu als undenkbar hinstellen. Allein es ist sicher, dass ohne die Erfahrungen der Paläontologie iiber die Veränderungen in den Formen der zeitlich sich folgenden organischen Tresen, und ohne diejenigen ïber das Torhandensein gewisser geographiseher Ausbreitungseentren, es rermessen wäre, rein morphologische Beziehungen im Sinne der Descendenz zu verwerthen. Die Frage, in wie weit l'ein molphologisehe Verhältnisse als Descendenzbeweise rerwerthbar sind, ist in ganz allgemeiner Weise iiberhanpt nicht zu beantworten. In besonderen Falle aber bleibt sie stets eine ausnehmend sehwierige. Es können morphologische Erfahrungen als Beweismittel nur den Werth beansprttehen, welcher im gerichtlichen Verfahren den Indicien znkonmmt, sie sind indirecte Beweismittel, um so beweiskräftiger, je massenhafter und je lïckenloser sie sind, und je mehr ihnen die directen paläontologisehen Beweise zur Seite stehen, bedentungslos, sowie șie rereinzelt, oder mit jenen nicht in genaner Uebereinstimmung sind. Die phylogenetische Untersuchung wird schon deshall) der morphologisehen Arbeiten nicht entbehren diurfen, weil sie ron diesen die Weisung erhält, wie sie den Kreis möglicher Ableitung zu ziehen, und nach welchen Seiten hin sie ihren Blick zu richten hat. Allein sie darf nicht aus den Auge verlieren, dass sie mit einem Hiilfsmittel ron sehr bedingter Zurerlissigkeit arbeitet, und 
dass die dermalen beliebte Uebertragung jeglicher morphologisehen Erfahrung in einen entsprechenden phylogenetischen Lehrsatz von Seiten wissensehaftlicher Methodik nicht für correct gelten darf. Ein Anderes ist es, einen Zusammenhang sicher zu beweisen, ein Anderes ihn als möglich hinzustellen. 


\section{Vierzehnter Brief.}

Die Erklärung organischer Körperform durch das Descendenzprincip, das „biogenetische Grundgesetz" und seine Begründung. Unmittelbare und mittelbare Erklärung.

Lieber Freund! Im Interesse leichter Verständigung befolge ich auch heute wiederum die Taktik, einen Nachweis als geleistet anzusehen, der noch Sache der Untersuchung und der Discussion ist. Ich nehme also, indem ich zunäichst von allen zu erhebenden. Einwendungen absche, an, es sei nicht nur das Descendenzprincip im Allgemeinen eine factisch ermittelte Thatsache, sondern es sei auch fuir alle einzelnen Formen der Nachweis ihres genetischen Zusammenhanges direct geleistet, und wir könnten uns auf irgend einen der veröffentlichten, odel noch zu veröffentlichenden Stammbäume mit eben der Sicherheit verlassen, wie wenn es unser eigener durch vorhandene Documente gewährlcisteter Stammbaum wäre.

Wenn wir einen solchen Stammbaum besässen, wäre alsdann unsere eigene, oder irgend eine andere der jetzt lebenden organisclien Formen vollständig erklärt?

Bekanntlich hat Fritz Miiller in seiner geistreichen Schrift "Fuir Darwin" zuerst den Satz formulirt: dass die Entwicklıng der Vorfahren auch ron den Nachkommen durchlaufen wird, und dass die geschichtliche Entwicklung einer Alt in deren Entwicklungsgeschichte sich abspiegelt. Rasch hat sich dieser fruchtbare Gedanke Beifall erworben, und sofort anch seinen Platz gefunden im festen Gefiige der Schuldoctrinen. "Die Keimesgeschichte ist ein Auszug der Stammesgeschichte, oder mit anderen Worten, die Ontogenie ist eine kurze Recapitulation del Phylogenie", so lautet das "biogene- 
tisehe Grundgesetz", welches Häekel an die Spitze seiner umfangreichen Anthropogenie gestellt hat, und dessen durehgreifende Giiltigkeit er auf jeder Seite ron Nenem rerkiindet.

Grundgesetz! ein stolzer Titel, woll werth, dass wir seiner Begriindung einige Aufmerksamkeit schenken. In der Sprache der Naturforseliung pflegen wir als Gesetz einen Satz zu bezeichnen, welcher den Znsammenhang bestimmter Vorgänge, oder Erscheinungen in einer unumstösslichen Weise ansdriiekt, und dessen Feststellung einestheils empiriseh durch ausgedehnte widerspruehslose Reihen von Beobaehtungen, anderntheils theoretisch dureh unanfeelitbare Ableitung aus feststehenden Prineipien geleistet sein kann. Nicht iiberall, wo wir das Vorhandensein eines Zusammenhanges erkemnen, vermögen wir dessen Gesetz zu präeisiren, und so sind wir oft genug genöthigt, von Gesetzen zu reden, deren Ausdruck uns noch nieht, oder doch nur bruchstickwweise bekannt ist. Spreehen wir aber einen bestimmten Satz als "Gesetz" an, dann muss rlerselbe in allen Stiieken beweisbar sein, nnd er muss uns die Möglichkeit geben, in jedem, von ilmm umfassten besondern Falle die eintretende Erscheinung, oder den eintretenden Vorgang mit Sicherheit vorauszusagen. Wie vorsiehtig die exacte Naturforschung" mit dem Worte "Gesetz" umgeht, das kannst Du am besten daraus ermessen, dass sie trotz der liuekenlosesten empirischen Bestätigung und trotz der tiefsten theoretischen Durcharbeitung bis zum hentigen Tage nieht von einem Undulationsgesetze, sondern nur ron einer Undulationstheorie des Liehts sprieht.

Sehen wir zu, ob das "biogenetische Grundgesetz" den an ein Naturgesetz zu stellenden Anfordermngen Genüge leistet. Wir fragen zuerst nach dem Beweise, und erwarten vielleicht die paläontologisch gefuihrte Induction an der Hand einer grösseren Reihe von besonderen Fällen. Aus nahe liegenden Grïnden verzichtet $\mathrm{H}$ : $\mathrm{ekel}$ anf diese Art der Beweisfïhrung, und es bleibt bei der Versicherung, dass die grosse Aehnlichkeit embryonaler Formen unter sich, sowie die Aehnlichkeit niedriger Thiere mit den embryonalen Formen höherer nur dureh das biogenetische Grundgesetz rerständlich sei.

Damit ist denn allerdings das angebliche Grundgesetz zul einer Hypothese geworden, geeignet, einen bestimmten Kreis 
vou Erfahrungen in innern /usammenhang zu bringen, vorausgesetzt natiirlich, dass sie mit diesen Erfahrungen durchweg in genauer Uebereinstimmung steht. - Etwas unbequem ist diese Forderung einer genanen Uebereinstimmung ron Hypothesen und Thatsache allerdings. Recapituliren wir uns z. B. den Entwickelungsgang, den wir selbst, den iiberhaupt die Säugethiere durchmessen haben, so ist klar, dass unsere hentigen Embryonen Entwicklungsstufen, und dass sie vor Allem Lebensbedingungen durchlaufen, welche unsere paläontologischen Vorfahren unmöglich kömnen durchlanfen haben. Ist unser heutiges Embryonalleben dem Verkehr mit dem mtitterlichen Uterus angepasst, so mussten unsere phylembryonalen Vorfahren ansgeriistet sein, $u m$ in selbstständiger Weise auf den Nahrungserwerb anszugehen. Die Eigenschaften der Haut sowie der iibrigen Sinnesorgane, die der Nahrungs- nnd der Athmungswerkzenge, diejenigen der Muskeln und des Nerrensystems mussten bei jenen, dem Kampf ums Dasein ansgesetzten Wesen andere sein, als bei unseren, behaglich im Fruchtwasser schwimmenden Embryonen, und da unsere Abhängigkeit von der Mutter schon auf der allerjugendlichsten Stufe des eben befruchteten Eies ihren Anfang nimmt, so miissen selbst unsere amöboiden und gastrulären Vorfahren zum mindesten physiologisch ganz anders organisirt gewesen sein, als wir selbst auf' den betreffenden Stufen. Aehnliche Betrachtungen lassen sich für eine jede Thierklasse wiederholen, und schon Fritz I iiller hat sich daher genöthigt gesehen, scinen Satz dahin zu beschrïnken: "dass dic, in der Entwicklungsgeschichte erhaltene geschichtliche Urkunde allmählig verwischt wird, indem die Entwicklung einen immer geraderen Weg rom Ei zum fertigen Thiere einschlägt, dass sie durch den Kampf der fieei lebenden Larven ums Dasein häufig gefälscht wird.')

Ist es nun schon bedenklich einer Hypothese eine ron Fälschung sprechende Hiilfshypothese beizugesellen, so heisst es allen Grundsätzen naturwissenschaftlicher Sprache geradezu ins Gesicht schlagen, wenn man, wie dies Häckel thut, erst ein "Grundgesetz" aufstellt, und dann ron dessen in der Natur rorkommenden „Fälschungen" spricht. Es werden zwar die der Natur zugeschricbenen Fälschungen auf das mindest mögliche Maass herabgesetzt, immerhin bleiben sie als solche 
bestehen. Es ist nämlich nach $\mathrm{H}$ äckel's Angabe ein voll. k $0 \mathrm{~mm}$ ener Parallelismus zwischen phylogenetischen und ontogenetischen Entwickelungsreihen vorhanden, jedoch sind in der ontogenetischen Reihe manche Glieder verloren gegangen, welche in del phylogenetischen Reihe friher existirt haben. Er vergleicht die Sache mit einem Alphabet, aus welchem einzelne Buchstaben verloren gegangen sind, in welchem aber die richtige Reihenfolge der itbrig gebliebenen sich erhalten hat. Das Bild kömnte dahin erweitert werden, dass man sagt, es hätte sich da und dort ein $\delta$, oder ein $\mu$ an die Stelle eines $d$, oder eines $m$ eingeschoben, $d$. h. es wären gleichwerthige Glieder an die Stelle der urspriinglieh vorhandenen eingerickt. Indess weiss ich nicht, ob diese Erweiterung des Bildes im Sinne Häckel's liegen wiirde, weil er in Wirklichkeit grosses Gewicht auf die Identität der, von der Theorie als ähnlich verlangten Formen legt, und weil er diese Identität als im ausgedehntesten Maasse bestehend erklärt. Wir Alle sind während der ersten Wochen unseres Fïtallebens ron einem Affen-, Hunds- oder Rindsembryo "mit den schärfsten Mikroskopen nicht zu unterscheiden, " wir durchlanfen ein Stadium der Kopflosigkeit, während dessen wir im Wesentlichen Amphioxusnatur besitzen. Solchen und ähnlichen Sätzen begegnen wir in Fülle bei $\mathrm{H}$ i ckel, sowohl in der Schöpfungsgesehiehte, als in der Anthropogenie, und ein reichliches Material von Abbildungen demonstrirt uns dieselben als unanfechtbar ad oculos.

Es ist wohl erlaubt, Häckel eine Strecke weit anf dem Boden thatsächlicher Darstellung zu folgen, und einige seiner beweisendsten Abbildungen einer genaueren Prüfung zu unterziehen. Wir nehmen die erste Auflage der natiirlichen Schöpfungsgeschichte zur Hand, und finden S. 242 abgebildet in drei untereinanderstehenden Abbildungen das Ei des Menschen, das Ei des Affen und dasjenige des Hundes, je 100 mal vergrössert, auf S. 248 aber in drei neben einanderstehenden Figuren den Embryo des Hundes, denjenigen des Hulms und den der Schildkröte. Die Ucbereinstimmung in jeder der beiden Figurenreihen ist eine vollkommene, und kaum kann man sich etwas Ueberzengenderes denken, als diese weitgehende Identität von Formen verschiedener Wesen. Selbst auf schein- 
bar unwesentliche Dinge erstreckt sich die Uebereinstimmung; wo die Körner im Hundeei etwas gröber sind, sind sie es auch im Ei des Menschen und des Affen, wo die Zona etrvas lichter ist in jenem, ist sie es auch in den beiden letzteren. Der Embryo des Hundes, des Huhnes und der Schildkröte zählen je 10 Urwirbel auf jeder Seite, und zwar ist bei allen drcien der erste der rechten Seite je ein bischen abgerundeter, der neunte ein bischen schmaler als die iibrigen. Sicher war es ein fiir die Wissenschaft nicht genug zu preisender Gliicksfall, der IHäckel drei so genau sich entsprechende Embryonen unter die Hände geführt, und ihm damit ein so entscheidendes Beweismaterial iiberliefert hat. Noch merkwiirdigere Uebereinstimmungen enthüllt indess eine weiter gehende Prifung der Figuren. Die absolute Identitait besteht nicht allein für die Eier der einen und für die Embryonen der anderen Bilderreihe, sie besteht auch fuir Ort und Form der bezeichnenden Buchstaben, ja sie besteht für die Zahl und fuir die Läng'e der Strichelchen, mittelst deren jene den Figuren angefiigt sind. Es hat uns mit anderen Worten Häckel je drei Clichés desselben Holzstockes unter drei verschiedenen Titeln aufgetischt! Das Verfahren war etwas stark, und ron Seiten eines, durch Tragweite, Tiefe und durch Gewissenhaftigkeit der Forschung gleich hoch dastehenden Mannes, von Prof. Ruitimeyer wurde es sofort geriigt als eine, den öffentlichen Creclit des Forschers tief schädigende Versündigung gegen wissenschaftliche Wahrheit. ${ }^{2}$ ) Darnach durfte man zum Mindesten eine Zuricknahme und Entschuldigung des begangenen Fehlers erwarten. Statt dessen hat Hickel in der Vorrede seiner spätern Auflagen schwere Schmähungen auf Prof. Rütimeyer gehäuft, gleich unwahr, was ihren Inhalt, wie unedel, was ihre Form betrifft. Dabei ist, was allerdings der Erwälnnung bedarf, der Holzstock jeder der beiden Reihen in der Folge nur einmal, der eine mit einer einfachen, der andere mit einẹ Collectivunterschrift versehen, abgedluckt worden.

Unverändert und durch zwei nene Figuren rermehrt erscheinen dagegen auch in der fünften Auflage der Schöpfungsgeschichte die paar grösseren Bilder, welche die Formidentitit von Hunds- und Menschenembryo, sowie die von Huhn- und 
Schildkröte erweisen sollen. Von diesen Figuren sind einige Copien, andere dazu componirt. Copien sind (ausser der Schildkrötenfigur) die Abbildungen des angeblich 4wöchentlichen Hundes (vergl. Bischoff Taf. XI, 42 B, Hundeembryo ron 25 Tagen) und diejenige des angeblich 4wöchentlichen Menschen (vergl. Eeker Icones physiol. Taf. XXX, 2, allda ohne Altersangabe). Allein es sind Copien in freier Behandlung, und zwar sind die genommenen Freiheiten der Art, dass sie eben der gewünschten Identitait zu statten kommen. Oder ist es ein Versehen des Lithographen, dass beim $\mathrm{H}$ ii $\mathrm{ckel}$ 'schen Hundeembryo gerade der Stimtheil des Kopfes um 31,2 Mm. länger gerathen ist, als bei Bisch off, beim Menschenembryo aber gegen Ecker der Stirntheil un 2 Mm. verkiirzt, und zugleich dureh Vorricken des Auges um volle $5 \mathrm{Mm}$. verschmälert ist, und dass dafür der Schwanz des letzteren zul doppelten seiner originalen Länge sich emporschwingt?

Reichliche embryologische Abbildungen entlält die Anthropogenie. Ein Theil derselben sind die wiederabgedruckten Holzstöcke der Kölliker'schen Eutwicklungsgeschichte. Soweit es sich aber um Häekel'sche Originalien handelt, stehe ich nicht an zu behaupten, dass die Zeichnungen, theils höchst ungetren, theils geradezu erfunden sind:

Erfunden ist Fig. 42, Urkeim des Menschen, in Gestalt einer Schuhsohle, 40mal vergrössert. Kein Beobachter hat bis jetzt dies Stadium gesehen, und zuversichtlich möchte ich nach dem bisher vorliegenden Material behaupten, dass es nicht so aussehen, und nicht die angegebenen Dimensionen besitzen kann. ${ }^{3}$ )

Erfunden sind ferner die 2 Figuren menschlicher Embryonen S. 272, bei welchen eine Allantois (beim Mensehen bekanntlich nie in Blasenform sichtbar) als "ansehnliches Blïschen" nicht allein abgebildet, sondern ansilriicklich beschrieben wird.

Erfunden ist dic Mehrzahl von den Figuren der Embryonentateln IV u. V, auf denen, um nur ein grobes Beispiel zu citiren, Fisch- und Froschembryonen ebenso unbefangen eine Scheitelkrimmung des Gehirns zur Schan tragen, wie die Embryonen der Schildkröte, des Huhnes und der Säıgethiere.

Kaun kann da erwidert werden, man diurfe es mit den 
Bildern nicht so genau nehmen, indem es sieh meh" um schematische Figuren handle. Nicht weniger als 24 Figuren, je drei Stadien von s verschiedenen Geschöpfen werden zusammengestellt mit der, in der Texterklairung ausdriicklich hervorgehobenen Absicht des Aehnlichkeitsbeweises. Anch ist bei Prof: H i ckel weder Ungeiibtheit im Zeichnen rorhanden, noch Unkenntuiss der, zur Gewinnung genaner Contouren anwendbaren Methoden. Er selbst hat bei friiheren Specialarbeiten Zeichnungsprismen benutzt, und jedenfalls in Jena, dem Sitze vortrefflicher Optiker, nie der Gelegenheit entbchrt, solche Aj)parate kennen zu lernen und sich dieselben zu rerschaffen.

Es bleibt das Verfahren ron Prof. Häekel ein leichtfertiges Spiel mit Thatsachen, gefähnrlicher noch als das friiher gerigte Spiel mit Worten. Letzteres fällt der Kritik jedes verständigen Denkers anheim, jenes vermag aber nur vom speciellen Fachmame durchschaut zu werden, und es ist um so weniger zu verantworten, da $\mathrm{Häckel}$ sich wohl des Einflusses bewusst ist, den er auf weite Kreise auszuiiben vermag:

Ich selbst bin im Glauben anfgewachsen, dass unter allen Qualifieationen eines Naturforschers Zuverlässigkeit und unbedingte Achtung vor der thatsächlichen Wahrheit die einzige ist, welche nicht entbehrt werden kann. Auch hente noch bin ich der Ausicht, dass mit Wegfall dieser eiuen Qualification alle iibrigen, und sollten sie noch so glänzend sein, erbleichen. Mögen daher Andere in Herm Häckel den thaitigen und riicksichtslosen Parteifiihrer verehren, nach meinem Urtheil hat er durch die Art seiner Kampfführung selbst auf das Recht verzichtet, im Kreise erusthafter Forscher als Ebenbürtiger mitzuzịhlen.

Sollen wir zum Miiller'schen Satze von der Zusammendrängung des Entwicklungsganges der Art im Entwicklıngsgange des Individums zuriickkehren, so ist jedenfalls unbestreitbar, dass derselbe niemals wörtlich verstanden werden darf, dass ihm indess ein gewisser Grad ron Näherungswahrheit zuzukommen pflegt, dessen thatsaichliche Bestimmung, falls itberhaupt möglich, in jedem hesondern Falle Sache besonderer Untersuchung sein muss.

Das näichste Interesse für uns liegt in der, schon zu Anfang des Briefes formulirten Frage: in wie weit die phyloge- 
netische Geschichte einer Form zugleich als deren Erklärung gelten darf, und wie sich ihre eventuelle Erklärung verhält zur physiologischen Erklärung? Prifen wir die Sache an einem speciellen Beispiele: Du hast mit einem sehr kurzsichtigen Menschen zn thun, und stellst die Frage nach der Ursache seiner Kurzsichtigkeit. "Es ist nicht wunderbar, sagt Dir ein Bekannter des Betreffenden, dass A. kurzsichtig ist, denn sein Vater war es anch schon in hohem Grade." "Das hat Nichts zu sagen, meint ein zweiter, denn A.'s Bruder ist nicht kurzsichtig, allein A. war in seiner Jugend ein äusserst eifriger Leser" - "Andere haben anch viel gelesen, spricht ein dritter, indess hat $A$. durch viele Jahre ein sehr dunkles Schullokal besucht, und die mit ihm die Schule durchgemacht haben, zeichnen sich beinahe sämmtlich durch ihre Kurzsichtigkeit aus." Endlich kommt als vierter der Augenarzt, und weist nach, dass der Angapfel von A, eine abnorme Luinge besitzt, womit die Kurzsichtigkeit genitgend erklärt sei.

Welcher von den vier Erklärern hat nun Recht? Offenbar hat der Augenarzt eine directe Erklärung des betreffenden Factums gegeben; denn eine abnorm verlaingerte Augenaxe muss unter allen Umständen zur Folge haben, dass die Bilder entfernter Objecte vor der Netzhaut entstehen. Die Kurzsichtigkeit ist eine unmittelbare und nothwendige Folge des abnorm verlängerten Auges. Das Factum des abnorm gebauten Auges ist aber selbst wiederum zu erklären. Auf statistischem Wegre ist nachgewiesen, dass Kur'zsichtigkeit oft sich vererbt, es ist ferner auf gleichem Wege nachgewiesen, dass schlecht belenchtete Schullokale Kurzsichtigkeit erzeugen. Die genanere physiologische Analyse der letzteren Erfahrung fiihrt aber weiterhin zur Ueberzengung, dass das Mittelglied dieser Abhängigkeit die iibertriebenen Accommodationsanstrengungen sind, und dass bei vielem Lesen oder bei feinen Arbeiten dieses selbe Mittelglied anch in Betracht kommt. Wir haben somit folg'ende Verkniipfung:

Die Kurzsichtigkeit ist unmittelbar erklärt durclı die abnorme Verlängerung der Augenaxe;

die abnorme Verlängerung der Angenaxe kann 1) auf erblicher Anlage bertuhen, 2) kann sie durch iibertriebene Accommodationsanstrengungen erworben sein, 3) kann eine erbliche 
Anlage gesteigert worden sein durch ubertriebene Accommodationsanstrengungen ;

die iibertriebenen Accommodationsanstrengungen kömmen ilren Grund gehabt haben 1) in zu vielem Lesen, 2) im Lesen in dunkeln Lokalen, 3) in zu feinem Druck der gelesenen Schriften u. s. w.

Hier sind also die zuletzt anfgezählten Momente die nächsten Bedingungen für die iibertriebenen Accommodationsanstrengungen, die mittelbaren für eine Verlängerung des Augapfels und noch mittelbarere fiir den Eintritt von Kurzsichtigkeit. Während wir aber die Kurzsichtigkeit als directe Folge der abnorm langen Angenaxe erkennen, wälırend wir sogar eine numerisch constatirbare Proportionalität zwisehen der Verlängerung der Augenaxe und dem Grade der Kurzsichtigkeit nachzuweisen vermögen, wird es im einzelnen Falle sehr sorgfältiger Erhebungen bedïrfen, um abzuschätzen, wie riel ron jener Abnormitiit auf Rechnung der Erblichkeit, wie riel auf Rechnung der übertriebenen Anstrengungen, und für letzteren Antheil, wie viel wieder auf Rechnnng der verschiedenen, möglicherweise als entferntere Bedingungen mitwirkender Factoren zn setzen ist. Im besten Falle werden wir dabei nieht iiber ein, selır unseharf ansdriickbares Abschätzungsresultat hinaus kommen.

Geben wir der Sache einen allgemeineren Ansdruck: eine plyysiologische Eigenschaft $(E)$ ist von einer anderen veränderlichen Eigenschaft $(x)$ abhängig, sie ist, um den üblichen technischen Ansdruck zu branchen, eine Function dieser letzteren, also:

$$
E=F(x) \text {. }
$$

Seien fiir eine Reihe von besonderen Fällen $E$ und das jeweilen zngehörige $x$ gegeben, so kannst Du daraus das Abhängigkeitsgesetz $F$ bestimmen; oder sind Dir in einem besonderen Falle $x$ und $F$ bekannt, so ist auch $E$ bestimmt.

Ist $E$, anstatt ron nur einem rerïnderlichen Werthe, ron zweien, z. B. von $x$ und $y$, oder von mehreren abhängig, hast Du also die Abhängigkeit:

$$
E=F(x, y) \text { oder } E=F(x, y, z \ldots)
$$

so wirst Du aus ciner Werthreihe von $x$ und gleichzeitigen $E$ weder $F$ bestimmen, noch aus dem Abhängigkeitsgesetze $F$ 
und aus $x$ ein bestimmtes $E$ erhalten, weil hierbei stets noch die veränderliche Bedingung y vernachlässigt bleibt.

Sind aber $x$ und y selbst wieder abhängig veränderliche Grössen, ist z. B. $x$ eine Function von den Veränderlichen $a, b, c$ u. s. w., y eine solche von den Veränderlichen $\alpha, \beta, \gamma$ u. s. w., haben wir also:

so ist

$$
\begin{aligned}
& x=\text { if }(a, b, c \ldots) \\
& y=\psi(\alpha, \beta, \gamma \ldots)
\end{aligned}
$$

$$
E=F[\varphi(a, b, c \ldots), \psi(\alpha, \beta, \gamma \ldots)]
$$

d. h. es besteht zwar eine Abhängigkeit des Werthes $E$ ron $a, b, c \ldots \alpha, \beta, \gamma \ldots$, allein diese Abhängigkeit ist eine mittelbare, im Allgemeinen nicht in einen einfachen Ansdruck zu bringende, und jedenfalls umfassen die Werthänderungen von ", oder von $b$ immer nur eine von den mehrfachen Bedingungen zur Aenderung des Werthes $E$.

Ich behaupte nun, die Körperform ist eine unmittelbare Folge des Keimwachsthums, und bei gegebener Anfangsform des Keimes aus dem Gesetze des Wachstlums abzuleiten. Mein Bestreben geht also 1) auf empirisehe Feststellung des Wachsthrumsgesetzes und 2) auf die Ableitung der sich folgenden Formen des entstehenden Körpers aus jenem Gesetz.

Weiterhin ist aber das Keimwachsthum eine Folge der Eigenschaften des eben befiuchteten Keimprotoplasmas. Diese sind eine Folge von den Eigenschaften der elterlichen Keimstoffe und der Art ihres Zusammentreffens u. s. w. Wir bekommen somit folgende Reihenfolge zu leistender Erklärungen:

1) Erklärung der Körperform aus dem Wachsthum des Keimes;

2) Erklïrung des Keimwachsthums ans den Eigensehaften des befruchteten Keimprotoplasmas und aus den Bedingungen seiner Entwickelung (Temperatur, Ernährungsbedingungen u. s. W.).

3) Erklärung der Eigenschaften des befruchteten Keimprotoplasmas ans den Eigenschaften der elterlichen Keimstoffe und der besonderen Bedingungen ihres Zusammentreffens;

4) Erklärung der Eigenschaften der Keimstoffe ans dem Gange der elterlichen Körperentwickelnng; 
5) Erkliirung der besonderen Beding'ungen der Befruchtung aus den Lebensverhältnissen der beiden Erzenger und so fort.

Erst mit Nr. 5 der obigen Kette beginnt das Gebiet der phylogenetischen Erklärung, und es erstreekt sich von da in periodischer Wiederkehr ins Unermessliehe nach riiekwärts.

Unterscheiden wir zwischen der allgemeinen Aufstellung eines Abhängigkeitsverhailtnisses und zwisehen der scharfen Präcisirung des Abhängigkeitsgesetzes, so werden wir im Grunde blos die letztere als Erklärung bezeichnen diirfen, und es ergiebt sich, dass das, einer wirklichen Erklärung zugängliche Gebiet ein ansmehmend besehrainktes ist. In der iiberwiegenden Mehrzahl der Fälle werden wir froh sein miissen, wenn sich iiberhanpt das Abhängigkeitsverhältniss unzweifelhaft constatiren lässt, oder wem an der Hand der empiriseh gewonnenen Regeln die Mögliehkeit bestimmter Verkniipfung anıähernd aufstellbar ist. Schon die Aehnlichkeit des Sohnes mit dem Vater lässt sich im besonderen Falle nicht durch ein empirisehes Vererbung'sgesetz erklären, weil in vielen Fällen die Aehmlichkeit mit der Mutter, oder mit einem entfernten Verwandten da ist, und weil nus der Grund nubekannt ist, weshalb die Gestalt des Erzengten einmal so, ein anderesmal anders ausfällt. Wir kommen schon hier nieht über die allg'emeine Erkenntniss des Abhängigkeitsrerhältnisses der einen Entwicklung ron der andern hinaus. Bedenken wir num, dass dieselbe Schwierigkeit ron Glied zu Glied sich wiederholt, und dass schliesslich die Abhängigkeit unserer Form ron der Entwicklungsweise unserer Vorfahren nur eine sehr mittelbare sein kamn, so ergiebt sich wenig Hoffnung aut dem Wege schrittweiser Erklärung unsere heutige Form mit Huilfe friiher vorhandener zu erklïren. Auf diese schrittweise Erklärung lässt sich die phylogenetische Formableitung auch gar nicht ein, sondern sie arbeitet mit Hïlfe von Principien, welche ihr erlauben, zahlreiche Stufen der Reihen mit einem Male zn iiberspringen. Das Prineip ron dem Kampt ums Dasein und dem Aussterben der im Kampfe untanglich sich erweisenden Geschöpte, sowie das Princip von der Variation in der Vererbung elterlicher Eigensehaften abstrahiren beide ron einer Erkliirung der Formbeziehungen zwischen Erzeugern und Erzeugten, sie nehmen dicselben als die empirisch gegebenen Elemente der Reehnung an. 
Es bedarf meiner Stimme nieht, nm den Aufsehwung zu schildern, welehen die organische Naturforschung dureh die Einfiihrung der Darwin'schen Prineipien gewonnen hat, noch um die Grossartigkeit und die Menge der neuen Gesiehtspunkte zu preisen, die wir denselben verdanken. Bei aller Dankbarkeit hierfür und bei aller begeisterten Freude hieriiber werden wir uns aber doeh erinnern müssen, dass 1) eine phylogenetisehe Ableitung der Körperform die Erklärung der letzteren aus ihren nächsten Bedingungen, aus den durch die Beobachtung f'estzustellenden Vorgängen im befruehteten Keime nicht entbehrlich macht, und, dass 2) eine, selbst lückenlos hergestellte Reihe der Aseendenten nicht mehr als eine Verknïpfung der Formen unter sich giebt. Eine Reihe aufeinander folgender Formen ist nun einmal, das muss immer wieder betont werden, keine Erklärung, sie zeigt uns nur den Weg, den die Erklärung zn nehmen hat. Für die phylogenetischen Reihen wird sich der Nachweis, dass die Formen gerade in der angegebenen Weise auf einander folgen mussten, d. h. also die wirkliche Erklärung ibrer Succession mittelst der Darwin'schen Principien wohl stets nur unter Znhiilfenahme mehr oder minder willkührlicher Hiilfshypothesen durehfiihren lassen. 


\section{Fünfzehnter Brief.}

Die Beziehungen embryonaler Formen zu einander; die erste Entwicklung ron Amphioxus und ron Petromyzon rerglichen mit derjenigen ron Kinochenfischen.

Lieber Freund! Diesmal stellst Du mir die Forderung, ich möchte mich dariiber aussprechen, wie ich die Bezichungen embryonaler Formen zu einander auffasse, und Du bemerkst mit Recht, dass, falls iberhaupt physiologische und pliylogenetische Formbetrachtung sich nicht principiell ausschliessen, sie auf diesem Boden einander begegnen, und sich dic Hand reichen miissen. Ertreitern wir vorerst unsere thatsiichliche Unterlage; im Anschluss daran, wird uns die Terständigung keine Niihe machen, und zwar schlage ich Dir zumichst ror, mit mir die erste Eutwicklung ron Fischembryonen vergleichend durchzingehelien.

Wir beginnen mit dem Amphioxus, für den ich die bekannte Arbeit ron A. Kowalersky ans den Memoiren der Petersburger Akademie (1S67. Bd. XI) zu Grunde lege. Das Ei des Amphioxus monschliesst eine Protoplasmakugel, welche in ihrer Totalitait sich furcht. Schon rom Stadium der Viertheilung ab ist eine, zwischen den Furchungssegmenten frei bleibende Höhlıng, die Furchungshöhle bemerkbar, welche dureh alle nachfolgenden Stadien persistirt. Im Verlaufe ron $4-5$ Stunden wandelt sich der Keim zu einer aus zahlreichen Zellen gebildeten Hohlkugel (A. Fig. 117) um. Dieselbe flacht sich in der einen Hälfte ab, das abgeflachte Stiick sinkt ein (C), und binnen kurzem ist aus der Kugel cine zweiblïtrige Schale geworden, deren eines Blatt (das animale Blatt, oder 
das Ectoderm neuerer Autoren) die convexe, das andere (das vegretative Blatt, oder Entoderm) die concave Fläche der Schale bildet. Am Rande der Schale gehen beide Blitter in einander iiber, und die friiher kuglige Furehungshöhle ist zu einer schmalen, zwischen denselben vorhandene Spalte reducirt (B). Rasch wächst nunmehr der Umfang der Schale, und mehr und
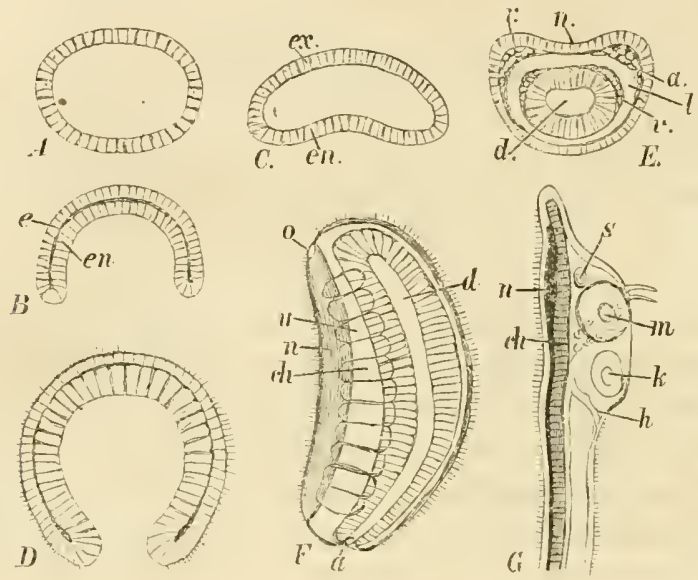

(i)

Fig. 117. Entwicklung des Amphioxus lanceolatus nach A. Kowalevsky, die Figuren sind auf die IIälfte der Originalien reducirt, und ich habe sie, mit Ausnahme von $\mathrm{E}$, so zu einander orientirt, dass die gleichwerthigen Theile gleich gerichtet sind. Bej $F$ weicht der grösseren Deutlichkeit halber die Schraffirung etwas rom Original ab.

A. Das Ei ist eine aus Zellen gebildete einschichtige Blase.

C. Beginnende Einstūlpung der Blase. ex. Ectoderm. en. Entoderm.

B. Die eingestülpte Wandhālfte (das Entoderm berührt die gegenûberstehende (das Ectoderm).

D. Die Oeffnung des secundär entstandenen Sclialenranmes hat sich erheblich verengt.

E. Optischer Querschnitt durch den bereits verläugerten und an der Dorsalseite abgeflachten Embryo, r. Rückenwülste, n. Medullarrinne, a. animale, v, regetative Iuskelplatte, 1. Leibeslróhle, d. Darmbōhle.

F. Embryo mit Medullarrohr (n), das nur vorn bei o. noch offen ist; ch. Ort der Chorda, u. Urwiıbelartige Segmente, d Darm, a. After.

G. Embryo mit leichter lirünmung des Nerveurohrs; n. Nervenrohr, ch. Chorda, s. Sinnesorgan, m. Mundöffuung, k. Kiemenspalte, b. Gefäss,

mehr nähert sich ihre Gestalt wiederum derjenigen einer vollständigen Kugel. Der Zugang zum Schalenraume wird dabei zusehends verengt, und persistirt schliesslich nur als eine kleine Oeffnung (D). Der also sich schliessende Schalenraum ist die Anlage der Darmhöhle, die persistirende Oeffnung der After; aus dem spaltförmigen Reste der Furchungshöhle wird 
die Leibeshöhle. Nach Wiedererreichung der Kugelgestalt wächst das Gebilde in die Länge; der mit der Oeffnung rersehene Pol wird zun hinteren, der entgegengesetze zum vorderen Körperende. Gleichzeitig bildet sich aber auch die Scheidung einer oberen und einer unteren Fläche des Keimes. Jene flacht sich nämlich ab, und sinkt der Länge nach ein $(\mathrm{E})$. Ihre sich erhebenden Seitenrïnder, die sogen. Riickenwiilste, treten sich entgegen, und verwachsen mit einander in einer gestreckten Nath; es bildet sich so die röhrenförmige Anlage des Centralnervensystems ( $F$ ). In diese gleiche Periode fallen die Bildung einer Chorda dorsalis, die Abspaltung einer animalen Muskelplatte vom Ectoderm, einer regetativen vom Entoderm, sowie die Längsgliederung der Muskulatur in urwirbelartige Segmente. Leider sind gerade itber diese wiclitige Periode die bekannt gemachten Thatsachen sehr liickenhaft, und es fehlt besonders die geniigende Controlle mittelst Querschnitten. Die nachfolgende Zeit bringt die Bildung eines vorderen Simnesorganes (Riechgrube), die asymmetrisch auftretende Bildung der Iundöffnung, die Bildung zweier am Kopt' befindlicher Driisen und diejenige der successire auftretenden Kiemenspalten.

Sollte die Entwickelungsgeschichte des Amplioxus im sinne mechanischer Formableitung vollständig durehgenommen werden, so bediurfte es dazu selbstverstäudlich neuer, mit Rücksicht auf die betreffenden Fragen angestellter Beobachtungen und Messungen. Allein auch so, wie sie vorliegen, eröffnen die Nittheilungen Kowalersky's eine Reihe interessanter Gesichtspunkte, von welchen ich Dir nur die wichtigsten hervorheben will. Olne grosse Ueberlegung wirst Du einsehen, dass, wenn eine Kugel in zwei, in einander gestiilpte Halbkugeln sich scheidet, die eine umschliessende Halbkugel grössere Ausdehnung besitzen muss, als die umschlossene, und das Missverhältniss muss sich steigern, je mehr die beiden Halbkugeln wieder zn Ganzkugeln auswachsen. Finden wir in der Folge, dass der, aus der entodermatischen Halbkugel herrorgegangene Primitivdarm nur einen Theil des Raumes ausfullt, welchen die Ectodermwand umschliesst, so besagt dies mit anderen Worten, dass das Flïchenwaehstlum der beiden Kugelhälften ein ungleiches war. 
Aus der Fig. 16 rou Kowalevsky (D Fig. 117) ergiebt sich ferner, dass die Zellen des Ectoderms kleiner sind, als diejenigen des Entoderms, und dass erstere am kleinsten sind in der, zur Bildung des Nerremrohres dienenden Strecke. Dies besagt, dass der Theilungsprocess und damit das Flichenwachsthum in dieser Strecke an raschesten muss ror sich gegangen sein.

Ist anch in friilhester Zeit die Anlage des Nervenrohres etwas rascher gewachsen, als die umgebenden Theile, so erreicht sie doch keinen merklichen Vorsprung. Die Anlage der Chorta dorsalis iiberragt ron Anfang an diejenige des Nervenrohres, und die iiberragende Streeke wird in der näehstfolgenden Zeit nicht kïrzer, sondern länger. Das Nervenrolı erreicht den vorderen Eipol niemals. Dieser Umstand, so wie das Fehlen einer festen Verwaehsung zwisehen den rorderen Enden des Nervenrolires, der Chorda nud des Vorderdarmes sind der Grund, weshalb das rordere Himende hier nicht in gleicher Weise hakenförmig sich umbiegt, wie bei allen iibrigen Wirbeithieren. Leichte Andentungen einer Brickenkrimmmng und einer Mittelwölbung treten in der Fig. 30 ron Kowalersky (117. G.) hervor, so nubedentend jedoeh, dass ich nicht sicher bin, ob iiberhaupt der Zeichner diese Krimmungen mit Absicht so wiedergegeben hat, oder ob es sich nur um Zufälligkeiten handelt. Bei anderen, als der bezeichneten Figm derselben Schrift kehren dieselben nicht wieder. Von einer Hakenkrimmung zeigt keine der vielen Abbildungen aneh nur eine spur. Mit dem Wegfallen ron longitudinalen Kriimmungen des Nervenrohres fällt beim Amphioxusembryo jeg-. liches Motir einer Hirngliederming hinweg, mit dem Fehlen der Hakenkriimmung dasjenige zur Abschnirumg der Augenblasen, mit dem Feblen der Briekenkriimmung das Motiv zur Rautengrubenbildung und zur Bildung einer, hinter dieser einsinkenden Gehörgrube. ${ }^{1}$ ) - Es tritt ferner am Amphioxusembryo weder eine vordere, noch eine lintere Querfalte auf, und dem entspricht der gainzliche Mangel ron Extremitaitenanlagen.

Ueber die Grundbedingungen der asymmetrischen Mundbildnug, so wie der, in eigenthimlicher Weise sich anlegenden Kiemenspalten erlaube ich mir aus dem vorliegenden Materiale keine Sehliisse, ebenso wenig wie iiber die Bildung der Chorda 
und der Muskelplatten. Dagegen mache ich Dich daraut aufmerksam, dass die Gliederung der Muskelplatten in urvirbelartige Segmente hier denselben Bedingungen unterliegt, wie wir sie friiher beim Hiihnchen kennen gelernt haben. Der Zeit nach faillt sie zusammen mit der Hebung der Medullarplatte umd mit einer dorsalwärts concaren Biegung der gesammten Körperaxe (Fig. 21 bei Kowalersky, oben 117, F).

Wemn Du Dir die Miihe ninmst, in : änlicher Weise, wie ich es eben gethan, die zahlreich vorhandenen Beschreibungen und Abbildungen wirbelloser Thiere durchzugehen, so wirst Du auf mancherlei Ankniipfungspunkte für die directe Ableitung der entsteheuden Formen stossen. Es ist, um nur ein Beispiel anzufïhren, anch bei Anneliden und Arthropoden der Eintritt der Längsoliederung des Körpers stets mit einer Läng’skrimmung seincr Axe verkniipft. Eine reiche Ausbeute steht hier demjenigen beror, der das bereit stehende Material mit Sachrerständniss wird zu ergreifen wissen. Meist liegen ja da die Verhältuisse viel einfacher, als bei den Wirbelthieren, und sie sind, was ror Allem ins Gewicht faillth, der messenden Beobachtung viel zugianglicher.

Schon bei den, nächst dem Amphioxus am niedrigsten gewertheten Wirbelthieren, bei den Cyclostomen weicht die Entwicklung ron jenem bedentend ab. Es liegt iiber die Cyclostomenentwicklung eine rortreffliche Arbeit von Max schultze (die Entwicklungsgeschichte rom Petromyzon Planeri. Haarlem 1556) ror, aus der ich die nachfolgenden Angaben und Zeichnungen entlehne. Es schliessen sich die Anfangsstadien in allen wesentlichen Punkten sehr nahe an diejenigen an, die wir für die Amphibien kemnen, und, beilïufig gesagt, ist mil nicht recht klar, weshalb die Zoologen bis in die neneste Zeit den Anschluss der letzteren nicht bei jenen suchen. Die Furchung des Dotters ron Petromyzon ist eine totale, und läuft ganz ähnlich ab, wie die oft beschriebene des Froschdotters. Auf die zwei znerst anfgetretenen Meridianfurchen folgt eine äquatoriale, und ron da ab macht sich, in steigendem Maasse, der Gegensatz geltend zwischen einer oberen und unteren Hailfte des Eies. Erstere ist heller, und ihre Durchfurchung: schreitet reit rascher ror, als diejenige der unteren Hiilfte. Die kleinzellige obere Eihälfte bildet die dïnnere Decke, die 
grosszellige untere Hälfte den dicken Boden einer, im Innern des Eies befindlichen Höhle, der Furchungshölıle (Fig. 11S. A u. B).
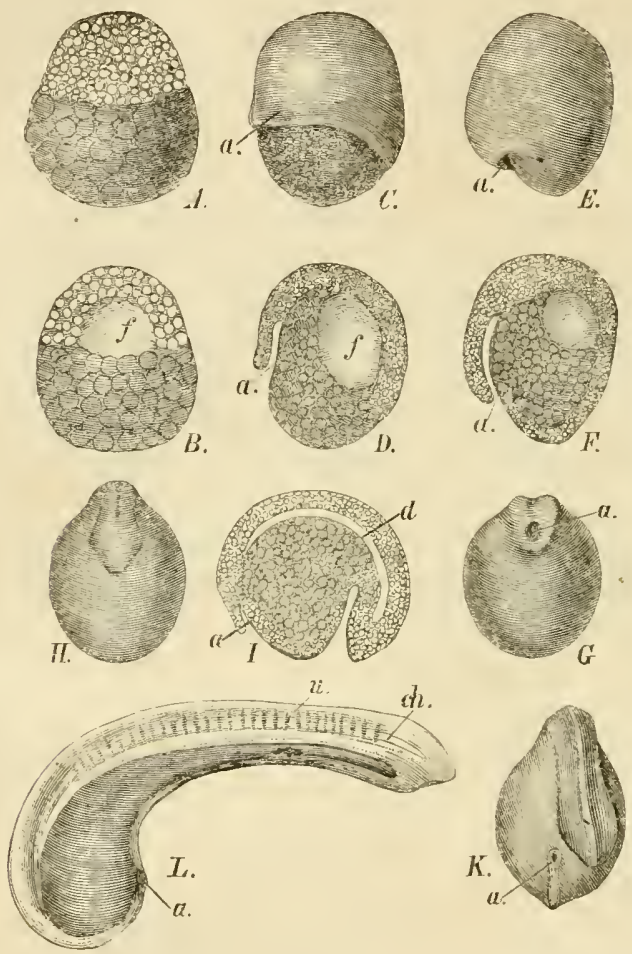

Fig. 118. Entwickelung ron Petromyzon Planeri nach Max Schultze. 2/3 Grōsse der Originalien, somit 20 fach vergrössert. Hit Ausnahme von G, H, K, L sind die Figuren gleich orientirt. Die Durchschnitte $B, D, F$ habe ich soweit modificirt, als zum leichten Anschluss an A, C, E nöthig war. Bedeutung der kleinen Buchstaben wie bei 117.

A. Ei in Furchnng. 35 Stuuden, ungleiche Grösse der Zellell oben und unten

B. Dasselbe in Durchschnitt zeigt die Furchungshöhle.

C. Zunehmende Unwachsung der unteren durclı die obere Hälfte. a, erste Andeutung des Rusconischen Afters. 5s stuuden.

D. Dasselbe in Durclischnitt.

E. 4 Tage alt, die nntere Hälfte ist ganz umwachsen, die obere hebt sich helmartig empor.

F. Dasselbe im Durchschnitt.

G. 51/2 Tage nach der Befruchtung, Ansicht von hinten. Die Rückenwülste und der After sind sichtbar.

H. 71/2 Tage, hopfende. Gehirnanlage geschlossen, Vorsprïnge der Augenblasen sichtbar.

I. Durchschnitt von einem etwas späteren stadinm; Kopfende schon frei abgehoben.

K. 12,-13. Tag. Embryo, dem Ei aufliegend.

L. Eben aus dem Ei gekrochenes Junges.

In rascherem Wachsthum dehnt sich die obere Hälfte aus, und iiberdeckt mit ihrem Rande die untere; schliesslich blcibt von dieser nur noch eine kleine Strecke frei (C u. D). Von einer 
Randstelle (dem Ruseonischen After) ausgehend, bildet sich eine ins Ei sich erstreckende Spalte, als eiste Anlage des Primitirdarmes ( $\mathrm{E}$ bis $\mathrm{F}$ ). Nummehr erheben sich als Längsfalten die zwei Riickenwïlste (G). Im grösseren Theil ihrer Länge dureh eine schmale Rimne getrennt, umkreisen sie mit ihrem vorderen Ende ein breites Feld, welches mit einer quergestellten Falte nach rorn absehliesst. Durch Zusammentreten der Riickenwiilste sehliesst sieh der von ihnen umsäumte Raum, es entsteht so die Anlage des Gehirns mit den Augenblasen und diejenige des Riickemmarkes (H). Zusehends hebt sich von da ab der Kopftheil des Embryo als sehmale Leiste aus der iibrigen Eifläehe empor, Aehnliehes gilt später vom Sehwanzende. Daun vollzieht sich, von rorn naeh riickwiirts fortsehreitend, die Trennung des vorderen Körperendes ron der iibrigen Eikugel (I, K). Der Enbryo durchläuft in seiner Form retortenähnliche Stadien, mit immer lünger werdendem Hals und immer kleiner werdendem Kïrper des retortenartigen Gebildes. Mit einem rerdickten, den unrerbranehten Riest der unteren Eihälfte umfassenden hinteren Körperanhang rersehen, rerlïsst endlich das junge Thier das Ei, um sein selbstständiges Leben zu beginnen (L).

Ohne mieh bei eingehenderen Betrachtungen aufzuhalten, constatire ieh zunäehst nur die, gegeniiber dem oben besprochenen Amphioxis rorbandenen Besonderheiten in den Grundziig'en der Entwickelung, und ich schliesse sofort eine summarische Betrachtumg des Entwicklung'sganges ron Knochenfischen an. Es liegt dariber, theils aus friberer, theils ans nenester Zeit ein reiches, zum Theil sehr sehätzbares, zum andern Theile aber anch sehr widerspruehsvolles literarisehes Material vor. Da hier nieht der Ort zu literariseher Auseinandersetzung ist, so halte ich mich, unbesehadet etwaiger Prioritätsreehte Anderer, an meine eigenen, seit Jahren gesammelten, bis dahin aber nielit im Zusammenhange veröffentliehten Beobachtungen uiber Salmen- und Forellenentwickelung.

Die, ron einer dicken Eikapsel umgebene Kugel des Salmen- und des Forelleneies besteht aus flissigem klaren Dotter, aus einer denselben umspamnenden, Kerme und Fetttropfen fiihrenden Rindenschicht und aus der Keimseheibe. Letztere bildet einen, rerhäItnissmässig nu geringen Theil des gesammten Eiinhaltes. Sie liegt flach ansgebreitet der 
Rindensehicht auf, und endigt unbestimmt mit zugeschärftem Rande. Nach Eintritt der Befinchtung zieht sie sich zusanmen zn einem compacten Klumpen, and nun begimnt die Durehfurchung auf deren nïhere Beschreibung ich hier nicht eingrehen werde. Das Eine hebe ich indess hervor, dass die untere und die obere Hälfte des Keimes von Anfang ab dureh ungleichen Fortgang des Processes sich unterscheiden. Die untere Hälfte ist noch eine zusammenhäingende Platte, wemn die obere bereits in $\delta$ Felder zerkliftet ist. $/ / u$ der Zeit ist auch zwisehen den Segmenten der oberen Hailtte einerseits
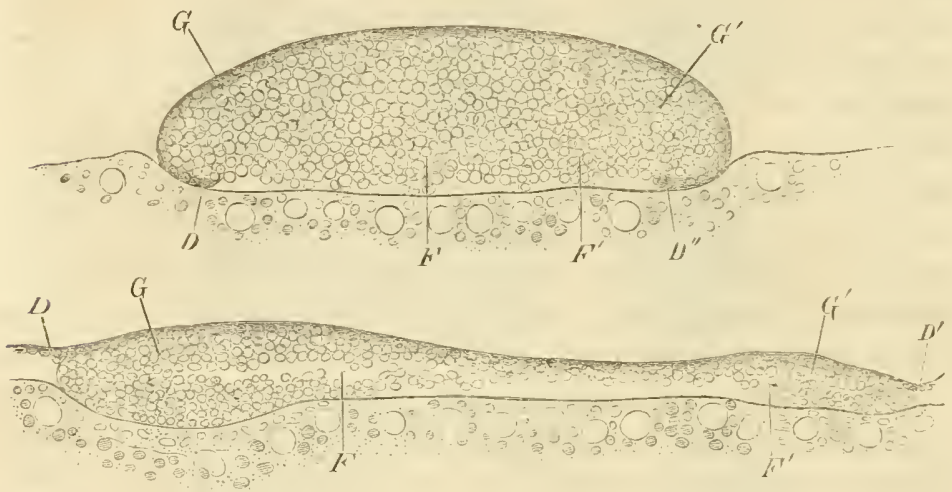

Fig. 11\%. Lachskeim im Beginn des 6. Tage nach der Befruchtung, senkrecht durchschnit-

D. Deckschicht. G. Ge Gewölbtheil. F. Füllungsmasse.

Die unter dem Keim befindliche, mit runden Köpern verschiedener Grösse dnrchsetzte Schicht gehört zur Dutterrinde.

Fig. 12n. Lachskeim im leginn des 7. Tages nach der Iefruchtung senkrecht durcli-chuitten. It mal vergrössert. Bezeichnungen wie bei $11 !$.

und der unteren Platte andererseits eine flache Höhle rorhanden. In den späteren Furchungsstadien rerlieren sich sowohl die Höhle, als der starke Gegensatz verschieden grosser Zellen.

Am 6. Tage etra erscheint der Keim als ein flach gewölbter Kuchen mit geruncleter Peripherie (Fig. 119). Sein Durchmesser betriggt zu der Zeit gegen 1,5 Mm., seine Dicke ca. 0,45 $\mathrm{Mm}$. Der Durchmesser der Zellen sehwankt um 25 " herum. Die Zellen, welche der Oberfläche zugekehrt sind, sind etwas kleiner, als die iibrigen, und sie bilden eine dichtgefiigte Sichicht mit glatter ausserer Oberfäche. Man hat die Schicht als Decksehieht bezeichnet. Die Deckschicht iiber- 
sehreitet den Aequator des Keimes, und endigt an seiner unteren Fläche mit freiem Rande. Die von der Deckschicht umfassten Zellenmassen zeigen noch keinerlei Schichtenseheiflung, nur soviel ist zu erkennen, dass sie in den der Deekschicht zugekehrten Abschnitten dichter sind, als in den tiefer liegenden. Leichterer Verstandigung halber wollen wir jene als Gewölbtheil, diese als Fiilungsmasse des Keimes bezeichnen. Die Fiillungsmasse ruht anf der unterliegenden Dotterrinde nur mit einzelnen Stiitzen auf, dazwischen bleiben kleine Liicken frei.

Raseh geht der Keim ans dieser Form in eine andere über, deren senkrechten Durchschnitt Fig. 120 wiedergiebt. Er flacht sich nimlich stark ab und sein Durehmesser wäichst nahezı um die Hälfte (bis zu 2,2 Mm.). WVahrend bis dahin die Mitte der dickste Absehnitt der Keimseheibe war, ist nunmehr die Mitte der Scheibe verdiinnt, und sie verdiinnt sich in der Folge noch riel beträchtlicher. Dagegen ist der Scheibenrand diek, und wir werden ihn demgemaiss als Randwulst von der diimnen Mittelscheibe unterscheiden. Letztere ist ist ron der Dotterrinde durch eine flache Spalte, die Keimhöhle gesehieden.

Die Mlasse des Randwulstes ist ungleichmässig gruppirt: in den einen Theile seines Umfanges besitzt der Wulst riel bedentendere Dicke und Breite als in anderen. Ferner ist im Randwulst, mit allerdings unscharten Anfange, eine Schichttrennung eingeleitet. Dieselbe prïigt sich in der nachfolgenden Zeit röllig scharf aus, ohne jedoch den äussersten Rand zu erreichen. Die eine obere Keimschicht ist die Anlage des animalen, die untere die des regetativen Blattes. Der centrale Saum der unteren Keimschicht verliert sich ohne bestimmte Gränze, theils am Boden der Keimhöhle, theils an der unteren Fläche der Mittelscheibe.

Ueber den Mechanismus, welcher der Keimscheibenumwandlung zu Grunde liegt, giebt das Verhalten der Deckschicht ziemlich klaren Anfschluss. Dicselbe war, wie Fig. 119 zeigt, Anfangs zur Basis des Keimes herabgebogen, num aber nach Abplattung des Keimes endigt sie (Fig. 120) frei am Rande der oberen Fliche, d. h. sie hat sich mitsammt der anhaftenden Dottermasse aufgebogen. Es tritt dabei folgende Unlagerung ein: 
Die obere Schicht des Randwulstes geht hervor aus der ¿iquatorialen und subäquatorialen Zone des friiheren Gewölbtheiles. Die Kuppel des urspriinglichen Gewölbes wird zur verdiinnten Mittelscheibe. Die untere (vegetative) Schicht des Randwulstes ist die zur Seite gezogene und auseinandergezerrte Fiillungsmasse. Kleine Reste der letzteren erhalten sich noch in Zellen, die theils an der Decke, theils am Boden der Keimhöhle vorhanden sind.

Untere und obere Schieht des Randwulstes stehen unter ungleichen mechanischen Bedingmingen. Anch hier ist die obere Schicht die raseher wachsende, auf die untere aber wirkt vermöge ihrer Randanheftung ein Zug, der sie, im einen kurzen Ausdruck zu brauchen, unter der oberen Keimschicht wegzieht. Als Folge dieser Verschiebung tritt die Spalte auf, welche die vegetative Schicht ron der animalen tremnt. Sie bekommt, wie andere Zerreissungsspalten, nur allnïhlig scharfe Umgr:inzung:

Den Grund fiir die so rasch eintretende Abflachung des Keimgewölbes möchte ich in dem zunehmenden Wachsthum der äquatorialen und subäquatorialen Zone suchen, welehe für das Gewölbe die Stelle des Widerlagers vertreten, und mit deren Ausweitung eine ähnliche Folge eintreten muss, wie beim Weichen der Widerlager eines Steingewölbes.

Nachdem der Keim die Gestalt einer flachen Scheibe mit dicker Randwulst und dünner Mittelscheibe angenommen hat, beginnen dié ersten Spuren einer geformten Embryonalanlage aufzutreten. An dem dicken Abschnitte des Randwulstes zeigt sich eine breite, gegen das Innere kleeblattförmig vortretende Platte, deren oberflichliche Gestaltung Dir am besten aus Fig. 121 ersichtlich werden wird. Eine in drei Buchten auslaufende Grube nimmt das Mittelfeld der Platte ein, und dureh eine tiefe Längsrinne wird sie in zwei Hälften geschieden.

Die Bedentung des Gebildes wird verständlich, wenn man es mit den nachfolgenden Stufen vergleieht: Der Lachsembryo Fig. 121 ist rom Beginn des 12. Tages, der ron Fig. 123 rom Beginn des 14. und der von 124 rom Beginn des 15 . Tages. Dazwischen habe ich noch einen Forellenembryo Fig. 122, gleichfalls rom 12. Tage, als Verbindungsglied cingeschaltet. Figur 124 und schon 123 zeigen uns einen weit gegliederten Embryo, an welchem wir keine Miihe haben, uns zurecht zu 
Die erste Entwicklung des Amphioxus und des Petromyzon. 197

finden: das Vorderhirn, die Augenblasen, letztere dem langgestreckten Mittelhirn seitlich anliegend, die breite Rautengrube mit Hinterhirn und Nachhirn, die Gehörgrube, die Riickenmarksanlage und die Urwirbel sind rorhanden und sogar die Anlagen der 2 Brustflossen erkennbar. Die 'Zeichnungen' sind

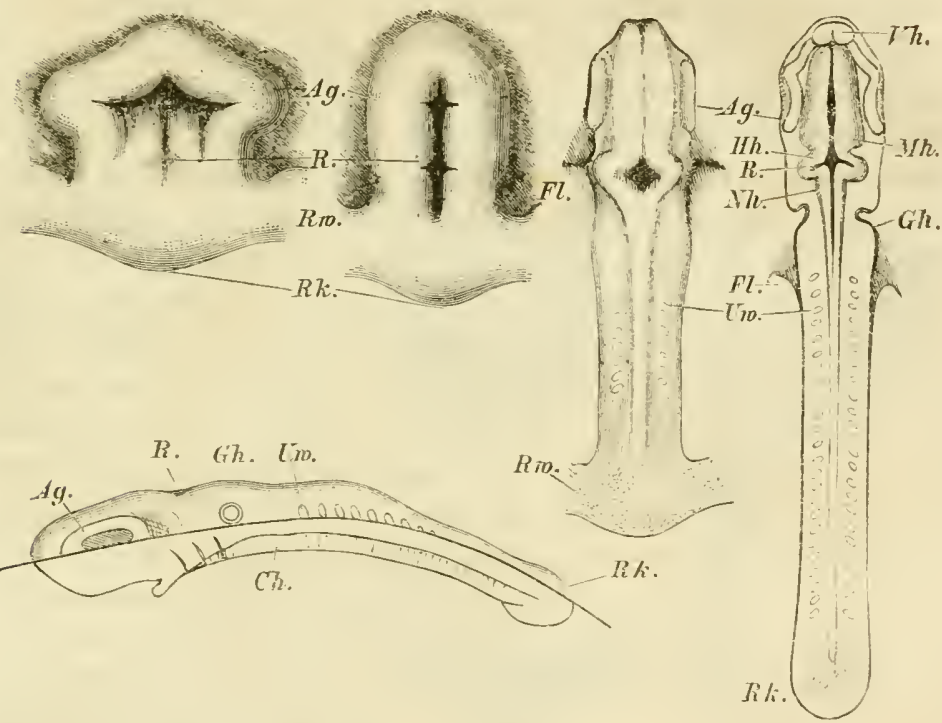

Fig. 121. Lachsembryo vom Beginn des 12. Tages.

Fig. 122. Forellenembryo vom 12. Tage.

Fig. 123. Lachsembryo vom Beginn des 14. Tages.

Fig. 124. Lachsembryo vom Beginn des 15. Tages.

Fis. 125. Profilansicht von 123. Die Theile unter dem Strich sind nach Durchschnitten linzu construirt.

Vergrösserung 20. Die beiden ersten Figuren sind in der Reliefansicht bei Beleuchtung ron oben gezeichnet. Die Fig. $124 \mathrm{im}$ durchfallenden lichte. Fig. Iㄴ? ist nrsprünglich anch im auffallenden Lichte gezeichnet, das Gehirn der äusseren Iodellirung entsprechend

Vh. Yorderhirn.
Mh. Mittelhirn.
Hh. Hinterhirn.
R. Rauten rube.
Nh. Nachlirn.
Ag. Augenblase.
eingetragen.

Gh. Gehörgrube.
Cr. Urwirbel.
Fl. Flossenanlage.
Pw. Randwulst.
Pk. Randknospe.
Ch. Chorda dorsalis.

alle bei derselben 20maligen Vergrösserung mit dem Zeiehnumgsprisma aufgenommen, und ieh labe sie so orientirt, dass deren vorderer Rand in eine Gerade faillt. Es wird dadurch möglich, sie auf einander zu beziehen, und aus den späteren Stufen die Orientirung für die friiheren zu gerrimen. 
Es ist offenbar, dass die Anlage Fig. 121 nur diejenige des Kopfes ist; die breiten Seitenlappen sind die beiden Augenblasenanlagen, die mit $\mathrm{R}$ hezcichnete hintere Quergrube die erste Andeutung der Rantengrube. Im Bereiche der, dem Ende einer Querfurche angefiigten Augenblasen ist, wie dies Medianschnitte ergeben, die Embryonalanlage ilırer gesammten Dicke nach, stark nach abwärts geknickt. - Die bei Fign1 121 weit offene Grube hat sich bei Fig. 122 nahezu geschlossen und die beiden Augenblasen, anstatt fast rechtwinklig' ron der Gehimanlage abzustehen, haben sich flach an diese angelegt. Noch bedeutender ist die Verschmailerung der Kopfanlage bei Fig. 123 u. 124. Dort klafft das Gehirnrohr an seinem rolderen Ende, bei Fig: 124 ist es völlig geschlossen.

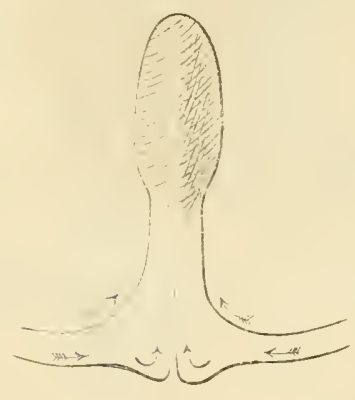

Fig. 1:21j.

Wenn nun aber die gesammte, bei Fig. 121 sichtbare Anlage nur Anlage des Koptes ist, wo bleibt dic Anlage des Rumpfes, da doch der Rumpf sehr rasch, und gleich in bestinunter Gliederung hinter dem Kopfe auftritt? Weun etwa jene aus der Kopfanlage hervorgesprosst sein sollte, so wiircle dies jedenfalls eine Rapidität des Wachsthums roranssetzen, die röllig in Widerspruch wïre mit Allem, was wir sonst auf numerischem Trege iiber den Ablanf dieses Processes erfalıren. -- Das Material zur Rumpfanlage ist im Randwulst aufgespeichert und es gelangt dadurch an seinen Ort, dass jeweilen die, dem hinteren Ende des bereits abgegliederten Embryo zunichst liegenden Strecken an diesen sich heranschieben, und iln nach riekwäirts verlängern. Dabei liefern die änsseren dem convexen Saume näher liegenden Zellen des Wulstes die Axialgebilde, die des inneren, concaven Saumes gehen in die Seitentheile des Körpers über. Am hinteren Ende der bereits geformten Embryonalanlage liegt ein kleiner gerundeter Vorsprung, die Randknospe, die wir uns eben durch die Zusammendringung hinterer Randzellen gebildet zu denken haben. Fig: 126 veranschaulicht schematisch den Hergang und die Pfeile bezeichnen dabei die Reihenfolge der, in 
der Riehtung ron hinten nach rorn auf einander folgenden gleichwerthigen Theile.

Es geht die Aulage des Embryonalkörpers Hand in Hand mit einer Umwachsung des gesammten Dotters durch die Keimseheibe. Diese dehnt sieh, nachdem sie sich cinmal in der friiher beschriebenen Weise abgeflacht hat, rasch aus, erreicht und übersehreitet mit ihrem Rand den Aequator der Knngel; sehliesslich bleibt rom Randwulst nur noch ein kleiner Ring iibrig, dessen Hïllten sich damn auch noch rerbinden. Es ist sonach die Urantage des Körpers ein platter King, dessen Breite mid Dicke an einer Stelle, dem zilkïnftigen Kiopfende, ein Maxinum, am gegeniiberliegenden, dem Schwanzende, ein Minimum besitzt. Sueeessir legen sich, in der Art, wie dies die Fig. 12i-130 schematisch reransehaulichen, die zwei Seitenhälften des Ringes an einander und rereinigen sich als symmetrische Körperliälften. Dabei bedürfen das Kopfende und das änsserste Schwanz-
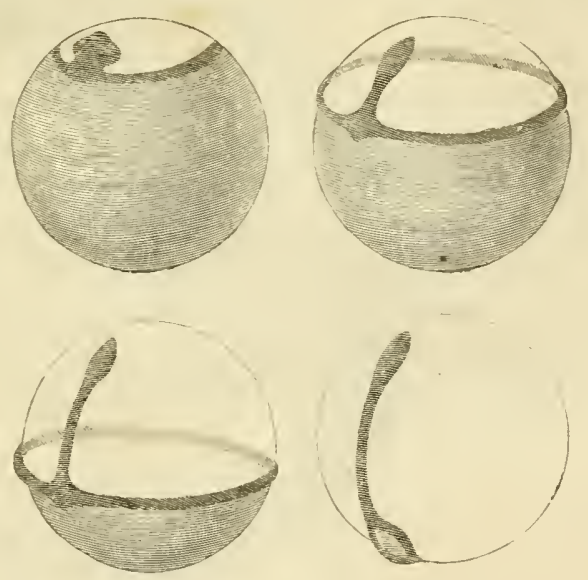

Fig. $127-13 v$,

Schematiche Zeichnungen un die Lmwaclisung des Do:ters durch die heinsoleibe und das bleichzeitige Lăngenwachsthum des Embryo darzustellen. ler unbedeckte lotter ist chraffirt, der Embryo und der liandwulst dunkel. der übrige Theil der lieimhant hell. ende keiner Verwach-

sung, weil ihre Seitenlü̈lften ron Anfang an verbunden sind. Die in der späteren Medianebene des Körpers liegenden Gebilde bilden Anfangs die Peripherie der Selheibe, nnd hier, wie unter den röllig anderen Verhältnissen beim Hühnehen siud liings der Axe animales und regetatires Blatt nicht ron einander geschicden.

In Fig. 131 habe ich, um Dir die Vorgänge der Dottermurachsung: und der gleichzeitigen Körperbildung in ihren gegenseitigen Beziehungen dentlich zu machen, vier Entwieklungsstadien des Lachsembryo mit den richtigen, 10faeh rer- 
grösserten Maassen auf eine und dieselbe Kugel projicirt. Die doppelte iiber die Kugel weglaufende Contourlinie $(1,2,3)$ bezeichnet jeweilen die der betreffenden Embryonallänge entsprechende Ausdehnung des Randwulstes.

Die mechanische Analyse der Dotterumwachsung und der gleichzeitigen Bildung des Embryo bietet bedentende Schwie- rigkeiten, mit deren Discussion ich Dich hier nicht behelligen will, weil sie ein Eingehen in detaillirte Betrachtungen verlangen wiirde.

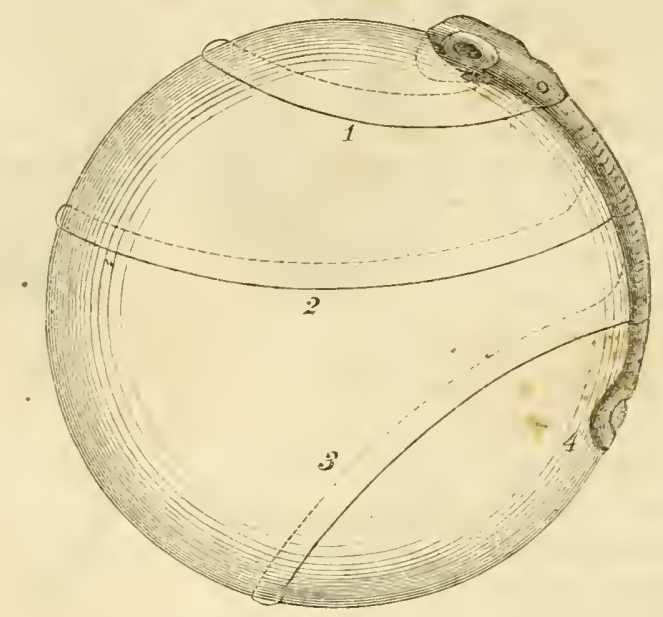

Fig. 131. Lachsei Inmal vergrỏssert. Der Embryo im Profil gesehen, der Kandwulst für vier verschiedene Entwicklungsstadien eingezeichnet.

Wirfst Du noch einmal einen Blick auf die eben betrachteten drei Formen von Fischentwicklung, vergleichst Du sie unter einander; und mit der friher betrachteten Entwicklung des Hiihnchens, so siehst Du, wie gerade einer der fundamentalsten Entwicklungsvorgänge, die Alogliederung des Embryonalleibes aus dem $\mathrm{Ei}$ in verschiedenster Art vor sich zu gehen vermag. Mit allem Aufwande Deiner Phantasie luättest Dn bei einem Versnche, aus der Amphioxusentwicklung diejenige des Petromyzon, oder des Salmens abzuleiten, sicherlich Schiffbruch gelitten; und jetzt, nachdem Dir jede dieser Entwicklungen ihrem allgemeinen Gange nach dargelegt ist, wirst Du doch kaum im Stande sein, ein allgemeines Schema der 
Fiseh- oder der Wirbelthierbildung zu entwerfen. Nicht einmal die Bildung der Chorda, oder diejenige des Medullarrolires lassen sieh zur Zeit miter gemeinsame Formel bringen. Nur wenige Ziige bleiben uns schliesslich als allgemeinste iibrig: die Ungleichleit in Wachsthum der verschiedenen, den Keim zusammensetzenden Zellenmassen, die in Abhängigkeit hiervon erfolgende Seheidung der Sehichten, die Verwendung der rascher wachsenden Schichten zur Bildung des centralen Nervensystems und der äusseren Leibeswand, die der langsamer wachsenden zur Bildung (les Primitivdarmes. ${ }^{2}$ ) So, wie die Dinge jetzt stehen, drängt sich vor Allem die Frage auf, wie bei so versehiedenartigen Anfüngen der Entwicklung die Aehnlichkeiten in der nachfolgenden Gliederung und in der bleibenden Organisation der sich entwickelnden Geschöpfé zu Stande kommen. Offenbar giebt die Aelnliehkeit der Formen im Beginn ihres Werdens keinen unmittelbar anwendbaren Maassstab fïr die tieferen Uebereinstimmungen in den die Entwicklung bestimmenden Grundbedingungen. Ein solcher ist auf dem Wege rein morphologischer Betrachtung und ohne Einfuhrung physiologiseher Gesichtpunkte iiberhaupt nicht zu finden. 


\section{Sechszehnter Brief.}

Ueber die specifische Physiognomie jüngerer Embryonen.

Lieber Fremd! Du hast Dich wohl aus meinem letzten Briefe itberzengt, dass ron einer Uebereinstimmung in den frihesten Formen embryonaler Wesen jedenfalls nur cum grano salis gesprochen werden darf. Ton einem Amphioxusstadium zum Beispiel bei einem Ḱnochenfischembryo zu reden, wiirde geradezu lächerlieh klingen, denn das erste was iiberhaupt am Knochenfischkeim ron Formanlage hervortritt, sind die Anlagen des Gehirns und der Angen d. h. von Organen, die dem Amphioxus zeitlebens fehlen. Auch miissten wir, um die Erfahrungen iiber Knochenfisehentwicklung mit denen iiber den Amphioxusbau phylogenetisch zusammen zu reimen, "Fülschungen “ der Miiller'schen Regel amehmen, die selbst das auf diesem dehmbaren Boden erlaubte Maass weit iiberschreiten wiirden. Hätte ich Dir hier iiber phylogenetische Untersuehungen zu berichten, so wiirde ich mich daher atteh in Betreff der Fische mit dem Geständniss begniigen, dass mittelst der jetzt giiltigen Methoden das Anssehen der "Urfische" nicht feststellbar sei.

Diese Anfgabe liènt mir indess fern, und so verweile ich auch nicht lïnger bei den Fischen, sonderı führe Dir heute cin paar Embryonen von höheren Wirbethieren, des Hubnes mond einiger Sängethiere ror, um daran zu untersuchen, welehe von deren äusserlichen Charakteren gemeinsam, welche bei verschiedenen Embryonen verschieden sind. Die zu betrachtenden Embryonen sind sämmtlich auf der Stufe bereits vorhandener, aber noch unvollkommen gegliederter Extremititen. leh habe sie so, wie mir sie der Zufall zuführte, nur mit der 
Riicksicht gewïhlt, möglichst entsprechende Entwieklungsstufen zu haben. Die beifolgenden Zeichnungen aber sind sämmtlich mit Hülfe des Zeichmungsprismas aufgenommen, ihre Vergrösserung eine Smalige.

Fig. 132 zeigt Dir einen menschlichen Embryo, Fig. 133 einen gleichgrossen Schweinsembryo in der Profilansicht. Letzterer ist um etwas Weniges in der Entwiekelung hinter ersterem zuriick, wenigstens was die Ausbildung der Extremitäten anbetrifft. Bei beiden Embryonen ist der Kopf in bekannter Weise stark vorn übergebengt, der Riicken im Bogen gekrümmt, das Schwanzende vor del unteren Bauchfläche emporsteigend. Am Kopfe erkennt man dureh die äussere Bedeckung hindureh die Hauptabtheilungen des Gehirns; auch die starke Brickenkrümmung macht sich äusserlich bemerkbar, sowie die dahinter befindliche Gehörblase. Zum Auge führt rom Mundnasenraume her eine noch offene Spalte (die Augennasenrinne). Zwischen sie und die, gleichfalls offen daliegende Riechgrube schiebt sich der dreieckig gestaltete seitliche Stirnfortsatz, dalinter folgt der breite, bis zur queren Mundspalte reichende Oberkieferfortsatz. Hinter dem Munde liegt der Unterkieferfortsatz, an welchem beim menschliehen Embryo schon deutlich ein Lippentheil sich absetzt. Nur folgen die Schlundspalten mit dẹn dazwischen liegenden Schlundbogen. Sowohl am rorliegenden menschliehen, als am Schweinsembryo sind jederseits drei Spalten mit Sicherheit zu erkennen.

Am Rumpfe heben sich Rïcken- und Banehtheil, oder hinterer und vorderer Theil ziemlich scharf von einauder $a b$ durch Vorhandensein einer Leiste, aus welcher die vordere und die hintere Extremität hervortreten (Wolff'sche Leiste). Am Riickentheil macht sich die Glieclerung der Urwirbel äusserlich bemerkbar. Die stark gewölbte Bauchfläche lässt zum Theil die Contouren von Herz und von Leber durehschimmern. Der Uebergang der Banchwand in den Nabel liegt bei beiden Embryonen verhältnissmässig weit unten.

Soweit stimmen beide Embryonen in ihrem äusseren Ansehen wesentlich überein. Sebr erlebliche Unterschiede sind aber namhaft zu machen, sobald wir auf die relative Massenvertheilung unser Augenmerk richten. Du siehst auf den ersten Blick, dass beim menschlichen Embryo die Entwicklung des 
Kopfes eine sehr viel beträchtlichere ist als beim Embryo des Schweines. Dort fällt auf den Kopf nahezu die Hälfte des vom Körperumriss eingenommenen Flächenraumes, hier kaum viel mehr als ein Fiinftheil. Der Kopf selbst aber, und der vordere Halsabschnitt sind bei beiden sehr von einander abweichend. Denkst $\mathrm{Du}$ Dir die Augennasenrinne ïber das Auge hinaus bis zur gegenuiberliegenden Contour verlängert, so fällt vor diese Linie beim menschlichen Embryo ein Stück,

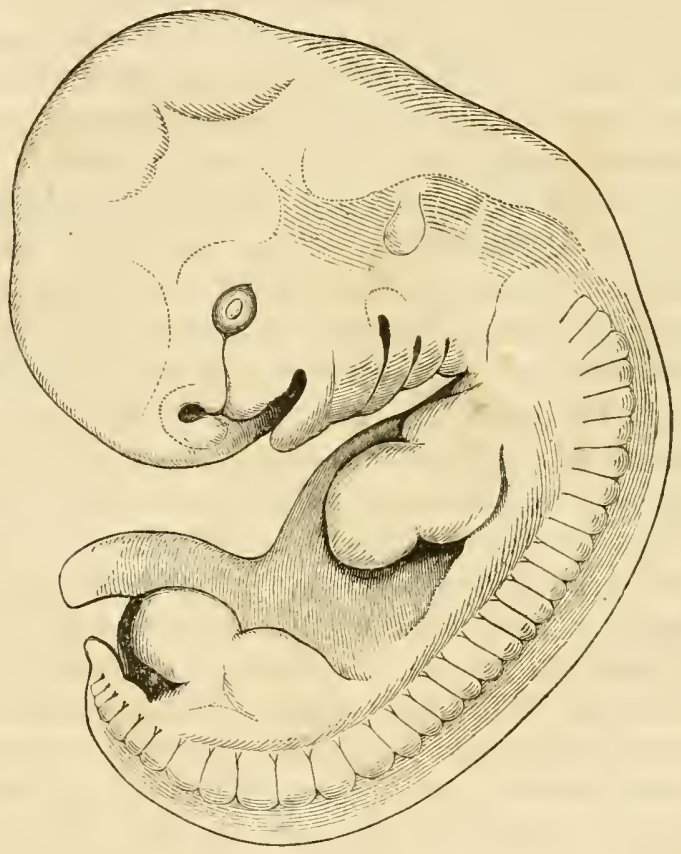

Fig. 132. Menschlicher Embrỹo, Smal vergrössert.

das nahezu die Hälfte, beim Schweinsembryo ein solches, das etwas über ein Viertheil von der Gesammtkopflaiche bildet. Somit besitzen beim menschlichen Embryo schon zu der Zeit das Gehirn überhaupt, und speciell das Vorderhirn einen sehr bedeutenden Entwicklungsvorsprung. Auf das Hemisphärenhirn entfallen bei Fig. 132 etwa $4 \sqsubset \mathrm{Cm}$., d. h. gegen ein Viertheil der Gesammtkopffläche, beim Schwein nur etwa nur $0,75 \square \mathrm{Cm}$., d. h. nur etwa ein Zehntheil der Gesammtkoptfläche. 
Umgekehrt als für das Gehirn stellt sich die Sache für die Anlage der Kiefer und der Schlundbogen. Wie plump erscheint insbesondere der (bei der Anlage des äussern Ohres vorzugsweise betheiligte) zweite Schlundbogen des Schweinsembryo gegeniiber demjenigen des Menschenembryo. Es bedarf beim Vergleich der beiden Figuren keines besonderen Scharfblickes, um zu erkennen, dass die Bedingungen für eine

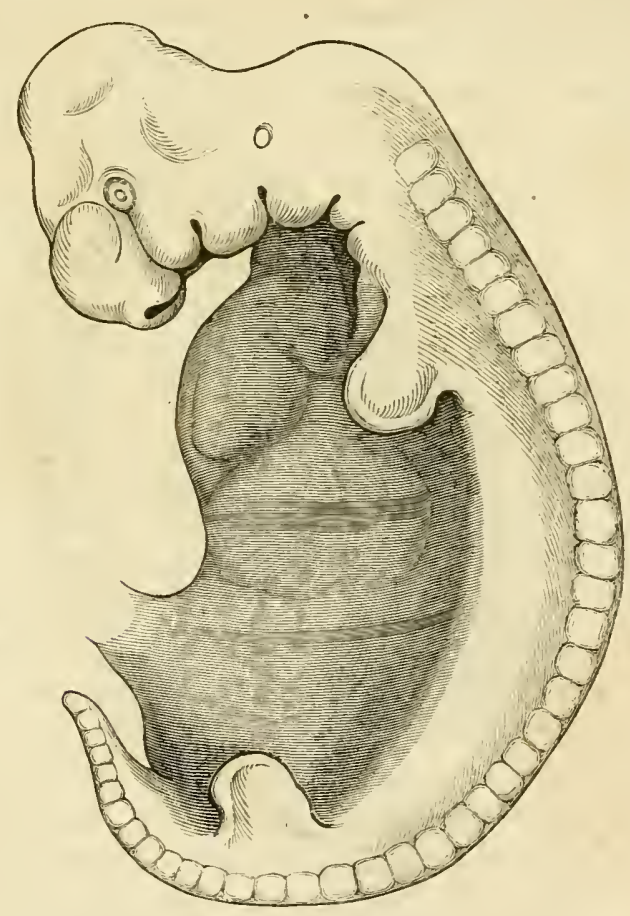

Fig. 133. Embryo des Schweines, Smal vergrössert.

relativ mächtige Entwicklung des Gesichtsschädels beim Schwein sehr viel günstiger liegen, als beim Menschen, und Du wirst in Einzelnen auch beachten, wie beim Schweinsembryo die Umgebung der Nasengrube bereits zu einem selbstständigen Riissel sich empor zu heben beginnt.

Was den Rumpf anbetrifft, so zeigt der Schweinsembryo eine auffallend starke Entwicklung des Bauchtheiles. Beim 
menschlichen Embryo ist besonders die Gliederung des Ruickens bemerkenswerth, die ich mit Sorgfalt copirt habe. Die einzelnen Segmente sind ungleich, und den späteren Grössenunterschieden der Ganglien und Nervenstämme entsprecheud, heben sich die unteren Hals- und oberen Riickensegmente, sowie die Segmente der Lenden- und oberen Sakralparthie durch ihre

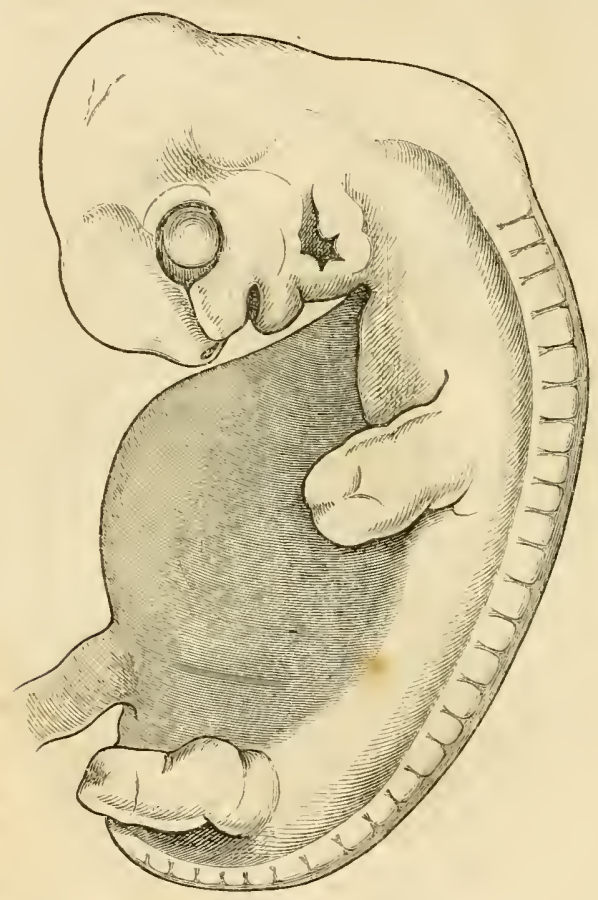

lig. 131. Embryo des Rehes, Smal vergrōssert

bedeutendere Breite von den iibrigen ab. Dass der Schwanztheil des Rumpfes auch beim menschlichen Embryo selbstständig hervortritt, wirst Dn zwar beachten, zugleich aber auch wahrnehmen, dass dieser Körperabschnitt von bescheidenen Dimensionen ist, und dass demnach seine spätere Verdeckung durch das Wurzelgebiet der unteren Extremitäten keine Schwierigkeiten für das Verständniss bietet. 
In Fig. 134 siehst Du den Embryo eines Rehes bei derselben 8maligen Vergrösserung. In allen zwischen dem menschlichen und dem Schweinsembryo hervorgehobenen Differenzen schliesst sich der Rehembryo dem letzteren viel näher an, als dem ersteren. Obwohl der Kopt nicht mehr das bedeutende Missverhältniss zeigt, wie beim Schwein, so bleibt er doch noch weit zuriick hinter dem menschlichen. Auch hier ist das Vorderhirn verhältnissmässig klein, die Gesichtsanlage dagegen, einschliesslich des mittleren Stirnfortsatzes wohl ausgeprägt. Der Bauchtheil des Rumpfes ist, wie beim Schwein sehr bedentend. Abgesehen von der weiter fortgeschrittenen Ausbildung des äusseren Ohres unterscheidet sich der Rehembryo vor Allem in Betreff der Angenentwicklung sowohl vom menschlichen, als rom Schweinsembryo. Der Durchmesser des Auges übertrifft um mehr als doppelt den des Schweinsauges. Es wird dadurch, wie leicht ersichtlich, die Gestalt des Oberkieferfortsatzes mit beeinflusst; der obere Abschnitt desselben wird entsprechend zuriickgedrängt.

Viel näher als Schwein und als Reh kommt dem menschlichen Embryo in mancher Beziehung derjenige des Kaninchens, Fig. 135. Bei ihm nimmt der Kopf nahezu 2/5 vom Flächenraum des iibrigen Körpers ein, und auch das Verhältniss zwischen dem Rücken- und dem Bauchtheile des Rumpfes ist ein weit menschenähnlicheres. Vergleichen wir indess den Kopf des menschlichen mit dem Kopfe des Kaninchenembryo, so ergeben sich noch Unterschiede genug. So ist bei letzterem der, das Mittelhirn umschliessende Scheiteltheil des Kopfes relativ viel mächtiger, als bei jenem. Es ist ferner das Auge bedeutend grösser; es tritt die Umgebung der Riechgrube in sehr viel selbstständigerer Weise hervor, sowie auch die äussere (aus der ersten Schlundspalte hervorgegangene) Ohröffnung weit und von einem vorspringenden Wulste umgeben ist.

Es ist von Interesse, auch die Embryonen zweier sich näherstehender Thiere zu vergleichen, und aus dem Grunde füge ich dem Kaninchenembryo einen gleich grossen Meerschweinchenembryo bei, Fig. 136. Die beiden Formen stehen sich allerdings näher als irgend welche der oben betrachteten. Immerhin wird Dein aufmerksames Auge hier noch eine 
Reihe von Unterschieden wahrnehmen, wie die grössere Länge des Kopfes im Vergleich zu seiner Höhe, das stärkere Vortreten des Vorderhirns gegeniiber dem Mittelhiru, die noch massigere Entwickelung des äusseren Ohres u. A. m.

Nehmen wir nun zu diesen paar Säugethierembryonen den Embryo eines Huhnes, so treten uns an diesem neue und höchst charakteristische Eigenthümlichkeiten entgegen. Der Körper ist schlanker als bei sämmtlichen, oben betrachteten

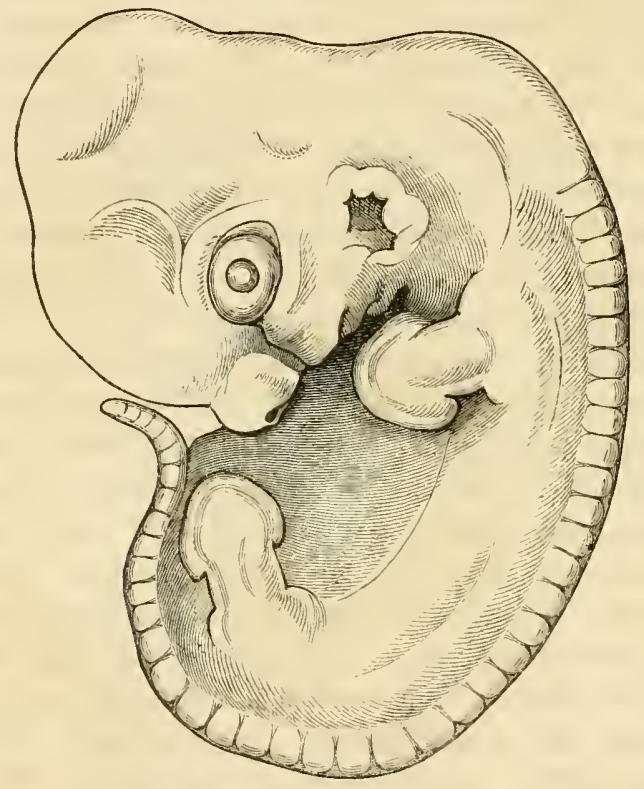

Fig. 135. Embryo des Kaninchens (14 Tage p. foec.) Smal vergrössert.

Embryonen, und wenn wir das Verhältniss des Kopfes zum Körper nur im Allgemeinen betrachten, so steht der Hühnerembryo dem menschlichen fast gleich. Auch bei ihm nimmt der Kopf beinahe die Hälfte der Gesammtfläche ein. Allein wie verschieden sind die beiden Köpfe! Beim Hühnchen ein kleines Vorderhirn, ein grosses Mittelhirn und ein colossales Auge, dessen Durchmesser den des menschlichen um mehr, als das vierfache iibersteigt. Denkst Du Dir die beiden Kugeln, das Mittelhirn und den Augapfel aus dem Kopf heraus ge- 
schnitten, so bleibt Dir vorn sowohl als hinten ein verhältnissmässig kleines Stück, jedes nicht viel iiber ein Sechstheil der Gesammtkopffläche betragend.

In der geringen Entwicklung der Gesichtsanlage im Vergleich zur Gehirnanlage bleibt das Hiilhnchen sogar noch hinter dem menschlichen Embryo zuriick. Die Stirn- und Kieferfortsätze, sowie die Schlundbogen sind, wenigstens für die

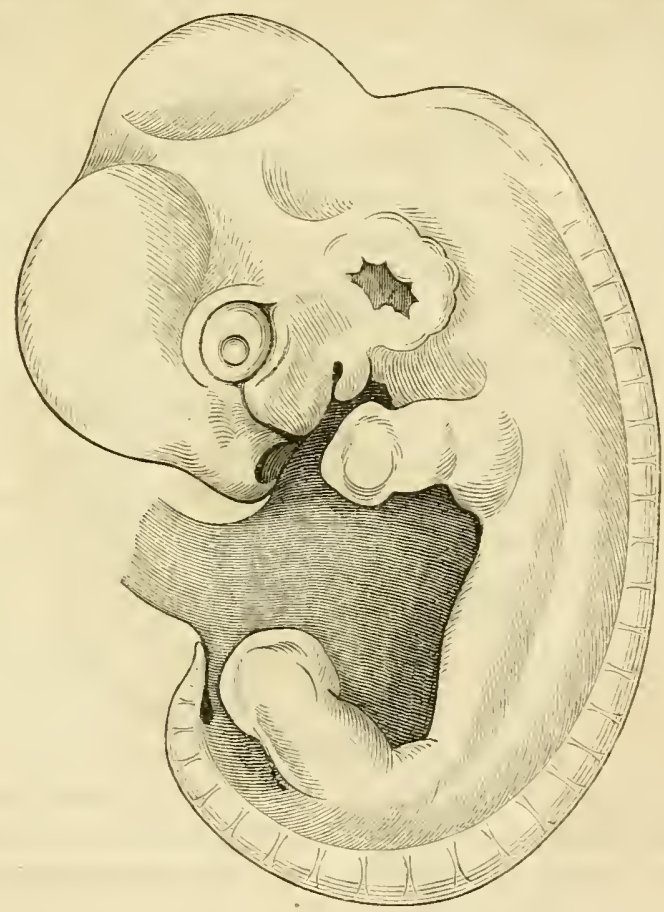

Fig. 136. Embryo des Jeerschweinchens, Smal vergrössert.

Profilansicht, sehr unbedeutend, und wie beim menschlichen Embryo ist ron einem iusseren Ohre nur eine leichte Andeutung vorhanden.

Bei Vergleichungen, bei welchen es sich, wie bei den eben angestellten, um Dimensionen bez. um Flächenräume und um Massenvertheilung handelt, ist es wiinschbar, nicht blos mittelst Abschätzung, sondern an der Hand von Zahlen vor- 
zugehen. In Ermangelung correct ausgefiihrter Wägungen der Embryonen und ihrer einzelnen Körperabschnitte, theile ich Dir einige für die oben mitgetheilten Zeichnungen ausgeführte Flächenbestimmungen mit. Es wurden zu diesem Behufe die Figuren auf ein starkes, gleichmäissiges Papier (wovon $100 \sqsubset \mathrm{Cm} .1 \cdot 564$ Grammes wogen) aufgezeichnet, ausgeschnitten, und aus dem Gervicht der ausgeschnittenen Figur der Flächenraum der Profilansicht im Ganzen, derjenige des Kopfes, sowie des Riickentheiles und des von den Extremitäten un-

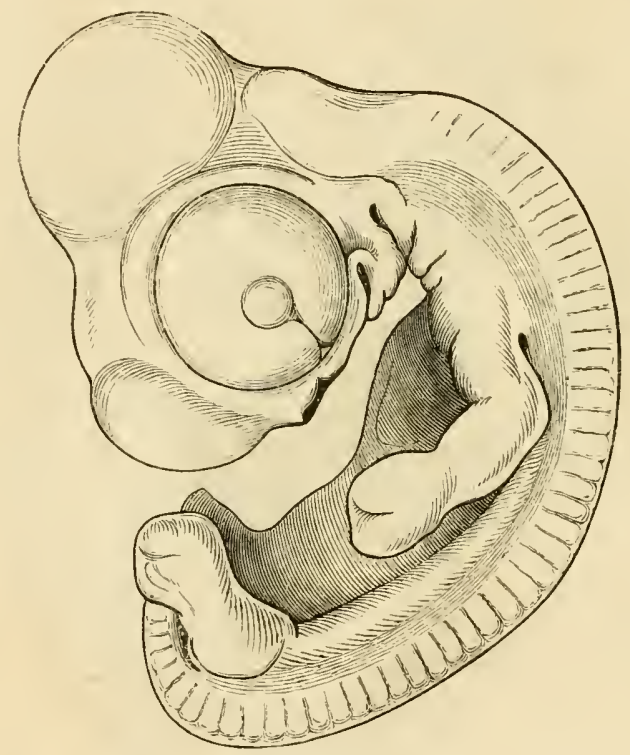

Fig. 137. Embryo eines Hühncbens (5 Tage bebrütet) Smal vergrössert.

bedeckten Bauchtheiles des Rumpfes berechnet. Die Gränze des Kopfes zog ich von der Einknickungsstelle hinter der letzten Schlundspalte zum Scheitelpunkte des Nackenhöckers; der Nabelstrang wurde durchweg dicht am Bauche abgetrennt.

Du siehst aus den Zahlen der vierten Columne wie nahe sich die fünf betrachteten Säugethierembryonen hinsichtlich ihrer absoluten Maasse stehen. Das Huihnchen bleibt etwas dahinter zurück. Sowohl in der einen, die absoluten Maasse, als in der anderen, die procentischen Antheile enthaltende 


\begin{tabular}{|c|c|c|c|c|c|c|c|}
\hline $\begin{array}{l}\text { Flächeninhalt des Umrisses } \\
\text { in } \\
\text { Quadr.-Centimetern. }\end{array}$ & Kopf. & 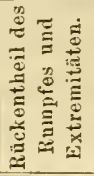 & 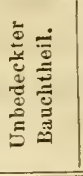 & Total. & Kopf. & 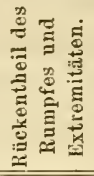 & 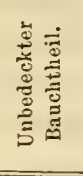 \\
\hline Mensch & 17,86 & 16,47 & 2,52 & 36,85 & $4 \subseteq, 4^{0}, 0$ & $44,7 \%$ & $6,9^{\circ}{ }^{\circ} 0$ \\
\hline Schwein . . & 7,46 & 14,56 & $12, \varsigma 2$ & 35,14 & 21,2 & 42,3 & 36,5 \\
\hline Reh . . . . . . . & $10,6 \mathrm{~S}$ & 15,77 & 9,17 & 35,62 & 30,0 & 44,3 & 25,7 \\
\hline Meerschweinchen . . & 14,59 & 18,35 & 4,56 & 37,50 & $3 \varsigma, 9$ & $4 \mathrm{~S}, 9$ & 12,2 \\
\hline Kaninchen . . . . & 14,32 & 18,52 & 3,17 & 36,11 & 39,6 & 51,6 & 8,5 \\
\hline Hühnchen & 14,06 & 13,19 & 2,79 & 30,04 & 46,7 & 44,0 & 9,4 \\
\hline
\end{tabular}

Abtheilung der Tabelle tritt eine bestimmte Gruppirung der Säugethierembryonen hervor. Die Embryonen vom Reh und vom Schwein stehen einander näher, als denen der Nager und als dem menschlichen. Beim Schweins- wie beim Rehembryo wird der schwächere Kopfantheil durch den stärkeren Bauchtheil compensirt. Die geringsten Schwankungen zeigt die Columne, die die procentischen Zahlen des Riickentheils des Rumpfes umfasst.

Es mögen die mitgetheilten Zeichnungen und Zahlen geniigen, Dir einen Begriff davon zu geben, welcher Art die Ergebnisse sind, welche eine Vergleichung thierischer Embryonen in Aussicht stellt. Eine Identität in der äusseren Form thierischer Embryonen, wie sie so vielfach behauptet worden ist, existirt nicht. Schon auf friihen Entwicklungsstufen besitzen die Embryonen ihre Klassen- und ihre Ordnungscharactere, ja wie wir kaum zweifeln diirfen auch ibre Art- und ihre Geschlechts-, selbst ihre individuellen Charactere. Es handelt sich eben nur darum, diesen Characteren nachzugehen, sie unserem Auge, oder iiberhaupt unserer Erkenntniss geläufig zu machen. Wir stehen heute mit der Differenzialdiagnose der Embryonen ungefahr auf dem Standpunkte eines einjährigen Kindes, das alle vierbeinigen Thiere mit einem Collectivlaute bezeichnet, und, wenn wir erst den Fleiss und die Schärfe, welche seit Linné auf den Ausbau des zoologischen Systemes verwendet worden sind, auf Characterisirung von Embryonen werden verwendet haben, werden wir sicherlich an Fächern und Fächlein eine genïgende Zahl gefunden haben, um die zur Beobachtung kommenden For- 
men darin einzuordnen. Mit der blossen Beschreibung allerdings werden wir, der Natur der Sache nach, nicht ausreichen. Waage und Maassstab werden um so mehr zu Hülfe genommen werden miissen, auf je frühere Stadien wir zurïckgehen.

Welcher Art sind nun die Charactere, durch welche Embryonen von einander sich unterscheiden? Es ist klar, dass wir Embryonen niemals durch Charactere unterscheiden werden, welche wie Gefieder, Behaarung, Bezahnung erst in später Zeit sich bilden. Zur Unterscheidung von Embryonen miissen wir selbstverständlich stets auf die embryonalen Charactere zuriickgehen. Insofern aber die Embryonen einfachere Gestalt besitzen, als die ausgebildeten Thiere, wird auch bei jenen die Summe äusserlich wahrnehmbarer Charactere mehr und mehr abnehmen, und mit dem Wegfall des vielen, secundär entstandenen Beiwerkes wird sie immer mehr auf die durchgreifenden Fundamentalverhältnisse sich zuriickführen.

Wären die Embryonen derselben Klasse in der That identisch, wäre, wie uns dies so oft wiederholt worden ist, ein menschlicher Embryo nicht von einem Hunds- oder Rindsembryo zu unterscheiden, so wiirde uns durch solch eine Erfahrung ein geradezu unlösbares Problem gestellt. Es müsste nämlich in dem Falle erklärt werden, wie in der absolut identischen Anlage der Inhalt verschiedenster Vererbung könne enthalten sein, wie ferner von diesen absolnt identischen Durchgangsformen aus die verschiedenen Entwicklungsg:inge könnten eingeschlagen werden. Beim Versuch, solch ein Problem zu lösen, wiirden wir schliesslich unsere Zuflucht bei transscendenten Vorstellungen nehmen müssen, wie sie bis dahin in der Physiologie keine Verwendung gefunden haben.

Die Sachlage ist zum Glïck einfacher, und so wie die Dinge factisch stehen, handelt es sich nur darum zu constatiren, wie schon aus den Ungleichheiten in der Ausstattung der allerersten Formanlage die Verschiedenheiten späterer Gestaltung sich ableiten lassen. Wo eine kleine Vorderhirnanlage und grosse Kieferfortsätze vorhandeu siud, da haben wir keine Mühe, das spätere Hervorwachsen einer mächtigen Schnauze zu verstehen. Wo sich Federn, wo sich Klauen, wo sich Zähne bilden, da wird schon in frither 
Zeit und lange ehe diese Theile molphologisch ausgeschieden sind, durch Anhäufung des Materiales, durch entsprechende Dicke der Epithelialdecke die Bedingung zur Bildung jener Theile gegeben, und bei sorgfältiger Untersuchung auffindbar sein.

Verschiedenheiten im Aussehen verschiedener Keime mïssen vorhanden sein, ron der ersten Zeit ah, da iiberhaupt die Gliederung des Keimes ihren Anfang nimmt. Schon die ersten Falten und Rinnen des aus der Keimfläche sich emporwölbenden Körpers bestimmen die allgemeine Bezirksabgränzung, und die für die Folge entscheidende Massenzutheilung an die besonderen organbildenden Bezirke. In friihester Zeit schøn wird geschieden, was bei der animalen, was bei der regetativen Schicht Verwendung finden soll, was zum Kopf, was zum Rumpf, was zur Anlage des Centralnerrensystems, was zur Bildung der Körperdecke dienen wird. Es ist als ob auf einem $z u$ bebauenden Grunde der Grundriss des zu errichtenden Gebäudes rorgezeichnet würde. Wie der erfahrene Baumeister aus dem Grundriss die Besonderheiten des zu errichtenden Baues herausliest, wo das unerfahrene Auge kaum eine Vorstellung von der Bedentung der gezogenen Linien sich zu bilden vermag, so wird auch dereinst der erfahrene Embryologe im Stande sein, beim Herrortreten der ersten wabrnehmbaren Gliederung des Keimes zu erkennen, was aus dem sich entwickelnden Gebilde werden soll.

Und fragen wir uns, welches in letzter Instanz das bestimmende Moment ist fiur die Scheidung der organbildenden Keimbezirke, so kommen wir wieder zurick auf die Vertheilung des Wachsthums im Keim. Menge und Form des anfänglich gegebenen Keimmateriales und die ihm innenwohnende Wachsthumserregung bleiben schliesslich die allgemeinsten Bedingungen fiir die specifische Gestaltung, die der Keim im Laufe seiner Entwicklung annimmt.

Es sind diese letzten Betrachtungen anch ihrerseits geeignet, uns in eindringlicher Weise die gegenseitige Abhängigkeit vor Augen zu halten, in welcher alle Entwicklungsvorgänge ron einander stehen. Schon in einem der ersten Briefe habe ich bei Aufstellung des Princips der durchgreifenden Gräinzmarken (S. 16 u. f.) Anlass genommen, Dich auf den 
nothwendigen inneren Zusammenhang scheinbar sehr verschiedenartige Entwickelungsvorgänge hinzuweisen, und die darauffolgenden speciellen Betrachtungen diurften die damals gewonnene Ueberzeugung in Dir noch mehr befestigt haben.

Es mag Dir von Interesse sein, auch für spätere Entwickelungsphasen ein Beispiel vorkommender Abhängigkeiten zu betrachten, und ich wähle dazu das Beispiel der Schnabelbildung beim Vogelembryo. Du kennst vom siebenten

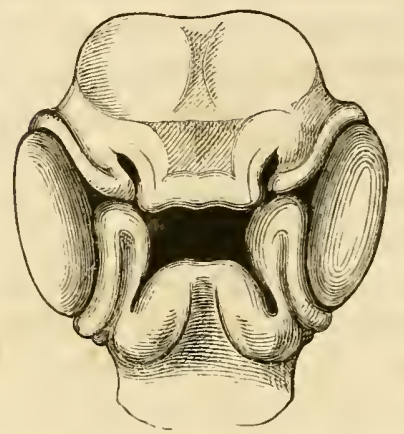

Fìg. 138 (80). Kopf eines Hühnchens nach 5tāg. Bebrūtung. :mal vergrössert.

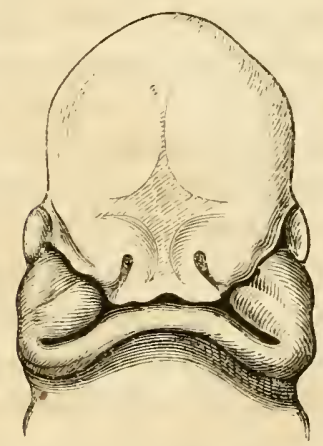

Fig. 139. Kopf eines Kaninchens (14 Tage p. foec.), Emal vergrössert.

Briefe her (S. 89) die vordere Gesichtsansicht eines Hiihnchens von etwa 5 tägiger Bebriitung. Mittlere und seitliche Stirnfortsätze, Oberkiefer- und Unterkieferfortsätze, die Riechgruben und die grosse viereckige Mundöffnung sind Dir von damals her noch gelïufig. Zur Vergleichung setze ich der damals besprochenen Figur eine gleiche Ansicht eines Kaninchengesichtes bei. Die beiden Figuren entsprechen in ihrer Entwickelung den Figuren 135 und 137. Dasselbe Uebergewicht der Augäpfel, das wir schon bei der Profilansicht des Huihnchens kennen gelernt hatten, tritt auch in dessen Vorderansicht hervor, und bedingt einen Hauptunterschied vom darunter stehenden Säugethiergesicht.

Der Einfluss der grossen Augäpfel macht sich an allen, in ihrer Umgebung befindlichen Theilen bemerkbar. Der seitliche Stirnfortsatz und der Oberkieferfortsatz sind zu schmalen, an ihren Rändern sich aufwulstenden Streifen zusammengedrängt, und auch in der Form des Unterkiefers, sowie in der starken Herabziebung der Mundwinkel tritt bereits deutlich 
der Einfluss einer seitlichen Compression zu Tage; dagegen ist der, den oberen MInudrand bildende mittlere Stirnfortsatz noch ein breiter viereckiger Lappen. Von einem Schnabel ist, wie anch ans Fig. 137 herrorgeht, noch in keiner Weise zu reden.

Schon nach einem Tage jedoch ist ein wohlangelegter, spitz vortretender Schnabel vorhanden. Der untere Abschnitt desselben ist aus den Unterkieferfortsatz, der obere aus dem

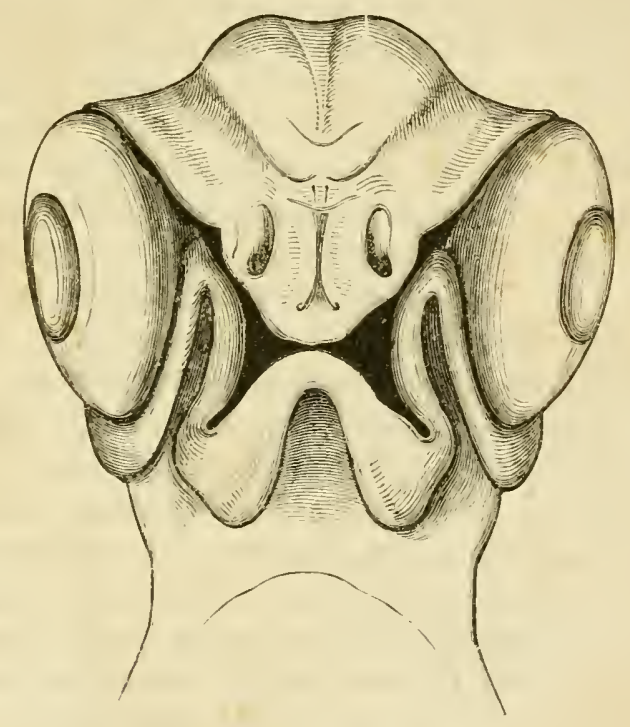

Fig. 140. Kopf eines Hühnchens nach btăgiger Bebrūtung. Smal vergrössert.

mittleren Stirnfortsatze, und an der Wurzel aus den beiden seitlichen hervorgegangen, "und zwar auf einfachstem Wege, durch Zusammendrängung and winklige Yortreibung in der Mittelebene. Der quere Abstand der heiden Riechgruben, welcher bei Fig. $13813 \mathrm{Mm}$. beträgt, ist bei dem weit grösseren Kopf von Fig. 140 auf $9 \mathrm{Mm}$. heruntergegangen; die schon in Fig. 138 sichtbaren, gewulsteten Innenrïnder der beiden Gruben sind sich bei Fig. 140 in der Mittelebene bis beinahe zur Berührung entgegengerïckt. Dagegen beträgt die Höle des mittleren Stirnfortsatzes hier fast das Doppelte rou dort (17 gegen $10 \mathrm{Mm}$.), und wo er dort mit einer breiten Querlinie abschloss, geht er hier in eine vortretende Spitze aus. 
Dass der Grund von dieser Zusammendrängung der mittleren Gesiehtstheile in den colossalen Augen zu suchen sei, zeigt der Blick auf jede der beiden Figuren unmittelbar, und wir kommen somit zum Ergebniss, dass die Entwicklung des Vogelschnabels einedirecte Folge ist von der mächtigen Entwicklung der Vogelaugen.

Wir haben im obigen Beispiel einen Fall, in welchem von zwei, physiologisch in gar keiner erkemnbaren Beziehung stehenden Theilen der eine in direeter Abhängigkeit vom andern sich formt. Bedenken wir nun, wie das grosse Auge in Betreff der Innervation andere Anspriiche erhebt, als ein kleines, wie damit zugleich an das Gehirn bestimmte Entwicklungsanforderungen gestellt sind, wie ferner die Bildung der Augenanlage bestimmte Ausbildung der Hirnkriimmungen voraussetzt, und wie mit diesen wiederum die Gesammtgliederung des Gehirns zusammenhängt; bedenken wir dann weiterhin die physiologischen Anforderungen, welche das Vorhandensein eines Sehnabels von gegebener Länge und Form in Betreff der Ernährungsweise stellt, Bedingungen, die ihrerseits die Existenz gegebener Instinete und gleichzeitig ganz bestimmter Einrichtungen der inneren Organe voraussetzen: so bekommen wir eine schwache Vorstellung von der verwickelten Verkettung functioneller und morphologischer Beziehungen, und von dem Gemenge von Abhängigkeiten, welche bei einer eingehenderen Erklärung beriicksichtigt zu werden verlangen. Der gesetzliche Zusammenhang' aller, der Körperentwicklung zu Grunde liegenden Vorgänge ist ein Princip, mit welchem in Zukunft auch die Descendenzlehre in noch ganz anderem Maasse wird zu reehnen haben, als dies bis dahin gesehehen ist. So lange man sich bei phylogenetischen Untersuchungen damit begnïgt, unabhängige Specialgeschichten fiir einzelne Organe oder Organtheile zu entwerfen, hat man die zu leistende Aufgabe in einem, sicherlich nur höchst beschränkten Abschnitt ihrer wirklichen Breite erfasst; denn jede einzelne Organentwickelung ist immer wieder nur eine abhängige Theilerscheintung eines grossen, nach allen Richtungen sich verkettenden Gesammtprocesses. 


\section{Siebzehnter Brief.}

Beziehungen zwischen Descendenzprincip und Wachsthumsprincip.

Schlusswort.

Lieber Freund! Wenn die in den beiden rorigen Briefen iiber embryonale Formen mitgetheilten Thatsachen und Anschauungen nicht unerheblieh von dem abweichen, was uns von eifrigen Vorkämpfern der dermaligen Deseendenzlehre pfiegt rorgetragen zu werden, so stehen sie doeh in keiner Weise in Widerspruch mit dem Descendenzprincipe selbst. Maehen wir uns noch einmal klar, welehes die Ergebnisse der physiologisehen Formbetrachtung sind, und wie sich die Forderungen des Descendenzprincipes dazu stellen:

An Wachsthum ist, wie wir sahen, die gesammte Entwickelung des aus dem Keim hervorgehenden Organismus geknüpft, an ungleich vertheiltes Wachsthums die erste Schichtenscheidung und die nachfolgende, zumeist durch Faltenbildung eingeleitete Abgliederung seiner Primitivorgane. Ob die zuerst auftretenden Formen so oder anders aussehen, stets ist, soweit bis jetzt erkennbar, die scheidende Grundursaehe dieselbe. An einer weichen, in Zellen zerkliifteten Masse scheidet sich der raseher wachsende Theil von dem, im Wachsthum zuriickbleibenden. Die in ihm vorhandenen Differenzen des Wachsthums setzen zwischen seinen Theilen neue Spannungen, denen gemäss er sich faltet, und in einzelne Stiicke gliedert, so lange, bis die aus der Zertheilung hervorgegangenen Stücke zu rorlänfigen Gleichgewichtsformen und Gleichgewichtsstellungen gelangt sind. Die absolute und relative Ausdelnnung der also von einander abgegliederten Organbezirke, ihre gegenseitige Lagerung und die, einem jeden derselben immewohnende Wachsthumserregung sind anf dieser Entwickelungsstufe das, 
was nach Ordnung, Geschlecht und Art weehselt, und was der, formell noeh unscheinbaren Anlage ihr speeifisches Gepräge verleiht. Auf noch friiheren Entwickelungsstufen im allerersten Beginne verbleiben die Unterschiede in der Menge und in der Anfangsform der Keimmasse, diejenigen der, ibr innewohnenden Wachsthumserregung und die Unterschiede der, dem Keim gesetzten besonderen Entwickelungsbedingungen, (seine Beziehungen zu accessorischen Eibestandtheilen: Eihülle, Nebendotter oder Nahrungsdotter, mütterlichem Organismus u. s. w.). Dass selbst die äusserlich hervortretenden Untersehiede dieser frïhesten Stufen nicht versehwindend sind, das zeigt Dir jeder Vergleich versehiedener Thiereier, der Vergleich der grossen Kugel des Batrachiereies mit der minimalen des Säugethiereies, oder dieser mit der flachen, einem fliissigen Nebendotter aufgesetzten Scheibe des Knochenfisch- und des Vogeleies. Unverständlich müsste es uns iiberhaupt erscheinen, dass aus so differenten Entwicklungsanfängen so ähnlich gegliederte Embryonen hervorgehen, zeigte nicht die genauere Beobachtung, dass trotz aller Anfangsdifferenzen die sich entsprechenden Formgliederungen des Keimes jeweilen nur eintreten, wenn die Dimensionen des sich gliedernden Materiales annähernd dieselben sind. A ehnliche Formen bilden sich aus ähnlichem Materiale erst dann, wenndas sich formende Material auch in Betreff der absoluten Dimensionen ähnliche Bedingungen darbietet. Von der grossen Masse des Froscheies kommt ein Theil vorweg als Vorrath bei Seite, und nimmt an der Gliederung keinen activen Antheil; das kleine Ei der Säugethiere aber wächst auf Kosten der Mutter so lange als Kugel fort, bis es die zur Gliederung erforderlichen Dimensionen erreicht hat.

Im Salmen- und Forellenei treten die ersten Spuren eines sich abgliedernden Embryos auf, wemn die Keimscheibe einen Durchmesser von 21/2-3 Mm. besitzt, desgleichen im Hechtei. Die Keimscheibe des Hiihnehens misst zu der Zeit $4-6 \mathrm{Mm}$, ihr Fruchthof 2-21/2 Mm. Beim Hunde ist nach Bischoff der Fruchthof' zur Zeit der Embryonalbildung $21_{2} \mathrm{Mm}$. lang, 2 Mm. breit (s. Fig. 32 u. 33, Taf. VI s. Abhandlung), beim Frosch misst die Länge der eben sich abgliedernden Medullarplatte $2,3 \mathrm{Mm}$. 
Beziehungen zwischen Descendenzprincip und Wachsthumsprincip. 209

Die Breite der Embryonalanlage in der Augenblasengegend vor eingetretenem Schluss bestimme ich:

\begin{tabular}{|c|c|c|}
\hline beim & Lachs & 1,25 \\
\hline , & Frosch & 1,3 \\
\hline & Hiihnchen & 1,0 \\
\hline & Hunde & 0,9 \\
\hline
\end{tabular}

n. B ischoff's (Fig: 34 e) " Hunde 0,9 "

Die Breite des schon abgegliederten, mit Urwirbeln soeben rersehenen Riickens:

nach Bischoff's Abb. " Hunde 0,4 "

$\begin{array}{clll}\text { beim Hecht } & 0,45 & \text { Mm. } \\ \text { " Lacis } & 0,4 & \\ " & \text { Froseh } & 0,4 & \\ " \text { Hühnchen } & 0,5 & \\ & \text { Hunde } & 0,4 & \end{array}$

Die Länge des Gehirns vom vorderen Ende bis zur Rautengrubenmitte nach erfolgtem Hirnschluss:

\begin{tabular}{|c|c|c|}
\hline beim & Lachs & 0,9 \\
\hline & Frosch & 1,0 \\
\hline & Hiihnehen & 1,1 \\
\hline 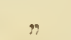 & Hunde & 1,0 \\
\hline
\end{tabular}

nach Bischoff"s Abb. " Hunde 1,0"

Der Abstand zwischen den vorderen Rïndern zweier Urwirbel in der ersten Zeit ihrer Entstehung:

$\begin{array}{cll}\text { beim Lachs } & 0,06 \mathrm{Mm} . \\ & \text { Frosch } & 0,12 " \\ " \text { Hiihnehen } & 0,1 & \\ " \text { Hunde } & 0,14\end{array}$

nach Bischoff's Abb. " Hunde 0,14 "

Die Dicke der Medullarplatte im Vorderhirnabschnitte zur Zeit des Hirnschlusses:

$$
\begin{array}{cccc}
\text { beim Hiihnchen gegen } & 0,05 \mathrm{Mm} . \\
" \text { Frosch } & " & 0,15 \quad \\
" \text { Lachs } & \text { " } & 0,15 \quad "
\end{array}
$$

Im vorderen Riickemmarkstheile:

$$
\begin{aligned}
& \text { beim Hiihnchen } 0,035 \mathrm{Mm} \text {. } \\
& \text { " Frosch gegen } 0,1 \text { " } \\
& " \text { Lachs " 0,075 " }
\end{aligned}
$$

Dic bemerkenswerthe Uebereinstimmung obiger Zahlen entspricht, wie Du siehst, dem eben aufgestellten mechanischen Postulate. Denn auch die Voraussetzung ist ja als eine in der Erfahrung begriindete anzunehmen, dass dem in Zellen zerkliifteten Keimmateriale hinsichtlich seiner Cohäisions- und Ela- 
sticitätsverhältnisse bestimmte, nicht allzubreite Gränzen gesteckt sind. Indem nun durch das ungleich vertheilte Wachsthum die Spannungen im Bereiche der Keimscheibe stetig zunehmen, miissen sie bei den sonst ähnliehen Bedingungen auch innerlalb ähnlieher Werthgränzen ähnliche Faltungen und Abgliederungen erzeugen. Die Ableitung aber der Besonderheiten entstehender Formen aus den innerhalb der gesteckten Werthgränzen auftretenden Schwankungen bleibt ein Gegenstand der weiteren Forschung.

In del ganzen Reihe von Formen, welche ein sich entwickehnder Organismus durchläuft, ist jede vorangegangene Form die nothwendige Vorstufe der nachfolgenden. Soll der sich entwickelnde Organismus zu complicirten Endformen gelangen, so muss el schrittweise die einfachen durchlanfen haben. Das vollkommen gegliederte Gehirn und Riickenmark setzen das unvollkommen gegliederte Medullarrohr als Vorbedingung voraus, das Medullarrohı die Medullarplatte, diese das Vorhandensein eines sich faltenden Keimblattes, das Keimblatt einen sich durchfurehenden Keim. Eine jede, aus der Reihe der iibrigen herausgegriffene Entwickelungsstufe ist ebensowohl die pliysiologische Folge der vorangegangenen, als sie die nothwendigen Beding'ungen zư nächstfolgenden umfasst. Spriinge oder "Abkiirzungen" des Entwickelungsganges kennt die physiologische Entivickelungsgeschiehte nicht.

Hältst Du Dir diesen Gedanken gegenwäirtig; dass embryonale Formen die unvermeidliche Vorbedingung der reifen Formen sind, weil diese als complicirtere durch jene, als die einfacheren miissen hindurehgegangen sein, so erscheint Dir die Thatsache, dass paläontologisch alte Formen vielfach den heutigen embryonalen ähnlich sind, in einer etwas anderen, als der gewöhnlich beanspruchten Verknüpfung: Jene sind embryonale, weil sie auf unteren Stufen der Entwicklung stehen geblieben sind, diese mussten die unteren Stufen iiberschreiten, um zu den oberen zu kommen. Keineswegs aber liegt fiur die Späteren die Nöthigung des Durehgangs dureh embryonale Formen darin, dass ihre Vorfahren einmal darauf sich befunden haben. Nimm, falls Dir der Gedankengang in der abstraeten Darstellung noch nieht klar genug erseheinen sollte, statt irgend weleher Formeigeuthiimliehkeiten die Lebensdaner 
als coneretes Beispiel. Setze voraus, es hätte für irgend eine bestimmte Reihe von Gesehöpfen im Laufe der Generationen eine stätige Zunahme der Lebensdauer stattgefunden. Es seien Vorfahren dagewesen von einjähriger, dann zweijähriger u. s.w. Lebensdauer und die heutigen Naehkommen hätten eine solche ron 80 Jahren zu beanspruchen. Sicherlieh wird es Dir in dem Falle nieht einfallen, zu sagen, der sojährige Naehkomme habe suecessive 1, 2, 3 u. s. w. Jahre alt werden miissen, weil er Vorfahren ron nur 1, 2, 3jühriger Lebendaner besessen habe, sondern Du wirst Dir einfaeh sagen, dass man nieht so Jahre alt werden kann, ohne einmal ein- und zweijährig. gewesen zu sein.

Du kannst das eben gebrauchte Beispiel sofort noch erweitern. Denke Dir, es hiitte in der ganzen Generationsreihe bei iibrigens gleiehen Anfängen, die Periode des Körperwachsthums stets ein Viertheil der Gesammtlebensdauer betragen. Unter dieser Voraussetzung hat der ailteste Vorfahre sein Waehsthum sehon in einem Vierteljahre vollendet, ein Folgender hatte ein halbes Jahr Zeit dazu u. s. w. Der heutige Descendent kann sieh während 20 Jahren fortbilden. Dem entsprechend wird der letztere absolut grössere Dimensionen erreiehen, el wird weit eomplieirtere, reieher gegliederte Formen besitzen, als seine ersten Vorfahren. Jene erseheinen daher in ihrer Form als dessen embryonale Vorstufen.

Sobald also das Deseendenzprineip richtig ist, dass ältere einfachere Formen die Vorfahren del späteren complicirteren gewesen sind, ist auch die Aehnliehkeit jener mit den embryonalen von diesen erklärt, ohne dass es der Hinzunahme irgend weleher Vererbungsgesetze bedarf. Jene Aehnlichkeit zwisehen alten einfaehen und hentigen embryonalen Formen wiirde selbst dann verstaindlieh bleiben, wenn keine Verwandtsehaft rorhanden wäre. Die stufenweise Weiterentwiekelung thieriseher Formen im Laufe der sich folgenden Generationen kamn theilweise als Folge zunehmender Waehsthumsdauer aufgefasst werden. Dabei sind natiirlieherweise seln versehiedene Modalitäten denkbar: es kann das Nervenwachsthum in anderem Maassstabe, als das Muskelwachsthum, dieses wieder in anderem, als das Epithelialwaehsthum sieh verändert haben, und fî̀ jedes der besonderen zeitlichen Wachsthumsgefälle ist ein 
unendlich reieher Variationsspielraum gegeben, In welche. Weise durch die Zunahme des zeitlichen Wachsthums die Differenzirung ähnlieh anfangender Formen beeinflusst wird, das bedarf kaum der Auseinandersetzung: Zwei dureh ähnliche Anfänge lindurchgegangene Formen miisse̊n selbstverständlich um so mehr divergiren, je länger iiberhaupt ihre Entwicklung andanert.

Organismen, fuir welche die Anfangsform des Keimes und die räumliche Anfangsvertheilung des Wachsthums eine ähnliche gewesen ist, erfahren dieselbe typische Gliederung, und werden vermöge dieser als zusammengehörig erkennbar sein, selbst dann, wenn das zeitliche Wachsthum in Grösse und in äusserer Erseheinung sehr erhebliche Differenzen zur Ausbildung: gebracht hat. - Es können sich nun aber bei den Descendenten gemeinsamer Vorfahren allmaililich auch die Anfangsform des Keimes und die räumliche Anfangsvertheilung des Wachsthums rerändert haben. Im Einzelnen vermögen wir uns z. B. zu denken, dass die Differenzen zwischen Maxima und Minima der Wachsthumsgeschwindigkeit zugenommen, dass die Zonen maximalen Wachsthums sich ausgebreitet haben und was dergleichen Fälle mehr sind, Durch solche Aenderunges der Wachsthumsgesetze sind dam aber auch die Grundbedingungen für die Blätter- und die Organabgliederung andere geworden. Wenn Du meiner friheren Darstellung ron der Mechanik der ersten Formbildung aufmerksam gefolgt bist, so hast Du eingesehen, dass gerade die anfängliche Anordnung der räumlichen Wachsthumsgefälle, das primäre Wachsthım, wie wir es S. 127 nannten, den typischen Bauplan der Organisation bestimmt. Dann wirst Du auch verstehen, wie deren Aenderung im Lanfe der Generationen zu Aenderungen jenes Banplanes führen und den Uebergängen aus einem Typus in einen anderen zu Grunde liegen musste.

Besässen wir die ideale Klarheit jenes ron Laplaee gedachten Geistes, dem der Weltprocess in einer mathematischen Formel vorliegt, dann wiirden uns auch die Wachsthumsformeln organischer Wesen nach ihrem letzten Ausdrucke bekannt sein, und wir vermöchten sie nach ihrer Form, und innerhalb jeder Form nach dem Werth ihrer eonstanten Glieder in Reihen zu ordnen. Den höehsten iiberhaupt denkbaren Au- 
forderungen an die Systematik wäre damit Genüge geleistet. Wiirden wir alsdann die Formeln nach ihrer phylogenetischen Succession zusammenstellen, dann würden auch diese Reihen fortlaufende Aenderungen der Coefficienten neben steigender Complication der Formeln aufweisen, und aus den dabei zu Tage tretenden Gesetzen miisste wohl ohne Weiteres erkennbar sein, ob die im Laufe der Generationen erfolgten Umbildungen ihren Grund im Wesen der Entwickelung selbst gehabt haben, oder ob sie ausschliesslich ans Anpassungen an äussere Lebensverhältnisse hervorgegangen sind.

Die physiologische Ableitung der thierischen Körperformen und die Aufsuchung ihrer phylogenetischen Geschichte sind zwei Aufgaben, deren Wege für die nächste Zeit getrennt neben einander herlaufen. Die rauheren Pfade allerdings fallen zunächst dem physiologischen Formenstudium zu. Aber, wenn ihre Verfolgung eine energische Concentration der Kraft und ein Verzichtleisten auf häufiges Schwelgen in grossen Ueberblicken verlangt, so gewährt sie dafür den unschätzbaren Vortheil einer steten Fühlung mit den exacten Grundlagen unserer Naturkenntniss, und sie verheisst Demjenigen, der sich ihr mit Ausdauer und mit Unsicht hingiebt, jene Schärfe der Anschauung und jene Sicherheit des Urtheiles, die das Merkmal und zugleich der Lohn jeder strengen Methode sind.

Soweit die an das Descendenzprineip sich anlehnende phylogenetische Forschung in den Gräinzen sich hält, innerhalb deren auch sie an der Hand zurerlissiger Methoden fortzuschreiten rermag, ist ein Conflict mit physiologischer Forschung kaum jemals zu befiurchten. Allein neben dieser soliden phylogenetischen Forschung erhebt sich jenes naturphilosophische, auf dem Descendenzprincip errichtete System, welches in so zahlreichen Darstellungen dem wissenschaftlichen wie dem nichtwissenschaftlichen Publikum rorliegt. In geschlossener Folm tritt es uns entgegen und als abgerundetes, einer Erweiterung nicht bediirftiges Ganzes.

In dieses System brechen die Forderungen einer physiologischen Formenlehre mit ihren nenen, weiten Zielen an mehr denn an einer Stelle ein, und stören dessen wohlgepflegte Ordnung. Seien wir indess auch iiber diesen Punkt offen! Mächtig hat die Descendenztheorie eingegriffen in unser ge- 
sammites Wissen und Denken von der organischen Natur. Unser Geist ist befreit worden von Schranken, die ihn durch Jahrhunderte behemmt hatten, unscr Gesichtskreis auf das umfänglichste erweitert, unsere Einsicht in der Zusammenhang der Dinge erheblich vermehrt. Aber sind wir denn wirklich soweit, dass wir daran gehen kömnen, lückenlos durchgefiihrte Systeme organischer Naturbetrachtung aufzustellen? Sind mit Anerkennung des Descendenzprincipes und der zu seiner Stiitze herbeigezogenen Sätze wirklich alle jene Probleme für uns durchsichtig geworden, an deren Lösung unsere wissenschaftlichen Vorfahren gearbeitet haben?

Der Dogmatismus liegt, wie dic Geschichte der Wissenschaften zur Geniige zeigt, aufs tiefste im Wesen menschlicher Natur begründet. Wissenschaft und Leben haben indess wenig Gutes ron ihm erfahren, und anzukämpfen gegen den Zug des Alles-wissen und des Alles-erklären-wollens hat gerade der Naturforscher besonderen Beruf. "Naturschulmeister" pflegte unser unvergesslicher Lehrer S c lı̈ n b e in Diejenigen zu nennen, welche mit einigen doctrinären Siitzen alle Probleme der Natur vermeinen gelöst zu haben. In der That hat ja die Schule das didaktische Bedürfniss, dass alles von ihr Dargestellte glatt und in widerspruchsloser Weise sich aneinander reiht, dass alle Liïcken iiberdeckt, alle Unebenheiten geglättet worden. Erreicht wird das Ziel durch sorgf:iltige Auswahl des Stoffes und durch Einfithrung einer gewissen Anzahl von Wörtern, dic elastisch genug sind, um sich in der allervielfältigsten Weise verwenden zu lassen. Der Klang bleibt derselbe, der Simn wechselt, oder fehlt, je nach Bedarf. In der Weise hat auch die dogmatische Descendenzschule ein Wörterbuch angelegt, ïber dessen Vorrath sie in freiester Weise waltet. Anpassung, Homologie, Rückschlag, abgekürzte Vererbung sind solche Bezeichmungen, die stets in einer dem Schulberlürniss angepassten Weise verwerthbar sind. Und in der Gewöhnumg an solch unzuverlässiges Riistzeng licgt meines Erachtens die Gefahr, welche jiingere Forscher bedroht, wenn sie rückhaltslos phylogenetischen Speculationen sich hingeben. Der stetige Umgang mit Begriffen, welche ihrer Natur nacl einer präcisen Fassung sich entziehen, und deren Anwendung auf den einzelnen Fall eine wissenschaftliche Controlle von vornherein 
ausschliesst, wirkt nothwendig abstumpfend auf deu kritischen Sinn und muss auf die Daner wissenschaftliche Zustände ungesumder Art erzeugen.

Das Ausarbeiten glatter Schuldarstellungen ist des Forschers liöchste Aufgabe nicht, und wer mit Ernst und mit strenger Wahrheitsliebe an den Problemen der organischen Natur sich versucht hat, der wird gar bald der Resignation bewusst werden, die er in Aussicht auf deren Lösung sich auferlegen muss. Es ist ein schweres, dem seiner Natur getren bleibenden Forscher anferlegtes Geständniss, dass die letzten Ziele, fiir deren Verfolgung er seine ganze Kraft einsetzt, hier, wie auf alleu Gebieten der Forschung, in um so entlegenere Ferne rïcken, je weiter er auf dem in ihrer Richtung fïhrenden Wege roranschreitet. In der kräftigenden Arbeit selbst, im Bewusstsein sicheren Voranschreitens und in den reichen, am Wege ihu erwartenden Friichten findet er den vollen Ersatz für alle geuibte Entsagung. 


\section{Bemerkungen.}

Die erste Hälfte der obigen Briefe reproducirt in abgekürzter Form die wesentlichsten Ergebnisse einer grösseren Monographie, welche ich vor $\bar{i}$ Jahren herausgegebell habe (Untersuchungen über die erste Anlage des Wirbelthierleibes. Die erste Entwicklung des Ḧ̈hnchens im Li. Leipzig 1868.). In Betreff aller weiteren Finzelnheiten, sowie zahlreicher bildlichen Belege muss hier auf jene Schrift verwiesen werden.

\section{Erster Brief.}

S. 1. Bei Fig. 1, 2, 5, 6, 9, 10, 14 und 15 sind die Contouren mittelst des Zeichnungsprismas nach der Natur (urspringlich bei genau 40 facher Vergrösserung) anfgenommen. Die körperliche Schraffirung der Oberfläche ist nach den Wachsmodellen ausgefiilurt, welche ich seiner Zeit unter der technischen Beihizlfe von Dr. A. ' Ziegler in Freiburg i'B. entworfen hatte, und die durch letzteren in den Handel gebracht sind. Es waren zu dem Zwecke durch die Embryonen fortlaufende Durchschnittsreihen geführt, und sämmtlich bei derselben 40 maligen Vergrösserung gezeichnet worden. Der Flächenriss, in Verbindung mit den Durchschnitten, erlaubte eine vergrösserte, möglichst genane Reproduction der körperlichen Form.

\section{Zweiter Brief.}

S. 19. Hier sind unter Organen nicht nur die bleibenden verstanden, sonder'n auch die vergänglichen, das Amnion, die Allantois, die Urnieren u. s. w.

S. 21. Dem Zwecke der Schrift entsprechend bin ich mit technischen Ansdriicken so sparsam als möglich nmgegangen, habe anch manche der in meinem monographischen Werke vorgeschlagenen Bezeichnungen vermieden, oder durch einfachere ersetzt. Das was hier Kieferleisten genannt wird, sind die Parietalleisten meiner Monograplie.

\section{Dritter Brief.}

S. 36. Zur Synonymik der Schichten lasse ich hier eine kleine Tabelle folgen. Die parablastischen Bestandtheile sind durch Cursivschrift hervorgehoben. 
Bemerkungen.

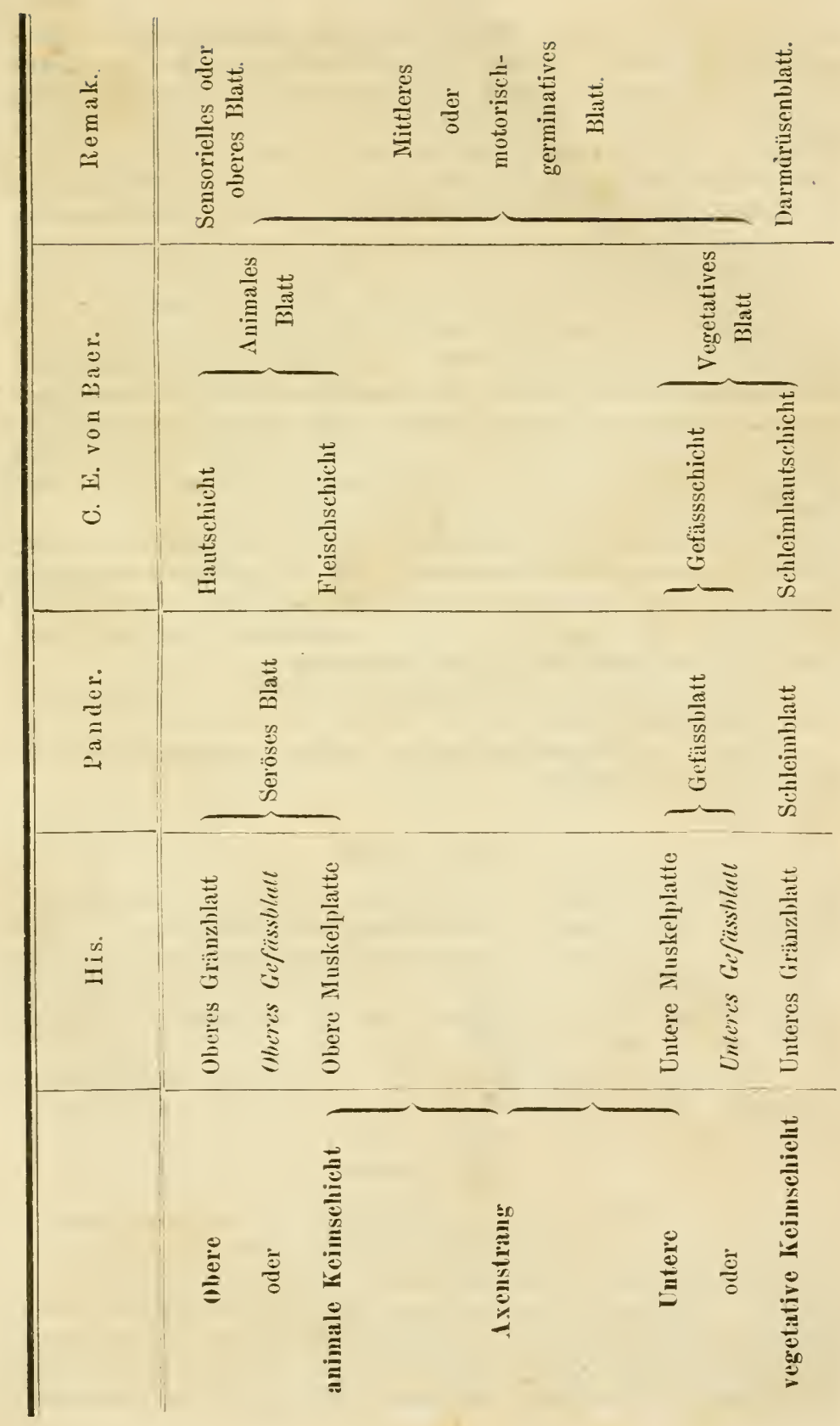


Remak's Sensorielles Blatt, identisch mit obigem „oberen Gränzblatt", zerfällt in die Medullarplatte und das Hornblatt. Von Erfahrungen am Batrachierkeime ausgehend, tremnt Stricker das sensorielle Blatt Remak's in ein oberflächliches Hornblatt und ein tiefer liegendes Nervenblatt. Remak's mittleres Keimblatt zerfällt in die Chorda dorsalis, die Urwirbelplatten, die Seitenplatten und den Urnierengang. Remak's Blätterscheidung war bis vor Kurzem am meisten adoptirt, neuerdings haben vergleichende Anatomen, auf Kowalevsky's Arbeit fussend sich, gleich mir, der älteren v. Baer'schen Blätterscheidung genähert.

S. 3S. 2) Dieser Satz wiirde unlıaltbar sein, sollte es sich herausstellen, dass, wie die Stricke r'sche Schule dies behauptet, das mittlere Keimblatt $R$ e mak's einschliesslich der Muskelanlagen aus eingewanderten Zellen bestände. Die Grundlagen dieser Behauptung sind indess unhaltbar, wie ich an einem anderen Orte nachgewiesen habe. (Untersuchungen iiber das Ei und die Eientwicklung bei Knochenfischen. Leipzig 1873. S. 39 u. f.)

Die Erfahrungen Kow alevsky's iiber die Blätterscheidung bei Amplioxus sprechen entschieden für die primäre Gruppirung $1+2,3+4$. In Betreff der Chorda zeigt der Amphioxus die bemerkenswerthe Erscheimung einer secundären Entstehıng desselben, olne voransgegangenen Axenstrang.

S. 43. 5) Weitere Ausfiilırungen hieriiber s. in meiner Entw. des Hïhnchens S. 38 u. f.

S. 43. $\left.{ }^{4}\right)$ Nenere Erfahrungen hieriiber gedenke ich an anderem Orte mitzutheilen.

\section{Vierter Brief.}

S. 48. Betreffend die Elasticität der Keimscheibe sagt E. Häckel: „Der Versuch, die Keimscheibe (welche nicht elastisch ist!) als elastische Platte aufzufassen, der Versuch u. s. w. . . . . . erscheinen nur einer humoristischen Beleuchtung, keiner ernsthaften Widerlegung fähig." E. Häckel, Kalkschwämme. Berlin 1S72. I. S. 472.

Aehuliche Aensserungen finden sich in Annals and Magazine of natural history 1873. Bd. XI. p. 260.

\section{Fiinfter Brief.}

S. 60. 1) Unter den von der Mechanik behandelten einfachen Fällen kommt der Fall eines senkrecht belasteten biegsamen Stabes, bei welchem die Last ausserhalb der verlängerten Axe angreift, dem unsrigen am nächsten. Die wirksame Kraft wird in dem Fall zerlegt in eine, in der Verlängerung der Axe wirkende zusammendriickende $\cdot$ Kraft, und in ein, die Biegung bewirkendes Kräftepaar. Ein solcher Stab wird sich biegen, und bei einer 
seine Tragkraft iiberschreitenden Belastung brechen. Die Theile des Stabes (oder der Platte), welche an der concaven Seite liegen, stehen unter allen Umständen unter positivem Drucke, die an der convexen Seite liegenden dagegen sind bei geringen Biegungsgraden gleichfalls noch gedriickt, bei höheren kann der Druck in Zerrung iibergehen, d. h. negativ werden. Die Gränze des Ueberganges hängt ron den besonderen Bedingungen ab (ron den Dimensionen des Stabes, vom Ort und von der Grösse der Last u. s. w.).

\section{Sechster Brief.}

S. 69. 1) Gegen meine Darstellung der Muskelplattengiiederung am Tiopfe hat sich nenerdings Go et te (Arch. f. mikr. Anat. Bd. X. S. 190) ansgesprochen und sie in etwas gereizter Sprache fuir eine kiinstliche Erffindung erkliirt. Die Grundlagen sind indess, wie mir scheint, nicht wohl anzufechten. Thratsache ist:

1) das Vorlandensein einer starken unteren Muskelplatte am Hinterkopf und die Verbindung derselben mit der oberen Platte durclı ein gemeinsames medianes Stiick (Fig. 52-57, S. 70),

2) das Hervorgehen des Herzens und der Pharynxmusculatur ans dieser unteren Platte,

3) der quergestreifte Charakter dieser letzteren Musculatur,

4) die Anlegung der unteren animalen Mnskelplatte an die obere im Halstlıeile des Embryo (Fig. 5S S. 71 und Fig. 64 S. 75).

Es kann also nur discussionsfälig bleiben:

1) die Frage, ob die Anlegung der unteren animalen Platte an die obere die Bedeutung einer primären oder einer secundären Verbindung habe;

2) ob die regetative Muskelplatte als die ummittelbare Fort. setzung der unteren animalen aufzufassen sei, oder ob sie, wie ich dies angegeben habe, als besondere Bildung unter der letzterell auftrete. Fiir die Discussion dariiber ist hier nicht der Ort.

S. 69. 2) Ueber das Zuriickweichen des Herzens und der Eingeweide s. meine Entwicklung des Hiilnchens S. 149 ॥. f.

S. 73.3$)$ S. ebendaselbst S. 141 .

S. 79. 4) Anf Querschnitten erscheint, wie dies anch Fig. 70 zeigt, die Milz als eine kleine, nach links gerichtete Leiste des Gekröses, sie fällt beim Hülnnchen in die Höhe des unteren Halsund oberen Riickentheils des Leibes.

\section{Siebenter Brief.}

S. 92. 1) Für das zeitliche Zusammentreffen der Kopfkrüimmung mit der Leberwachsung des Vorderkopfes durelı das Amnion vergl. man Bischoff, Entwicklung des Kanincheneies 'Taf. XIII Fig. 55-58, Derselbe, Entwicklnng des Hundeeies Taf. VII Fig. 36 und 37. Coste, Déreloppement des êtres organisés (der 15 
-1Stägige menschliche Embryo hat ein vom Kopf abstehendes Amnion und keine Kopfkrimmung, beim 20-25 tägigen spannt sich das Amnion knapp ïber den Embryo weg und die Kopfkriummung ist vorhanden); bei Clark, Entwicklung der Schildkröte in Agassiz Contributions Il. Taf. XII Fig. 6, 9 und 10 ist der Kopf bei soeben im Gange befindlicher Krümmung vom Amnion gleichfalls knapp umschlossen.

\section{Achter Brief.}

S. 9S. 1) Vergl. Bis clı off, Entwickelung des Kanincheneies Fig. 52 ‥ f.; Entwicklung des Hundeeies Fig. 33-35.

S. 102. ") Hit der hier gegebenen entwickelungsgeschichtlichen Darstellung erledigt sich von selbst die durch MicluchoII iclay versuchte Undentung der Theile des Fisclihirns.

Wemn die Rantengrube bei den Darstellungen des S. und 9. Briefes als offen bezeichnet und der Hergang ihrer Bildung mit der Knickung eines geschlitzten Rohres verglichen wird, so ist dies insofern nngenan, als ja eine stark verdiunnte Decke vorhanden ist. ILan darf ron ihr bei der mechanischen Erörterung ebenso wohl abstrahiren, als man es in den herkömmlichen Hirnbeschreibungen bei der anatomisehen thut.

Schon bei Tiedemann findet sich die Aeusserung, dass im Bereiche der Rautengrube das Hirnrohr aufreisst und seine Ränder anseinander treibt.

Einige der in dem.S. und 9. Briefe enthaltenen Gesichtspunkte latte ich vor einigen Jahren in einem kleinen Aufsatz in den Verhandlungen der Basler naturfoschenden Gesellschaft 5. Bd. besprochen: "Leber die Gliedernmg des Gehirns." 1869. Ueber die Gestaltung der Hemisphären habe ich zwar seiner Zeit in derselben Gesellschaft vorgetragen, aber in deren Verhandlung nichts publicirt.

Obwohl schon von verschiedener Seite her die Correspondenz gewisser Furchen mit immeren Vorspriingen (Fiss. Hippocampi, F. calcarina, F. collateralis) anerkannt worden ist, ist doch der wichtige Gegensatz zwischen den, primär auftretenden Totalfalten und den, secundär auftretenden Rindenfalten nirgends scharf hervorgehoben worden.

\section{Semiter Brief.}

S. 105. 1) Vergl. Kowalersky Taf. II Fig. [30, s. oben S. 178 Fig. 117.

S. $\left.112.2^{2}\right)$ S. F. Schmidt, Entwicklung des Gehirns in der Zeitsehrift fuir wissenschaftliche Zoologie. Bd. XI. S. 43.

S. 115. 3) Hnguenin, Allg. Pathol. der Krankheiten des Nervensystems. I. Zürieh 1873 . H. giebt als Urheber der von ihm copirten Zeichnungen irrthimlicher Weise Gratiolet an, anstatt Le lu ret. 


\section{Zehuter Brief.}

S. 123. 1) Wenn im Gange des Wachsthumsgesctzes zu irgend einer Zeit grössere Spriinge vorkommen, so muss sich dies selbstverständlich kund geben dureh die plötzliche und ans der Reilue heraustretende Entwickelung gewisser Organe oder Organtheile. Im Bereich des Nervensystemes und des Muskelsystemes ist nichts Derartiges wahrumehmen, eher wirde sich die Entwicktung einzelner Driisen hieher ziehen lassen. So bieten speciell die Sexualdrisen das Beispiel einer, aus der Reihe tretenden rapiden Entwicklung. Bei Beurtheilung dieses Verhältnisses ist aber ein Punkt ins Auge zu fassen, von dem wir in den allerersten Entwicklungsphasen absehen dürfen; es ist dies der Factor der äusseren Bedingungen. Speciell ron den Sexualorganen wissen wir, dass deren Entwicklung von der reichlichen Materialzufuhr, sei dies in Folge giinstiger Ernährungsverhältnisse iiberlaupt, sei es in Folge nachlassender Gefässmuskeleontractionen in innigster Abhängigkeit steht. Wie haben hier, wie im ruhenden Samenkorn, eimen Wachsthumsantrieb, der nicht zur Aeusserung kommt, weil eine von den Grundbedingungen des Wachsthums, der aufzunehmende Stoff fehlt. In ähulicher WVeise wiurden vielleicht auch die im Thierreiche so verbreiteten periodischen Aenderung vou Haarkleid und Gefieder oder die sog. Mauserungen ihren Schliissel finden.

S. 126. 2) In Curier, Anat. comp. ist das Verhältniss des Thunfischlirns zum Körper sogar $=\frac{1}{37000}$ oder rund $=3$ Hunderttausendstel angegeben. Lant Brehm steigt das Gewicht eines Thunfisches bis auf $15 \mathrm{ja}$ bis auf $1 \mathrm{~s} \mathrm{Ctr}$. Fiir $15 \mathrm{Ctr}$. ergibt obige Proportion ein Hirngewicht ron 221/2 Grammes.

S. 12S. 3) Hieriber vergleiche man ansser His, Häute und Höhlen des Körpers. Programm. Basel 1565, auch meine Entwicklung des Hiihnchens. S. 200 u. f. Der Gedanke, dass die Gelenke dureh die Muskeln geschliffen werden, ist ron dem verdienstrollen, zur Ausführung seiner Gedanken leider zu friihe verstorbenen L. Fick zuerst ausgesprochen worden. Müller's Archiv 1559. S. 65\%.

\section{Elfter Brief.}

S. 137. 1) Ueber Ma u p ertuis' Ideen, betreffend die Artbildnng, veroleiche dessen Venus pliysique 1746 und seine Lettres. Dresden 1752. Einige del hauptsächlichsten Sätze ron Ma upertuis habe ich im Archiv fur Anthropologie abgedruckt. Bd. IV. 355 ; vergl. anch daselbst Bd. T. S4.

Needham streift wiederholt an die richtige Fassung des Begriffes rom Keim. „Si la plus petite partie d'u polype, on d'une étoile de mer, suffit pour nous domner l'être organique entier, 
je dirai pour m'exprimer philosophiquement selon mes principes, que cette partie n'est pas l'être lui-même en miniature, mais qu'elle est le germe de l'être, on une très-petite portion dans un état de simple végétation vitale et specifique, qui doit pousser et produire tontes les parties nécessaires pour completter le corps entier." (Notes des nouvelles recherches. p. 194.)

Hauptgegner von Ne edham war der, als Beobachter ihm weit iiberlegene Spallanzani, bekanntlich gleichfalls ein Geistlicher und lebliafter Vertreter der Evolutionslehre. Ilm gegeniiber betont $\mathrm{N}$ eedham ausdriicklich, dass er die Epigenese fiir religiöser halte als jede andere Theorie. (1. c. 148).

So theilt uns Needham u. A. auch mit, wie er sich die Erschaffung der Eva denkt, nämlich durch einen raschen Knospungsprocess. "Les nouveaux germes et leur développement viennent ensuite de ces mêmes corps primitifs par la mutrition et la prolongation des parties, de manière que le corps de la première femme ne se forma par de la terre comme celni de son mari, mais procéda de lni pendant son sommeil par une végétation accélérée et nourrie de sa substance. Il s'en détacha dans un état de perfection, comme font les jeunes polypes et les antres corps organisés du même genre."

Was N e edham seiner Urkraft alles zumuthete, davon kamn man sich aus dem nachfolgenden Satze eine Vorstellumg machen. "Cette exaltation gradnée, cette activité progressive dont la matière est donée, principe de toutes les metamorphoses pliysiques, ou chymiques, qui végète dans les plantes; qui compose et vitalise les corps organisés; qui sirrite dans leurs membres, qui constitue leurs idiosyncrases; qui donne naissance aux différens phènomènes microscopiques dont nous avons parlé; qui vivifie la semence animale et végétale, qui diversifie toutes les sécrètions, qui fixe le nombre des espéces par des analogies secrètes; qui s'exalte dans les vivipares et les serpens vénimenx; qui se dissipe en particules contagieuses; qui en agissant sur lâme par des impressions sensibles, l'éxcite á penser et lui en fournit la matière; qui sépare les élémens, les uns d'avec les autres dans une échelle exactement graduée et variẻe à claque pas etc."

In solch einem Medium ist allerdings kaum der Ort zu suchen fiir die Entwicklung eines an und für sicl guten Grundgedankens.

S. $\left.139.2^{2}\right) \mathrm{K} l \mathrm{ebs}$, Ueber Cretinismus. Archiv f. experimentelle Pathologie. Bd. II. S. 426.

\section{Zwölfter Brief.}

S. 149. I) Nach den Fourier'schen Reihen für die Zusammensetzung einfacher Schwingungen, die ja durch Helmholtz anch in der neneren physiologischen Akustik eine so hervorragende Bedeutnng gewomnen haben. 


\section{Dreizehnter Brief.}

S. 159. 1) Ueber die Erblichkeit erworbener Eigenschaften vergleiche man die Erzililungen bei Dar win, das Variiren. Uebersetzt von Carus. 1 866 . II. 31 u. f., sowie bei Hä ckel, Schöpfungsgeschichte. 5. Aufl. 192. „M a n (iiber den Gebrauch dieses IVörtleins s. Fiirst Bismarck's Schreiben an den Grafen v. Arnim) liat schwanzlose Innderassen dadurch g'ezogen, dass man mehrere Generationen hindureh beiden Geschlechtern des IImdes consequent den Schwanz abschnitt. Noch vor ein paar Jahren kam hier auf einem Gute der Fall ror, dass beim unvorsichtigen Zuschlagen eines Stallthores einem Zuchtstier der Schwanz an der Wurzel abgeklemmt wurde, und die von diesem Stier erzeugten Kälber wurden sämmtlicl schwanzlos geboren." Wer beglanbigt solche Anecdoten? und wenu sie zu beglaubigten Thatsachen erhoben wiirden, wären sie damit schon geniigend zum gewollten Schlusse?

\section{Vierzehuter Brief.}

S. 167. 1) Fr. Miiller, Für Darwin. Leipzig 1S64. S. 77.

S. 169. 2) Ritimeyer, Arehiv f. Anthropologie. Bd. III. S. 301 ul. f.

S. 170. 3) Zum Vergleiche kömnen die Abbildungen junger Hunde- und Kanincheneier von Bischoff dienen und die der jiingsten bis dalin bekannt gewordenen menschlichen Embryonen von A. Thomson. Letztere, von welchen eines auf $12-13$ Tage, das andere auf 15 Tage geschätzt werden, sind in Kölliker's Entwicklungsgeschichte S. 122 und 123 abgebildet. Häckel's Figur 42 scheint aus den Zeichungen Bisclo off's construirt zu sein und weicht von der ihr am niichsten stehenden 'Thomson'schen in sehr erheblichen Punkten ab.

\section{Füfzehnter Brief.}

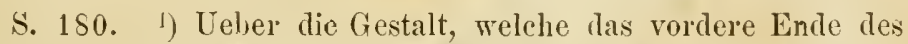
Medullarolues bei Amplioxus besitzt, und iiber die Abwesenheit eines Anges vergleiche man die schöne Abhandlung von W. M iiller in dem soeben zu Elren C. Ludwig's erscheinenden Jubelbande. Es war mir durch die Giite des Herru Verfassers vergönnt, sie noch vor ihrem Erscheinen einzusehen.

Die elsten sichtbaren parablastischen Zellen erscheinen in K o walevsky's Tafeln als isolirte Lencocyten (Fig. 39). Ihre Herkunft ist nicht festgestellt.

S. 191. 2) Man kann allenfalls noch etwas weiter gehen, als im Texte geschchen ist, und in dem Fig. 120 abgebildeten Stadium des Knochenfisclikeimes, das Planulastadium Fig. 117 C. des Amphioxus, in den Umwachsungsstadien Fig. 127-130, das Gastrulastadium Fig. 117 D. des Amphioxus wieder erkennen, sowie 
man selbst die Umwachsung des Cyclostomen- oder des batrachierdotters auf dies Schema beziehen kann. Das Gemeinsame liegt alsdann in der Bildung einer inneren Hölle ("Darmlöhle“ im weitesten Sinne, inclus. Dottersack) durch Schliessung einer zuvor offenen Platte oder Scliaale. Dabei bleiben indess; um ron anderen Unterschieden nicht zu sprechen, die bedeutenden Abweichungen in der Art der Bildung der primären Blase und in Art und Ort des Schlusses der secundären. Beim Knochenfischembryo schliesst sich die Rückenwand, beim Amplioxus und bei Petromyzon die Banchwand.

Ueber die Abweichungen in der ersten Keimentwicklung wirbelloser Thiere vergleiche man den Aufsatz von Salensky in Troschel's Archiv f. Naturgesch. 1S74. 40. Jahrg. S. 136 ul. f.

\section{Verbesserungen.}

S. 4. Notenbezeichnung ${ }^{1}$ fällt weg.

S. 5 in der Mitte lies, an der Stelle b" statt a.

S. S. Figurenbezeichnung lies: „Querschnitt durch den Embryo bei a“ statt b.

S. 15. Im betreffenden Holzschnitt Fig. 10 ist der Buchstabe a, anf den in den obersten 2 Zeilen hingewiesen wird, ausgefallen, derselbe sollte hinter Uwp, stehen.

S. 1S. 2. Zeile lies „am“ statt vom.

S. 56. Figurenbezeichnung soll heissen: Fig. 40 (Fig. 34). Querschnitt etwas weiter hinten als Fig. 33 u. s. w.

S. 56. 3. Zeile von unten lies „der Ḱeimhöhle" statt die.

S. 60, 6. Zeile von unten lies "dass sie dort" anstatt hier.

S. 1 i3 letzte Zeile "deren einer" statt eine.

S. 70. Figurenbezeichnung von Fig. 53: u. G. unteres Herzgekröse.

S. 79. Figurenbezeichnung: M. Nedullarrohr. Uw. Urwirbel. Ch. Chorda. Ao. Aorta. Cd. Cardinalvene. Un. Unnieren. Ex. obere Extremitäten. Lw. Leibeswand. Mz. Milz. Mg. Magen. Dr. Dottervene.

S. 117. Z. 10. lies: „bei welchen" statt bei welcher. 


\section{UNSERE KÖRPERFORM}

UND

DAS PHYSIOLOGISCHE PRORLEM IHRER ENTSTEHUNG.
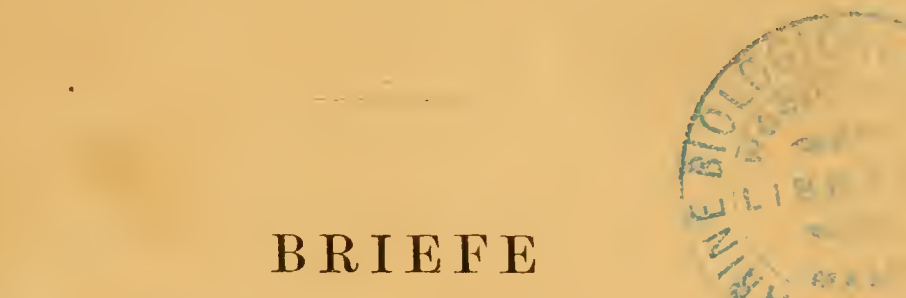

AN EINEN BEFREUNDETEN NATURFORSCHER

VON

WILHELI HIS.

MIT 104 HOLZSCHNITTEN.

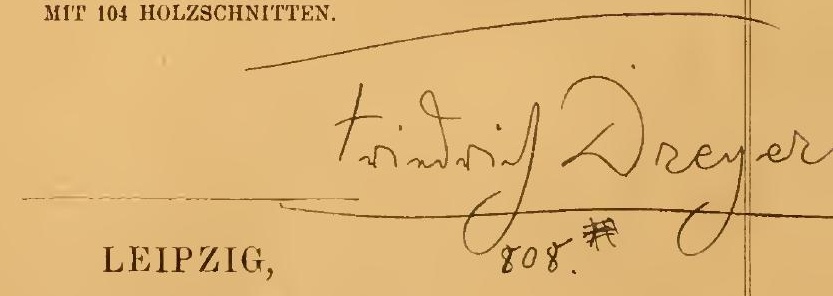

VERLAG VON F. C. W. VOGEL.

1875 . 


\section{Verlag von F. C. W. Vogel in Leipzig.}

\section{Untersuchungen}

über die

\section{Erste Anlage des Wirbelthierleibes von \\ Wilhelm His.}

Die erste Entwicklung des Hïhnchens im Ei.

Nit 12 Tafeln.

gr. 4. 1865. 37 M. 50 Pf.

Untersuchungen

ïber

das Ei und die Eientwicklung bei Knochenfischen

Wilhelm His.

I. Ueber das reife Ei von Knochenfischen, besonders iiber dasjenige einiger Salmoniden.

II. Beobachtungen an den Eierstöcken einiger Knochenfische.

Mit 4 Tafelı.

gr. 4. 1873. 10 M. 50 Pf.

Ueber die Bedeutung der Entwicklungsgeschichte

\section{Auffassung der organischen Natur \\ Wilhelm His. \\ gr. 8. 1870. 75 Pf.}

\section{Ueber die Aufgaben und Zielpunkte der wissenschaftlichen Anatomie von \\ WILHELM HIS. \\ gr. 8. 1872. $40 \mathrm{Pf}$.}

Demnachst werden erscheinen:

Beiträge zur Anatomie und Physiologie. Carl Ludwig als Festgabe zum 15. October 1874 gewidmet von Seinen Schülern. Mit 14 Tafeln. 40 Bogen Text. 4.

(Eine Sammlung ausgezeichneter Originalarbeiten aus dem Geliete der Anatomie, Physiologie und Entwicklungsgeschichte.) 


\section{Verlag von F. C. W. Vogel in Leipzig:}

\section{Ziemssen's}

\section{Handhoch der speceiellen Pathologie mad Therangie.}

Erschienen sind:

I. Band. Handbuch der öflentl. Gesundheitspflege u.d. Gewerbekrankheiten. Zweite

Auflage. 1575.

$10 \mathrm{M}$.

II. Band. Acute Infectionskrankhelten. I. II. Theil. $25 \mathrm{MI}$.

III. Band. Chroulsche Infectlouskrankhelten. 12 M.

V. Band. Krankbeiten ues Respirationsapparates II. $13 \mathrm{M}$.

VII. Band. Krankheiten des chylopoëtischen Apparates. I. 1. 6 M.

I. Band. Kraukheiten der weiblichen Ceschlechtsorgane. $10 \mathrm{M}$.

XII. Band. Krankbelten des Nervensystems II. 1. 10 M. $50 \mathrm{Pf}$.

Gerlach, Dr. A. (Prof. in Erlangen). Das Verhältniss der Nerren zu den willkürlichen Muskeln der Wirbelthiere. Eine histologische Untersuchung. Mit 4 Tafeln. gr. 8. 1874.

$4 \mathrm{M}$.

Heubner, Dr. 0. (a. ö. Prof. in Leipzig), Dje luetische Erkrankung der Hiruarterien nebst allgeneinen Erörterungen zur normalen unil pathologischen llistologic sowir zur llirucirculation. Eine Monographie. Mit 4 Tafeln. gr. 8. geh. $1874.99 \mathrm{M}$.

Klebs, Dr. E. (Prof. in Bern). Beiträge zur Patholog. Anatomie der Schusswumlen. Nach Beobachtungen in den Kriegslazarethen in Carlsruhe 1870 u. 1871. Mit Holzschnitten u. 11) Tafeln. 4. 1872.

$13 \mathrm{M}$.

Kölliker, Dr. A. (Prof. in Würzburg). Die normale Resorption des Kuochengewebes und ihre Bedeutnng für die Entstehung der typischen Knochenformen. Mit \& Tafeln. 4. 1873. 19 M.

\section{ARCHIV}

FüR

\section{EXPRRIMENTELLE PATHOLOGTE und PHARMAKOLOGTE}

Dr. Edwin Klebs,

Prof. d. patholog. Anatomie in Prag.
Dr. B. Naunyn,

Prof. d. medic. Klinik in Ǩ̈nigsberg.

Dr. 0. Schmiedeberg,

Prof. der Pharmakologie in Strassburg.

Erster bis Dritter Band.

gr. S. Preis eines Bandes von 6 Heften 13 M.

DEUTSCHE ZEITSCHRIFT

FǗR

\section{THIRMEDICIN UND VERGLELCHENDE PATHOLOGIE}

Dr. 0. Bollinger,

Prof. an der Universităt und Thierarzneischule in Mrunchen.

\section{Redigirt von} und

\section{Ersten Bandes Erstes Ileft.}

Die ,Deutsche Zeitschrift für Thiermedicin und vergleichende $\mathrm{Pathologie"} \mathrm{erscheint} \mathrm{in} \mathrm{zwanglosen} \mathrm{Heften,} \mathrm{von} \mathrm{denen} 6$ Einen Band bilden.

Preis Eines Bandes 9 Mark: 
RUCK VON J. B. HIRSCHFELD IN LEIPZIG. 



